Tiago Fernando Thomazelli da Silva

\title{
ESTUDO DA INTERAÇÃO ENTRE EDIFÍCIOS DE ALVENARIA ESTRUTURAL E PAVIMENTOS EM CONCRETO ARMADO
}

Dissertação apresentada à Escola de Engenharia de São Carlos da Universidade de São Paulo, como parte dos requisitos para obtenção do Título de Mestre em Engenharia de Estruturas.

Orientador: Prof. Assoc. Márcio Antônio Ramalho

São Carlos

2005 
Aos meus pais, Benedito e Noemi, que me tem amado, ajudado e ensinado a rogar a Deus para alcançar essa grande vitória

À minha irmã Thaís, que com paciência, amor e carinho me tem auxiliado nessa jornada

Aos meus avós paternos Sebastião (in memoriam) e Floripes, e maternos José Thomazelli e Mathilde, que sempre me animaram a enfrentar minha luta. 


\section{Agradecimentos}

Agradeço ao meu Deus pela vida, saúde e forças para caminhar até aqui, suplantando todos os obstáculos e esmorecimentos que têm se apresentado.

Aos meus pais, irmã e avós, as palavras são pequenas para expressar minha gratidão por tudo que proporcionaram à minha vida. A todos os meus familiares: tios, tias, primos e primas, nada no mundo pode pagar as forças que me tens dado em todos estes anos!

Também sou grato à FAPESP e a Capes, pelo auxílio financeiro concedido durante estes dois anos, sem o qual não seria possível a realização do trabalho que se apresenta.

Quando cursei a disciplina de Resistência dos Materiais em 1998 com o Prof. Márcio Antônio Ramalho, nunca imaginava que um dia teria a oportunidade de ser seu orientado. Hoje, finda mais uma etapa em minha vida, agradeço a compreensão, paciência e incentivo que me tem dispensado, pontos estes que também posso estender ao Prof. Márcio Roberto Silva Corrêa. Ambos têm contribuído, e muito, para minha formação profissional e pessoal.

Aos amigos, reconheço serem amplos os sentimentos de gratidão. Todos tiveram o seu mérito, que até mesmo em conversas informais me tem ajudado a alavancar o trabalho e a vida. Entretanto, não poderia deixar de mencionar o Jerônymo, com as suas idéias sobre a interface do aplicativo, o Claudius, com seu modo otimista e sério de trabalhar, e a Larissa, alegrando e perfumando nossa turma de mestrado. Os colegas de graduação, como o Cilmar e o Dorival, entre outros, que sempre me incentivaram na labuta que enfrentei.

Chegando à cidade de São Carlos em 1997, foram inúmeras as pessoas que marcaram minha vida. Agradeço a Deus por ter colocado em meu caminho as famílias do irmão Arnaldo e irmã Dora, irmão Manoel e irmã Ivani, irmão Manoel (Manesinho) e irmã Maria Helena. Entre tantas amizades que tive a felicidade de cultivar, este simples texto é pequeno 
para expressar minha gratidão pela paciência das meninas (Cláudia, Priscila, Taís, etc) e do restante da turma (Silas, Misael, Jampane, Aziel (Pitta), Oséias, Ezequias, etc). Não tenho como citar todos, mas ainda restam dois, Himer e Arnaldo (Arnaldinho), que me tem auxiliado muito quando nos encontramos para conversar, principalmente no período final do trabalho.

Aos amigos que fiz durante o estágio na Tecsof: Rivelli, Suzana, Valéria, Fabiana, Juliana, Gilberto, Hallan, Wellington e Tatiane, que sempre me auxiliaram e ensinaram a vencer as dificuldades que encontrei.

Agradeço a todos os funcionários do Departamento de Estruturas da Escola de Engenharia de São Carlos.

Muitos outros teria para lembrar entre familiares, amigos e companheiros, que me tem apoiado e torcido por ver completo mais este capítulo de minha vida.

Que Deus abençoe a todos!

Amém! 


\section{Resumo}

SILVA, T. F. T. (2005). Estudo da interação entre edifícios de alvenaria estrutural e pavimentos em concreto armado. Dissertação (Mestrado) - Escola de Engenharia de São Carlos, Universidade de São Paulo, São Carlos, 2005.

Um edifício de alvenaria estrutural normalmente se apóia sobre uma estrutura de concreto armado. Devido à existência do efeito arco, a interação entre a alvenaria e a estrutura de concreto se dá de forma complexa. Usualmente essa interação é desconsiderada e as cargas das paredes de alvenaria são simplesmente colocadas na estrutura de concreto de maneira uniforme. Este trabalho propõe um procedimento numérico seguro e eficiente, baseado no Método dos Elementos Finitos, para se considerar essa interação. Inicialmente são discutidos alguns conceitos básicos sobre o efeito arco e estabelecida uma estratégia de cálculo baseada na modelagem de um pavimento de alvenaria sobre a estrutura de concreto armado. Em seguida é apresentado um programa para gerar dados e visualizar resultados, de forma que a construção dos modelos e a visualização dos resultados seja realizada com facilidade. Como aplicação, consideram-se casos reais de edifícios completos de forma a se mostrar a possibilidade de utilização prática dos procedimentos propostos.

Palavras-chave: efeito arco, interação de estruturas, Método dos Elementos Finitos, alvenaria estrutural. 


\section{Abstract}

SILVA, T. F. T. (2005). Interaction between structural masonry buildings and reinforced concrete structures. Dissertação (Mestrado) - Escola de Engenharia de São Carlos, Universidade de São Paulo, São Carlos, 2005.

A structural masonry building is commonly supported by a reinforced concrete structure. That interaction is complex to evaluate due to the existence of the so-called "arch effect". In fact, usually this interaction is not considered and the loads are uniformly applied over the concrete structure. This work proposes a simple and efficient numerical procedure based on the Finite Element Method in order to consider that interaction. First, basic concepts about arch effect and the adopted strategy for considering it are shown. After, a computational program for data generation and results visualization is presented. This program was developed for making easier to build the numerical models for the analysis. Finally, real cases of complete buildings are considered so that the practical use can be clearly established.

Keywords: arch effect, structural interaction, Finite Element Method, structural masonry. 


\section{Sumário}

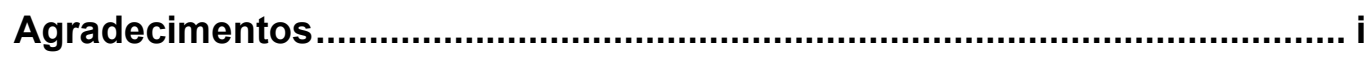

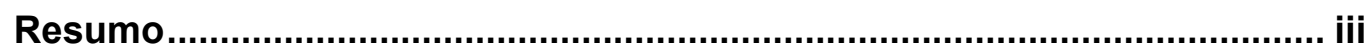

Abstract

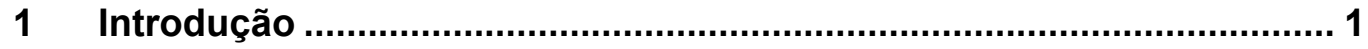

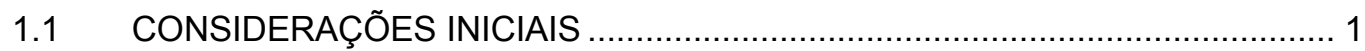

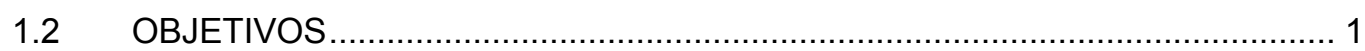

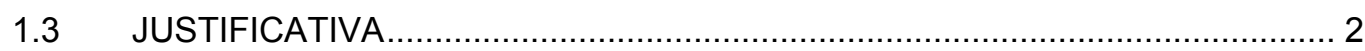

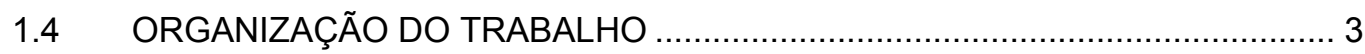

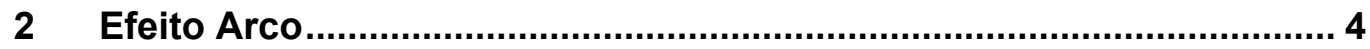

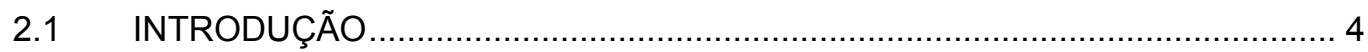

2.2 CONSIDERAÇÕES DA RIGIDEZ RELATIVA PAREDE-VIGA ………………... 6

2.3 TRECHO DE FORMAÇÃO DO ARCO ………………................................ 7

3 Análise das Cargas Verticais em Edifícios de Alvenaria Estrutural .... 8

3.1 ARRANJOS ESTRUTURAIS DE EDIFÍCIOS................................................ 8

3.2 ESTUDO DO CAMINHAMENTO DE CARGAS VERTICAIS ............................. 10

3.2.1 Interação entre Paredes .............................................................................. 10

3.2.2 Procedimentos de Distribuição de Cargas Verticais........................................ 11

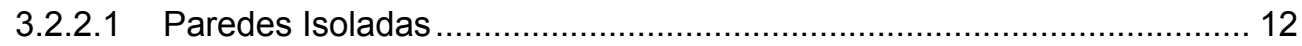

3.2.2.2 Grupos de Paredes Isoladas ............................................................. 12

3.2.2.3 Grupos de Paredes com Interação....................................................... 12

3.2.3 Automatização da Análise ................................................................... 13

3.2.4 Exemplo Desenvolvido.............................................................................. 14

$4 \quad$ Programa Gerador de Dados .............................................................. 17

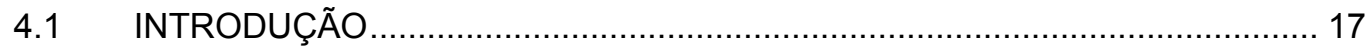




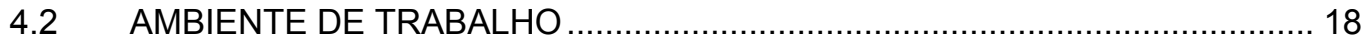

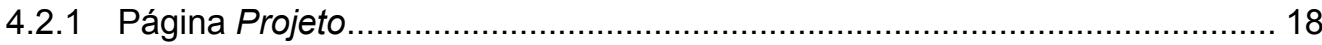

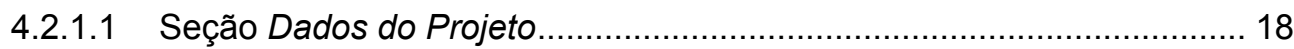

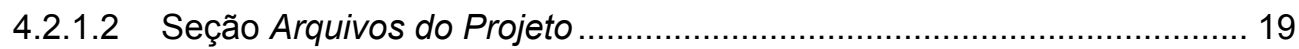

4.2.1.3 Seção Dados da Estrutura de Concreto............................................... 20

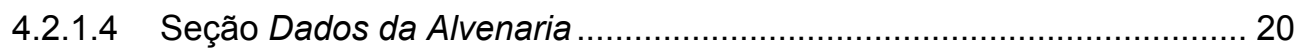

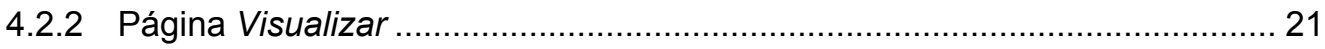

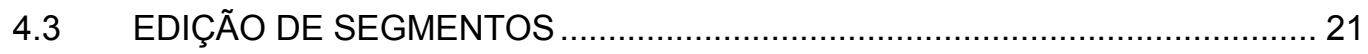

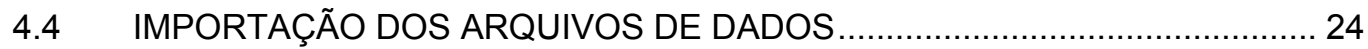

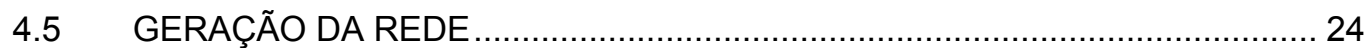

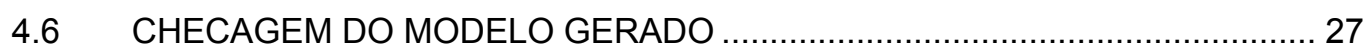

4.6.1 Verificação da Geometria via Arquivo DXF .................................................... 28

4.6.2 Verificação Direta da Geometria via Sistema GMPAE .................................. 29

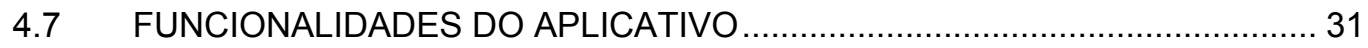

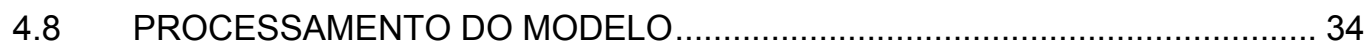

4.8.1 Processamento da Estrutura de Apoio do Pavimento de Alvenaria............... 34

4.8.2 Exportação do Arquivo de Processamento .................................................... 36

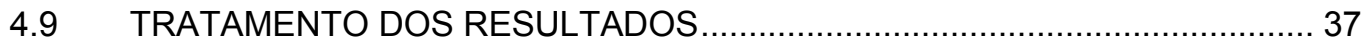

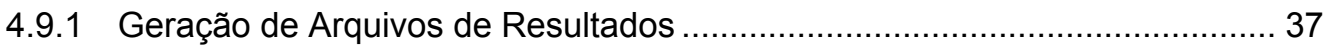

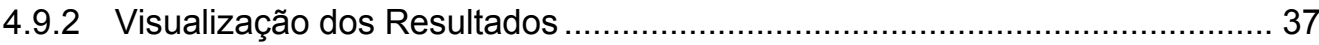

4.9.2.1 Visualização via Planilha Eletrônica ..................................................... 37

4.9.2.2 Visualização via Sistema GMPAE ....................................................... 38

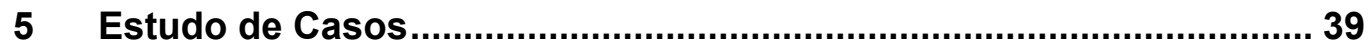

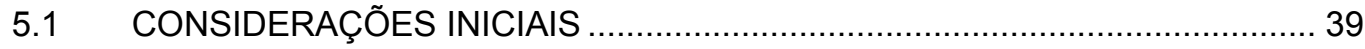

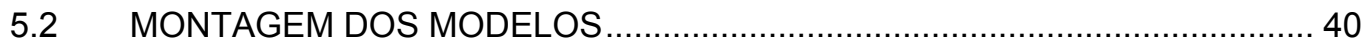

5.3 EXEMPLO 1 - EDIFÍCIO VIVENDA DOS SONHOS …............................... 41

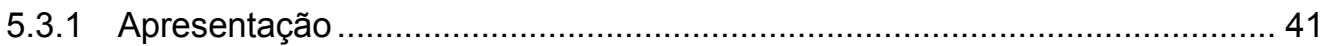

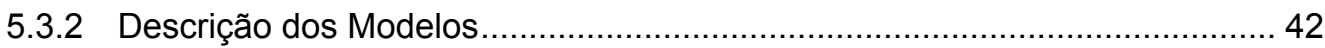

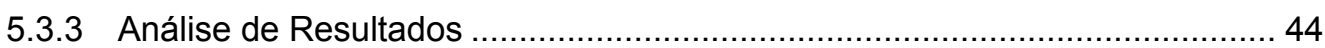

5.4 EXEMPLO 2 - EDIFÍCIO MIRANTE DO UMARIZAL ...................................... 61

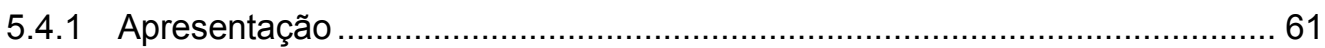

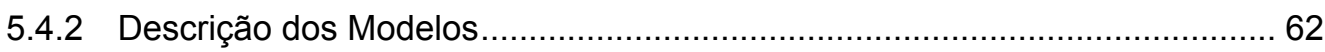

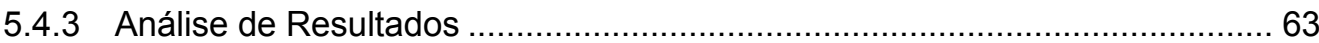

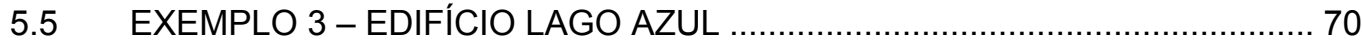

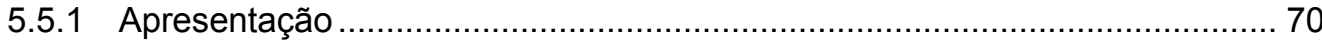

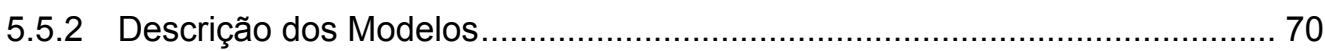

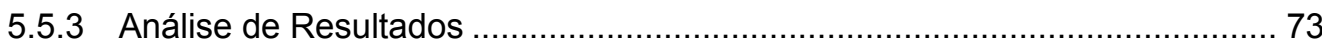


5.6 EXEMPLO 4 - EDIFÍCIO LA DEFENSE ……......................................... 79

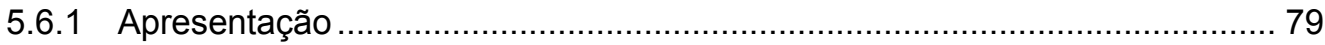

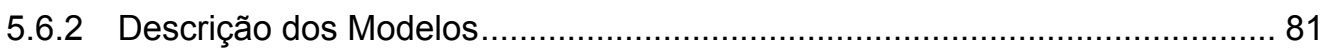

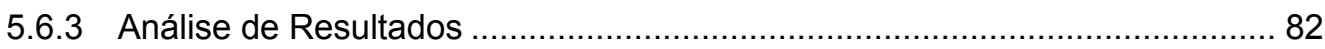

5.7 EXEMPLO 5 - EDIFÍCIO CASA PARA TODOS ............................................. 90

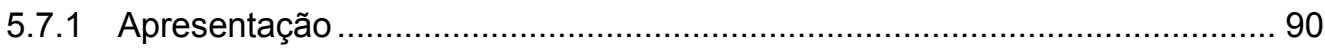

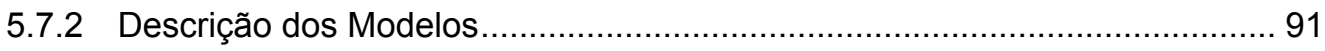

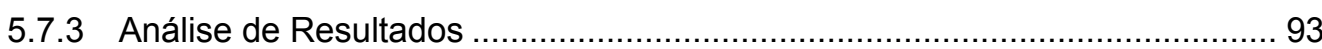

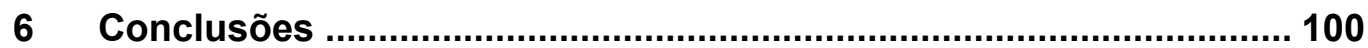

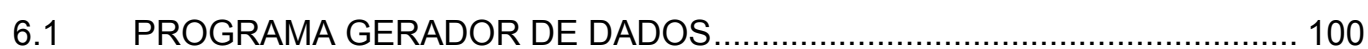

6.2 ANÁLISE DOS RESULTADOS OBTIDOS ................................................. 101

6.3 SUGESTÕES PARA NOVOS TRABALHOS .............................................. 103

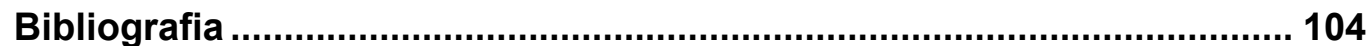




\section{Capítulo 1 Introdução}

\subsection{CONSIDERAÇÕES INICIAIS}

Desde a antiguidade a alvenaria tem estado presente no cotidiano do homem, sendo de conhecimento comum diversas obras realizadas com esse material.

No início do século passado, um dos fatores que inibiram um crescimento mais racional desse sistema construtivo foi a facilidade de seu uso puramente empírico em construções residenciais. De acordo com Hendry, Sinha e Davies (1997), após 1950 essa situação começou a mudar com a introdução de normas estruturais em diversos países, possibilitando bases mais racionais para o cálculo da espessura de paredes e da resistência da alvenaria.

No Brasil, após sua implantação em 1966, quando em São Paulo foram construídos alguns prédios de quatro pavimentos, o desenvolvimento da alvenaria estrutural se deu de maneira lenta. Isso ocorreu não obstante suas vantagens econômicas, especialmente associadas ao fato de se utilizar as paredes não apenas como elementos de vedação, mas também como elementos estruturais. Por muitos anos a alvenaria estrutural foi pouco utilizada devido a muitos fatores, tais como: preconceito, maior domínio da tecnologia do concreto armado por parte dos construtores e projetistas e pouca divulgação do assunto nas universidades durante o processo de formação do profissional. Muitos projetistas são leigos no que diz respeito a esse sistema construtivo e acabam optando pelo concreto armado. Essa conjuntura é também influenciada pelo reduzido número de publicações em português sobre o assunto, pois a maior parte é estrangeira e voltada para as peculiaridades de cada país.

Nos últimos anos essa situação tem se alterado de forma significativa. O interesse por esse sistema estrutural cresceu de forma notável, especialmente pelas condições nitidamente favoráveis que se obtêm em termos de economia. E, no momento, a demanda por tecnologias que possam embasar a execução de obras econômicas e seguras é realmente muito grande.

\subsection{OBJETIVOS}

O objetivo geral deste trabalho é analisar a interação entre edifícios de alvenaria estrutural e estruturas de suporte em concreto armado, de forma a quantificar os esforços nas peças 
de concreto armado e também as tensões na alvenaria. Esses esforços e tensões serão obtidos considerando-se o chamado "efeito arco", que usualmente reduz de forma significativa os esforços nas vigas, especialmente o momento fletor, mas introduz pontos de concentração de tensões nas alvenarias. A análise é realizada através de um procedimento numérico, baseado no Método dos Elementos Finitos (MEF), e deve ser econômica, segura e prática, podendo ser utilizada em projetos usuais de edifícios de alvenaria estrutural.

Como objetivos específicos, podem ser mencionados:

- Desenvolvimento de um programa gerador de dados que possa, munido de informações das alvenarias e da estrutura de concreto armado, modelar automaticamente a região de interação utilizando elementos de barra e de membrana;

- Estudar alguns casos reais, obtendo-se uma comparação entre o procedimento proposto e aqueles usualmente utilizados para a análise das estruturas de concreto armado que suportam estruturas de alvenaria;

- Demonstrar que os procedimentos simplificados podem produzir resultados antieconômicos e, em alguns casos, inseguros, alertando os profissionais que trabalham com esse tipo de estrutura da necessidade de se considerar um procedimento mais confiável e com maior acuidade.

\subsection{JUSTIFICATIVA}

Uma das áreas da engenharia civil que tem apresentado maior potencial de crescimento é, sem sombra de dúvida, a execução de edifícios em alvenaria estrutural. Isso se deve principalmente à economia obtida por esse processo construtivo em relação ao concreto convencional, por propiciar uma maior racionalidade na execução da obra, reduzindo o consumo e o desperdício dos materiais. Essa economia pode chegar a $30 \%$ do valor da estrutura em casos de edifícios em alvenaria não-armada de até oito pavimentos. Dessa forma, o custo das edificações é menor para o comprador final, havendo uma melhor penetração no mercado, em especial junto às classes média e baixa. Portanto, é evidente o grande benefício social que pode advir do desenvolvimento desse processo construtivo.

Entretanto, o projeto de edifícios de alvenaria estrutural ainda necessita de alguns avanços para se aproximar do desenvolvimento que se observa para as estruturas convencionais em concreto armado. A própria normalização nacional carece de melhorias, devendo-se voltar esforços nessa direção para que se possam projetar edifícios mais econômicos e seguros. Esse empenho traduz-se em pesquisas voltadas para a realidade brasileira, sem o que é impraticável o desenvolvimento satisfatório dos procedimentos normativos nessa área.

Assim sendo, é imprescindível e urgente uma concentração de esforços para se implementar um conjunto de pesquisas que possam permitir o desenvolvimento de tecnologias adequadas à elaboração de projetos de edifícios em alvenaria estrutural cada vez mais econômicos e seguros. 
Os métodos tradicionais de cálculo das cargas verticais têm se mostrado conservadores quando comparados aos resultados obtidos quando se considera o efeito arco. No entanto, a discretização de um pavimento em elementos finitos é um trabalho que demanda muito tempo se realizado manualmente.

A presente pesquisa fundamenta-se no desenvolvimento de um programa gerador de dados que permite a elaboração automática de uma rede em elementos finitos para um pavimento em alvenaria estrutural, eliminando todas as etapas de pré-processamento necessárias em programas comerciais que utilizam o MEF.

\subsection{ORGANIZAÇÃO DO TRABALHO}

No presente capítulo são apresentados alguns dados históricos e um breve quadro da alvenaria estrutural no Brasil, juntamente com as justificativas, objetivos e os tópicos de organização do trabalho.

No capítulo dois disserta-se sobre o efeito arco, descrevendo sua atuação na estrutura, parâmetros que o influenciam e o trecho de formação do arco.

Para o cômputo do fenômeno descrito, faz-se necessário um adequado tratamento das cargas verticais em edifícios de alvenaria estrutural. Para tanto, o terceiro capítulo proporciona o conhecimento indispensável para a realização da referida tarefa, apresentando um processo automatizado desenvolvido por alguns pesquisadores, finalizando com a abordagem de um exemplo didático que elucida o exposto.

O aplicativo construído, batizado de Sistema GMPAE, é apresentado no quarto capítulo, procurando-se abranger os principais pontos no tratamento dos dados com o programa, assim como explicitar as interfaces para visualização da estrutura gerada e análise de resultados.

O quinto capítulo engloba o estudo de casos desenvolvido, no qual cinco edifícios em alvenaria estrutural são analisados, exibindo-se os resultados mais significativos e ressaltandose a importância e cautela ao se considerar o efeito arco na análise dos esforços.

No capítulo 6 podem-se acompanhar as conclusões do trabalho, destacando-se a facilidade na elaboração de um projeto mais sofisticado ao se utilizar o aplicativo desenvolvido, além de advertir o meio técnico das variações ocasionadas pela simplificação da modelagem empregada corriqueiramente em projeto.

O último capítulo cita a bibliografia empregada e consultada para o desenvolvimento da presente pesquisa. 


\section{Capítulo 2 \\ Efeito Arco}

\subsection{INTRODUÇÃO}

É intuitivo pensar que existe uma interação entre a parede de alvenaria e a sua estrutura de suporte que, para o caso estudado, vem a ser uma viga em concreto armado. Hendry (1998) explica que, simplificadamente, pode-se representar esse sistema assumindo-se que apenas uma parte da viga suporta a parede, sendo esta representada por um diagrama de cargas na forma aproximada de um triângulo, com ordenadas nulas nos apoios e valor máximo no meio do vão. De acordo com Hendry (1997), antes de 1952 essa era uma prática comum no projeto da viga de suporte. O carregamento para o restante da parede pensava-se estar sendo transmitido aos pontos de apoio por uma ação em forma de arco, como ilustra a Figura 2.1.

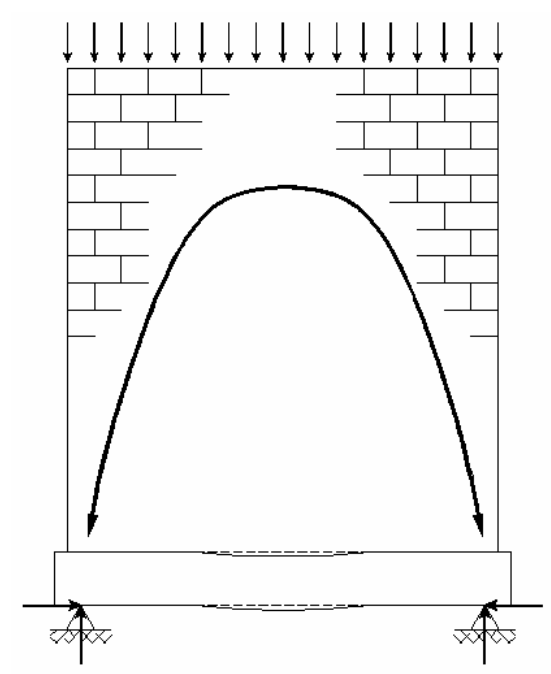

Figura 2.1 - Configuração do arco

Uma gama significativa de estudos teóricos e experimentais desse problema mostrou claramente que as tensões verticais e de cisalhamento na interface parede-viga concentram-se na região dos apoios. Rosenhaupt (1962) escreveu que para uma parede de alvenaria apoiada sobre uma viga o carregamento não é uniforme, havendo concentração sobre os apoios, aliviando-se a região central do vão. 
Wood, um dos pioneiros no estudo aqui abordado, descreveu em 1952 o comportamento de uma parede sobre viga como sendo a de um arco atirantado, onde a viga funciona como um tirante e o arco se forma na parede. Além disso, enunciou regras empíricas baseadas em resultados de ensaios que permitiam a redução do momento fletor até uma relação da ordem de PL/100 (situação sem aberturas de portas ou janelas próximas aos apoios) ou PL/50 (para o caso de aberturas de portas ou janelas próximas aos apoios). Na notação empregada, $\mathrm{L}$ é o vão da viga e $\mathrm{P}$ a carga dada pelo peso próprio do sistema parede-viga acrescido de alguma sobrecarga existente.

Diversos autores como Riddington e Stafford Smith (1977) e Hendry (1998) escreveram que as distribuições de tensões de cisalhamento e vertical podem ser aproximadamente representadas por diagramas triangulares, assim como o mostrado na Figura 2.2.

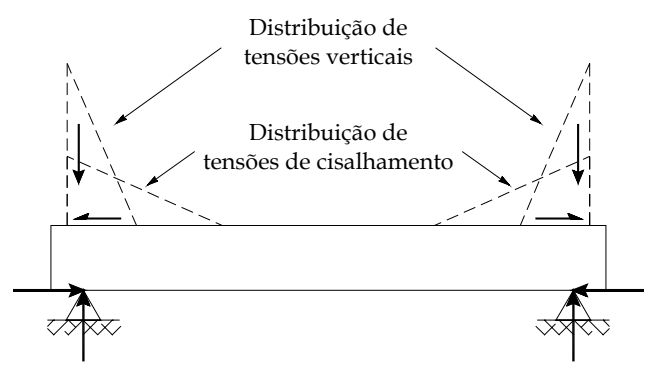

Figura 2.2 - Tensões verticais e de cisalhamento na viga

O formato do diagrama de tensões horizontais é bem conhecido, sendo idêntico ao de uma viga-parede comum, apresentando uma região comprimida e outra tracionada como se verifica na Figura 2.3. Como Barbosa (2000) observa, a linha neutra pode estar localizada tanto dentro da viga como na parte inferior da parede. Para o primeiro caso, tem-se a situação usual de uma viga trabalhando à flexão, com a armadura superior comprimida, a inferior tracionada e compressão em toda a altura da parede. Já para o segundo caso, a viga se encontra totalmente tracionada, assim como a base da parede.

Lu et al. (1985) realizaram ensaios em 69 paredes de alvenaria sobre vigas de concreto armado, tendo verificado a influência do efeito arco nas flechas obtidas. Segundo os autores, o fenômeno estudado reduziu significativamente os deslocamentos, tendo-se obtido valores, no momento da ruína, da ordem de L/500 a L/1000.

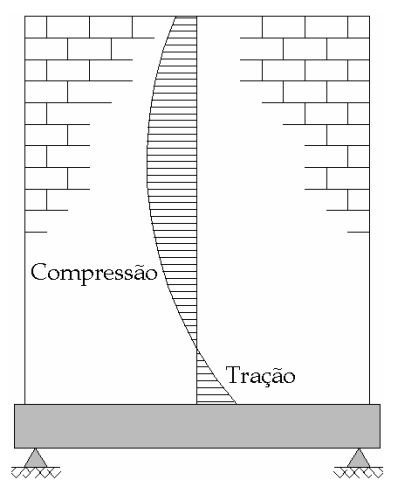

Figura 2.3 - Diagrama de tensões horizontais 


\subsection{CONSIDERAÇÕES DA RIGIDEZ RELATIVA PAREDE-VIGA}

De acordo com Lu et al. (1985), a posição da linha neutra é influenciada basicamente pelo carregamento e pelo valor da relação $H / L$ (altura pelo vão). Os autores indicam que, para o caso de paredes com $\mathrm{H} / \mathrm{L} \leq 0,5$, antes do início da fissuração da viga a linha neutra está localizada no interior da viga, sendo que a armadura superior da mesma se encontra comprimida. Com o aumento da fissuração, a linha neutra caminha para fora da viga, ocasionando tensões de tração na armadura superior. No caso de paredes com $H / L \geq 0,75$, nota-se que, desde o princípio do carregamento, as armaduras superior e inferior já estão sendo solicitadas por tensões de tração.

Como se enuncia no parágrafo anterior, além da altura da parede e do vão da viga, a distribuição de tensões sofre a influência de outros fatores como, por exemplo, inércia da viga, espessura da parede e razão entre os módulos de elasticidade da parede e da viga.

Esses fatores são usualmente computados com a utilização do conceito de rigidez relativa. Riddington e Stafford Smith (1977) e Davies e Ahmed (1977), nas Equações (2.1) e (2.2) respectivamente, relacionam as propriedades da parede e da viga como segue:

$$
\begin{aligned}
& K=\sqrt[4]{\frac{E_{p} \cdot t_{p} \cdot L^{3}}{E_{v} \cdot I_{v}}} \\
& R=\sqrt[4]{\frac{E_{p} \cdot t_{p} \cdot H^{3}}{E_{v} \cdot I_{v}}}
\end{aligned}
$$

Onde:

- $E_{p}$ : módulo de elasticidade longitudinal da parede;

- $E_{v}$ : módulo de elasticidade longitudinal da viga;

- IV: inércia da viga de apoio;

- H: altura da parede;

- $t_{p}$ : espessura da parede;

- L: distância entre apoios.

Para se realizar um breve comentário a respeito desses fatores, imagina-se um sistema parede-viga onde todos os parâmetros apresentados são mantidos constantes, variando-se apenas a inércia da viga de apoio. Quando se diminui essa variável, o valor da rigidez relativa aumenta e a influência do efeito arco é mais patente. Com isso, pode-se inferir que valores elevados de rigidez relativa indicam sistemas com vigas mais flexíveis em relação às paredes, havendo aumento das concentrações de tensões na parede, sendo menor a parcela de carga vertical que a viga recebe no meio do vão. Por outro lado, com valores mais baixos de rigidez relativa, são observadas vigas mais rígidas em relação às paredes, o que acarreta uma diminuição da concentração de tensões na parede, aumentando a carga no meio do vão da viga.

Utilizando o fator K, Riddington e Stafford Smith (1978) propuseram um método direto e simples para o projeto de estruturas com paredes de alvenaria estrutural sobre vigas de aço. 
Usando a rigidez relativa parede-viga como base para prever a distribuição das tensões de interação, são feitas estimativas da máxima tensão na parede e do momento fletor na viga.

\subsection{TRECHO DE FORMAÇÃO DO ARCO}

Pode-se imaginar, inicialmente, que a configuração do arco muda sempre quando se aumenta a altura da parede sobre uma viga. Entretanto, isso não ocorre, sendo essa configuração constante a partir de uma determinada relação entre a altura da parede e o vão da viga.

Wood (1952) indica que o arco se forma a partir de uma relação entre a altura da parede e o comprimento da viga, maior ou igual a 0,60. Para valores inferiores a este, ocorre uma elevação das tensões cisalhantes na interface parede-viga, podendo romper o material nessa região.

Hendry, Sinha e Davies (1997) escrevem que a ação composta entre a viga e a parede não pode ser alcançada a menos que haja ligação suficiente entre esses elementos, permitindo o desenvolvimento das forças de cisalhamento necessárias. Grandes tensões de compressão próximas aos apoios resultam em altas forças de atrito ao longo da interface. Isto tem sido observado quando a relação $H / L$ é superior a 0,60 , onde as forças de atrito desenvolvidas são suficientes para fornecer a requerida capacidade cisalhante.

Riddington e Stafford Smith (1977) chegaram em 0,70 do vão como sendo a altura da parede em que ocorre a formação do arco, valor este demonstrado por Tomazela (1995) e posteriormente usado por Barbosa (2000). Porém, em Riddington e Stafford Smith (1978), estes retomam a sugestão de Wood (1952) descrita acima.

Essa discussão é de grande valia, pois com ela se pode limitar o estudo de um edifício de alvenaria estrutural em apenas um pavimento. Isso quer dizer que, para a correta consideração do efeito arco no cômputo dos esforços na estrutura, a modelagem de apenas um pé-direito de paredes já é suficiente para permitir a atuação desse fenômeno. Como as construções usuais em alvenaria estrutural têm pés-direito na casa dos $2,80 \mathrm{~m}$, seriam necessários vãos superiores a 4,0 m para comprometer a abordagem descrita. 


\section{Capítulo 3}

\section{Análise das Cargas Verticais em Edifícios de Alvenaria Estrutural}

\subsection{ARRANJOS ESTRUTURAIS DE EDIFÍCIOS}

Para se projetar uma edificação em alvenaria estrutural, geralmente parte-se de um conjunto de desenhos básicos que compõem o projeto arquitetônico. Em se tratando da alvenaria estrutural, a concepção da estrutura consiste na determinação de quais paredes serão consideradas como estruturais ou não-estruturais.

Os benefícios econômicos na execução de edifícios em alvenaria estrutural apenas são satisfatórios com a observância de algumas condições, quer seja na concepção estrutural quanto no aproveitamento da edificação.

Com a finalidade de resistir aos esforços e garantir a estabilidade local e global do edifício, as paredes estruturais desempenham papel de extrema importância, devendo, sempre que possível, serem contínuas do nível mais baixo (fundação ou pilotis) até o nível do telhado.

A norma brasileira NBR 10837:1989 classifica como paredes estruturais todas aquelas que são consideradas no projeto "como suporte de outras cargas, além de seu peso próprio".

As paredes devem ser adequadamente dispostas, procurando garantir resistência a forças laterais nas duas direções. Arranjos muito assimétricos devem ser evitados, pois esses geram efeitos importantes quando sujeitos ao carregamento lateral. Segundo Hendry, Sinha e Davies (1997), é possível distinguir uma grande variedade de arranjos de paredes. Entretanto, de forma simplificada, pode-se admitir a seguinte classificação:

- Sistemas de paredes celulares;

- Sistemas de paredes transversais simples ou duplas;

- Arranjos complexos.

A Figura 3.1 apresenta uma explicação sucinta das representações utilizadas nas próximas ilustrações. 


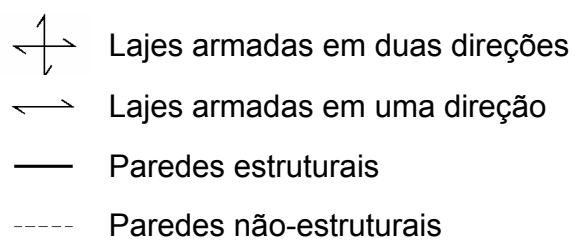

Figura 3.1 - Simbologia adotada por Hendry, Sinha e Davies (1997)

Um arranjo de paredes celulares é caracterizado por ter paredes internas e externas estruturais, como mostrado na Figura 3.2.

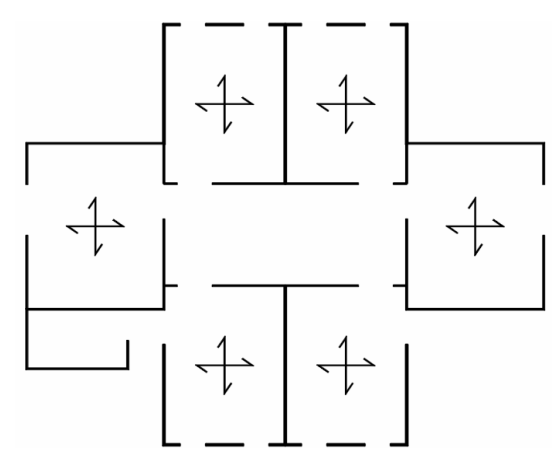

Figura 3.2 - Arranjo de paredes celulares

O sistema de paredes transversais simples é muito apropriado a hotéis, pois permite a construção de vários quartos idênticos, sendo que a maior parte das paredes estruturais é perpendicular ao eixo longitudinal da construção e a estabilidade nesse sentido é garantida pelas paredes dos corredores. O esquema da Figura 3.3 ilustra o exposto.

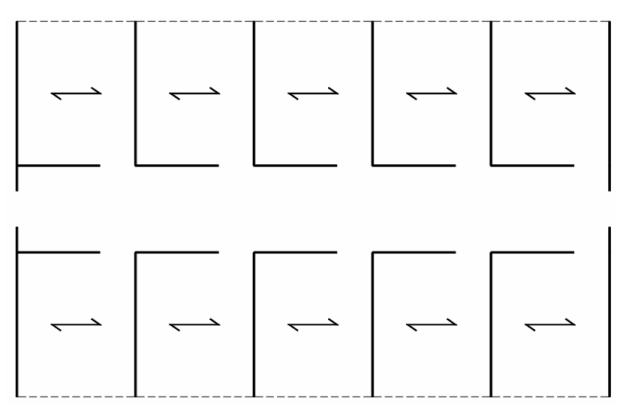

Figura 3.3 - Estrutura de paredes transversais simples

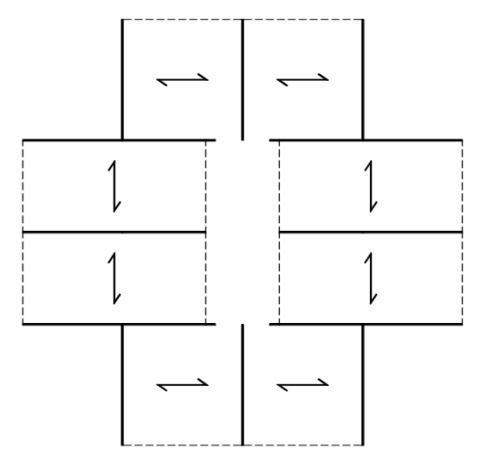

Figura 3.4 - Estrutura de paredes transversais duplas 
Um sistema mais elaborado, que necessite de uma iluminação natural ampla, pode ser obtido com o arranjo de paredes transversais paralelas aos eixos da edificação, como exemplificado na Figura 3.4.

Todos os tipos de combinações entre os sistemas até agora apresentados são possíveis, tendo sido incluídos sob o título de arranjo complexo, ilustrado na Figura 3.5.

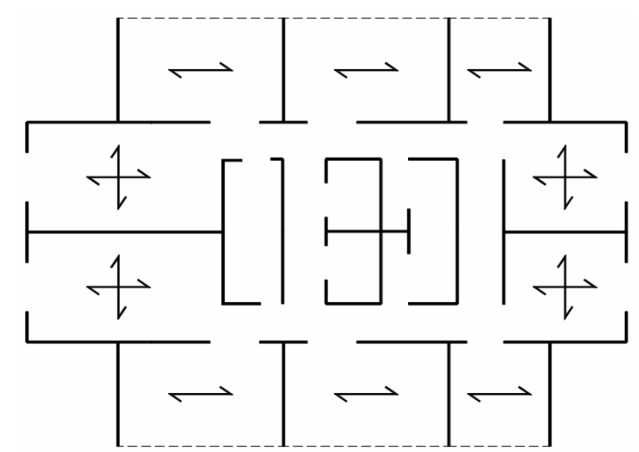

Figura 3.5 - Arranjo complexo de paredes

\subsection{ESTUDO DO CAMINHAMENTO DE CARGAS VERTICAIS}

Para que se possa realizar uma análise apropriada de um edifício em alvenaria estrutural, com as facilidades propiciadas pelo programa desenvolvido, deve-se empregar um processo adequado que permita o conhecimento das cargas verticais atuantes na base da estrutura.

Segundo Corrêa e Ramalho (1994), pelo menos dois pontos devem estar bem determinados para que o projetista possa desenvolver a sua análise: a) como tratar a ação das lajes sobre as paredes que Ihe servem de apoio; b) como simular a interação das paredes. Um procedimento simples consiste na consideração de paredes isoladas suportando um carregamento uniformemente distribuído proveniente das lajes. Porém, a rigor, as lajes não carregam as paredes de maneira uniforme, havendo tendência de aumento da taxa de distribuição nas porções centrais da região de contato. No entanto, como comprovam simulações numéricas descritas em Corrêa e Ramalho (1990-1992) e resultados experimentais obtidos por Stockbridge (1967), tais diferenças de carregamento ficam propensas ao desaparecimento conforme se distancia da região de aplicação.

\subsubsection{Interação entre Paredes}

É sabido que, quando um carregamento é aplicado sobre um trecho do comprimento da parede, tende a ocorrer um espalhamento dessa carga ao longo da altura.

Corrêa e Page (2001) indicam que diversos códigos, como a NBR 10837:1989, ACl 530:1992, BS 5628:1992 e AS 3700:1998 assumem que o espalhamento ocorre dentro de uma região compreendida por duas linhas que fazem um ângulo de $45^{\circ} \mathrm{com}$ a horizontal, como se vê na Figura 3.6(a). 
Havendo uma amarração eficiente entre paredes de cantos e bordas, pode-se esperar a ocorrência do mesmo processo, exemplificado pela Figura 3.6(b). Cabe salientar que o caminhamento das cargas verticais em cantos e bordas apenas ocorre quando for possível o desenvolvimento de forças de interação.

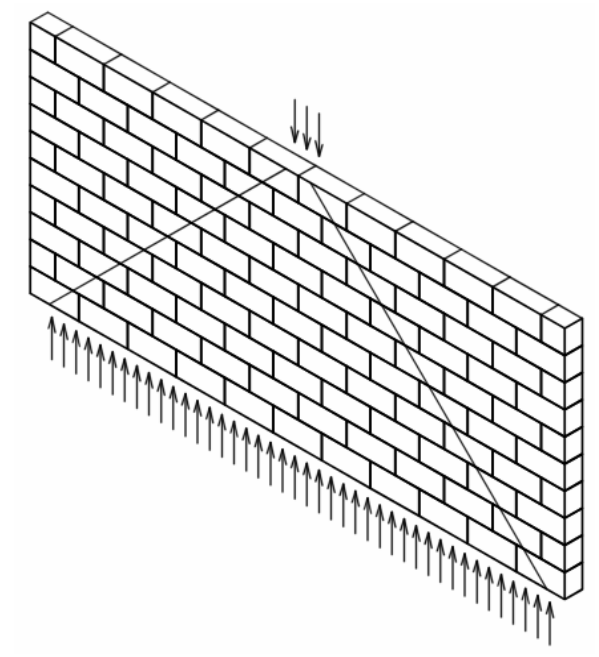

(a)

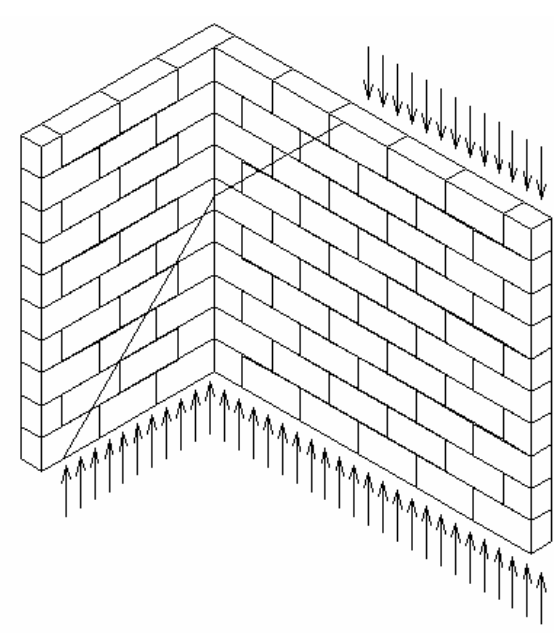

(b)

Figura 3.6 - Espalhamento do carregamento Fonte - Adaptado de Corrêa e Page (2001)

Para Corrêa e Ramalho (2003), outro ponto em que se pode discutir a existência ou não de forças de interação são as aberturas. É usual considerar que a existência de uma abertura também represente um limite entre paredes, ou seja, a abertura caracteriza a interrupção do elemento. Assim sendo, uma parede com aberturas normalmente é tomada como sendo uma seqüência de paredes independentes, ocorrendo, também nesse caso, forças de interação entre esses diferentes elementos e, portanto, havendo espalhamento e uniformização de cargas. A consideração dessas forças de interação nos limites entre paredes e aberturas é um dos pontos-chave para o desenvolvimento do procedimento para análise de cargas verticais em edifícios de alvenaria, proposto por Corrêa e Ramalho (1994).

\subsubsection{Procedimentos de Distribuição de Cargas Verticais}

Na pesquisa que se apresenta, procurou-se realizar o cálculo das cargas verticais em edifícios de alvenaria estrutural tendo seguido a sistemática mais utilizada em projetos, que é a de grupos de paredes isoladas. Assim como para um edifício em concreto armado existem diversas formas de se realizar um lançamento estrutural (variável em função da experiência do calculista), o mesmo acontece com a definição desses grupos de paredes para os edifícios em alvenaria estrutural.

Segue a explicação de três métodos para auxiliar a definição da distribuição das cargas verticais (CORRÊA e RAMALHO, 2003). 


\subsubsection{Paredes Isoladas}

Todas as paredes são consideradas como elementos isolados, não interagindo entre si. Processo simples e rápido, que consiste na acumulação das cargas atuantes sobre determinada parede, partindo do nível mais elevado até aquele em que se está fazendo a análise.

Processo seguro para o cálculo das resistências de cada parede, mas extremamente antieconômico, além de poder ocasionar uma estimativa errônea das ações atuantes sobre as estruturas de suporte das alvenarias.

\subsubsection{Grupos de Paredes Isoladas}

Consiste em se delinear grupos de paredes que possam trabalhar de forma solidária, sendo usualmente delimitados por aberturas de portas e janelas, como ilustra a Figura 3.7.

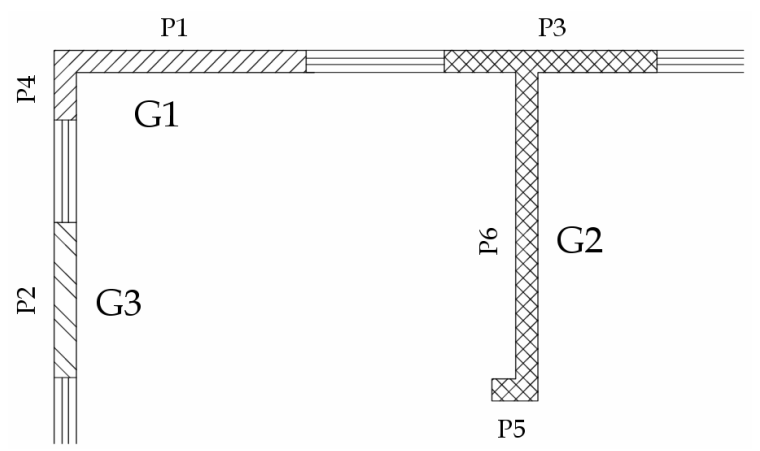

Figura 3.7 - Exemplo de grupos de paredes isoladas

Qualquer carga agindo numa parede do grupo atuará em todo o grupo. Para tanto, é necessário acumular as cargas de todas as respectivas paredes, distribuindo-as pelo comprimento total do grupo.

\subsubsection{Grupos de Paredes com Interação}

Este processo usa a mesma abordagem de reunir as paredes em grupos do procedimento anterior, permitindo agora a consideração de algum tipo de ligação entre os grupos, ou seja, admite-se a existência de forças de interação na região das aberturas.

Segundo Corrêa e Ramalho (1994), é apropriada a definição de uma taxa de interação, representando o quantil da diferença de cargas entre os grupos que deve ser uniformizada em cada nível. A distribuição pode ser feita com base nas seguintes equações:

$$
\begin{aligned}
& q_{m}=\frac{\left(q_{1}+q_{2}+\ldots+q_{n}\right)}{n} \\
& d_{i}=\left(q_{i}-q_{m}\right) \cdot(1-t) \\
& q_{i}=q_{m}+d_{i}
\end{aligned}
$$


Onde:

- $\mathrm{n} \quad$ = número de grupos que estão interagindo;

$-\mathrm{q}_{\mathrm{i}} \quad$ = carga do grupo $\mathrm{i}$;

- $\mathrm{q}_{\mathrm{m}}$ = carga média dos grupos que estão interagindo;

- $\mathrm{d}_{\mathrm{i}} \quad$ = diferença de carga do grupo em relação à média;

$-\mathrm{t} \quad=$ taxa de interação.

Conforme se pode verificar pelas equações anteriores, se for considerada uma taxa de interação igual a 1,00 (100\% de interação entre as paredes), haverá uniformização total do carregamento. $O$ resultado desse procedimento é o mesmo que se teria com a divisão da carga total de um pavimento pelo comprimento total das paredes estruturais, obtendo-se a mesma carga média para todas as paredes.

Corrêa e Ramalho (2003) ressaltam que, quanto à segurança do procedimento exposto, é difícil adotar uma posição simplista. Como devem ser definidos os grupos, quais grupos interagem entre si e ainda a taxa de interação adotada, é um procedimento que exige experiência do projetista. Quanto bem utilizado é seguro, produzindo inclusive ações adequadas para eventuais estruturas de suporte.

Dos processos para o cálculo da carga vertical em edifícios de alvenaria este é o mais econômico. No entanto, é imprescindível que se garanta a real existência das forças de interação em cantos e bordas, assim como nas regiões das aberturas.

\subsubsection{Automatização da Análise}

Com o intuito de otimizar a análise de edifícios em alvenaria estrutural, Corrêa e RamaIho $(1994,1998)$ desenvolveram uma ferramenta computacional que permite a automatização do procedimento sugerido, discretizando a geometria e carregamentos da estrutura a ser avaliada. Para tanto, faz-se necessária a entrada de alguns dados gerais da estrutura, como unidades dimensionais adotadas, peso específico da alvenaria, pé-direito dos andares, espessura das paredes e o número de pavimentos.

A geometria é definida com a utilização dos seguintes elementos:

\section{a) Pontos}

Indicam as extremidades dos segmentos, sendo representados por um número e por suas coordenadas cartesianas $\mathrm{X}$ e $\mathrm{Y}$, de acordo com um sistema adotado.

\section{b) Segmentos}

São de duas classes básicas: parede estrutural, denominada apenas como segmento Parede, ou parede não estrutural, representando segmentos de Janela, Porta e Abertura Total. Número, ponto inicial, ponto final, tipo de segmento, altura e espessura são os dados necessários para a sua definição. 
Se o usuário não definir a altura do segmento, esta será automaticamente calculada pelo programa como segue:

- h $\quad$ : segmento de Parede;

- 2h/3 : segmento de Janela;

- $\mathrm{h} / 3$ : segmento de Porta;

- $0 \quad$ : Abertura Total.

Onde "h" é o pé-direito fornecido no começo do arquivo de dados.

\section{c) Grupos}

Os grupos são formados por conjuntos de segmentos tipo Parede com mesma espessura, estando sujeitos a uma mesma carga vertical. São definidos por um número e pela relação de segmentos que os compõem.

Todos os carregamentos incidentes sobre uma parede são automaticamente distribuídos sobre as demais paredes de um grupo, gerando sempre um valor único de carga.

\section{d) Macrogrupos}

São conjuntos de grupos que interagem mediante uma determinada taxa de uniformização previamente definida pelo usuário (ver item 3.2.2.3). Essa sistemática é usualmente empregada para criar uma interação entre grupos de paredes separados por aberturas.

O carregamento pode ser definido tanto por cargas distribuídas atuantes em segmentos, como por cargas concentradas atuantes em pontos, tendo o usuário a capacidade de optar pelo seu cômputo em um ou mais pavimentos.

\subsubsection{Exemplo Desenvolvido}

Para exemplificar os processos de distribuição de cargas enunciados nos itens anteriores, realiza-se a modelagem de um edifício de dez pavimentos em alvenaria estrutural. Por simplicidade, usa-se apenas a planta do pavimento tipo sem fazer estimativa de cargas para o ático. A Figura 3.8 exibe a distribuição de paredes adotada. As definições de grupos e macrogrupos seguem o esquema apresentado na Figura 3.9, onde os grupos são definidos pela letra $G$ e os macrogrupos pelas letras $M G$.

Realizam-se três abordagens para o cálculo de cargas verticais, seguindo as metodologias descritas no item 3.2.2. Para o primeiro caso, trabalhando-se com paredes isoladas, basta distribuir as cargas separadamente pelas paredes. Em seguida, o estudo é desenvolvido usando-se o conceito de grupos de paredes isoladas. Finalmente, os grupos são reunidos em macrogrupos, com taxa de interação de 50\%. Entretanto, como explicado no item 3.2.2.3, a definição da taxa de interação fica a critério do projetista, sendo usualmente empregados valores de $0 \%$ a $50 \%$. 


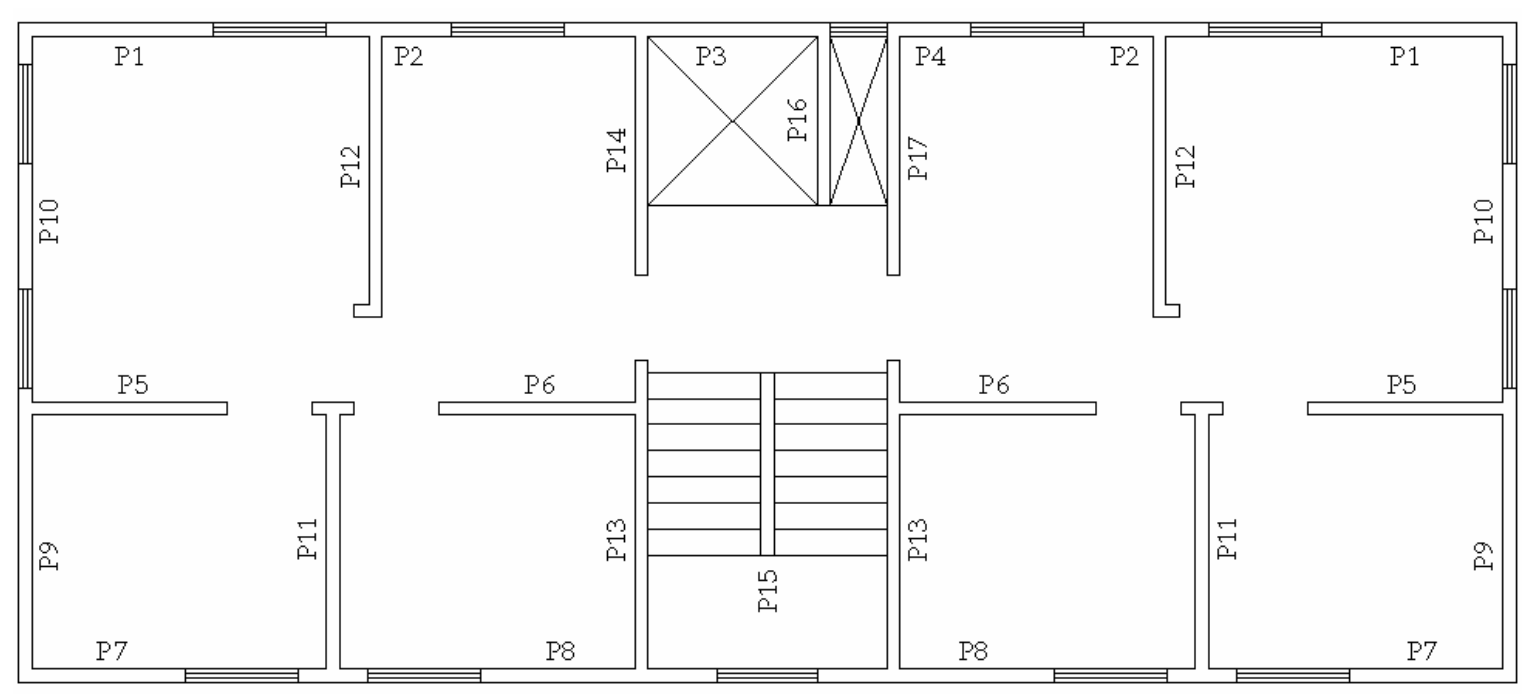

Figura 3.8 - Definição de paredes do exemplo desenvolvido

Os macrogrupos foram estabelecidos de forma a propiciar uma homogeneização das cargas entre grupos separados por aberturas de janelas. Entretanto, não se propõe realizar nenhum tipo de discussão mais ampla no que compete à definição das taxas de interação, uma vez que o exemplo aqui elucidado tem caráter apenas teórico e informativo. O objetivo desta etapa do trabalho é ressaltar a importância da abordagem adotada pelo projetista no cálculo das cargas verticais.

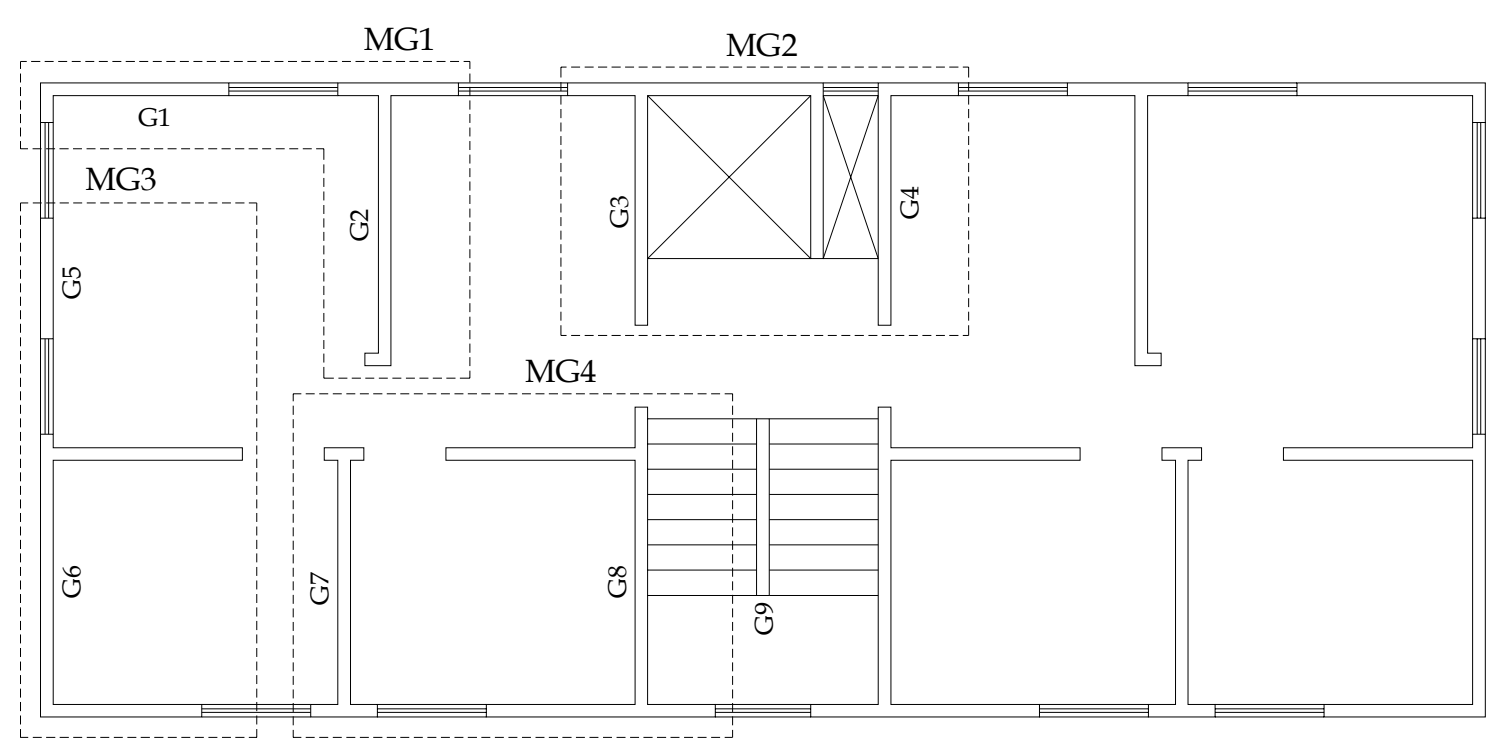

Figura 3.9 - Definição de grupos e macrogrupos

A Tabela 3.1 apresenta os resultados obtidos para os três processamentos desenvolvidos, onde as três últimas colunas expressam, respectivamente, Paredes Isoladas (PI), Grupo de Paredes Isoladas (GP) e Grupo de Paredes com Interação (GPI). 
Tabela 3.1 - Resultados obtidos para as cargas nas paredes

\begin{tabular}{|c|c|c|c|c|c|}
\hline $\begin{array}{c}\text { Parede } \\
P\end{array}$ & $\begin{array}{c}\text { Grupo } \\
\text { G }\end{array}$ & $\begin{array}{c}\text { Macrogrupo } \\
\mathrm{MG}\end{array}$ & $\begin{array}{c}\mathrm{PI} \\
(\mathrm{kN} / \mathrm{m})\end{array}$ & $\begin{array}{c}\mathrm{GP} \\
(\mathrm{kN} / \mathrm{m})\end{array}$ & $\begin{array}{c}\mathrm{GPI} \\
\mathrm{kN}(/ \mathrm{m})\end{array}$ \\
\hline 1 & 1 & 1 & 139,3 & 139,3 & 152,4 \\
\hline 2 & 2 & 1 & 164,0 & 161,4 & 154,6 \\
\hline 3 & 3 & 2 & 87,1 & 100,8 & 144,3 \\
\hline 4 & 4 & 2 & 154,6 & 147,6 & 119,0 \\
\hline 5 & 6 & 3 & 156,4 & 126,3 & 132,7 \\
\hline 6 & 8 & 4 & 147,3 & 144,7 & 153,9 \\
\hline 7 & 6 & 3 & 121,8 & 126,3 & 132,7 \\
\hline 8 & 8 & 4 & 127,5 & 144,7 & 153,9 \\
\hline 9 & 6 & 3 & 107,5 & 126,3 & 132,7 \\
\hline 10 & 5 & 3 & 170,5 & 170,5 & 137,1 \\
\hline 11 & 7 & 4 & 175,3 & 175,3 & 157,0 \\
\hline 12 & 2 & 1 & 160,4 & 161,4 & 154,6 \\
\hline 13 & 8 & 4 & 156,1 & 144,7 & 153,9 \\
\hline 14 & 3 & 2 & 142,6 & 100,8 & 144,3 \\
\hline 15 & 9 & - & 166,8 & 166,8 & 166,8 \\
\hline 16 & 3 & 2 & 62,7 & 100,8 & 144,3 \\
\hline 17 & 4 & 2 & 145,4 & 147,6 & 119,0 \\
\hline
\end{tabular}

As análises mostradas neste item são de grande valia no estudo de casos que se desenvolve no trabalho, pois se podem perceber algumas diferenças consideráveis de carregamento para as estruturas de apoio, dependendo do método para o cálculo das cargas verticais que se adota.

Como exemplo bastante elucidativo do argumento postulado acima, tem-se o caso da parede 16 que, pela análise por paredes isoladas, transmite uma carga para os pilotis de 62,7 $\mathrm{kN} / \mathrm{m}$. Com o procedimento de grupos com interação, o valor da carga passa a $144,3 \mathrm{kN} / \mathrm{m}$, registrando-se um aumento de 130,1\%. Observando-se a tabela apresentada, distinguem-se casos em que também ocorre diminuição das cargas na parede ou mesmo variações pouco significativas.

Com isso, fica comprovada a importância da realização de uma análise muito bem fundamentada, para que os resultados colhidos venham a retratar o mais fielmente possível o verdadeiro comportamento da estrutura de alvenaria. 


\section{Capítulo 4 \\ Programa Gerador de Dados}

\subsection{INTRODUÇÃO}

O programa desenvolvido na pesquisa que se apresenta foi batizado de Sistema GMPAE - Sistema Gerador de Modelos para Pavimentos de Alvenaria Estrutural, como enunciado pela tela da Figura 4.1.

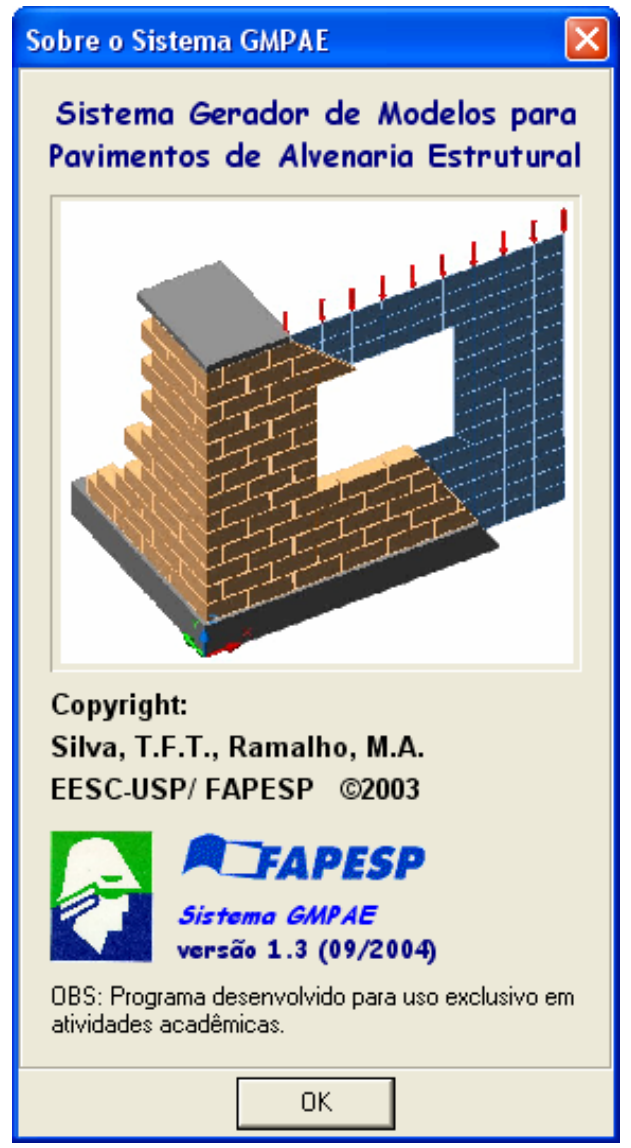

Figura 4.1 - Tela de informações do programa

O aplicativo foi inteiramente implementado com a linguagem de programação Delphi versão 6.0, da Borland Entreprise. Optou-se pelo Delphi por ser uma ferramenta computacional 
de grande funcionalidade para o trabalho em ambiente Windows, além de possuir as seguintes características:

- Permite o trabalho com Programação Orientada a Objetos;

- Uso de grupos de ações, que facilitam a organização do programa, bem como otimizam a construção de barras de ferramentas, manipulação de eventos ativos, etc;

- Possuiu um tipo de variável denominada dinamic array, que facilita sobremaneira o trabalho com vetores sem dimensão prefixada no código fonte, sendo possível manipulá-los sem que haja necessidade de trabalhar diretamente com alocação dinâmica de memória;

- O componente TeeChart permite a elaboração, com grande simplicidade, de gráficos sofisticados, o que otimiza bastante o tratamento de resultados para a apreciação de esforços, deslocamentos e tensões.

Para o desenvolvimento da interface do programa, balizou-se na idéia de criar um aplicativo amigável, com campos auto-explicativos (para os usuários que tem algum conhecimento do tratado no trabalho) e de acesso fácil e rápido aos diversos comandos implementados.

\subsection{AMBIENTE DE TRABALHO}

A Figura 4.2 apresenta a tela principal do programa desenvolvido, onde se observam as diversas seções criadas (Dados do Projeto, Arquivos do Projeto, Dados da Estrutura de Concreto, Dados da Alvenaria), o menu principal, que comporta todas as ações implementadas, e uma barra de ferramentas com atalhos para rotinas de abrir e salvar um projeto, criar um novo projeto e sair do aplicativo.

Os próximos itens detalham as funcionalidades e outros pormenores da ferramenta computacional desenvolvida.

\subsubsection{Página Projeto}

Contém todas as informações necessárias para a geração da rede, assim como campos que facilitam a organização do projeto, tendo sido dividida em quatro seções.

\subsubsection{Seção Dados do Projeto}

Usada para formatação dos campos que contém informações sobre o projeto em curso, como:

- Título do Projeto;

- Nome do Usuário;

- Nome do Arquivo;

- Diretório de Trabalho. 


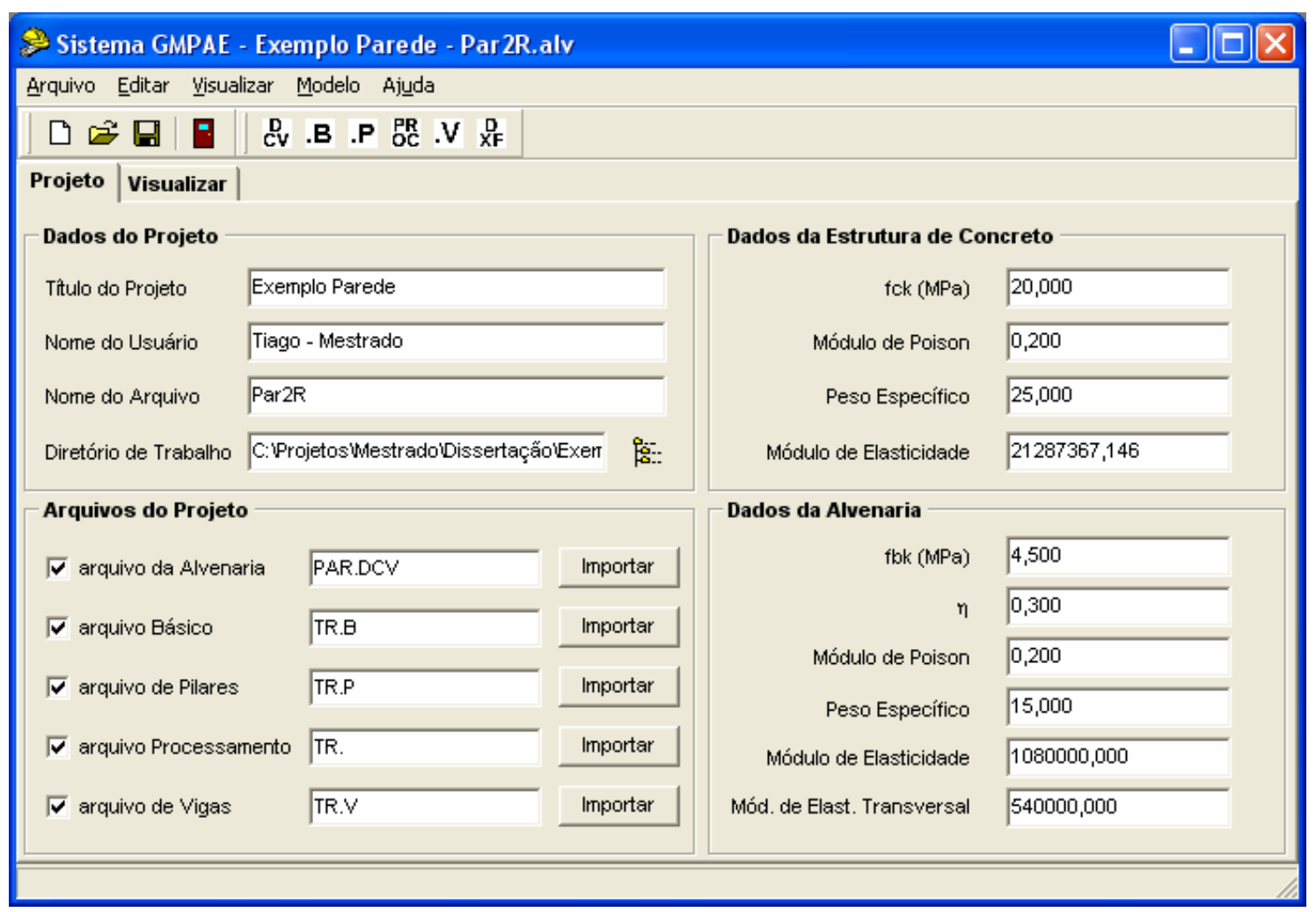

Figura 4.2 - Tela principal do aplicativo desenvolvido

\subsubsection{Seção Arquivos do Projeto}

Esta seção é, sem dúvida, a espinha dorsal do sistema desenvolvido. Vale observar que todos os arquivos utilizados, tanto os de dados de entrada como os de saídas de resultados (apresentados posteriormente), são do tipo texto.

A geração da rede para as paredes de alvenaria depende de algumas informações essenciais que são passadas pelos arquivos descritos a seguir:

- Arquivo da Alvenaria: é gerado com o processamento da estrutura de alvenaria usando-se o procedimento automatizado desenvolvido por Corrêa e Ramalho (1994). Contém informações sobre a estrutura de alvenaria, como dimensões das paredes, portas e janelas, peso específico, grupos, pé-direito do pavimento, etc;

- Arquivo Básico: é o arquivo de base dos nós da estrutura do pilotis, guardando as informações das coordenadas e restrições dos nós definidos antes da discretização do pavimento em barras;

- Arquivo de Pilares: armazena os dados dos pilares da estrutura de concreto. É de grande importância, pois contém a informação do tamanho de barra que o usuário estabeleceu para discretizar o pavimento, variável que servirá de base para definir o tamanho dos elementos das paredes;

- Arquivo de Processamento: gerado após o processamento da estrutura de concreto, é o principal arquivo importado, pois engloba os dados de todos os nós, barras e cargas nodais; 
- Arquivo de Vigas: fornece os dados referentes à incidência das vigas, bem como os nós de extremidade e propriedades (geométricas e dos materiais) dos diversos tramos que as constituem.

\subsubsection{Seção Dados da Estrutura de Concreto}

O valor de $f_{c k}$ é lido diretamente do arquivo de pilares, sendo que os outros três campos (Módulo de Poison, Peso Específico e Módulo de Elasticidade) vêm das informações de materiais constantes no arquivo de processamento.

É de inteira responsabilidade do usuário a checagem da ordem de grandeza dos valores importados, devendo averiguar se os mesmos estão adequados ou não ao padrão de unidades em curso. A única exceção refere-se ao campo de resistência característica do concreto, que sempre deve ser informado em MPa.

Como são feitas apenas análises elásticas nos processamentos, visando a determinação de esforços solicitantes e deslocamentos, quando se altera o campo de $f_{c k}$, o programa automaticamente calcula o novo valor do Módulo de Elasticidade, usando, para tanto, a expressão do módulo de elasticidade secante, expresso no item 8.2.8 da NBR 6118:2003, como segue:

$$
E_{c s}=0,85 \cdot 5600 \cdot \sqrt{f_{c k}}
$$

Sendo $E_{c s}$ e $f_{c k}$ dados em MPa na expressão acima.

\subsubsection{Seção Dados da Alvenaria}

O primeiro campo contém o valor da resistência característica dos blocos do primeiro pavimento (ou do nível para o qual será efetuada a análise), devendo ser obrigatoriamente expresso em MPa. O campo seguinte possibilita a colocação de um valor para eficiência, que permite estabelecer uma relação entre a resistência dos blocos e a resistência à compressão das paredes. Com isso, pode-se extrair o valor da resistência de prisma $\left(f_{p}\right)$ para o pavimento estudado, como apresentado na seguinte equação:

$$
f_{p}=\eta \cdot f_{b k}
$$

Caso um desses parâmetros venha a ser alterado, o programa recalcula os valores para os Módulos de Elasticidade Longitudinal e Transversal de acordo com os valores apresentados na eq.(4.3) e eq.(4.4), adequados para blocos de concreto.

$$
\begin{aligned}
& E_{\text {alv }}=800 \cdot f_{p} \\
& G_{\text {alv }}=400 \cdot f_{p}
\end{aligned}
$$




\subsubsection{Página Visualizar}

Para que o usuário possa realizar uma simples conferência dos dados importados com os arquivos, clicando-se na aba Visualizar se tem acesso à tela apresentada na Figura 4.3.

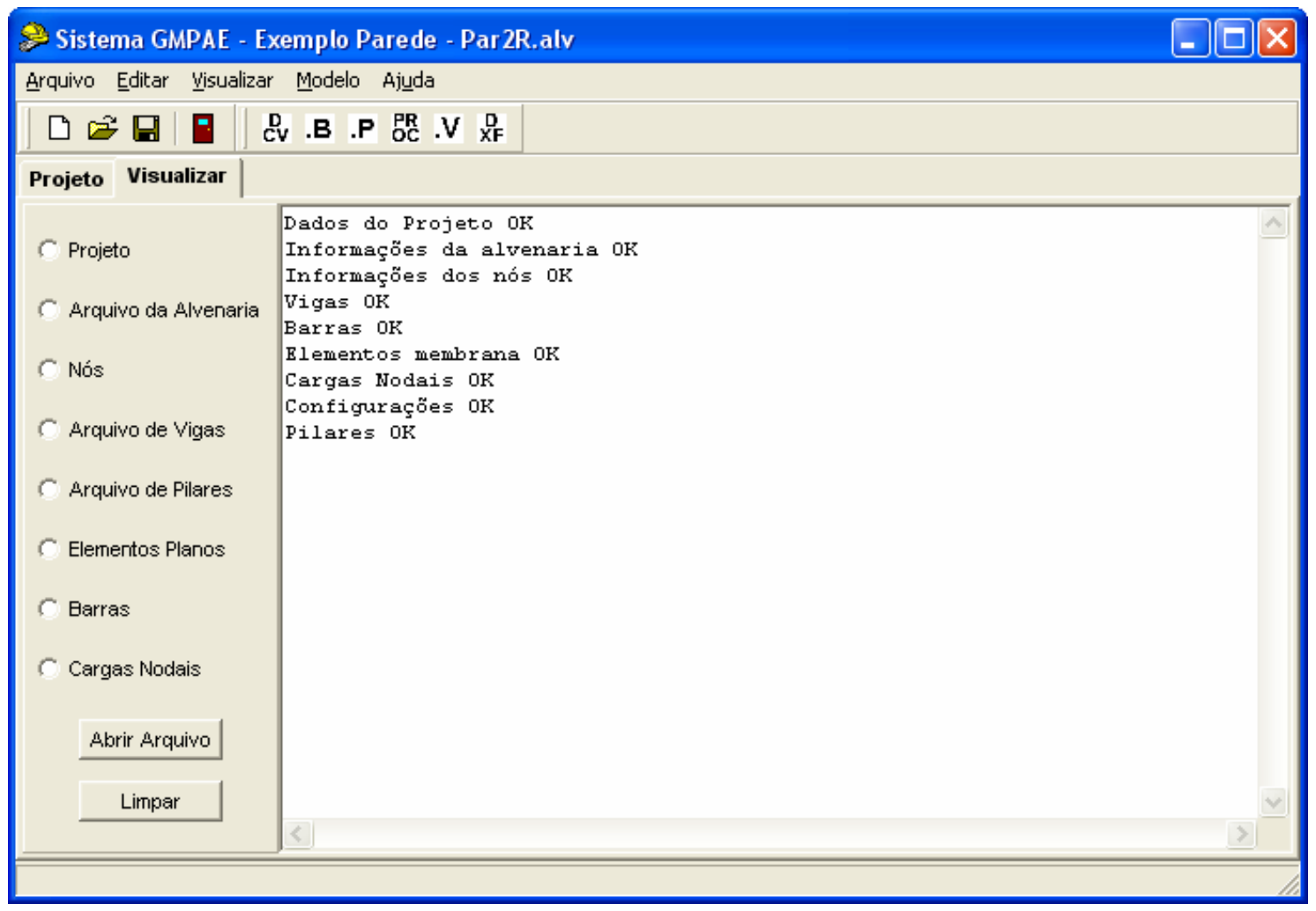

Figura 4.3 - Tela com a página Visualizar

Com a interface apresentada, é possível visualizar os dados referentes a todos os elementos importados ou criados pelo programa, verificar quais informações foram lidas com sucesso num arquivo de projeto ou abrir um arquivo texto qualquer, não necessitando de nenhum outro aplicativo.

\subsection{EDIÇÃO DE SEGMENTOS}

Conforme descrito no item 3.2.3.b, os segmentos podem ser do tipo parede, janela, porta e abertura total. Para que a rede gerada possa representar fielmente a estrutura a ser projetada, criou-se uma interface que permite a configuração da dimensão da abertura, altura do peitoril e espessura da parede de forma rápida e segura.

Vale ressaltar que a compatibilização correta entre as dimensões da abertura e do peitoril deve ser feita pelo usuário, isto é, caso se queira fazer uma alteração na abertura de uma janela, deve-se informar a nova dimensão do peitoril, sendo que apenas o trecho de parede acima da janela é recalculado pelo programa. Também são feitas algumas verificações concernentes a entradas de valores errôneos, o que poderia gerar, por exemplo, um trecho com dimensão negativa. 
Acessando-se o menu principal em Editar > Segmentos, são apresentadas as telas ilustradas na Figura 4.4 e Figura 4.5, para segmentos de janela e porta, respectivamente.

Para o trabalho de edição dos segmentos, faz-se necessária a definição das seguintes variáveis:

- HPDir: altura do pé-direito;

- HS: altura de alvenaria no segmento;

- HPt: altura do peitoril;

- DA: dimensão da abertura;

- h: trecho de alvenaria sobre as aberturas.

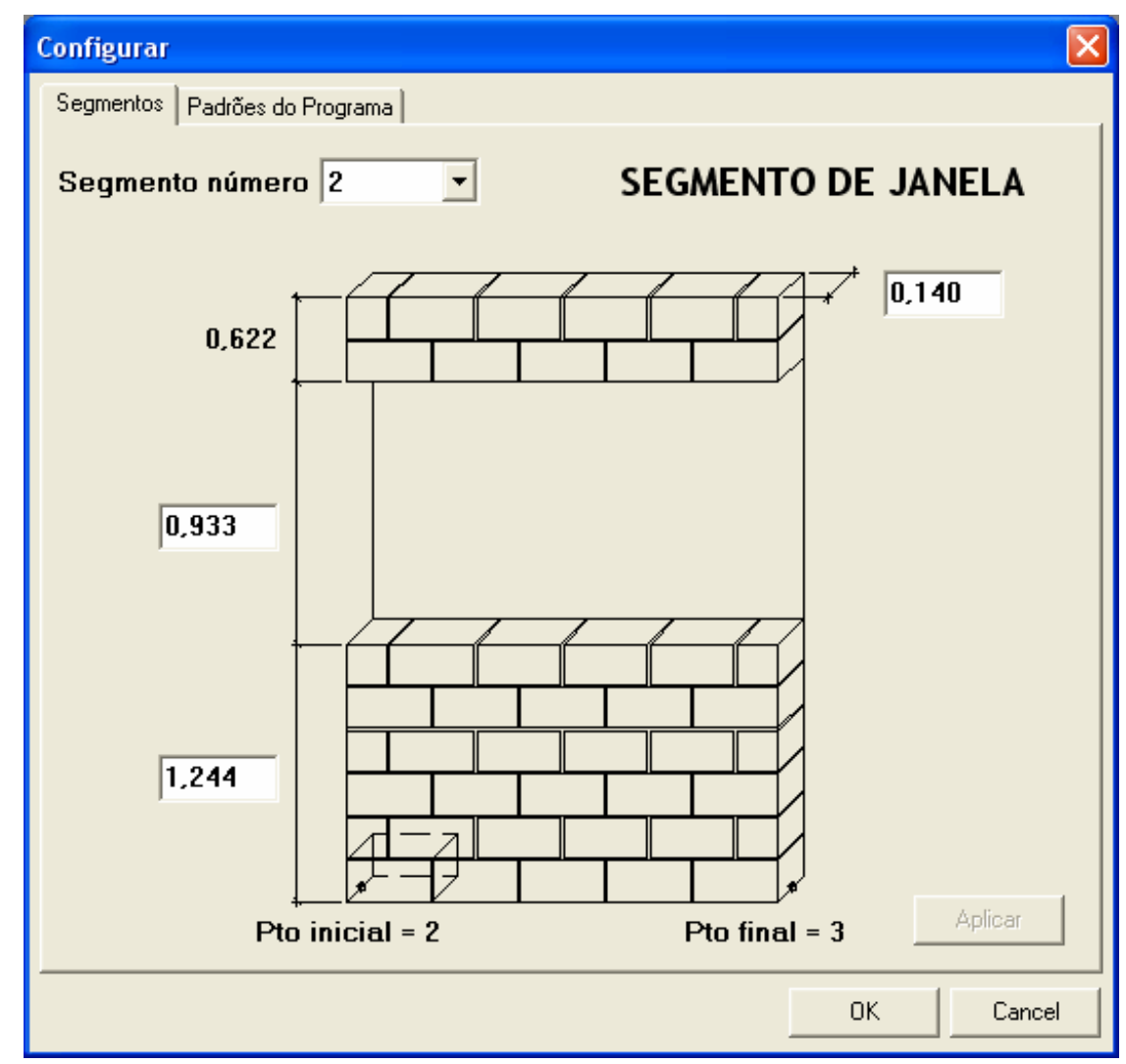

Figura 4.4 - Edição de um segmento de janela

O procedimento desenvolvido por Corrêa e Ramalho (1994) adota como padrão para o cálculo das cargas verticais que um segmento de janela possuiu dois terços do pé-direito do pavimento em alvenaria. Levando isso em conta e observando-se a Figura 4.6 pode-se escrever que, para um segmento de janela, as seguintes relações são válidas:

$$
\begin{aligned}
& \mathrm{HS}=\mathrm{HPt}+\mathrm{h}=\frac{2}{3} \cdot \mathrm{HPDir} \\
& \mathrm{HPt}=\frac{2}{3} \cdot \mathrm{HS}=\frac{2}{3} \cdot\left(\frac{2}{3} \cdot \mathrm{HPDir}\right) \\
& \mathrm{h}=\frac{1}{3} \cdot\left(\frac{2}{3} \cdot \mathrm{HPDir}\right)
\end{aligned}
$$




$$
\mathrm{DA}=\mathrm{HPDir}-\mathrm{HS}=\frac{1}{3} \cdot \mathrm{HPDir}
$$

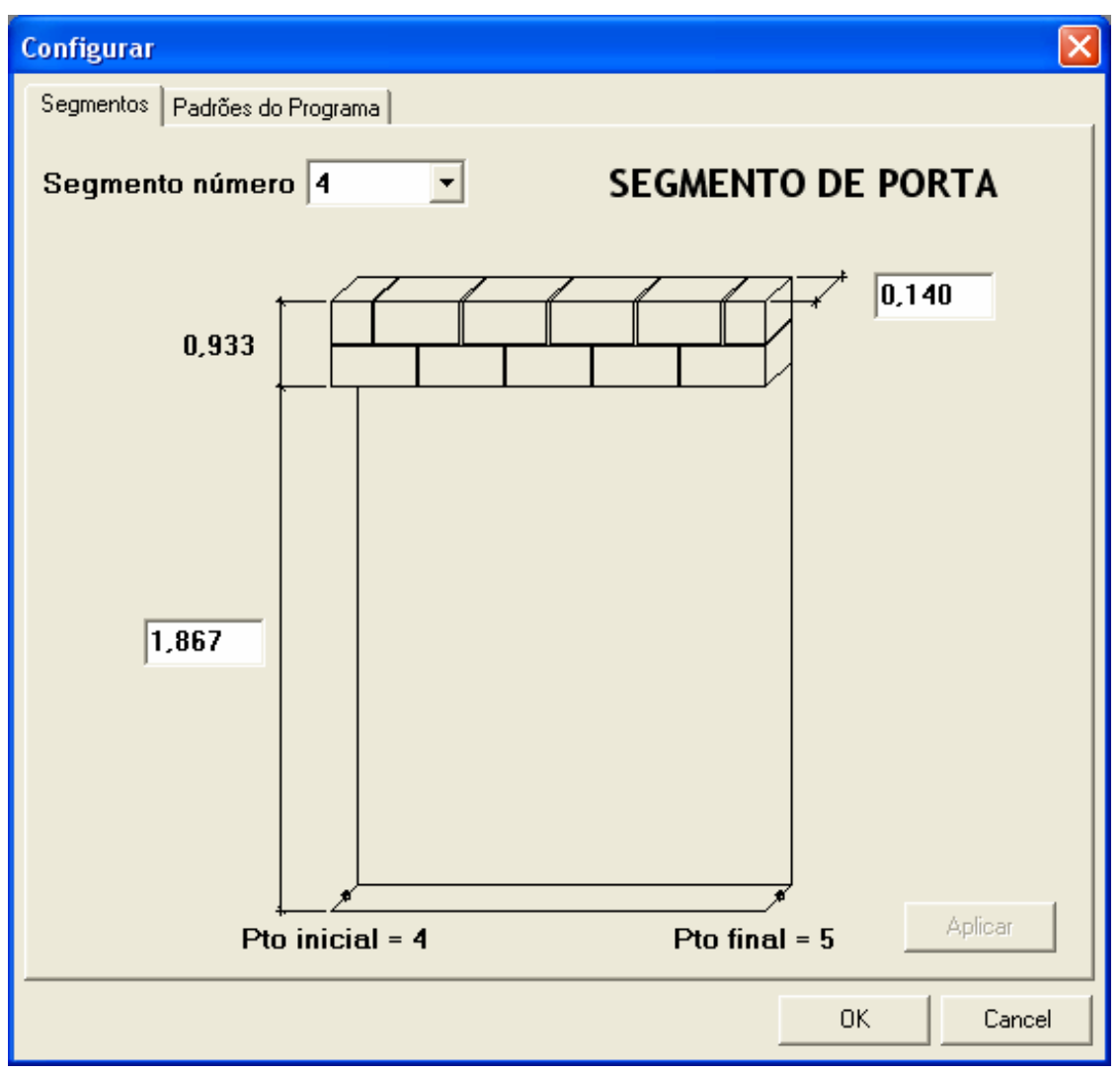

Figura 4.5 - Edição de um segmento de porta

Por simplicidade, resolveu-se adotar no trabalho que o peitoril representa dois terços da altura do segmento, como se observa na eq.(4.6), inferindo-se da mesma a dimensão do trecho de alvenaria sobre a abertura, definido pela eq.(4.7).

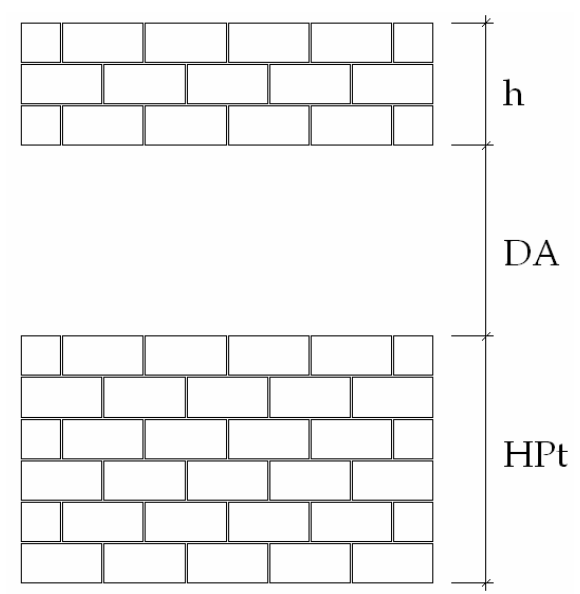

Figura 4.6 - Dimensões de um trecho de janela

Para o caso do segmento de porta que, obviamente, não possui o trecho de alvenaria do peitoril, podem-se deduzir as seguintes equações: 


$$
\begin{aligned}
& H S=h=\frac{1}{3} \cdot H P D i r \\
& D A=H P D i r-H S=\frac{2}{3} \cdot H P D i r
\end{aligned}
$$

A facilidade de edição desses parâmetros permite ao usuário montar uma rede que represente perfeitamente as dimensões de paredes e aberturas que são especificadas no projeto de modulação.

\subsection{IMPORTAÇÃO DOS ARQUIVOS DE DADOS}

Para que se possa trabalhar com o Sistema GMPAE é necessário que, previamente, sejam elaborados um modelo para a alvenaria (computando-se as cargas verticais) e outro para a estrutura de suporte em concreto armado (pilotis), para o qual se define o tamanho das barras para discretização das vigas. Este dado será adotado como padrão para posterior geração dos elementos da parede, ponto abordado em um item subseqüente. Este procedimento fornece os arquivos que servem de base para a geração da rede em elementos finitos para as paredes.

Todos os arquivos descritos no item 4.2.1.2 podem ser facilmente importados da seguinte maneira: primeiro deve-se habilitar o campo do arquivo desejado, clicando-se na respectiva caixa de checagem; pelo botão Importar tem-se acesso a uma caixa de diálogo Abrir (padrão do Windows) com os filtros referentes ao referido arquivo. A operação é exemplificada nas telas da Figura 4.7, para o caso do arquivo de alvenaria, com extensão DCV.

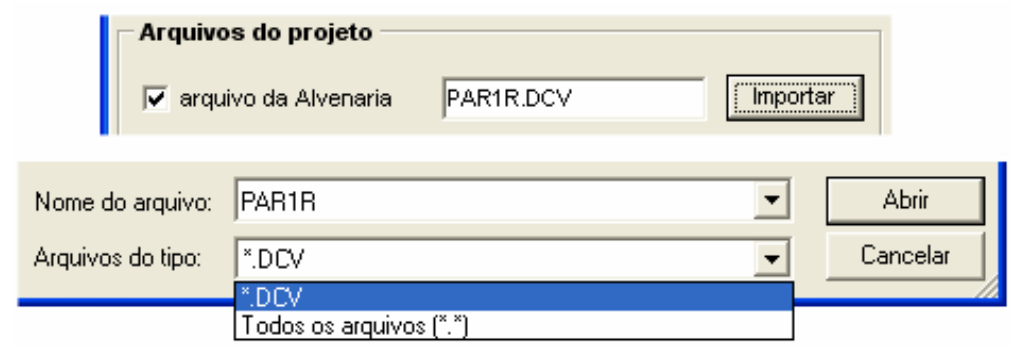

Figura 4.7 - Esquema de telas para importação de arquivo

\subsection{GERAÇÃO DA REDE}

Com a base de dados importada, passa-se ao trabalho de geração da rede em elementos finitos para a parede. A rotina desenvolvida admite o trabalho com todo o tipo de leiaute de paredes facilmente, o que permite, com a execução de apenas um comando, a montagem de um modelo que, quando calculado, leva em conta o efeito arco na análise de esforços, tensões e deslocamentos.

Como o trabalho se apóia em um conjunto de dados peculiar, buscou-se uma linha de processamento que facilitasse a elaboração da rede, além de garantir segurança, eficiência e que permitisse a confecção de modelos tão refinados quanto se queira. 
A rotina que processa os dados importados e desenha a rede pode ser acessada diretamente pela tecla de atalho F10, ou pelo comando de menu Modelo > Gerar Rede. Os parágrafos seguintes procuram esclarecer os passos realizados pelo programa para a obtenção da rede em elementos finitos para o pavimento em alvenaria.

A operação que se mostrou mais interessante foi a geração da rede individualmente para cada segmento, realizando-se, posteriormente, possíveis compatibilizações na interface entre segmentos.

Sendo NumDiv o número de elementos na altura da parede e TamBar o tamanho das barras definidas pelo usuário no arquivo de pilares, o espaçamento vertical (Delta) adotado para a geração da rede será:

$$
\begin{aligned}
& \text { NumDiv }=\text { arredondar }\left(\frac{\text { HPDir }}{\text { TamBar }}\right) \\
& \text { Delta }=\frac{\text { HPDir }}{\text { NumDiv }}
\end{aligned}
$$

O algoritmo de geração da rede deve prever a ocorrência de regiões como a indicada na Figura 4.8.

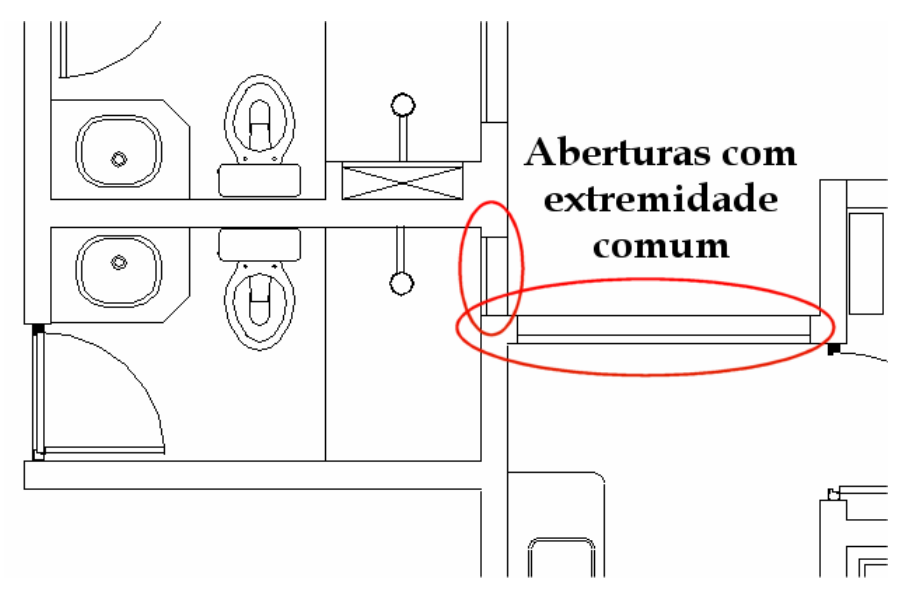

Figura 4.8 - Aberturas com extremidades comuns

A geração de nós e elementos, permitindo a compatibilização e adequação de casos como o exposto acima, pode ser sumarizada pelas seguintes etapas:
a) Primeiro geram-se os elementos para os segmentos do tipo parede;
b) Geração dos elementos para os demais segmentos (tipo porta e janela);
c) Verificação de nós internos a arestas de elementos;
d) Verificação de nós livres.

Conforme o programa executa as diversas etapas descritas, uma mensagem aparece na barra de status do aplicativo, com os dizeres que seguem:

- Etapas (a) e (b): "Gerando rede primária..."; 
- Etapa (c): "Procurando por nós em arestas de elementos...";

- Etapa (d): "Procurando por nós livres...".

Caso ocorra uma exceção (um erro) em qualquer um dos passos, uma mensagem é emitida ao usuário, informando-Ihe resumidamente da ocorrência de algum problema no processamento da rede.

A Figura 4.9 demonstra o resultado das duas primeiras etapas descritas, fornecendo a geometria da discretização em elementos finitos das paredes do exemplo desenvolvido no final do Capítulo 3.

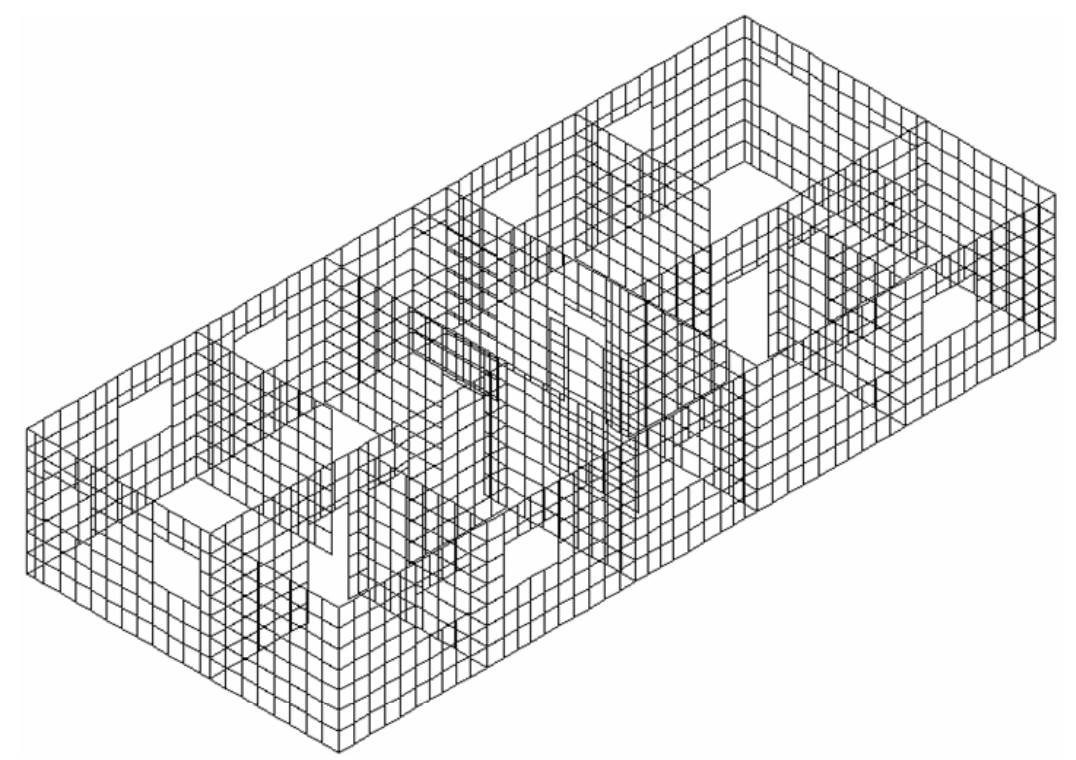

Figura 4.9 - Rede sem compatibilização de nós e elementos

Destaca-se que a rede exibida não pode ser obtida diretamente do aplicativo. Entretanto, para fins puramente elucidativos, trabalhou-se dentro do código do programa de forma a propiciar a extração da mesma.

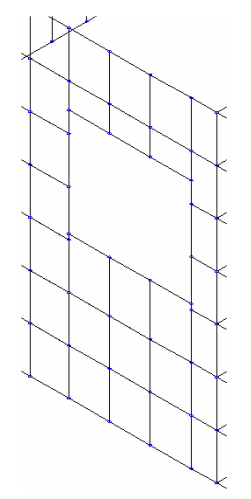

4 nós em arestas

(a)

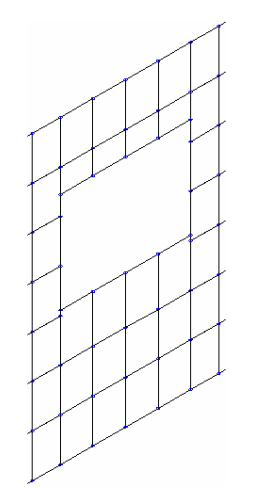

4 nós em arestas

(b)

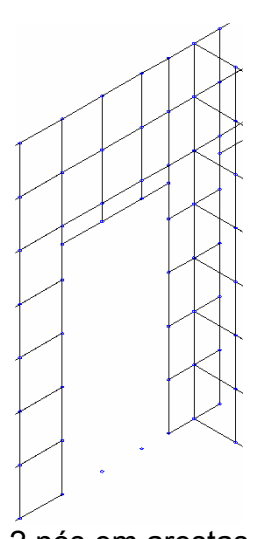

(c)

Figura 4.10 - Exemplos de incompatibilidades da rede primária

A continuação do código de geração de elementos procura ajustar os pontos problemáticos da rede, efetuando-se as tarefas descritas nas etapas (c) e (d) anteriormente apresenta- 
das. Para tanto, como se observa na Figura 4.10, faz-se necessária a verificação da ocorrência de nós em arestas de elementos para apenas dois ou quatro nós, nos casos de aberturas de portas e janelas, respectivamente.

Como verificado em alguns modelos na fase de testes do programa, é interessante que se analisem todos os nós da interface entre dois segmentos, pois, em um determinado ponto, é possível a concorrência de diversos trechos de aberturas com diferentes dimensões. Sendo assim, considerando-se apenas os nós descritos no parágrafo anterior, haveria casos em que as correções adequadas não seriam exeqüíveis.

A Figura 4.11 e a Figura 4.12 ilustram o formato definitivo da rede obtida com o processamento da estrutura de exemplo com o Sistema GMPAE. Deve-se salientar que a rotina de geração da rede tem como resultado os desenhos que são agora apresentados.

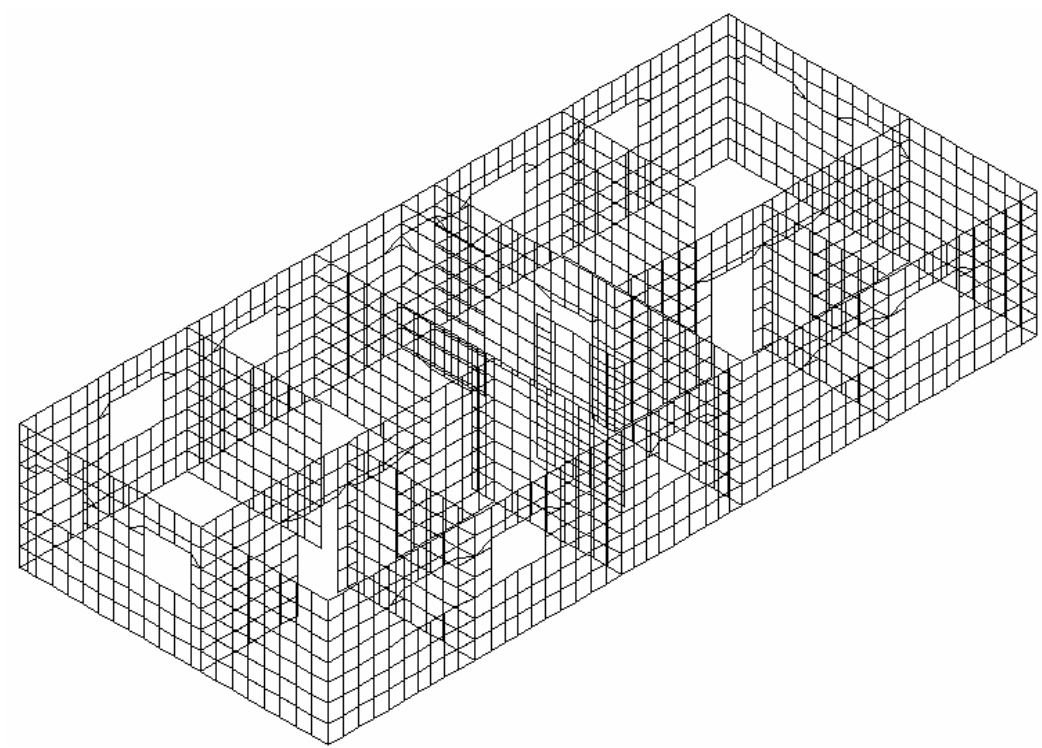

Figura 4.11 - Rede com a compatibilização de nós e elementos

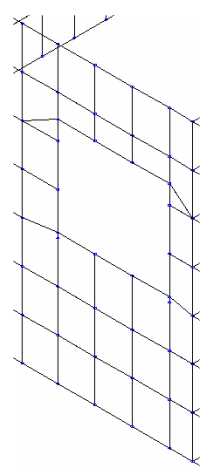

(a)

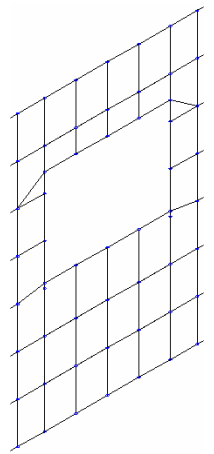

(b)

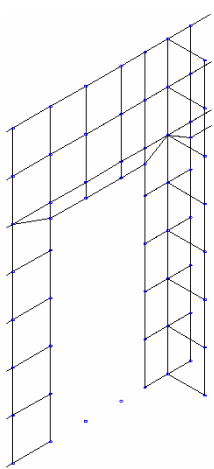

(c)

Figura 4.12 - Exemplos de correções da rede primária

\subsection{CHECAGEM DO MODELO GERADO}

O programa desenvolvido gera uma rede em elementos finitos partindo-se de arquivos previamente importados, e seguindo padrões de dimensão de elementos definidos pelo usuá- 
rio. Sendo assim, deve-se fazer uma avaliação da qualidade da rede obtida antes de se efetuar o processamento do modelo gerado.

Para isso, criaram-se dois caminhos possíveis de serem tomados:

a) Verificação via arquivo DXF;

b) Verificação direta via Sistema GMPAE.

A seguir, detalham-se as duas sistemáticas desenvolvidas.

\subsubsection{Verificação da Geometria via Arquivo DXF}

Acessando o item de menu Arquivo $>$ Exportar $>$ Arquivo DXF (atalho tecla F6), exporta-se um arquivo no formato DXF (Drawing Interchange Format), que pode ser aberto em programas CAD (Computer Aided Design).

Como se nota nas figuras apresentadas no item 4.5, com a visualização que se utiliza é difícil observar as posições das aberturas e, principalmente, verificar alguma imperfeição nesses pontos. Como os elementos membrana são desenhados no arquivo DXF usando a entidade 3Dface, basta executar o comando shade no AutoCAD ${ }^{\circledR}$ para se obter o resultado mostrado na Figura 4.13.

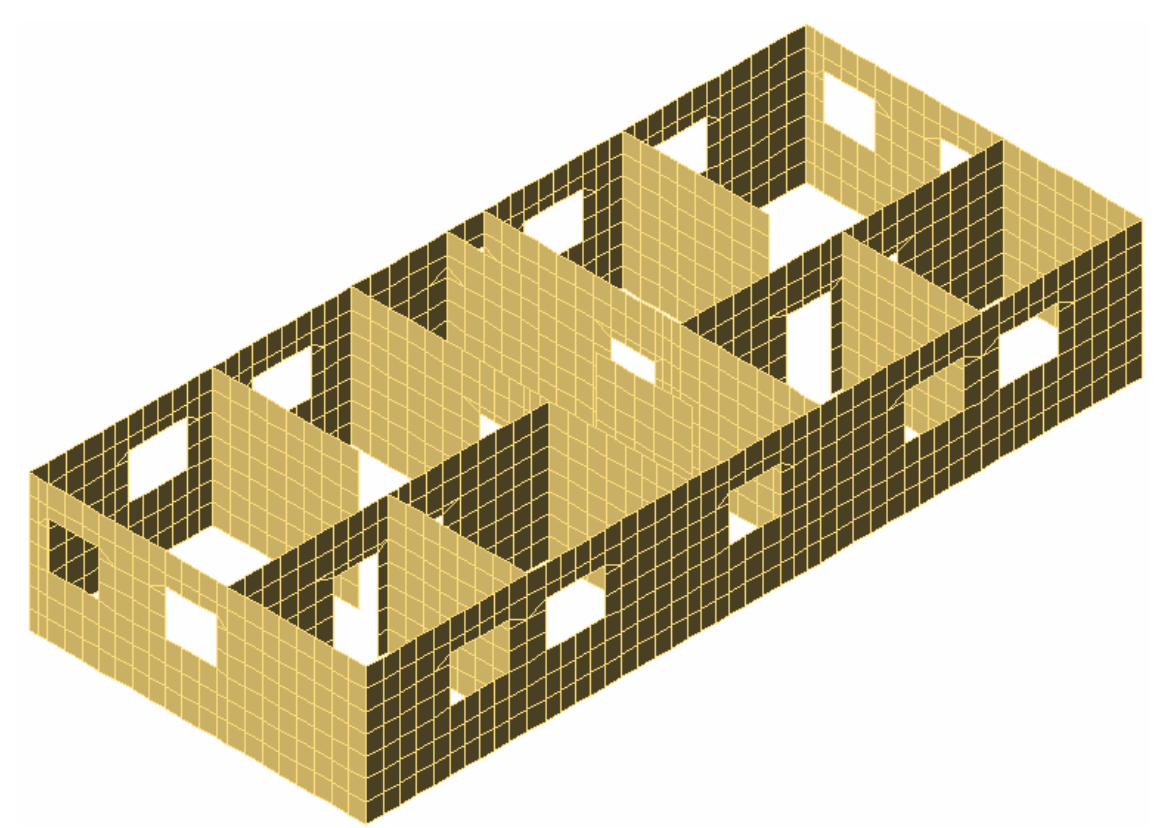

Figura 4.13 - Rede após o uso do comando shade no AutoCAD ${ }^{\circledR}$

A Figura 4.14 exibe a tela de configuração do arquivo DXF, onde podem ser feitas alterações na nomenclatura dos layers e cores adotadas, assim como dimensões de textos e tamanho dos nós a serem desenhados. Tem-se ainda a facilidade na escolha das entidades a serem exportadas, sendo apenas necessário mantê-las marcadas, conforme indicado na tela apresentada. 


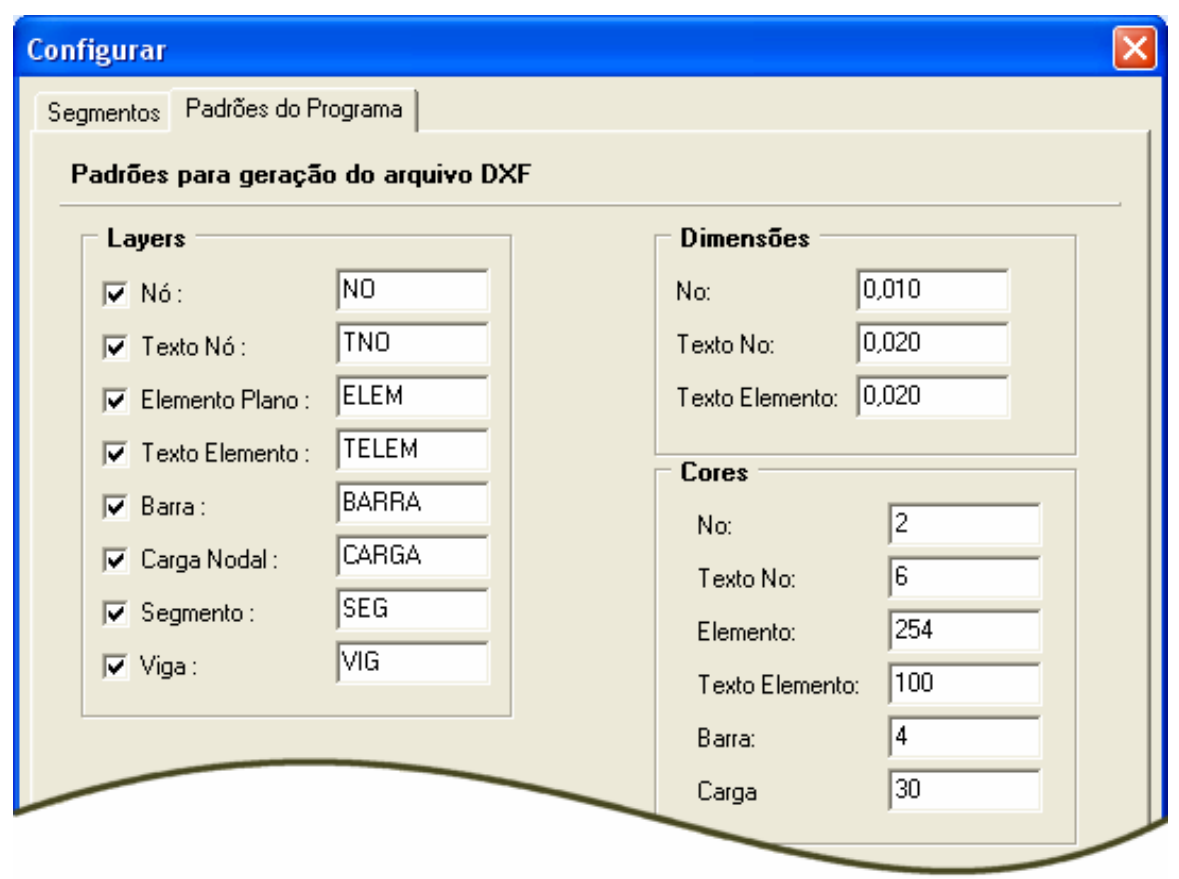

Figura 4.14 - Padrões para geração do arquivo DXF

\subsubsection{Verificação Direta da Geometria via Sistema GMPAE}

Para facilitar a verificação da geometria criada com o aplicativo, o usuário pode optar pela visualização da geometria executando-se o item de menu Visualizar $>$ Estrutura. Esse comando exibe a tela apresentada na Figura 4.15.

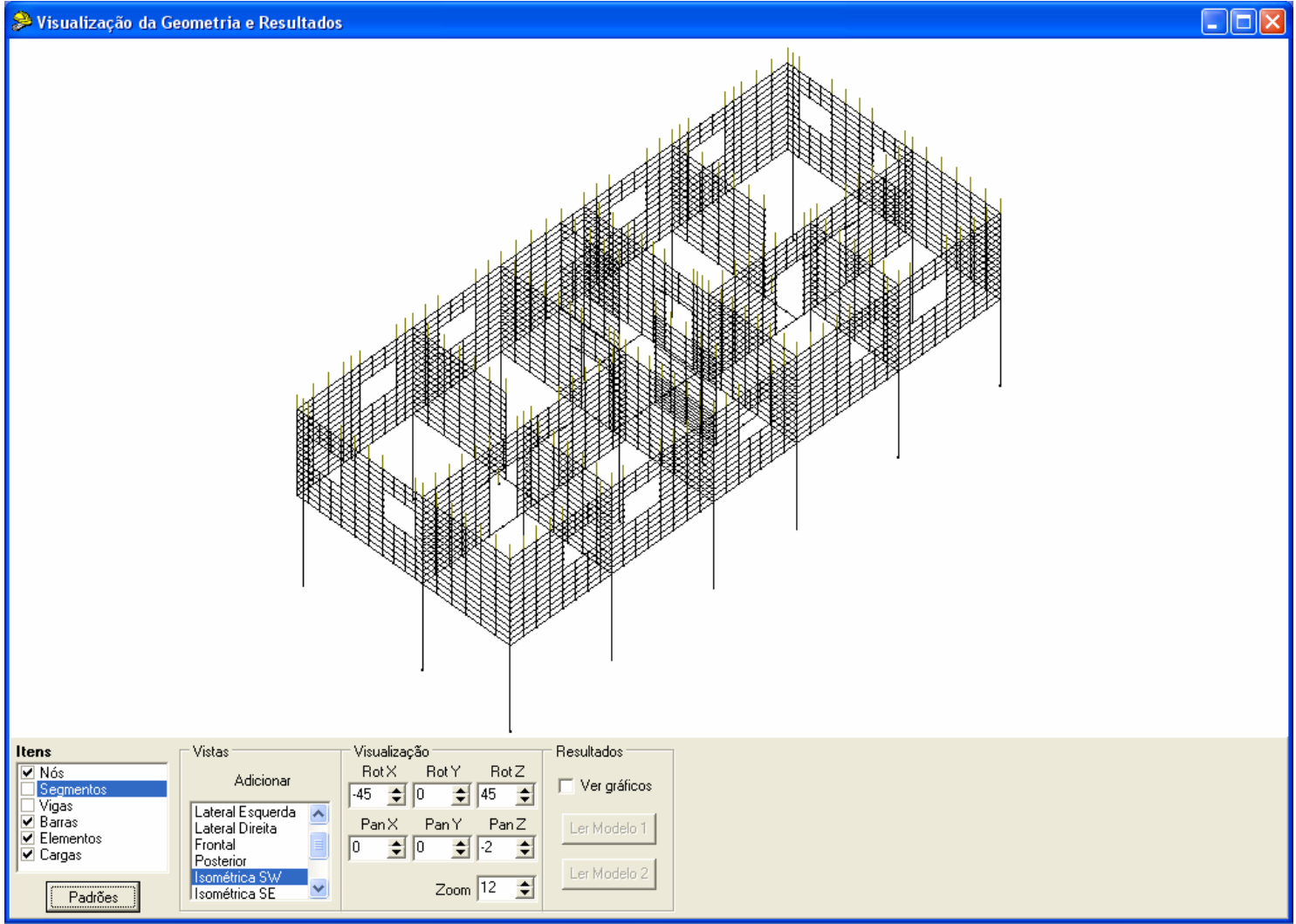

Figura 4.15 - Ambiente de visualização da estrutura no programa 
A estrutura é desenhada usando-se a biblioteca gráfica OpenGL (introduzida em 1992 pela Silicon Graphics) e permite, manipulando-se algumas entidades básicas, a criação de desenhos complexos. No caso tratado, o ambiente de visualização foi desenvolvido para permitir que o usuário analise rapidamente (e sem necessitar de nenhum outro aplicativo) a geometria das barras importadas e principalmente a forma dos elementos criados para discretizar as paredes, além de verificar os nós que estão sendo carregados.

A interface de visualização desenha todas as entidades importadas ou geradas pelo programa, que podem ser ligadas (permitindo sua visualização na tela) ou desligadas (no caso contrário) acessando-se os campos contidos na caixa ltens da figura anterior.

No campo Vistas foram criadas nove visualizações padrão, sendo:
a) Vista de Topo;
b) Vista Lateral Esquerda;
c) Vista Lateral Direita;
d) Vista Frontal;
e) Vista Posterior;
f) Vista Isométrica SW (Sudoeste);
g) Vista Isométrica SE (Sudeste);
h) Vista Isométrica NE (Nordeste);
i) Vista Isométrica NW (Noroeste);

Além destas, pode-se criar uma nova vista clicando-se no botão Adicionar.

Com os botões definidos dentro da caixa Visualização, pode-se configurar uma perspectiva qualquer, alterando-se a rotação, translação e zoom da imagem exibida, salvando tais valores ao se criar uma nova vista.

O botão Padrões exibe a tela da Figura 4.16. Com esta janela o usuário tem a possibilidade de configurar qualquer objeto desenhado. Na caixa Cores, clicando-se em cada um dos campos apresentados, a cor com que será exibido o respectivo item pode ser alterada. Em Configurações tem-se como mudar a espessura das linhas de barras, vigas, segmentos e dos bordos dos elementos planos, assim como o tamanho dos nós, sendo todas as dimensões expressas em pixels.

A caixa de checagem Antialised OFF permite o desenho dos nós com ou sem arredondamento nos vértices. Em Visualizar nós, pode-se selecionar a apresentação de todos os nós na tela, apenas os que estão no plano das vigas ou os que definem as extremidades de barras de vigas e pilares. Também existe a possibilidade de preencher os elementos planos, habilitando-se a caixa de checagem ON/OFF.

A Figura 4.17 exibe a tela de visualização da geometria com algumas alterações conseguidas com a interface desenvolvida, variando-se a rotação, translação e zoom do objeto, tendo sido criada uma vista de nome Teste para abrigar as mudanças realizadas. 


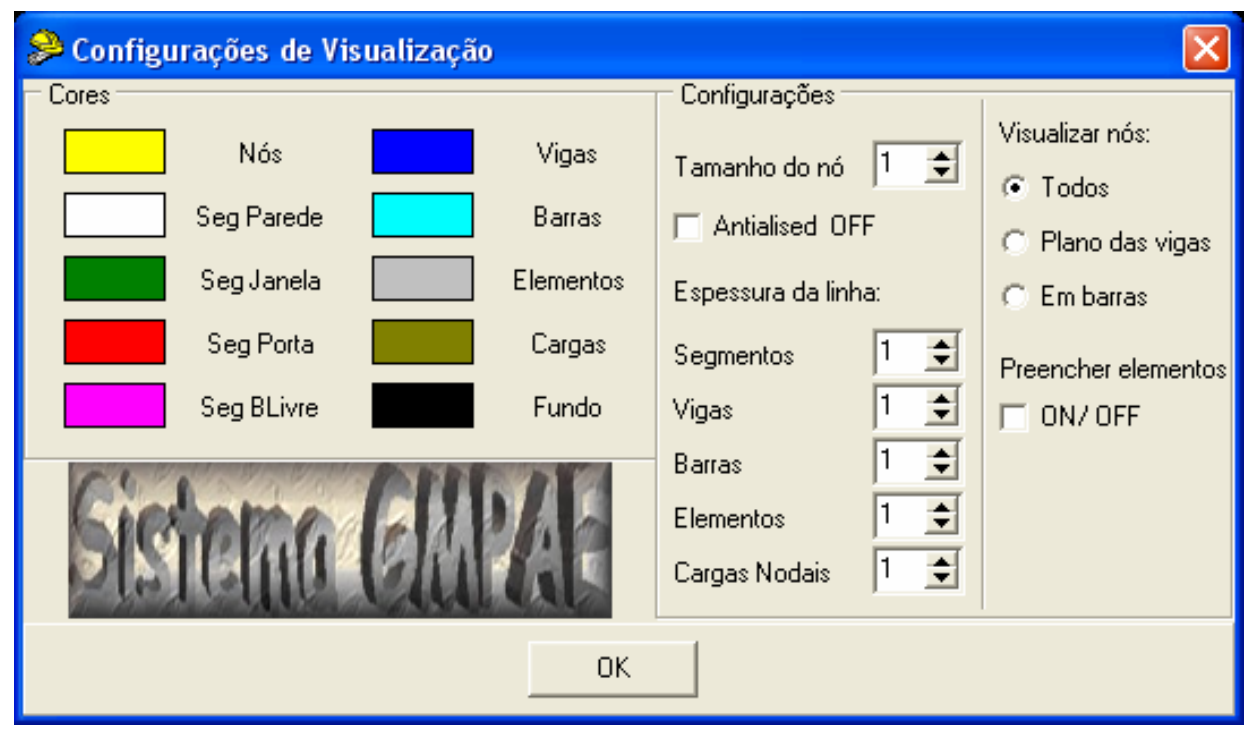

Figura 4.16 - Tela Configurações de Visualização

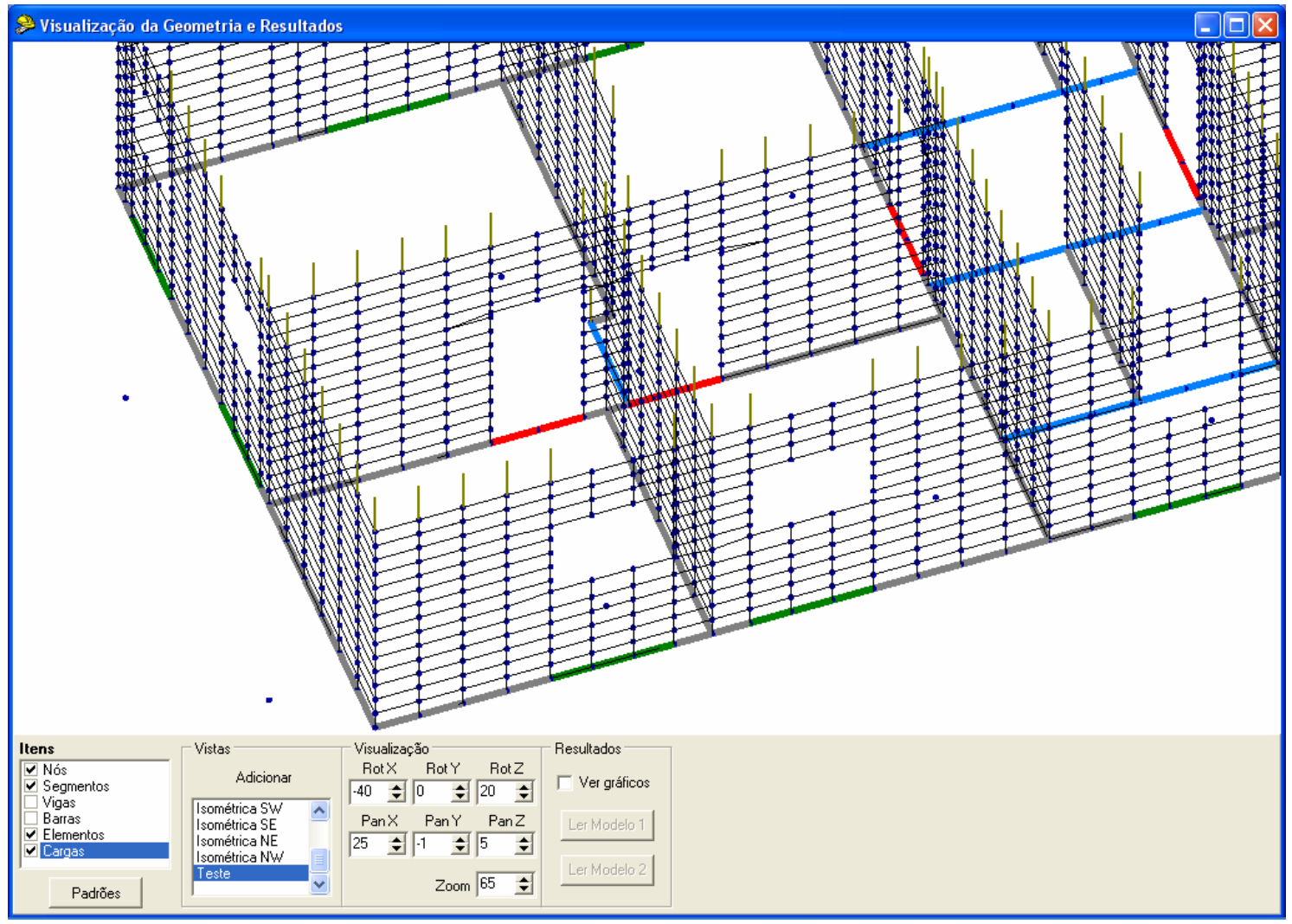

Figura 4.17 - Tela com visualização criada pelo usuário

\subsection{FUNCIONALIDADES DO APLICATIVO}

Com o intuito de evidenciar os recursos de adaptação das dimensões das aberturas e os critérios contidos no campo Padrões para geração da rede, explicitado na Figura 4.18, prepara-se um exemplo simples.

A Figura 4.19 evidencia o painel elaborado, com uma abertura de janela com 281 x 121 $\mathrm{cm}$, e uma abertura de porta com $121 \times 221 \mathrm{~cm}$. Na parte inferior vê-se o campo segmentos, 
com cinco linhas numeradas e seis nós. Estes são os elementos que compõem o modelo de alvenaria a ser importado pelo programa.

Os segmentos de números 1, 3 e 5 são definidos como Segmentos Parede, o de número 2 como Segmento Janela e o de número 4 como Segmento Porta. Esta classificação é a mesma definida por Corrêa e Ramalho (1994), no desenvolvimento de uma ferramenta computacional que permite a automatização do procedimento para cálculo de cargas verticais em edifícios de alvenaria estrutural, descrevendo-se a geometria e carregamentos da estrutura analisada.

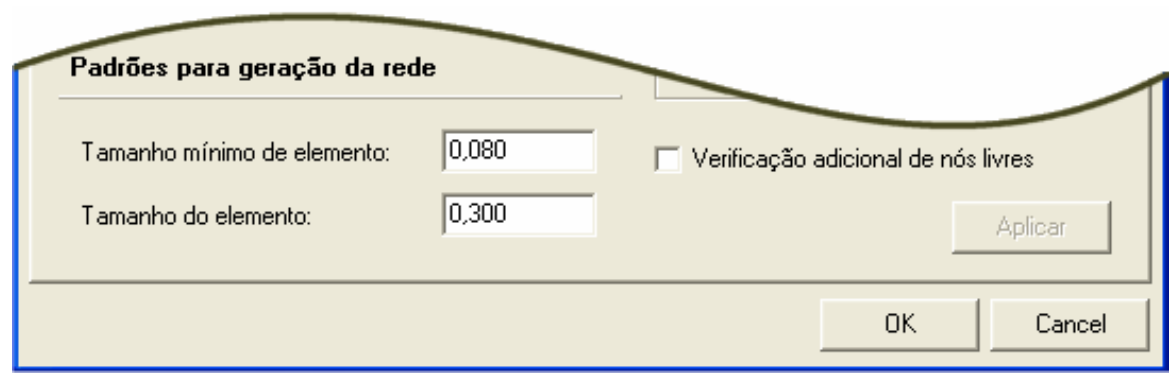

Figura 4.18 - Configurações para geração da rede

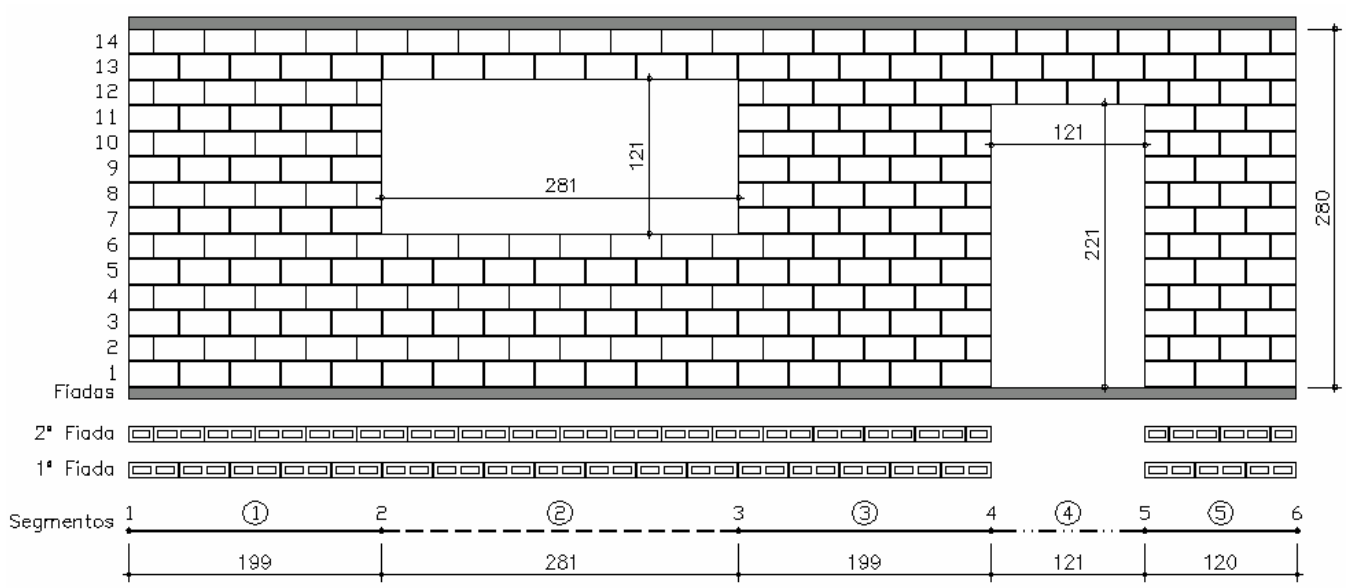

Figura 4.19 - Painel de exemplo

Elaborou-se uma estrutura de suporte em concreto armado formada por pilares e vigas, para que se pudesse dar continuidade ao processamento do exemplo.

Com a base de dados importada e executando-se o comando para geração da rede, obtém-se a geometria apresentada na Figura 4.20.

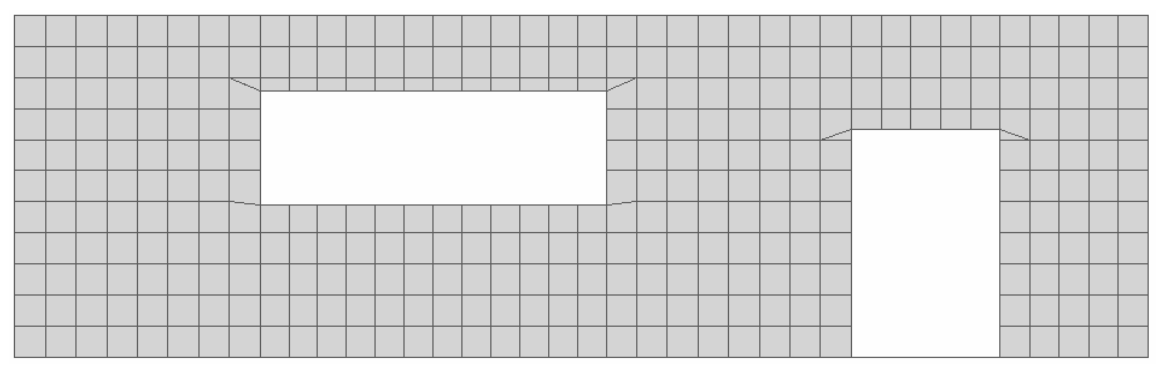

Figura 4.20 - Rede inicial, sem acertos na dimensão das aberturas 
Alterar o tamanho da porta e da janela para as dimensões reais (expressas na Figura 4.19) é tarefa simples, pois basta corrigir os valores de peitoril e abertura, como apresentado nas telas do item 4.3. A execução dessa etapa, seguindo-se com uma nova geração da rede, possibilita a obtenção da geometria evidenciada na Figura 4.21 .

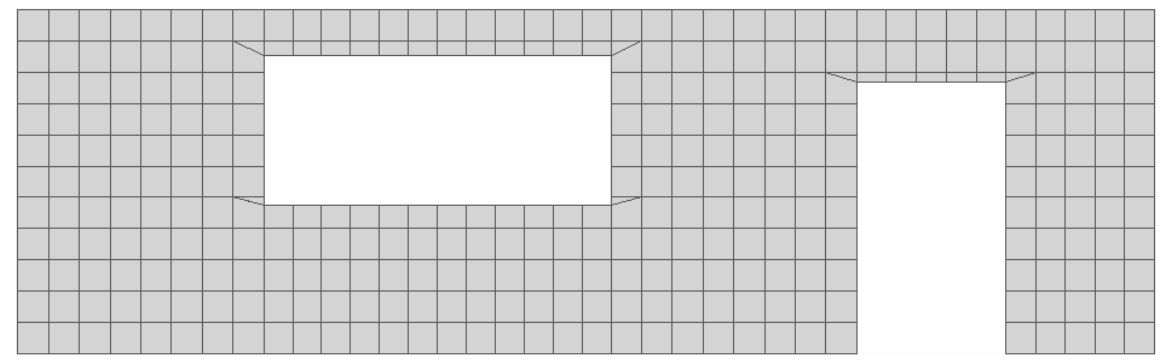

Figura 4.21 - Rede com acertos nas dimensões das aberturas

Como uma rede já havia sido criada, os elementos planos existentes podem ser eliminados acessando-se o item de menu Modelo > Eliminar Rede. Porém, caso se use direto o comando para geração de uma nova rede, o gerador verifica que existem elementos planos, elimina os mesmos, e em seguida monta uma nova rede. A rotina que elimina os elementos planos foi criada caso o usuário queira salvar uma cópia de seus dados base mesmo após a execução do comando Gerar Rede.

Nos vértices das aberturas, quando as linhas que definem seus limites não coincidem com uma linha de arestas de elementos planos, o programa divide os elementos que contêm os vértices em dois, sendo um deles triangular. Caso se queira apenas elementos quadrilaterais, deve-se definir um valor maior para a variável Tamanho mínimo de elemento, apresentada na Figura 4.18.

Como se definiu o tamanho das barras em $0,25 \mathrm{~m}$, o programa configura automaticamente o Tamanho mínimo de elemento em 0,0625 m. Alterando-se essa variável para 0,15 m, pode-se construir um modelo em que se tenham apenas elementos quadrilaterais, como ilustra a Figura 4.22 .

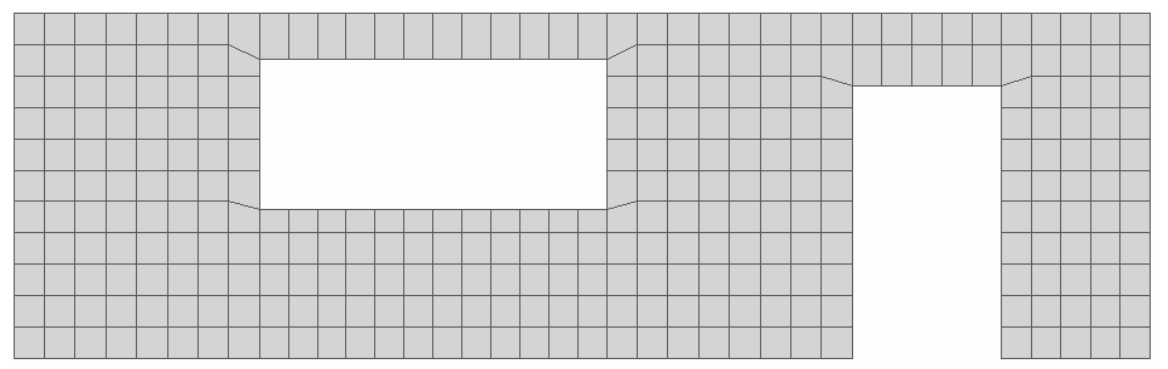

Figura 4.22 - Rede apenas com elementos quadrilaterais

A dimensão vertical dos elementos planos pode ser alterada mudando-se o valor da variável Tamanho do elemento. A título de exemplo, modificando esse parâmetro para $0,50 \mathrm{~m}$, 
e reprocessando o modelo, tem-se uma rede menos refinada, como se evidencia na Figura 4.23.

Como as cargas nodais importadas estão todas definidas no plano do pavimento de pilotis, faz-se necessário a implementação de uma rotina para transladar os nós de aplicação das cargas para o topo das paredes. Essa tarefa é simples, pois depende apenas da localização do nó no alto da parede que tenha as mesmas coordenadas x e y de determinada carga nodal, transportando o valor da carga para este novo nó.

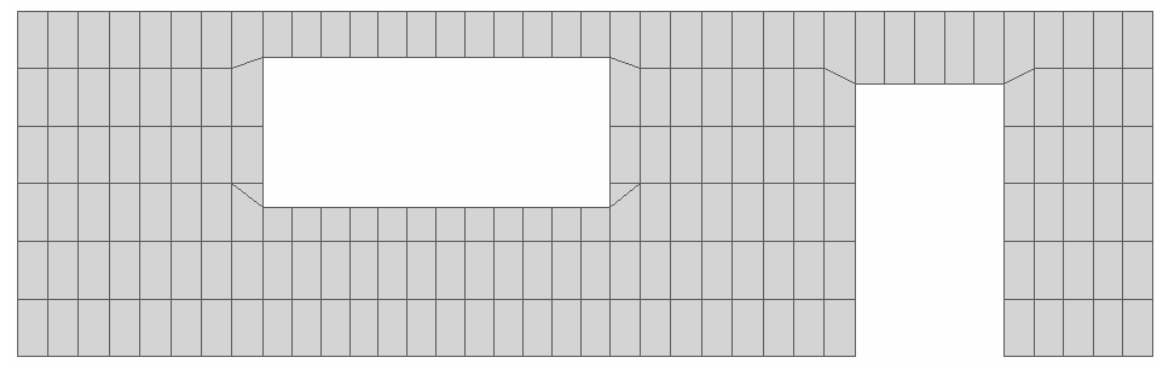

Figura 4.23 - Rede com discretização menos refinada

O carregamento aplicado nos modelos consiste, basicamente, nas reações da base das paredes do primeiro pavimento, e nas reações das lajes do pilotis. Como somente as primeiras sofrem a influência do efeito arco, apenas estas devem ter sua cota de aplicação alterada. Para tanto, basta defini-las no primeiro grupo de carregamentos do Sistema LASER (Linguagem para Análise de Sistemas Estruturais Reticulados), que o aplicativo desenvolvido irá modificar os nós de aplicação corretamente.

Explicações referentes aos recursos do aplicativo são extensas. Varrer uma gama maior de opções de geração da rede alongaria demasiadamente a explanação.

\subsection{PROCESSAMENTO DO MODELO}

Como apresentado nos itens 4.2.1.2 e 4.4, deve-se importar uma série de arquivos para se alcançar a etapa de construção da rede dos elementos que representam as paredes, culminando na elaboração de um modelo completo (estrutura de apoio mais paredes), conforme se evidencia no próximo capítulo (item 5.2). Nesse ponto, faz-se necessário um maior esclarecimento de como a estrutura de apoio das paredes de alvenaria é montada.

\subsubsection{Processamento da Estrutura de Apoio do Pavimento de Alvenaria}

No projeto de edifícios em alvenaria estrutural, é corriqueira a utilização de estruturas de concreto armado servindo de apoio para as paredes, seja na forma de pilotis ou diretamente no sistema de fundação.

As cargas verticais são determinadas conforme uma das abordagens apresentadas no item 3.2.2, usando a automatização implementada por Corrêa e Ramalho (1994). Antes da 
modelagem tridimensional das paredes do pavimento, deve-se realizar a montagem do modelo da estrutura de apoio.

A Figura 4.24 ilustra uma estrutura extremamente simples para o edifício exemplo apresentado no item 3.2.4. O lançamento da estrutura do pilotis tem finalidade apenas didática, servindo unicamente para suprir as etapas necessárias para obtenção dos arquivos que são lidos pelo Sistema GMPAE.

Para a análise da estrutura do pilotis utiliza-se o Sistema LASER, desenvolvido por Ramalho (1990), que possui oito tipos de elementos em sua biblioteca:
a) Tipo 1: elemento treliça;
b) Tipo 2: elemento barra;
c) Tipo 3: elemento contorno;
d) Tipo 4: elemento membrana;
e) Tipo 5: elemento plano (estado plano de tensão, deformação e axissimétrico);
f) Tipo 6: elemento sólido;
g) Tipo 7: elemento placa ou casca;
h) Tipo 8: elemento sapata.

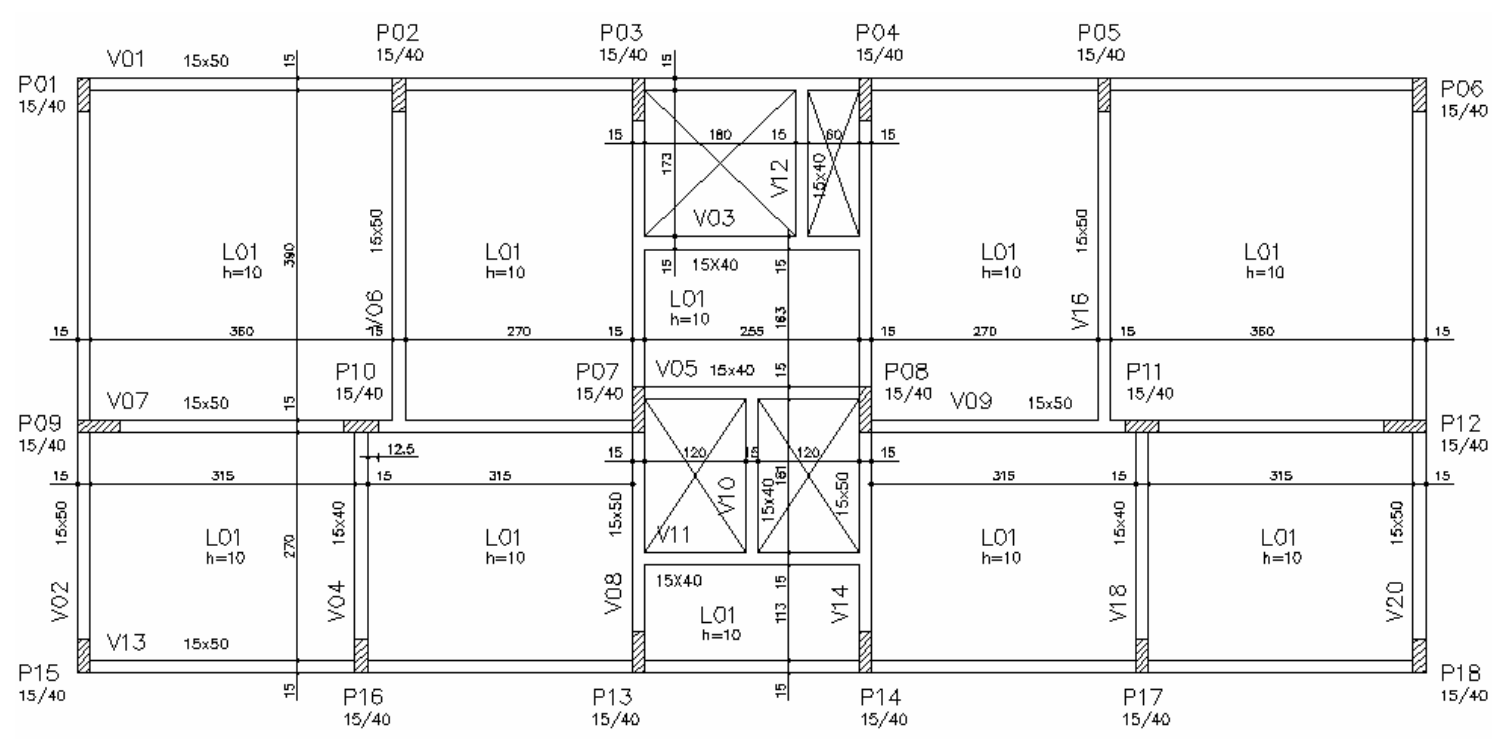

Figura 4.24 - Planta de forma do pilotis

No estudo apresentado, a estrutura de apoio das paredes de alvenaria é formada apenas por elementos barra (vigas e pilares) que, de acordo com Ramalho (1990), "pode ser colocado em qualquer posição do espaço definido pelo sistema de referência global da estrutura. De modo geral, têm seis graus de liberdade por nó, três translações e três rotações".

A etapa de geração da estrutura de apoio é de fundamental importância, pois fornece a discretização das vigas e pilares do pavimento em concreto armado, assim como as informações de nós e carregamento nodal que servem de base para a geração da rede das paredes. Além disso, é neste ponto que o usuário pode informar qual o tamanho das barras. Caso este parâmetro não seja fornecido, o programa adota uma dimensão padrão. 


\subsubsection{Exportação do Arquivo de Processamento}

Sumarizando o exposto até este ponto, tem-se o seguinte:

a) Cálculo das cargas verticais de um edifício em alvenaria estrutural;

b) Montagem e processamento da estrutura de apoio;

c) Importação dos arquivos base pelo Sistema GMPAE;

d) Adaptações em aberturas e acerto dos diversos parâmetros do aplicativo (opcional);

e) Geração da rede;

f) Cálculo das cargas verticais de um edifício em alvenaria estrutural;

g) Verificação da geometria do modelo.

Para se completar a análise, basta exportar o arquivo a ser processado no Sistema LASER, lendo-se os resultados pelo Sistema GMPAE.

Esse arquivo de processamento exportado difere do seu homônimo importado por conter os elementos membrana com que se discretiza as paredes. Ramalho (1990) declara que esse elemento é utilizado para análises de estados planos de tensão. Também pode ser colocado em qualquer posição do sistema global de referência da estrutura, sendo definido por três (elemento triangular) ou quatro nós (elemento quadrangular).

Permitindo o trabalho apenas com materiais isotrópicos com rigidez apenas no seu próprio plano, o elemento membrana possui três graus de liberdade por nó, sendo as três translações de um ponto no espaço tridimensional.

Os eixos normais $\mathrm{X}_{\mathrm{L} 1}$ e $\mathrm{X}_{\mathrm{L} 2}$ compõem o sistema de referência local, definidos pela numeração dos nós do elemento, tanto para os de forma triangular, quanto quadrangular. $O$ eixo $\mathrm{X}_{\mathrm{L} 1}$ situa-se sobre o lado "I - J" do elemento, sendo positivamente orientado de "I" para "J". O eixo $x_{\mathrm{L} 2}$ forma um ângulo reto com o primeiro eixo. $\mathrm{O}$ sistema global é composto pelos eixos $\mathrm{x}_{\mathrm{G} 1}, \mathrm{x}_{\mathrm{G} 2}$ e $\mathrm{x}_{\mathrm{G} 3}$, conforme explicita a Figura 4.25.

Finda essa explanação sobre o tipo de elemento finito que se modela as paredes em alvenaria estrutural, como o modelo já se encontra completo, basta exporta o arquivo de processamento pelo item de menu Arquivo > Exportar > Arq Processamento, ou utilizar a tecla de atalho $F 5$.

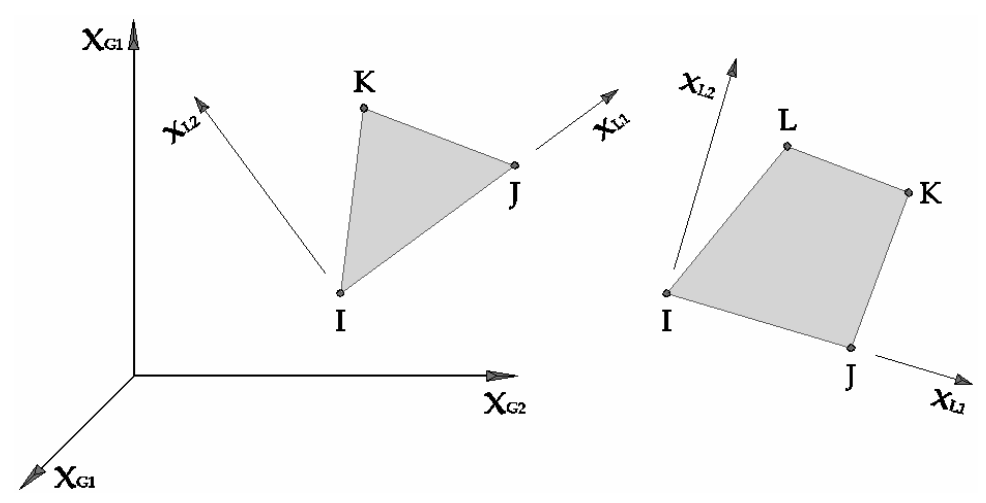

Figura 4.25 - Sistema global e local de referência do elemento membrana 


\subsection{TRATAMENTO DOS RESULTADOS}

Após o processamento do modelo com o Sistema LASER, pode-se partir para a análise de esforços, deslocamentos e tensões na estrutura, levando-se em conta o efeito arco.

\subsubsection{Geração de Arquivos de Resultados}

Com o intuito de se otimizar a busca por tais resultados, criou-se o item de menu Modelo > Gerar Arq Resultados, que permite a escolha dos valores necessários ao traçado de diagramas, como momento fletor, esforço cortante, entre outros. Essa etapa gera até três arquivos texto, com extensões DES, ESF e TEN.

O primeiro contém, para todas as vigas do pavimento, os resultados de deslocamentos nos seis graus de liberdade dos nós que as definem. Com isso, pode-se traçar o diagrama de elástica da viga de suporte da parede de alvenaria. Já no segundo arquivo, encontram-se os valores de esforço normal, cortante e momento fletor nas vigas de apoio. O último encerra as tensões para os elementos na base das paredes, sendo tomadas no centróide dos mesmos.

\subsubsection{Visualização dos Resultados}

Os arquivos são criados no formato texto, com os dados montados em colunas e separados sempre por espaços. Isso facilita sobremaneira a realização de gráficos usando-se planiIhas eletrônicas, como o Microsoft Excel ${ }^{\circledR}$, ou qualquer outro programa para geração de gráficos, assim como a confecção de rotinas para o tratamento dos dados em outros aplicativos.

\subsubsection{Visualização via Planilha Eletrônica}

No item 4.7 desenvolveu-se o exemplo de um painel com uma abertura de janela e outra de porta. Realizando-se a montagem completa desse modelo, e processando-o conforme já explicado, pode-se obter os arquivos de resultados aqui abordados.

Abrindo o arquivo de esforços (ESF) no Microsoft Excel ${ }^{\circledR}$ e tratando os dados de forma conveniente, os diagramas de esforços podem ser desenhados, sendo um exemplo apresentado na Figura 4.26.

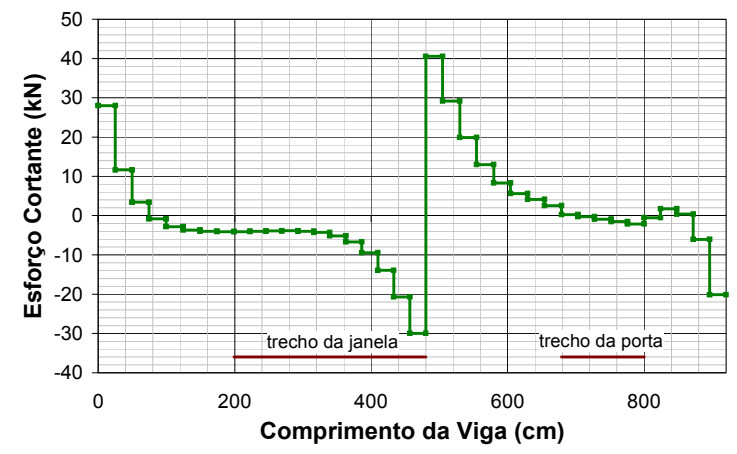

Figura 4.26 - Diagrama de esforço cortante 


\subsubsection{Visualização via Sistema GMPAE}

Como os resultados advindos do processamento de um modelo são muito extensos, optou-se por desenvolver uma interface gráfica que possibilite a visualização dos diversos diagramas das vigas do pavimento de suporte das paredes em alvenaria estrutural. Acessando-se o item de menu Visualizar > Gráficos, a tela da Figura 4.27 é exibida.

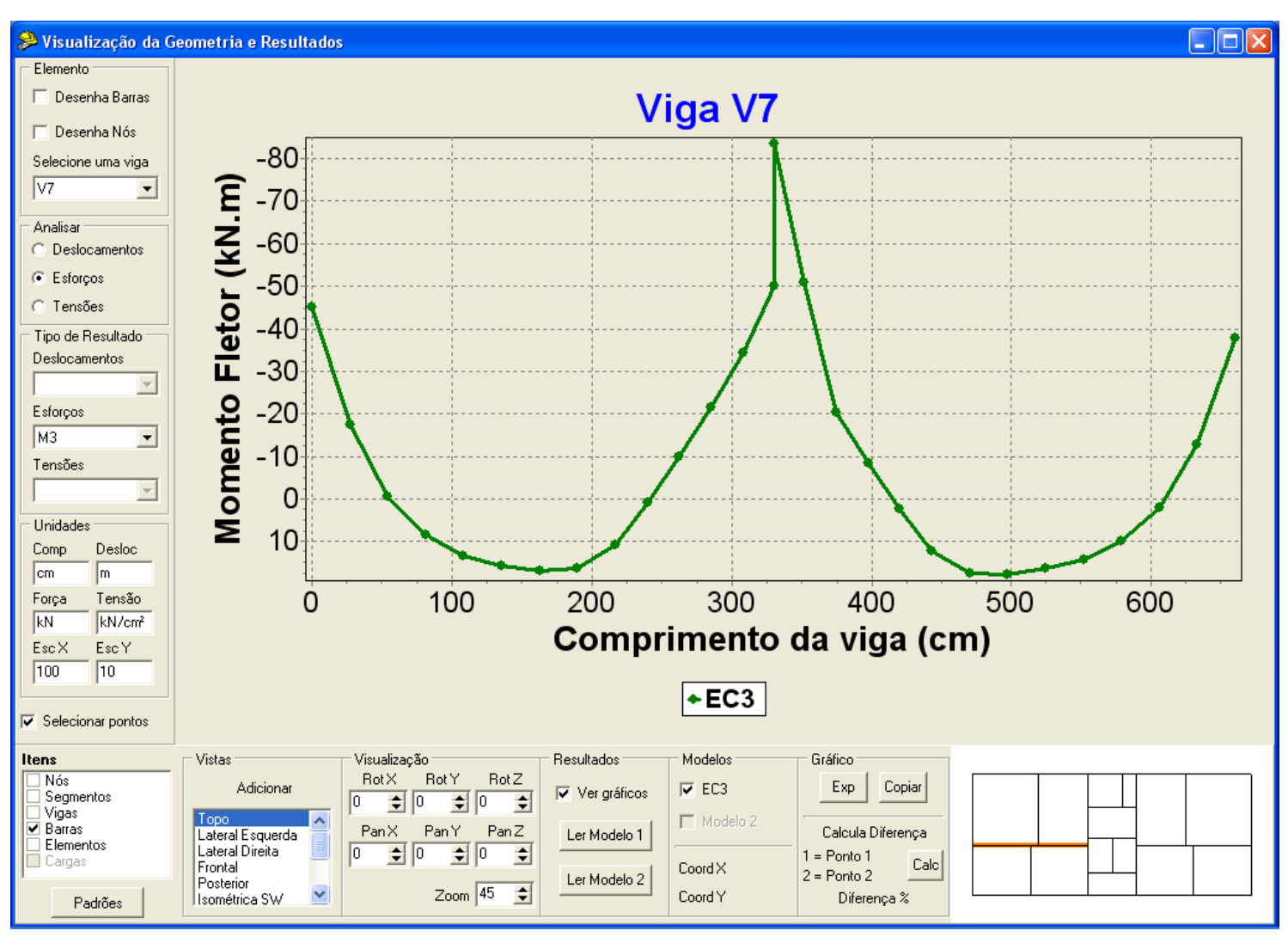

Figura 4.27 - Tela de análise de resultados

Deve-se, inicialmente, fazer a leitura dos arquivos de resultados clicando-se nos botões Ler Modelo 1 e Ler Modelo 2, que habilita as caixas de checagem do campo Modelos. Isso possibilita a exibição de duas curvas por viga, podendo-se comparar os resultados de um processamento onde se considera o efeito arco com outro em que tal fenômeno não é contabilizado.

Em seguida, seleciona-se a viga e o tipo de resultado que se deseja exibir, configurando-se, caso necessário, os fatores de escala e as unidades de força, tensão, comprimento e deslocamento. O título do gráfico, bem como os rótulos dos eixos, são definidos automaticamente. A viga escolhida tem sua posição no pavimento evidenciada no desenho apresentado no canto inferior direito da tela do aplicativo. Os botões do campo Gráfico permitem exportar figuras nos formatos $B M P, W M F$ e $E M F$, ou colocar o desenho diretamente na área de transferência do Windows, para que seja posteriormente colado diretamente em algum editor de texto para a elaboração de relatórios. 


\section{Capítulo 5 Estudo de Casos}

\subsection{CONSIDERAÇÕES INICIAIS}

Quando se considera a interação entre alvenaria e concreto armado, a grande maioria dos trabalhos encontrados na bibliografia trata de paredes de alvenaria estrutural sobre vigas biapoiadas. Rosenhaupt e Sokal (1965) realizaram modelos experimentais de paredes sobre vigas contínuas, e Barbosa (2000) desenvolveu modelos numéricos de pavimentos completos empregando o software ANSYS 5.5. A desvantagem no uso de pacotes comerciais é justamente a etapa de criação da rede para as paredes, consumindo muito tempo e permitindo pouca ou quase nenhuma alteração sem incorrer na necessidade de recomeçar a montagem do modelo analisado. A ferramenta computacional desenvolvida permite a criação da rede de forma rápida e simples (com o tempo de processamento limitado pela velocidade do computador utilizado). Se a mesma não for adequada, basta redefinir os parâmetros e gerá-la novamente.

$O$ estudo de pavimentos completos permite a avaliação de situações corriqueiras na construção civil que têm sido pouco analisadas em trabalhos acadêmicos. A Figura 5.1 exibe um pavimento de alvenaria estrutural sobre estrutura de pilotis, evidenciando-se algumas situações passíveis de análise mais efetiva, como trechos de paredes apoiadas em vigas contínuas e outros de vigas apoiadas em vigas.

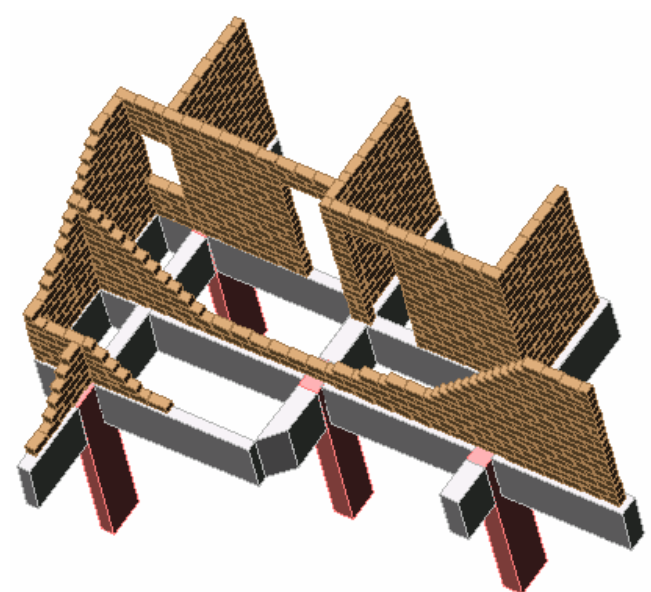

Figura 5.1 - Exemplo de paredes sobre pilotis em concreto armado 
Formam escolhidos cinco projetos reais de edifícios em alvenaria estrutural para que fosse possível a realização de um estudo comparativo entre rotinas usuais de cálculo, adotadas em escritórios de projeto, e a sistemática proposta, que é facilitada pelo uso do Sistema GMPAE. A análise sugerida tem como objetivo verificar as diferenças encontradas entre uma modelagem tradicional de projeto, com as cargas verticais da alvenaria sendo colocadas diretamente sobre a estrutura do pilotis, e a sistemática tratada no presente trabalho, onde o carregamento das alvenarias é colocado sobre as paredes do primeiro pavimento do edifício. Os modelos desenvolvidos serão chamados de Proj1 (para a primeira abordagem) e Proj2 (para a segunda). A palavra Proj será substituída por uma abreviação mnemônica para referenciar-se ao projeto estudado. A análise que se realiza nesses modelos leva em conta a rigidez real dos pilares. Seguindo o mesmo padrão explicitado, porém com o nome seguido da letra $R$, encontram-se os modelos com alta rigidez axial para os pilares. Essa sistemática permite a simulação de apoios rígidos nos pontos referentes aos apoios de pilares.

Os elementos utilizados na elaboração dos modelos são encontrados na biblioteca do Sistema LASER. Usa-se o elemento barra tridimensional para a discretização das vigas e pilares, e o elemento membrana para discretizar as paredes de alvenaria estrutural, conforme descrição apresentada no item 4.8 do capítulo anterior.

\subsection{MONTAGEM DOS MODELOS}

Como já mencionado, serão criados quatro modelos para cada edifício analisado, comparando-se os resultados no final.

Para um melhor entendimento da abordagem proposta, a Figura 5.2 apresenta um esquema do processo adotado para confecção dos modelos. Parte-se da estrutura real de um edifício completo em alvenaria estrutural e, com o procedimento proposto por Corrêa e RamaIho (1994), calculam-se as cargas verticais na base das paredes do primeiro pavimento. Montando-se a estrutura do pilotis e colocando-se as cargas verticais mencionadas, obtém-se o Modelo 1. Para a elaboração do Modelo 2, mantém-se a estrutura e cargas já definidas para o primeiro modelo e, usando-se o Sistema GMPAE, cria-se a rede das paredes e se altera o nível de aplicação das cargas para o topo do primeiro pavimento.

A modelagem do pavimento de pilotis (em barras tridimensionais) é a mesma para os dois modelos desenvolvidos. Sendo assim, as dimensões de vigas e pilares que se observam nas plantas de forma não serão alteradas para a elaboração do segundo modelo (que considera o efeito arco), sendo as paredes modeladas com elementos membrana. Poder-se-ia fazer uma diminuição nas dimensões de algumas vigas no segundo modelo, entretanto a comparação com o primeiro não seria muito adequada. Se essas reduções fossem feitas, certamente seriam encontradas diferenças ainda maiores do que as obtidas, pelo menos no que se refere à análise dos momentos fletores.

Nas plantas de modulação da primeira fiada, as paredes tracejadas são de alvenarias não estruturais. Sendo assim, por não receberem carregamento, não aparecerão no modelo tri- 
dimensional gerado pelo Sistema GMPAE.

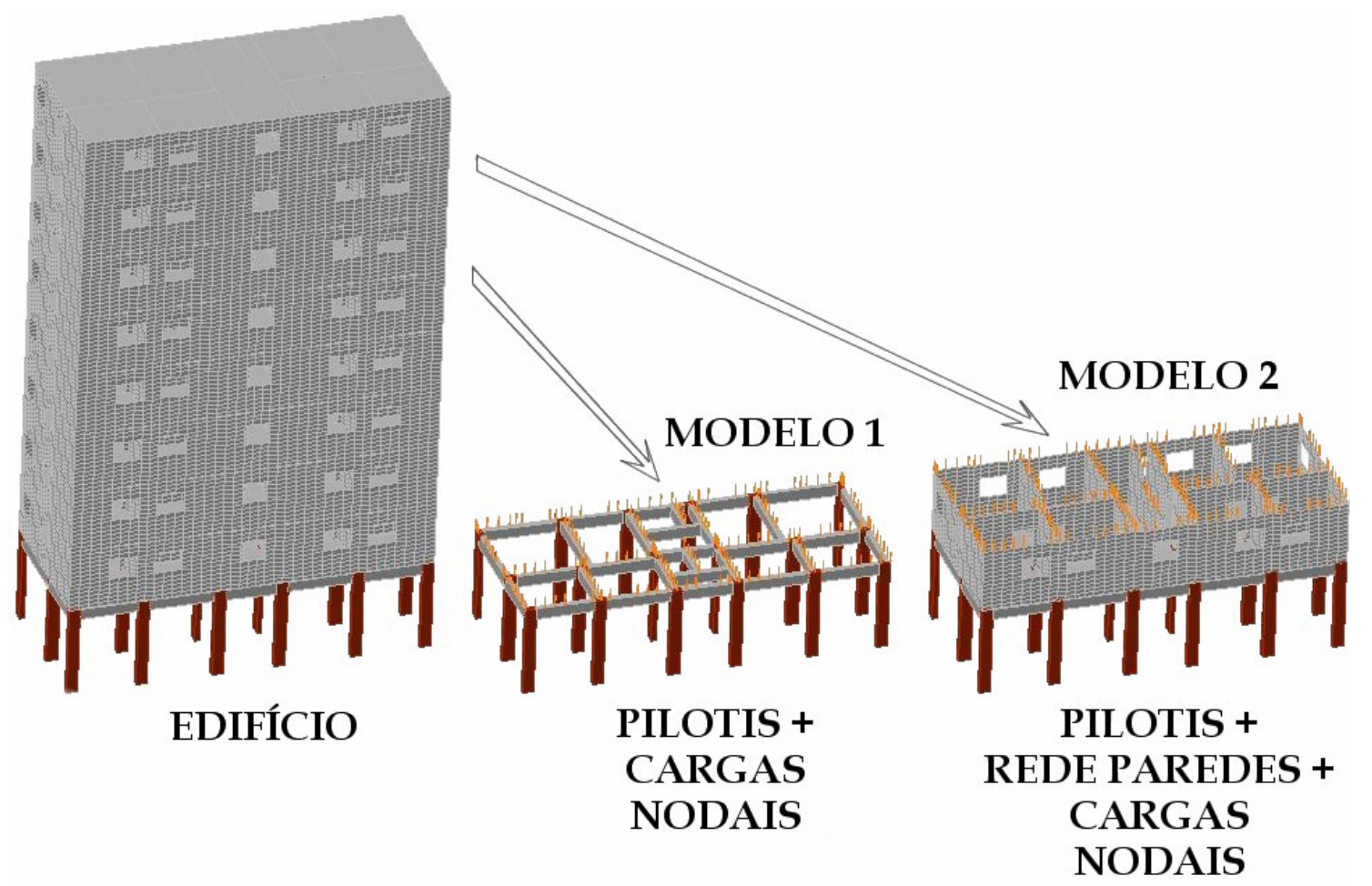

Figura 5.2 - Esquemática simplificada de modelagem

Os desenhos de forma do pilotis e modulação da primeira fiada do pavimento tipo referem-se à estrutura que será trabalhada dentro do Sistema GMPAE. O processamento pelo Sistema LASER permite a elaboração do modelo do pilotis que, sendo importado pelo programa desenvolvido na presente pesquisa, permite a geração da rede em elementos finitos para as paredes.

Para o cômputo das cargas verticais toda a torre em alvenaria estrutural é considerada, desde o ático, caixas d'água verticais, etc.

\subsection{EXEMPLO 1 - EDIFÍCIO VIVENDA DOS SONHOS}

\subsubsection{Apresentação}

O Edifício Residencial Vivenda dos Sonhos é composto por quinze pavimentos tipo sobre um pavimento de pilotis em concreto armado.

A planta da forma estrutural do pilotis é encontrada na Figura 5.3. Para otimizar o processamento da estrutura e também permitir o emprego de uma rede mais refinada, adotou-se simetria em torno do eixo Y, modelando-se apenas a metade direita do pavimento. A Figura 5.4 ilustra a planta de modulação com a simetria considerada. Nos itens subseqüentes são apresentados os resultados de esforços e deslocamentos, assim como tensões na base das paredes, para a maioria das vigas constantes na planta de forma. 


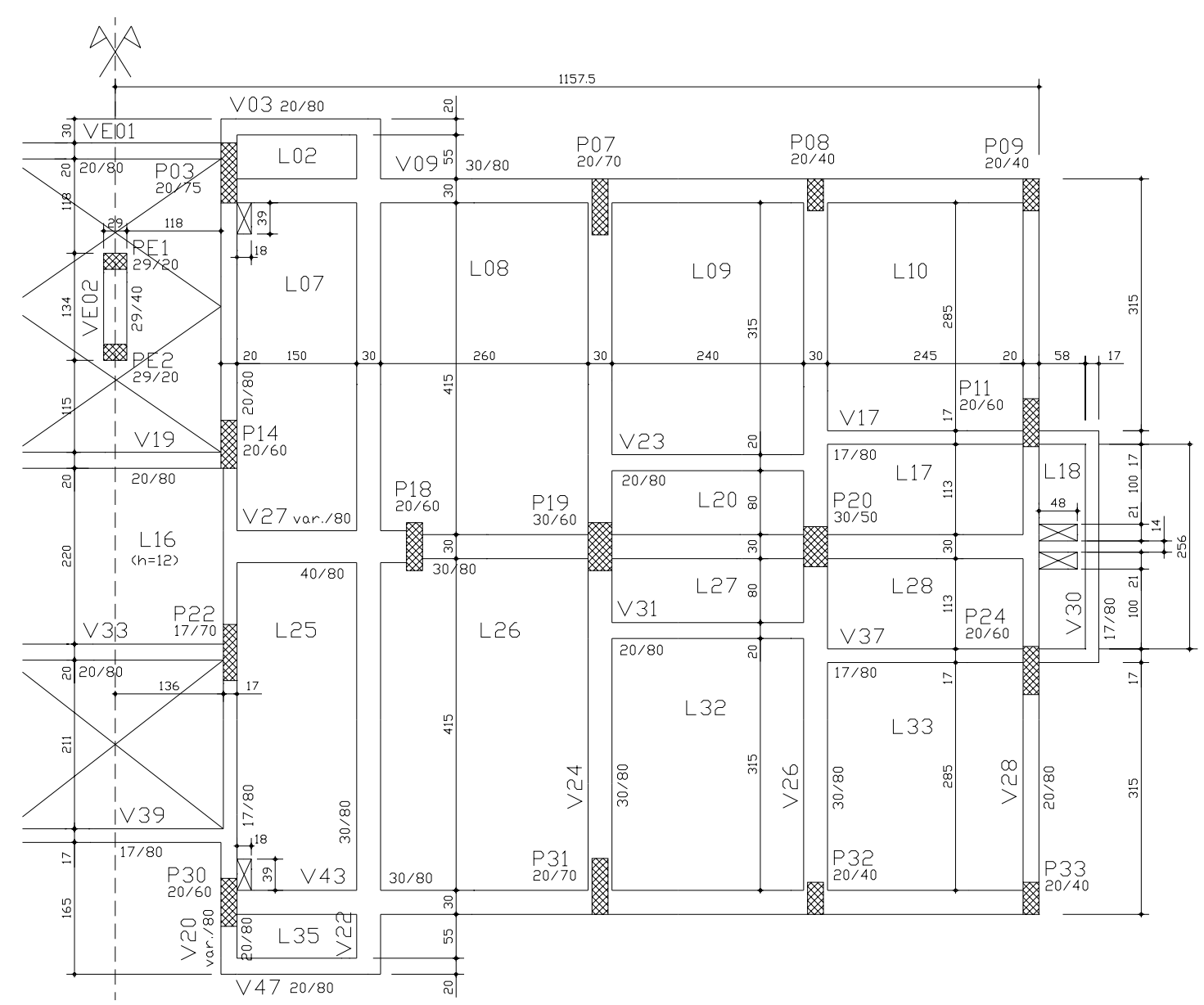

Figura 5.3 - Forma estrutural do pilotis do edifício Vivenda dos Sonhos

\subsubsection{Descrição dos Modelos}

A Tabela 5.1 apresenta alguns parâmetros e propriedades dos materiais empregados na estrutura do edifício analisado.

Tabela 5.1 - Parâmetros de modelagem do edifício Vivenda dos Sonhos

\begin{tabular}{ll}
\hline Espessura da parede $(\mathrm{m})$ & 0,14 \\
\hline Altura da parede $(\mathrm{m})$ & 2,60 \\
\hline$v_{\text {viga }}$ & 0,20 \\
\hline$v_{\text {parede }}$ & 0,20 \\
\hline $\mathrm{E}_{\text {parede }}\left(\mathrm{kN} / \mathrm{m}^{2}\right)$ & $5,76 \mathrm{E}+06$ \\
\hline $\mathrm{E}_{\text {viga }}\left(\mathrm{kN} / \mathrm{m}^{2}\right)$ & $2,38 \mathrm{E}+07$ \\
\hline $\mathrm{f}_{\mathrm{ck}}(\mathrm{MPa})$ & 25 \\
\hline
\end{tabular}

A Figura 5.5 apresenta uma vista das barras e nós carregados do chamado Modelo 1. Já na Figura 5.6, é ilustrada a rede, barras e cargas nodais do Modelo 2. 


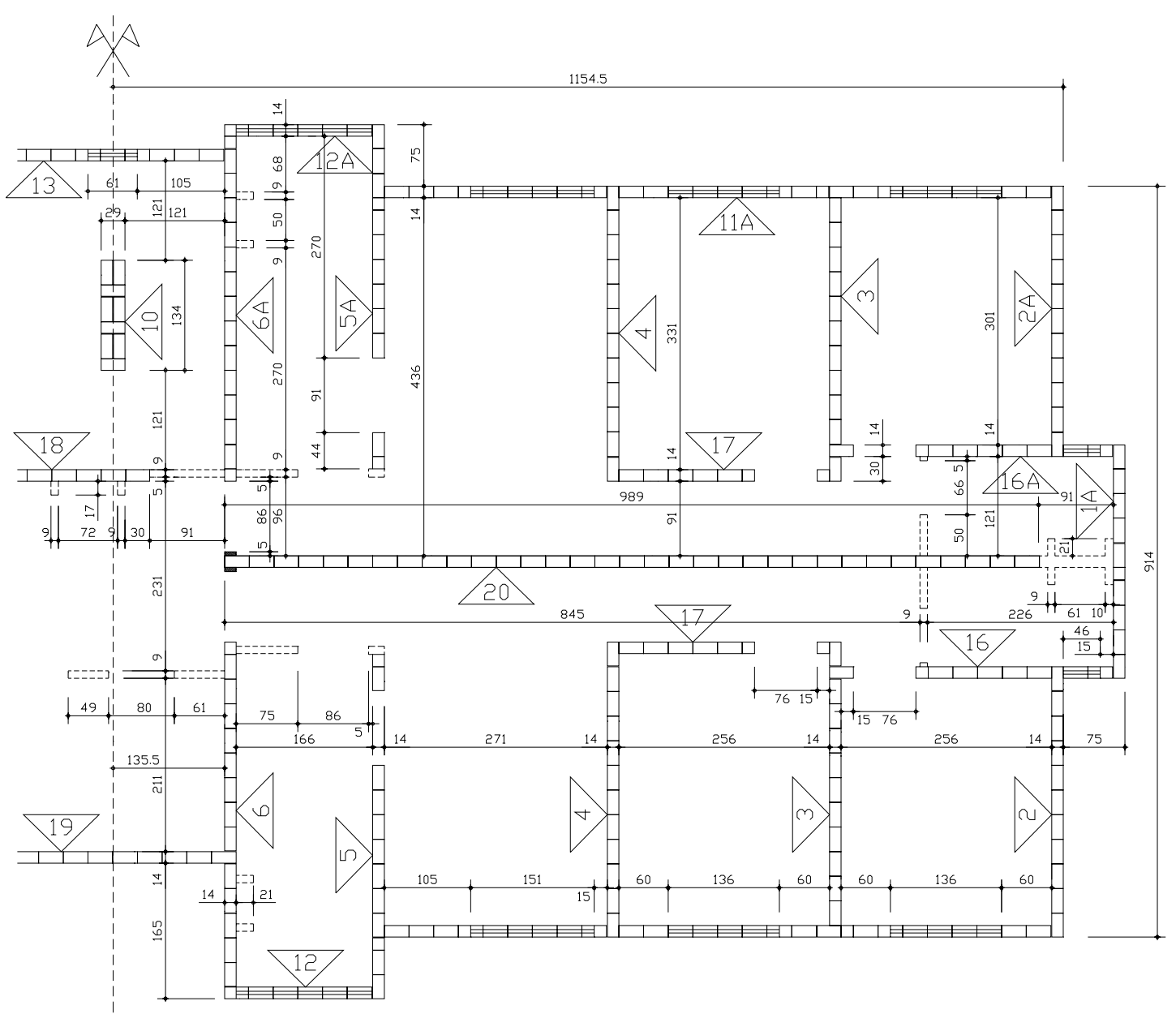

Figura 5.4 - Modulação do pavimento tipo do edifício Vivenda dos Sonhos

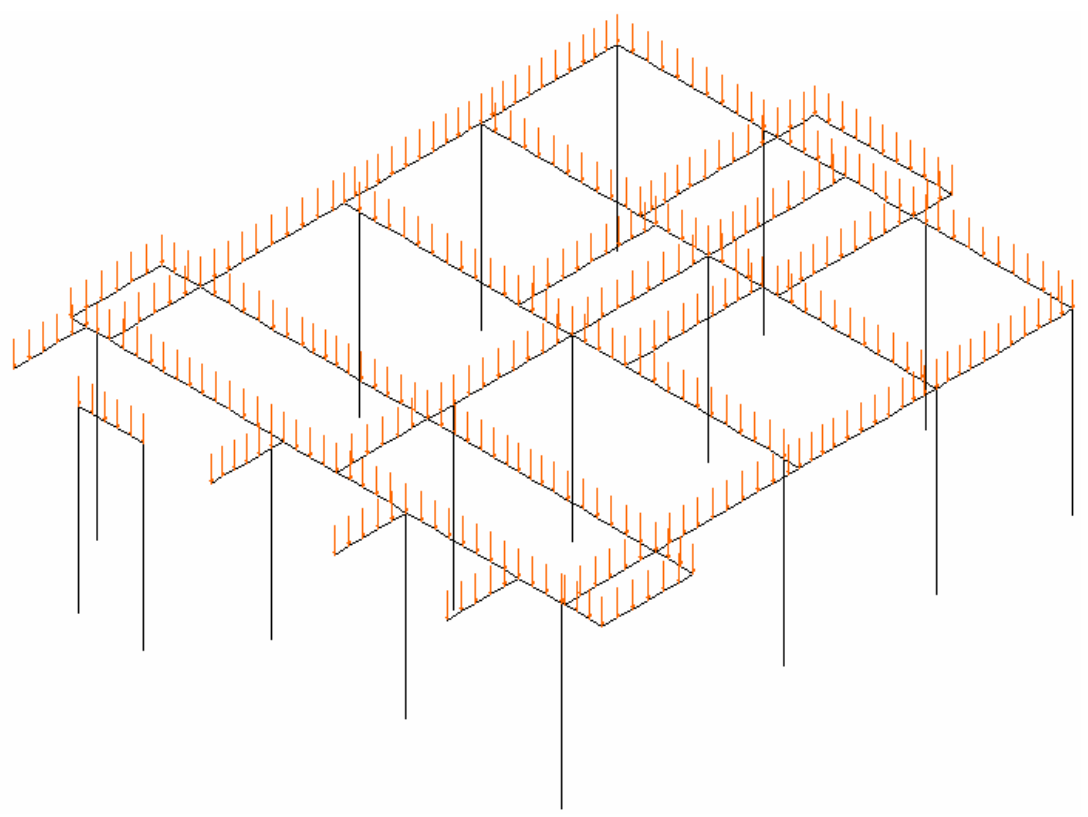

Figura 5.5 - Modelo 1 (VS1 e VS1R) do edifício Vivenda dos Sonhos 


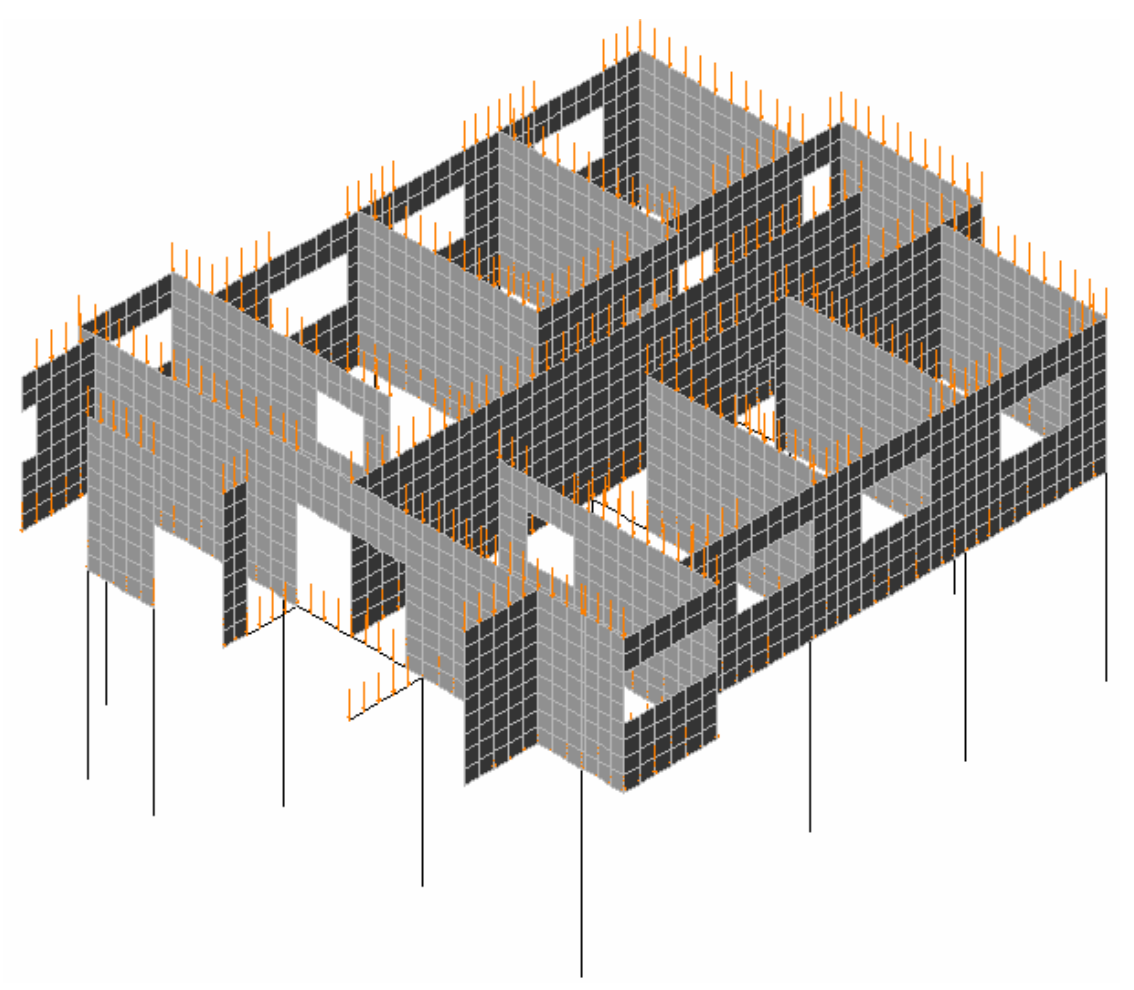

Figura 5.6 - Modelo 2 (VS2 e VS2R) do edifício Vivenda dos Sonhos

\subsubsection{Análise de Resultados}

Devido à grande facilidade que o Sistema GMPAE propicia na exportação de gráficos, optou-se pela exibição de esforços, deslocamentos verticais e tensões na base da parede, para a maior parte das vigas existentes nesse primeiro projeto. $O$ intuito de tal iniciativa é a de propiciar ao meio técnico e acadêmico um estudo mais amplo de um edifício em alvenaria estrutural levando-se em conta o efeito arco. Para cada tipo de resultado abordado, apresenta-se primeiramente o gráfico referente à modelagem com pilares de rigidez normal (chamados aqui de pilares deformáveis), e em seguida os com rigidez alta (denominados modelos com apoios rígidos).

Como para o Modelo 1 não se tem resultados de esforços normais nem tensões na base da parede, optou-se pela elaboração de um único diagrama em cada um destes casos, confrontando-se diretamente as curvas dos modelos com variação de rigidez do apoio (pilares deformáveis versus apoios rígidos).

\section{a) Viga VE01}

Os diagramas obtidos pela análise da presente viga podem ser visualizados na seqüência que segue, iniciando-se na Figura 5.7 e finalizando-se na Figura 5.10.

Esta viga se encontra na região da escada, servindo de apoio ao patamar. Para uma melhor compreensão da nomenclatura adotada, segue uma pequena explicação: 
- Curva VS1: análise tradicional de projeto (sem efeito arco - Modelo 1) e pilares modelados com sua rigidez real;

- Curva VS1R: análise tradicional de projeto (sem efeito arco - Modelo 1) e pilares modelados com rigidez axial alta;

- Curva VS2: paredes modeladas com elementos membrana (Modelo 2), permitindo a consideração do efeito arco, e pilares modelados com sua rigidez real;

- Curva VS2R: paredes modeladas com elementos membrana (Modelo 2), permitindo a consideração do efeito arco, e pilares modelados com rigidez axial alta.

Nos diagramas de deslocamento, esforço cortante e momento fletor percebe-se a influência do efeito arco (ver Figura 5.7, Figura 5.9 e Figura 5.10, respectivamente). Ainda nestes três resultados, a variação da rigidez do apoio não ocasionou mudanças significativas. Já para o esforço normal e tensão vertical (Figura 5.8), o modelo com pilares rígidos aumentou os esforços de tração e diminuiu as tensões verticais na base da parede sobre a viga VE01.

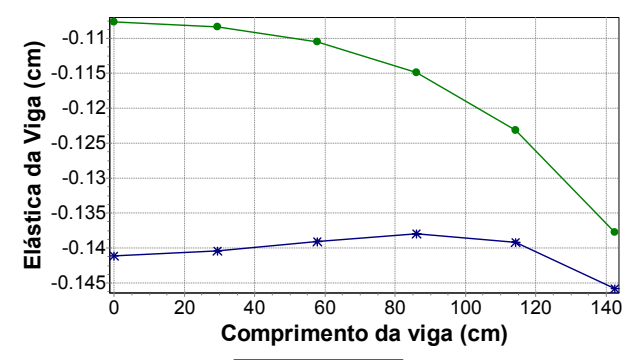

$\because-\mathrm{VS} 1 *$ * VS2

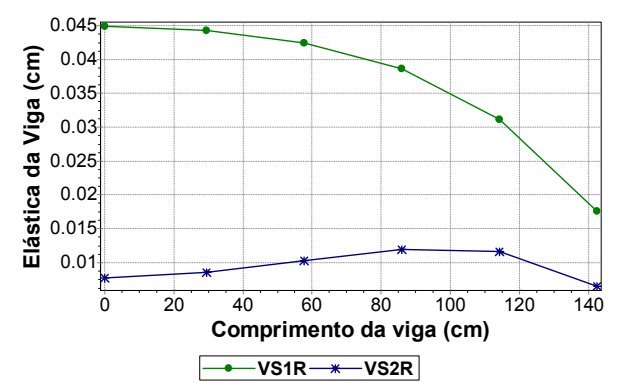

—VS1R *-VS2R

Figura 5.7 - Deslocamentos verticais - viga VE01
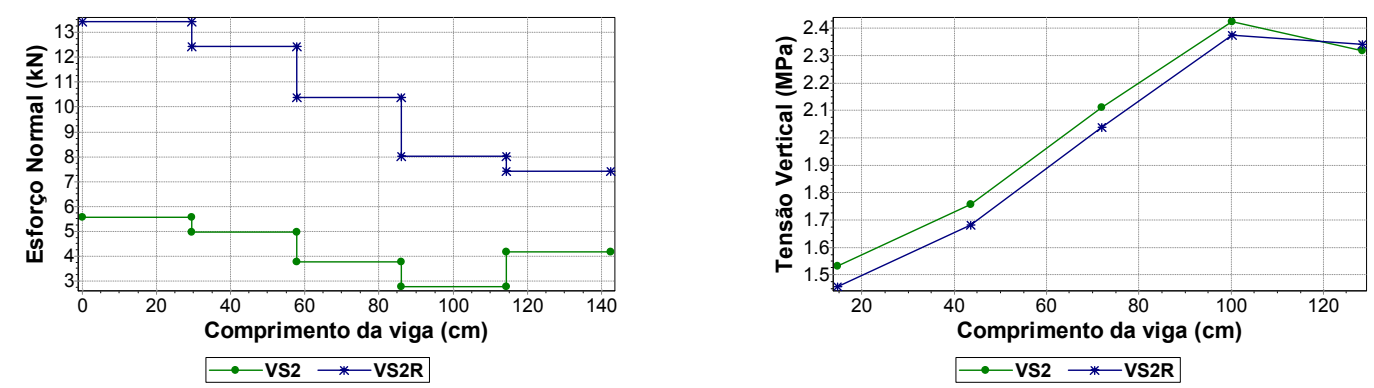

Figura 5.8 - Esforço normal e tensão vertical - viga VE01
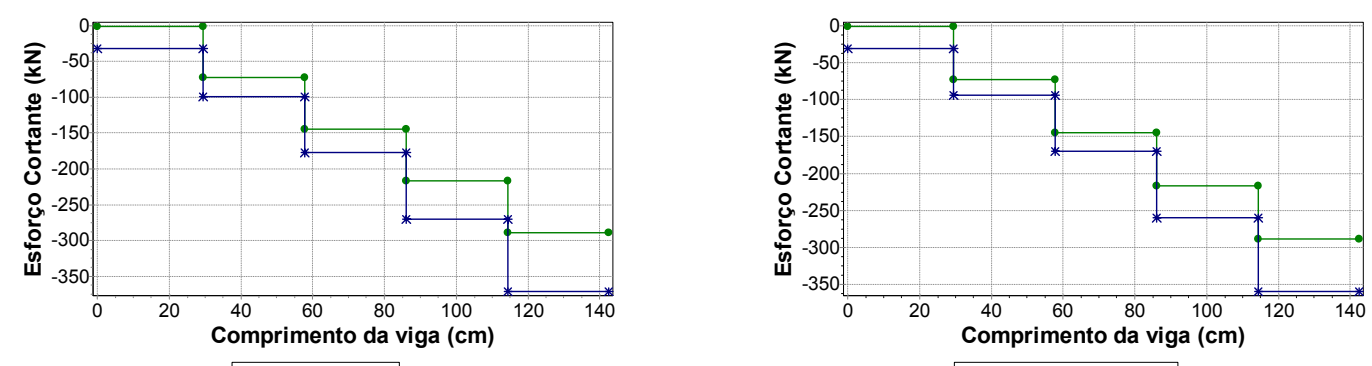

$\because-\mathrm{VS} 1 * \mathrm{VS} 2$ - - VS1R $\rightarrow$ * VS2R

Figura 5.9 - Esforço cortante - viga VE01 

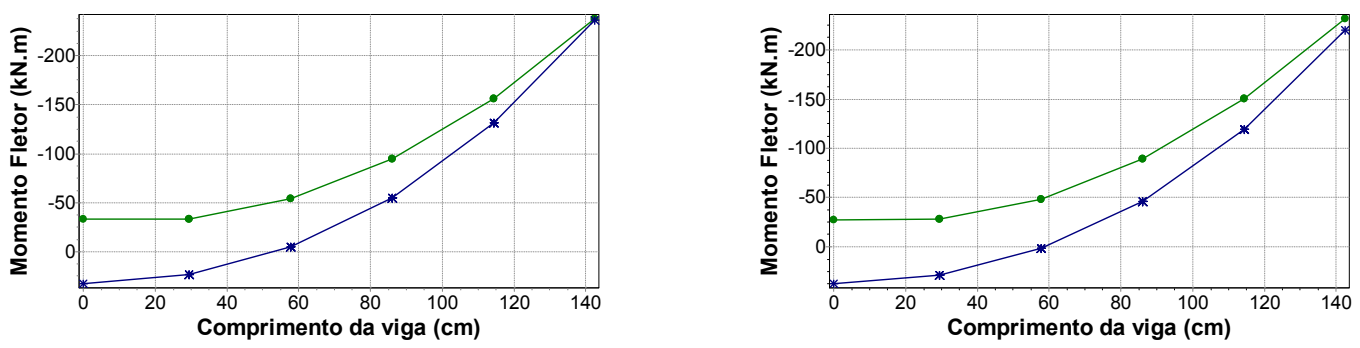

$\rightarrow-\mathrm{VS} 1 * \mathrm{VS} 2$

- $-\mathrm{VS} 1 \mathrm{R} \rightarrow$ * VS2R

Figura 5.10 - Momento fletor - viga VE01

\section{b) Viga V03}

É interessante a análise dos resultados encontrados para esta viga, pois a mesma serve de apoio para apenas um trecho de janela, não havendo parede completa em toda a sua extensão. A conseqüência desse fato é que, para o Modelo 1, a viga é carregada apenas com o seu peso próprio e as reações das lajes do pilotis.

Como a Figura 5.11 evidencia, os deslocamentos são pequenos para os dois modelos desenvolvidos, ficando pouco evidente a influência do efeito arco. A consideração de apoios rígidos não muda os deslocamentos relativos da viga $\mathrm{V} 03$.

O esforço normal e a tensão vertical na base da parede sobre a viga V03 não sofreram influência com a mudança da rigidez dos apoios, como apresentado na Figura 5.12. O efeito arco propicia um acréscimo bastante significativo no esforço cortante, como apresentado na Figura 5.13.

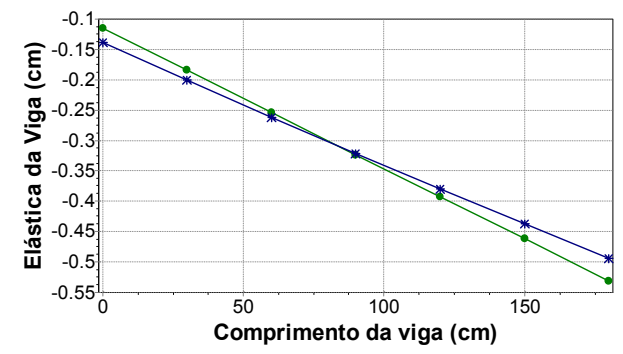

$-\mathrm{VSS1}^{-*} * \mathbf{v S 2}$

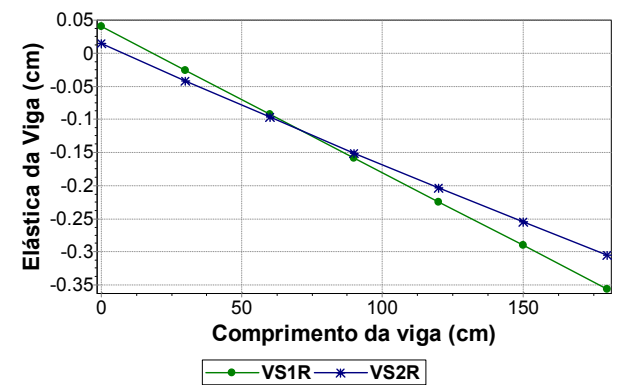

- - VS1R $\rightarrow$ - VS2R

Figura 5.11 - Deslocamentos verticais - viga V03
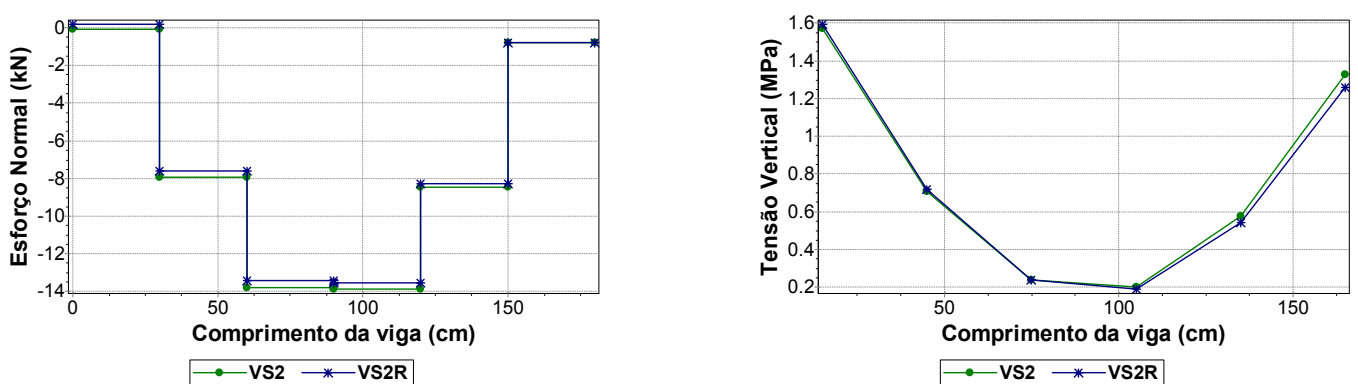

Figura 5.12 - Esforço normal e tensão vertical - viga V03

Como o Modelo 2 foi construído obedecendo a geometria das paredes, entende-se que alguma carga passa pela parede do peitoril, variando a solicitação sobre a viga e causando um 
aumento do momento fletor, como se observa na Figura 5.14. Como os valores máximos são absorvidos pela armadura mínima, não haveria maiores implicações no projeto.

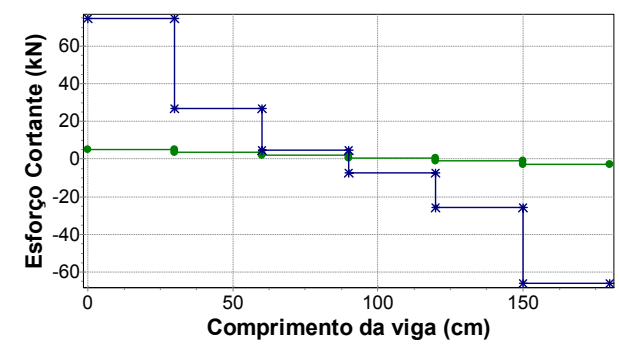

$\because$ VS1 *-VS2

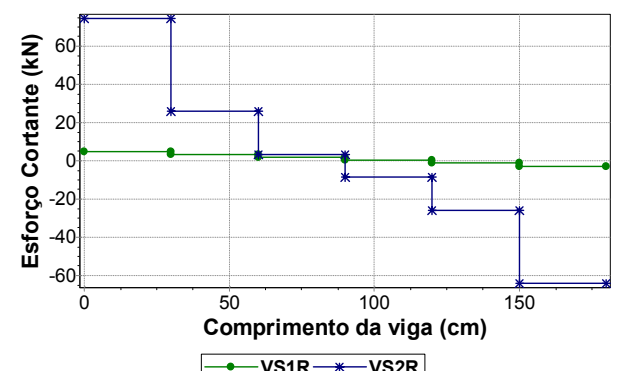

$\because$ VS1R $*$-VS2R

Figura 5.13 - Esforço cortante - viga V03

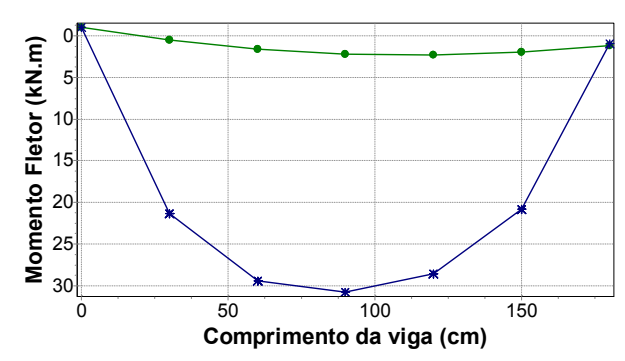

$-\bullet$ VS1 $*$ *VS2

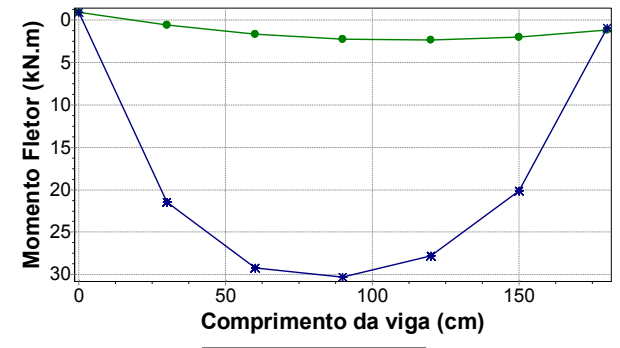

- - VS1R * * VS2R

Figura 5.14 - Momento fletor - viga V03

\section{c) Viga V09}

O efeito arco é mais efetivo no trecho que vai do pilar P03 ao pilar P07, propiciando as diferenças observadas na Figura 5.15 para os deslocamentos verticais. A variação na rigidez dos apoios não ocasiona mudanças significativas. Entretanto, percebe-se uma distância maior entre as curvas dos Modelos 1 e 2 no trecho descrito acima para a análise com pilares rígidos.

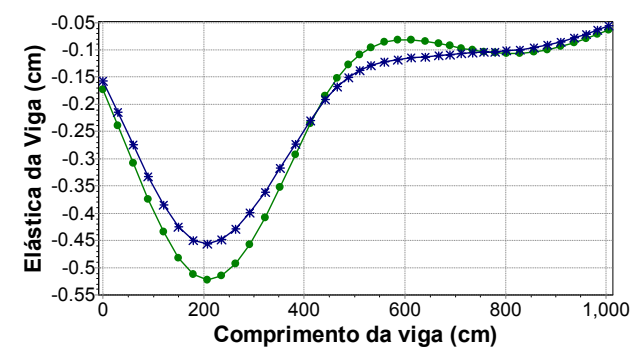

$\because-\mathrm{VS} 1 \rightarrow-\mathrm{VS} 2$

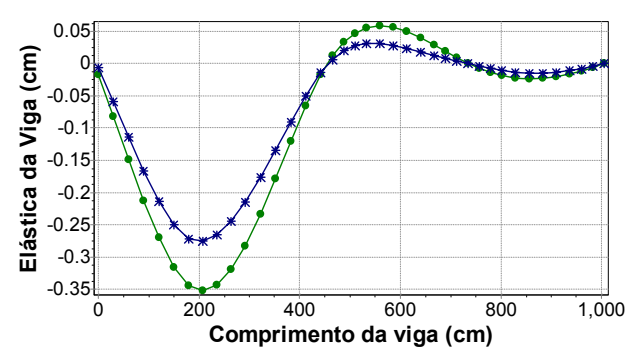

- - VS1R一*-VS2R

Figura 5.15 - Deslocamentos verticais - viga V09

As primeiras barras da viga V09 não são axialmente solicitadas, como se observa no diagrama de esforço normal da Figura 5.16. Situação semelhante ocorre no último tramo, onde o esforço normal é praticamente nulo. Já na região entre a viga V22 e o pilar P08 a viga fica tracionada (próximo à interseção com a viga $\mathrm{V} 22$ ), tendo o ponto de compressão máxima sobre o apoio do pilar P07. A análise com pilares rígidos ocasionou um aumento nos esforços de compressão. Ainda na mesma figura, percebem-se as variações no diagrama de tensão verti- 
cal. Os pontos de apoio ficam bem destacados, coincidindo com os picos de máxima tensão. Um pouco à direita da abscissa 200 aparece uma região tracionada na parede. Isso ocorre, pois não foram modelados elementos de contato entre a parede e a viga.

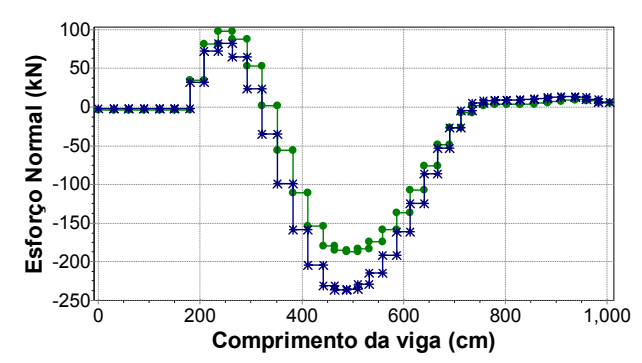

Figura 5.16 - Esforço normal e tensão vertical - viga V09

O efeito arco também fica patente nos diagramas que a Figura 5.17 apresenta, causando uma redução no esforço cortante entre a viga V22 e o pilar P07, e eliminando os trechos "lineares" entre os vãos formados pelos pilares P07 - P08 e P08 - P09, referentes às janelas existentes. Como se observa, a ordem de grandeza dos valores de esforço cortante não sofreu grande variação com a simulação ou não de apoios rígidos.
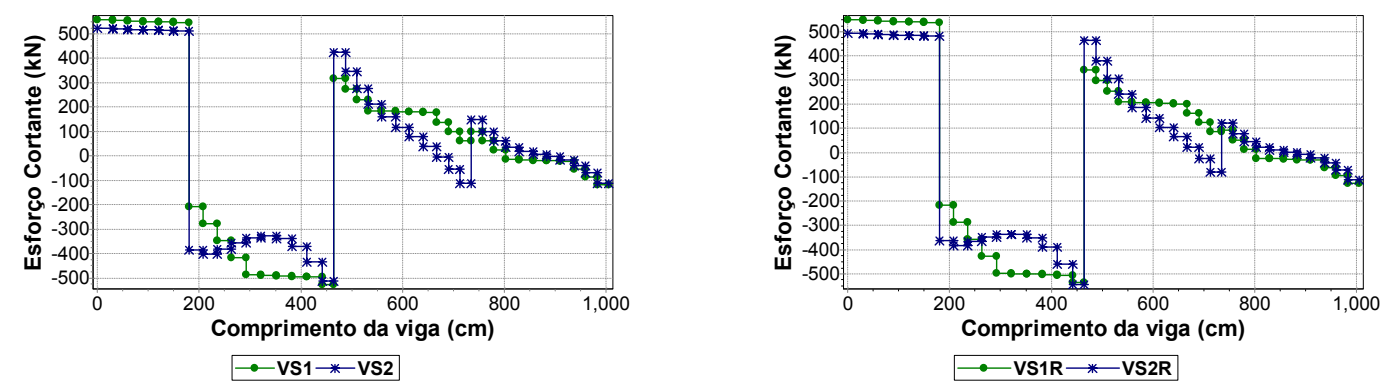

Figura 5.17 - Esforço cortante - viga V09

Como se observa na Figura 5.18, os picos de momento fletor não são tão influenciados pelo efeito arco. As diferenças existem, mas o ganho na diminuição da armadura não é tão expressivo quanto o observado em outras vigas. A variação na rigidez dos apoios também não ocasiona alterações muito perceptíveis nos diagramas.
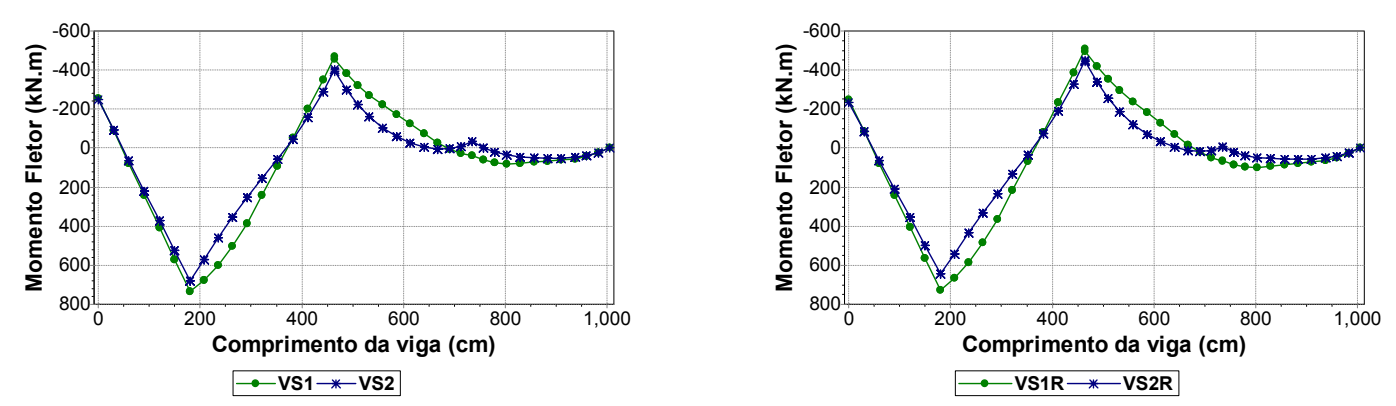

Figura 5.18 - Momento fletor - viga V09 


\section{d) Viga V17}

A contribuição do efeito arco na diminuição dos deslocamentos da presente viga é mais evidente no apoio da esquerda, definido pela sua interseção com a viga V26, como se percebe pela Figura 5.19 .
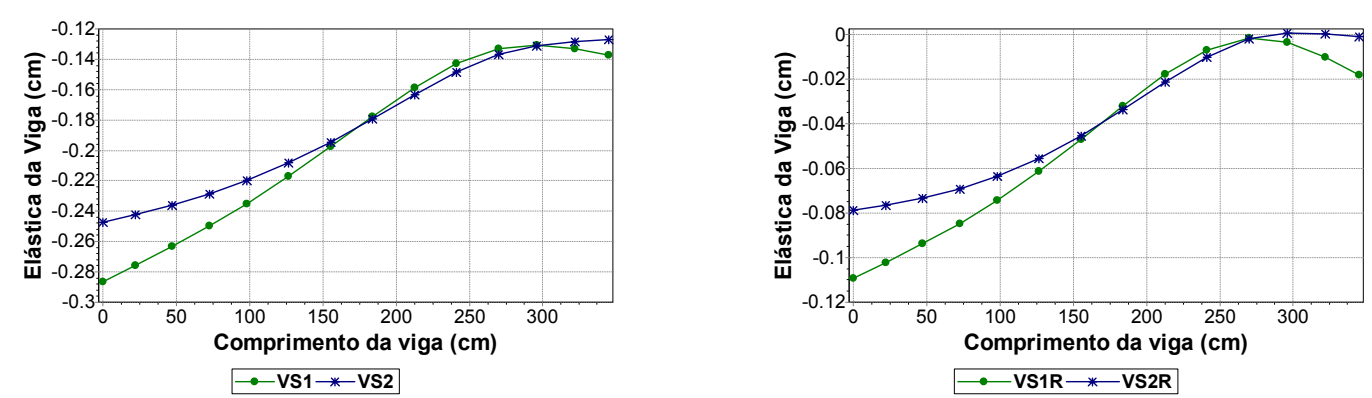

Figura 5.19 - Deslocamentos verticais - viga V17

A Figura 5.20 apresenta os diagramas de esforço normal. A variação da rigidez dos apoios não altera a forma dos diagramas, que apresentam picos de compressão sobre o apoio do pilar $\mathrm{P} 11$, e um trecho constante próximo de zero, ressaltando a região da porta (ver modulação, Figura 5.4). A tensão vertical também não sofre grande influência da diferença de rigidez dos apoios. A consideração do efeito arco permite uma análise mais efetiva de pontos em que ocorre concentração de tensão, como observado no pequeno trecho de parede à esquerda da viga V17.
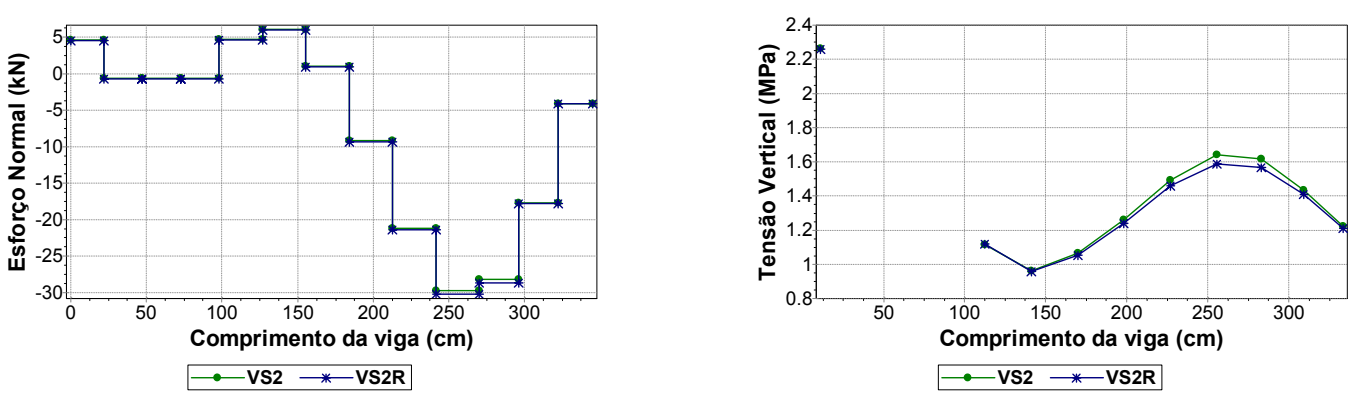

Figura 5.20 - Esforço normal e tensão vertical - viga V17

O esforço cortante sofre uma redução significativa sobre o trecho em balanço da viga quando se observam as curvas obtidas com os processamentos que computam o efeito arco (Figura 5.21). Isso reforça a idéia do caminhamento de cargas verticais, pois o carregamento atuante sobre a viga V30 está caminhando para os apoios com as vigas V17 e V37, sendo que parte dessa carga passa pelo trecho do peitoril da janela que está sobre o balanço da viga V17.

$O$ efeito arco diminui o pico de máximo momento fletor negativo, mas aumenta um pouco o momento positivo, como se observa na Figura 5.22. Novamente as duas simulações de apoio são praticamente idênticas. 

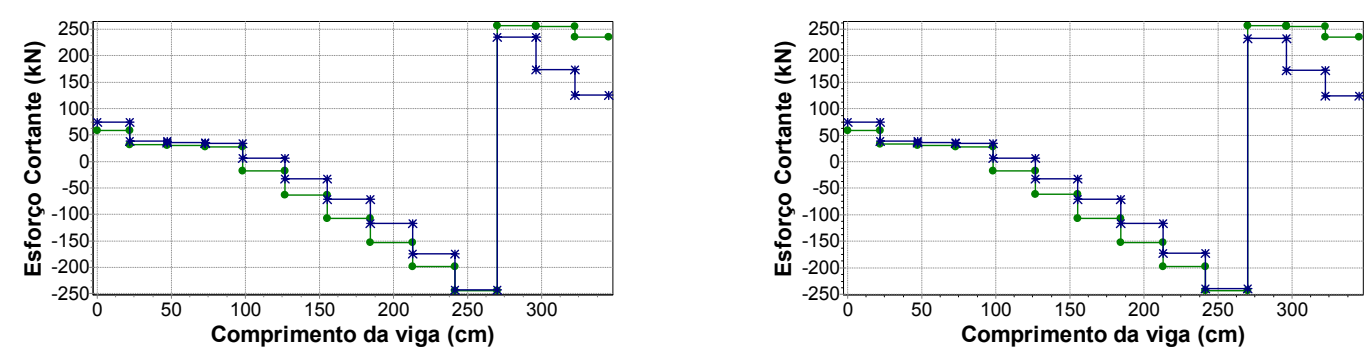

$-\bullet-\mathrm{VS} 1 * \mathrm{VS} 2$

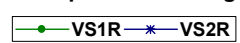

Figura 5.21 - Esforço cortante - viga V17

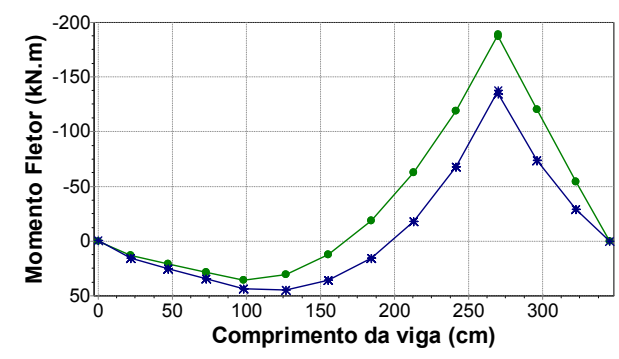

$\rightarrow-\mathrm{VS} 1 \rightarrow \mathrm{VS} 2$

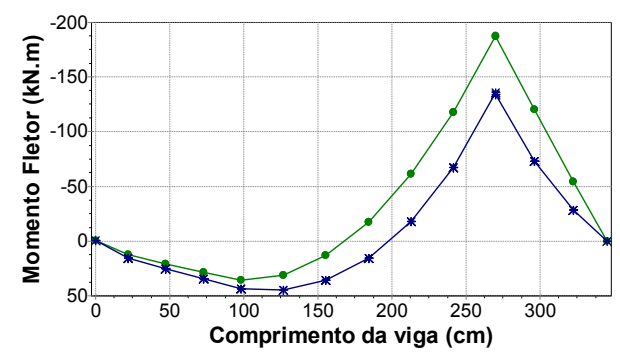

- V VS1R $*$ VS2R

Figura 5.22 - Momento fletor - viga V17

\section{e) Viga V23}

Os resultados encontrados no estudo da presente viga são ilustrados da Figura 5.23 até a Figura 5.26.

O efeito arco reduz o deslocamento da viga, como observado na Figura 5.23. Analisando-se os valores obtidos, as duas simulações de apoio resultam em deslocamentos relativos praticamente coincidentes. $\mathrm{O}$ trecho de porta fica bastante evidente nos diagramas de esforço normal e cortante (Figura 5.24 e Figura 5.25 respectivamente).

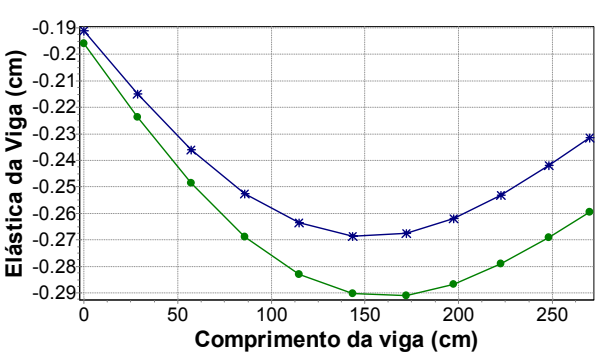

$\rightarrow-\mathrm{VS1} * \mathrm{VS2}$

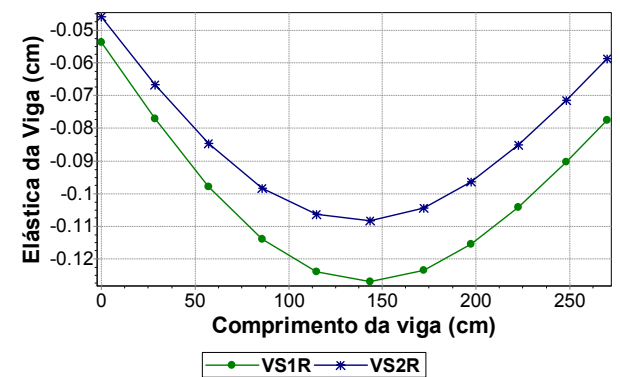

$\Longrightarrow$-VS1R *-VS2R

Figura 5.23 - Deslocamentos verticais - viga V23
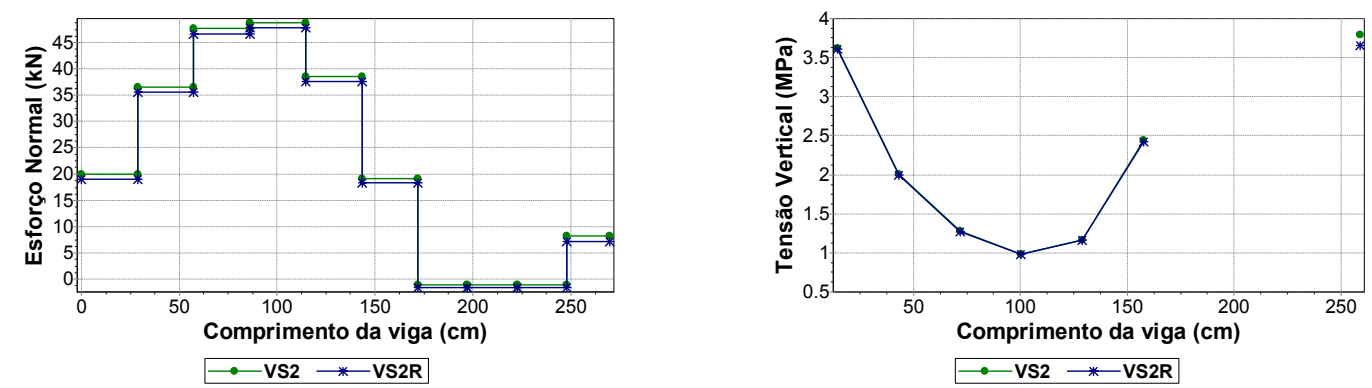

Figura 5.24 - Esforço normal e tensão vertical - viga V23 
A variação da rigidez dos apoios não influencia o momento fletor da viga V23, resultando em diagramas idênticos tanto para o Modelo 1 quanto para o Modelo 2. Já o efeito arco provoca uma pequena redução do fletor positivo, como se observa na Figura 5.26.

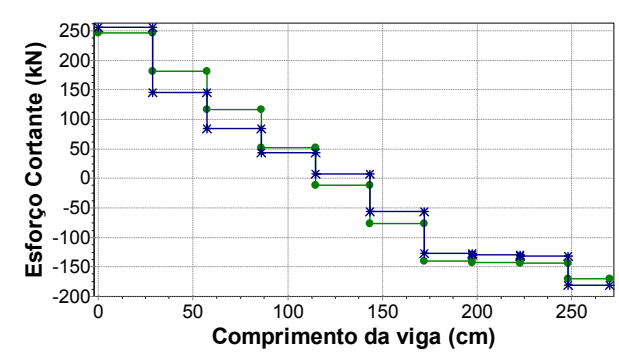

$\because-$ VS1 *-VS2

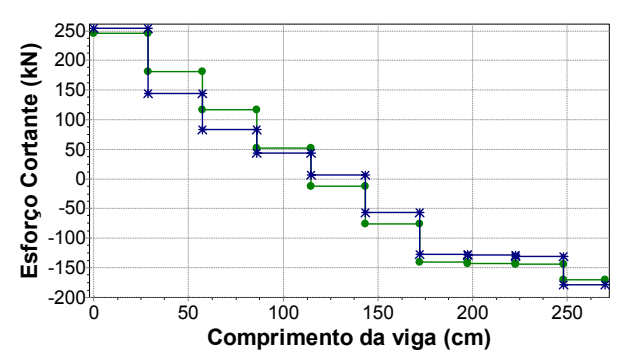

$\because-V S 1 R \longrightarrow$ * VS2R

Figura 5.25 - Esforço cortante - viga V23

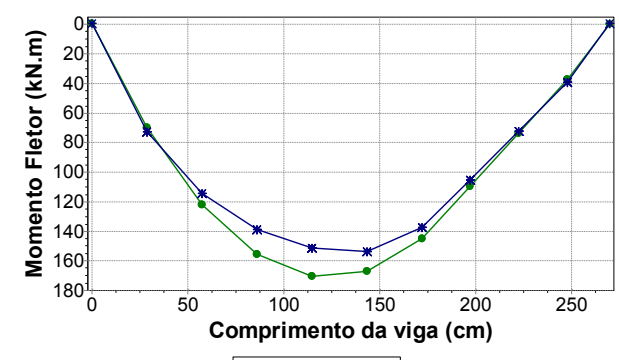

$-\mathbf{v S 1} * \mathbf{v S 2}$

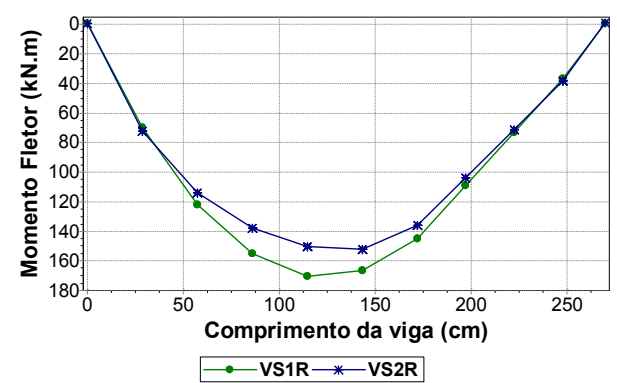

- - VS1R $*$ VS2R

Figura 5.26 - Momento fletor - viga V23

\section{f) Viga V27}

Como se percebe pelos diagramas apresentados na Figura 5.27, a influência do efeito arco nos deslocamentos é pequena, não havendo grandes diferenças entre as curvas dos Modelos 1 e 2. A situação ideal para análise das curvas de deslocamentos seria montá-las descontando-se os deslocamentos dos nós de pilares e interpolando-se os valores para os demais nós. Devido às dificuldades relacionadas à localização dos nós de pilares na listagem de resultados, optou-se pela apresentação das curvas de deslocamentos absolutos. Mesmo assim, é visualmente perceptível uma pequena diferença na forma dos diagramas quando se varia a rigidez dos apoios, o que denota alguma diferença nos deslocamentos relativos, sendo estes um pouco menores na análise com pilares deformáveis.

A presente viga possui dois apoios em vigas (V20 e V28) e três apoios em pilares (P18, P19 e P20). Como avaliado em vigas anteriores, a variação da rigidez dos apoios não provoca diferenças consideráveis nos resultados apresentados. Entretanto, a ocorrência de pontos com apoios em pilares e outros em vigas têm provocado diferenças entre os modelos com pilares deformáveis e os com apoios rígidos. Tal afirmação é constatada observando-se a Figura 5.28, onde a análise com pilares deformáveis apresenta maiores valores de esforço normal e tensão vertical.

O efeito arco não influencia muito o esforço cortante, como se observa na Figura 5.29, havendo maiores diferenças antes da interseção com a viga V22. A diferença ocasionada pela 
variação da rigidez dos apoios já não é tão pequena, havendo alterações mais perceptíveis no trecho compreendido entre os pilares P18 e P19.

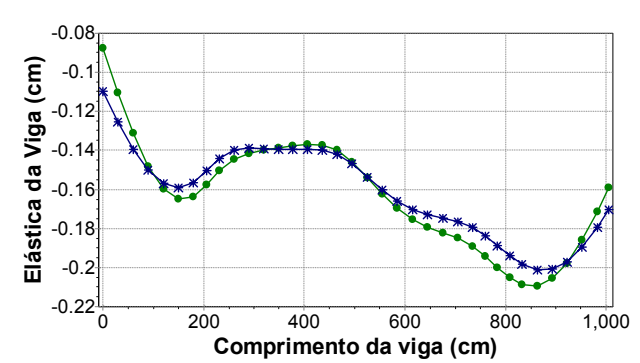

$\rightarrow$ VS1 *-VS2

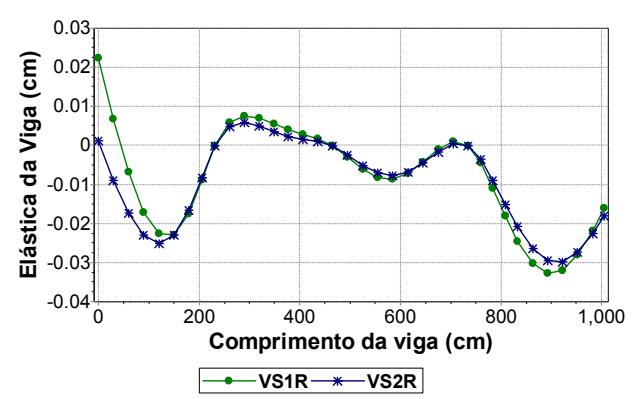

$\because$ VS1R * —VS2R

Figura 5.27 - Deslocamentos verticais - viga V27
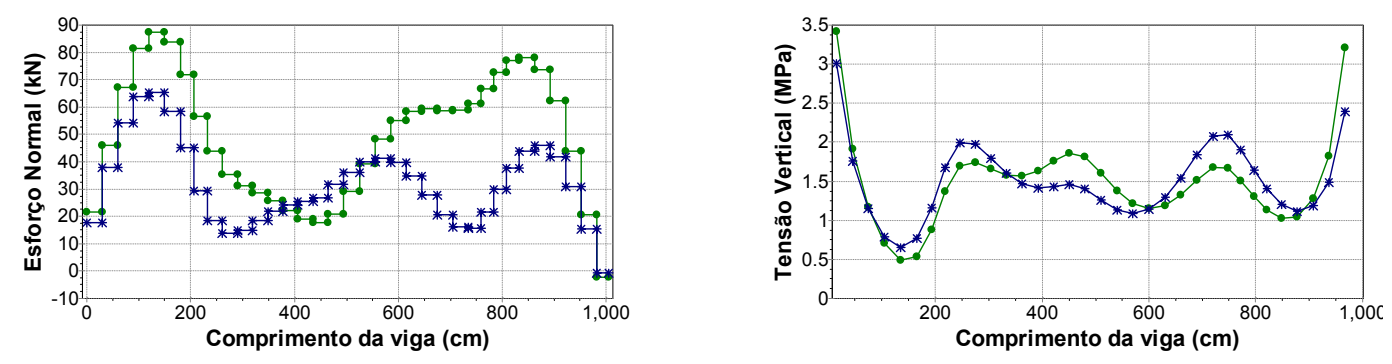

- vS2 * * VS2R

$\because$ VS2 $*$ * VS2R

Figura 5.28 - Esforço normal e tensão vertical - viga V27

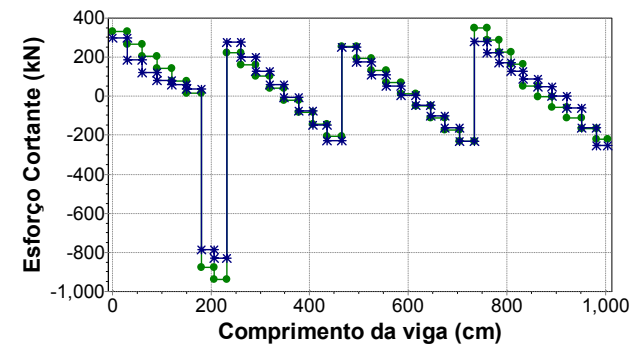

- -VS1 + * VS2

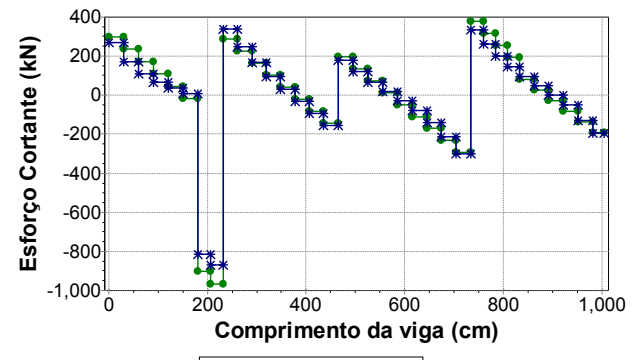

- $-\mathrm{VS} 1 \mathrm{R} \rightarrow$ * VS2R

Figura 5.29 - Esforço cortante - viga V27
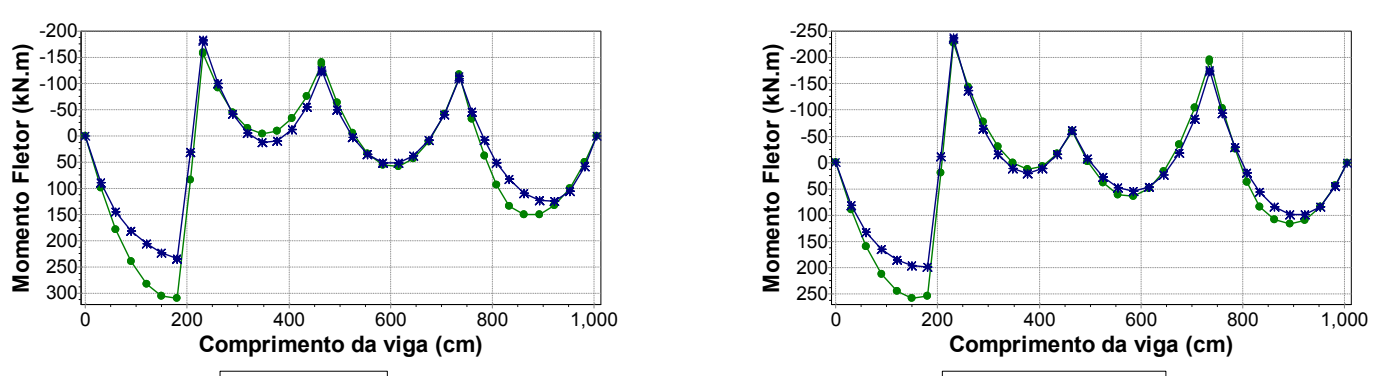

Figura 5.30 - Momento fletor - viga V27

Como ilustrado pela Figura 5.30, o diagrama de momento fletor da viga V27 sofre alguma influência quando se varia a rigidez dos apoios. A análise com pilares deformáveis apresenta maiores valores de fletor positivo nos tramos extremos, enquanto a análise com apoios rígidos leva a um incremento no fletor negativo sobre os pilares P18 e P20, diminuindo o valor do 
mesmo esforço sobre o pilar P19. Para ambas as simulações de apoio o efeito arco atua significativamente nos vãos extremos, propiciando uma diminuição do momento fletor positivo.

\section{g) Viga V20}

Os diagramas apresentados da Figura 5.31 até a Figura 5.34 demonstram os resultados obtidos com o estudo da viga V20.

A presente viga se apóia em quatro pilares, servindo de apoio para a viga V27 no vão central. A diminuição dos deslocamentos com o efeito arco é bastante patente, como se observa na Figura 5.31.
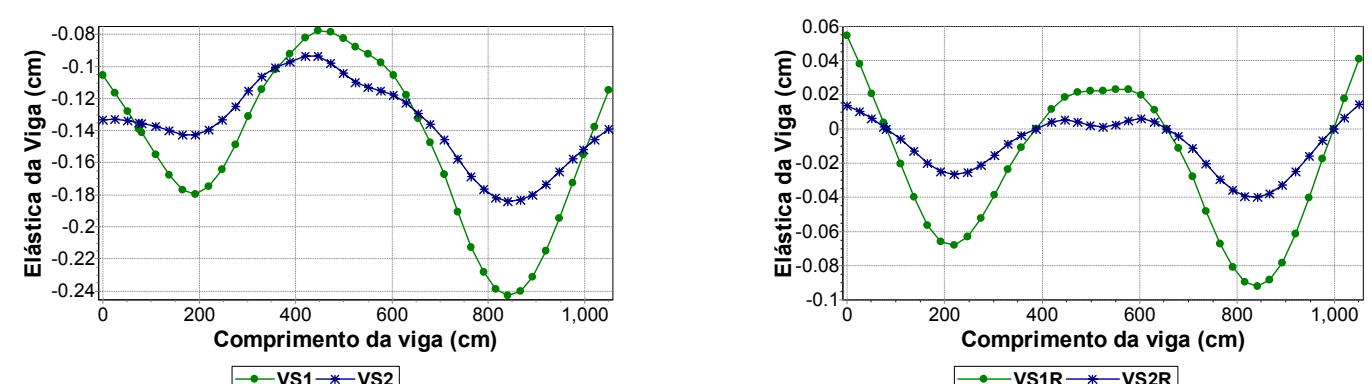

Figura 5.31 - Deslocamentos verticais - viga V20

O diagrama de esforço normal (Figura 5.32) apresenta alguma diferença para as modelagens com variação da rigidez dos apoios, sendo mais perceptível no trecho que vai do pilar P30 ao pilar P14 (região sem parede sobre a viga). O efeito arco é visível nos diagramas de esforço cortante (Figura 5.33), causando uma suavização nas curvas do Modelo 2 entre os pilares P30 - P22 e P14 - P03.
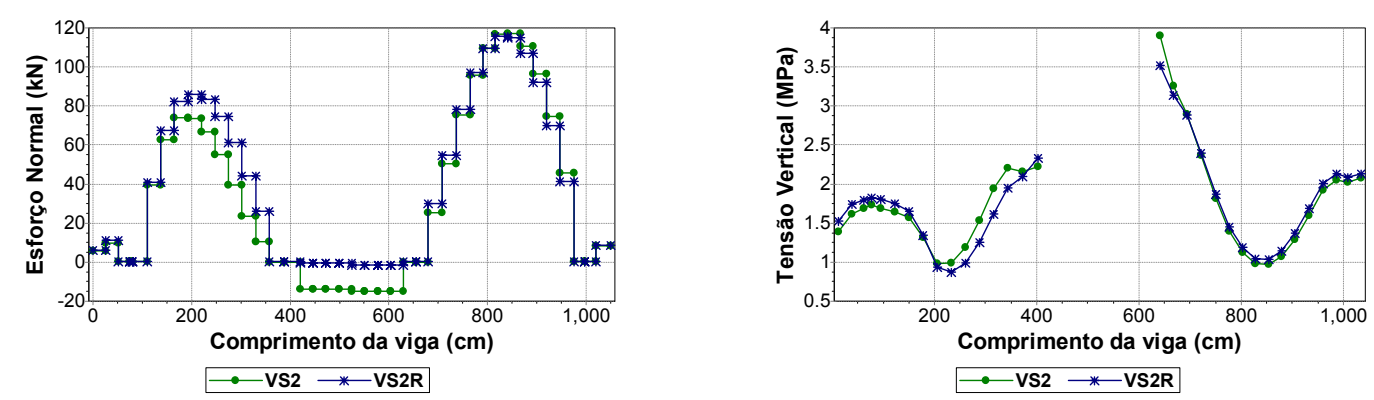

Figura 5.32 - Esforço normal e tensão vertical - viga V20

O diagrama de momentos fletores constante na Figura 5.34 ilustra a significativa diminuição no fletor positivo observada no modelo que considera o efeito arco (Modelo 2). Percebem-se dois trechos em balanço nos extremos da viga. As maiores diferenças aparecem nas regiões compreendidas pelos pilares P30 - P22 e P14 - P03. O vão central, delimitado pelos pilares P22 e P14, que não possui parede sobre o mesmo, acabou tendo o fletor positivo aumentado devido à consideração do efeito arco. $\mathrm{Na}$ análise com variação da rigidez dos apoios, 
o modelo com apoios rígidos alterou um pouco os picos de fletor negativo, tendo sido mais evidentes sobre o pilar P22.
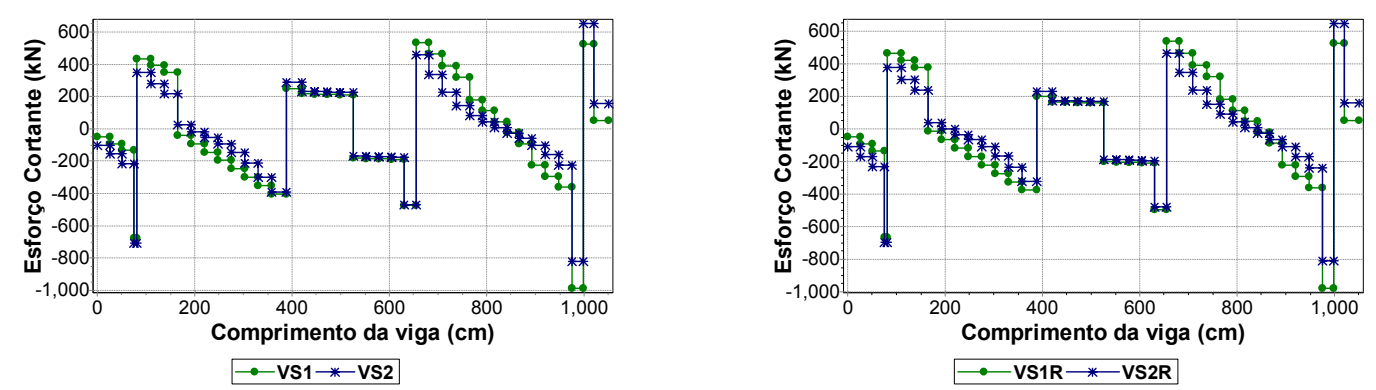

Figura 5.33 - Esforço cortante - viga V20

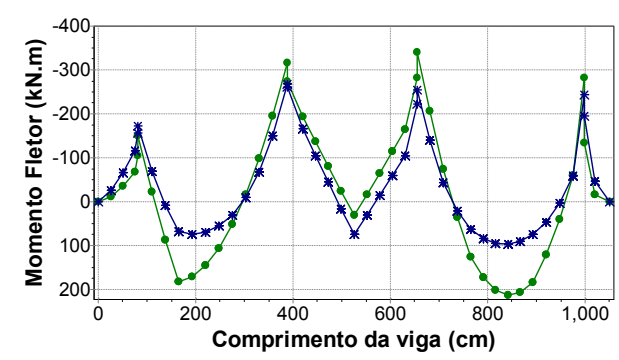

$\because-\mathrm{VS} 1-$ * VS2

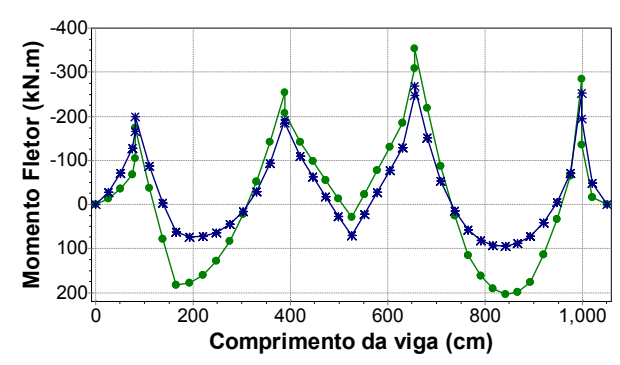

Figura 5.34 - Momento fletor - viga V20

\section{h) Viga V22}

A presente viga não tem nenhum ponto de apoio definido por pilares, mas apenas por outras vigas. Os deslocamentos verticais são novamente diminuídos quando se trabalha com modelos que permitem a consideração do efeito arco, como se verifica nos diagramas presentes na Figura 5.35. A variação da rigidez dos apoios resulta em diagramas muito parecidos. Observando-se a escala vertical é possível constatar que os gráficos se encontram apenas transladados, pois a análise com pilares deformáveis apresenta deslocamentos no topo dos pilares.

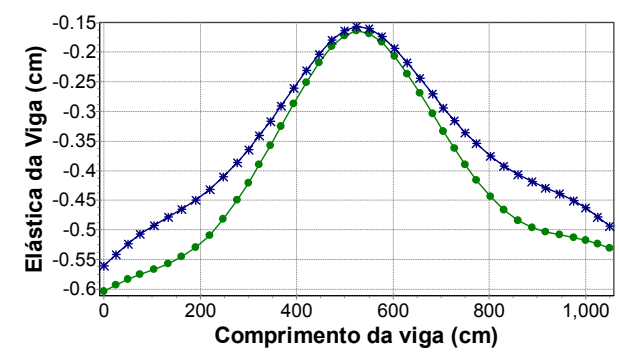

$\because$ VS1 *-VS2

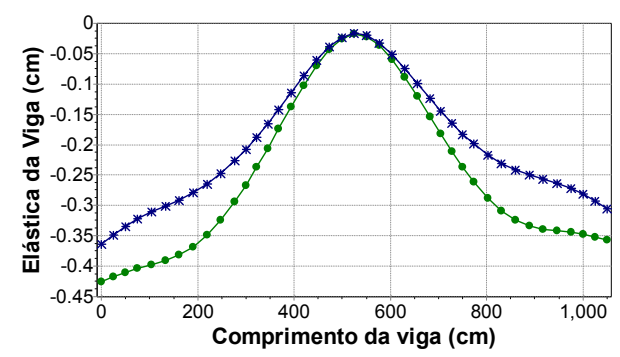

$\because-\mathrm{VS1R}$ *-VS2R

Figura 5.35 - Deslocamentos verticais - viga V22

A viga é inteiramente tracionada, excetuando-se o trecho sem paredes na proximidade do apoio com a viga $\mathrm{V} 27$, aparecendo uma região de valores próximos de zero nos diagramas da Figura 5.36. As diferenças observadas nos diagramas de esforço normal e tensão vertical, devido à variação da rigidez dos apoios, são menores nesta viga. Entretanto, percebe-se um 
pequeno aumento da tensão vertical sobre as interseções com as vigas V43 e V09 no modelo com pilares deformáveis.

Também são observadas reduções significativas no esforço cortante (Figura 5.37) entre as vigas V43 - V27 e V27 - V09, nos modelos que consideram o efeito arco. O mesmo ocorre para o momento fletor (Figura 5.38), principalmente o fletor positivo.
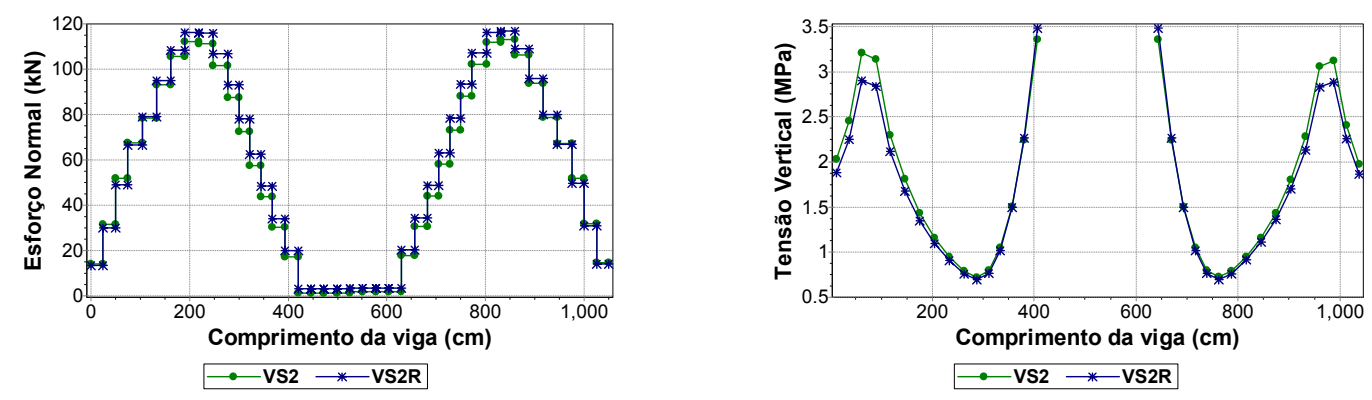

Figura 5.36 - Esforço normal e tensão vertical - viga V22
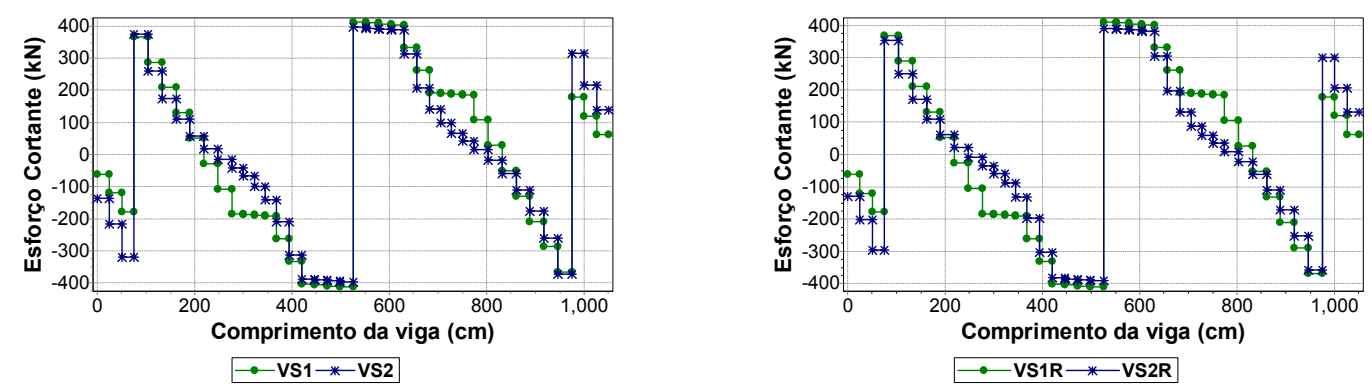

Figura 5.37 - Esforço cortante - viga V22
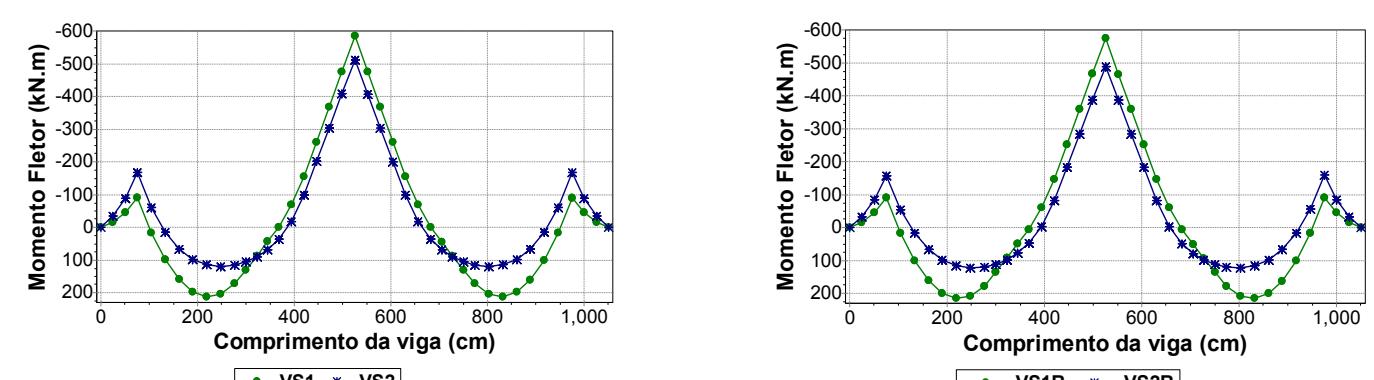

Figura 5.38 - Momento fletor - viga V22

\section{i) Viga V24}

Os diagramas de deslocamentos verticais são apresentados na Figura 5.39. A diminuição da flecha devido ao efeito arco é patente. Os deslocamentos relativos também se mantiveram muito próximos nas simulações com variação da rigidez dos apoios.

São encontrados picos de esforço normal entre os apoios de pilares (Figura 5.40), com uma região comprimida entre as interseções com as vigas V31 e V23 (trecho sem parede sobre a viga). A consideração de pilares deformáveis aumenta um pouco o esforço normal e provoca pouca variação nas curvas de tensão vertical. 


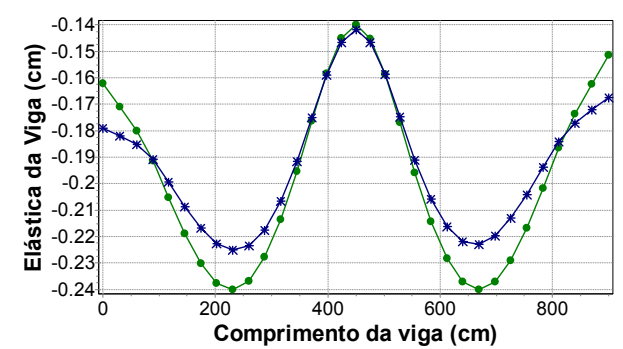

$-\rightarrow-\mathrm{VS} 1 \rightarrow \mathrm{VS} 2$

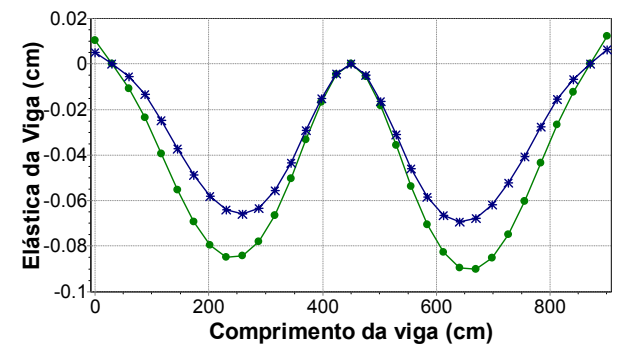

$-\mathrm{VS} 1 \mathrm{R} \rightarrow$ - $\mathrm{VS} 2 \mathrm{R}$

Figura 5.39 - Deslocamentos verticais - viga V24
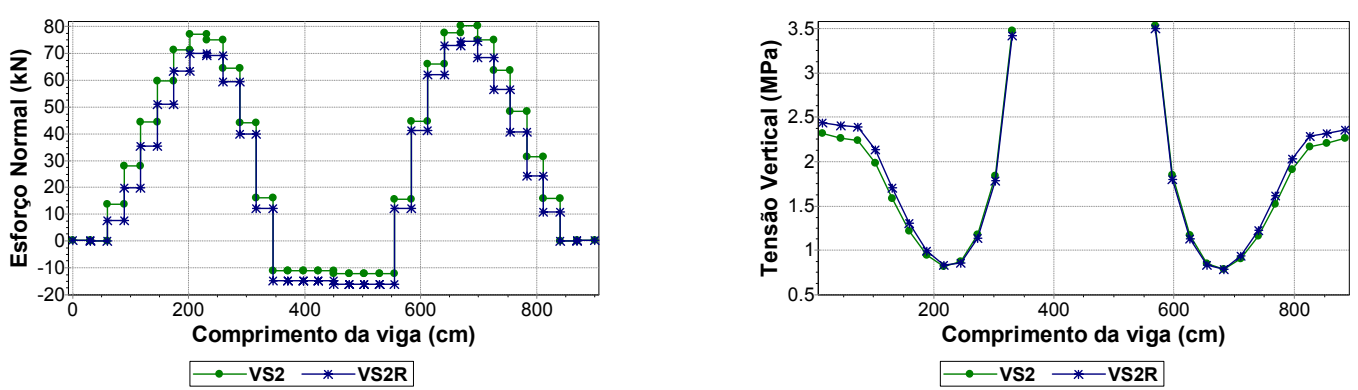

Figura 5.40 - Esforço normal e tensão vertical - viga V24

A variação da rigidez dos apoios ocasiona alterações pouco significativas no esforço cortante. A magnitude das diferenças advindas da consideração do efeito arco também se mostra pequena, como se observa nos diagramas da Figura 5.41.
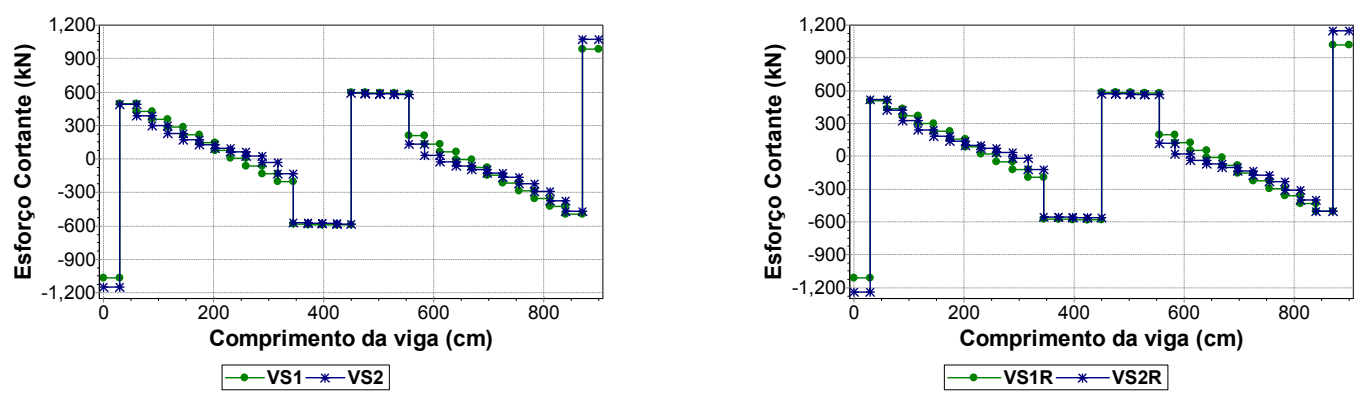

Figura 5.41 - Esforço cortante - viga V24

O efeito arco reduz um pouco os momentos fletores positivos (ver Figura 5.42). Já a variação da rigidez dos apoios conduz a diferenças muito pequenas nos fletores negativos, sendo mais evidente sobre os pilares de extremidade.
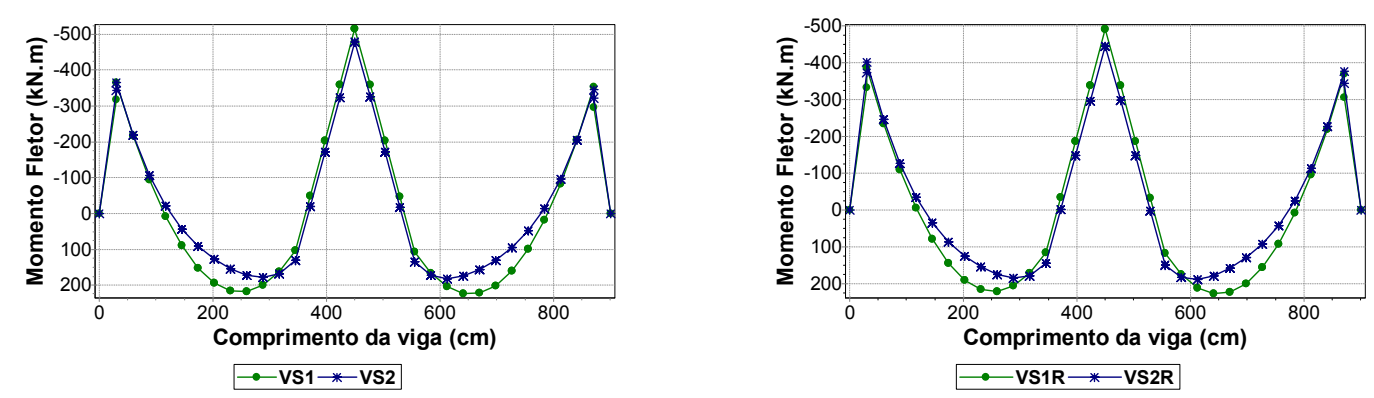

Figura 5.42 - Momento fletor - viga V24 


\section{j) Viga V26}

Pela análise das curvas de deslocamentos verticais (Figura 5.43), é possível visualizar a considerável redução ocasionada pelo efeito arco. O ganho percentual é mais significativo nos modelos com apoios rígidos. Porém, analisando-se os deslocamentos relativos entre as modelagens com variação na rigidez dos apoios percebe-se que a diferença encontrada não é tão grande, embora os deslocamentos relativos tenham sido um pouco menores na modelagem com pilares deformáveis.
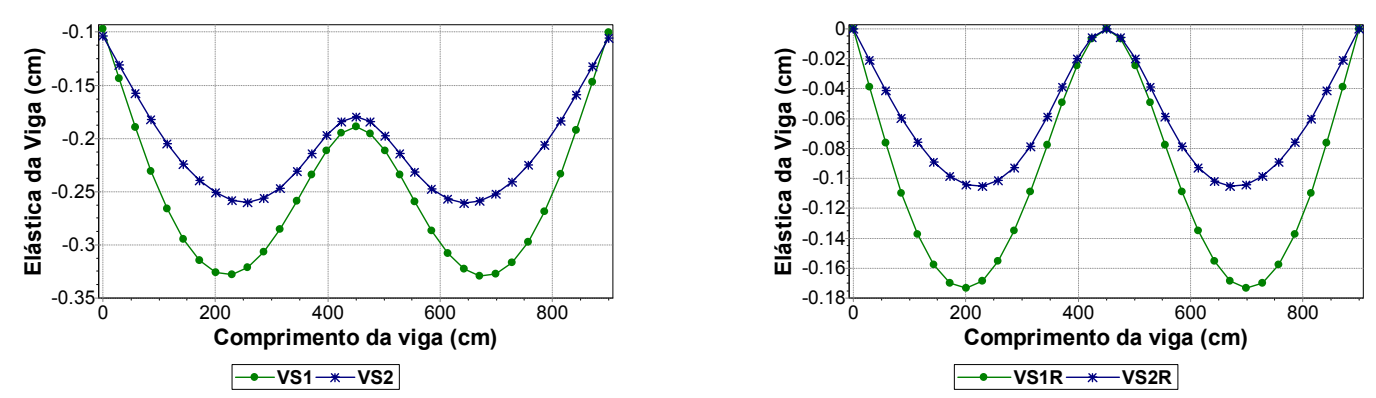

Figura 5.43 - Deslocamentos verticais - viga V26

Na Figura 5.44 são visualizados os diagramas de esforço normal e tensão vertical da viga V26, que não sofrem praticamente influência alguma devido à simulação com apoios rígidos ou pilares deformáveis. As curvas são bem características de um sistema parede-viga, com picos de tração entre os apoios. Entretanto, apenas a região sem paredes entre as vigas V31 e V23 aparece comprimida por um esforço bem pequeno. Os pontos de máximo esforço de tração coincidem com os pontos de mínima tensão vertical.
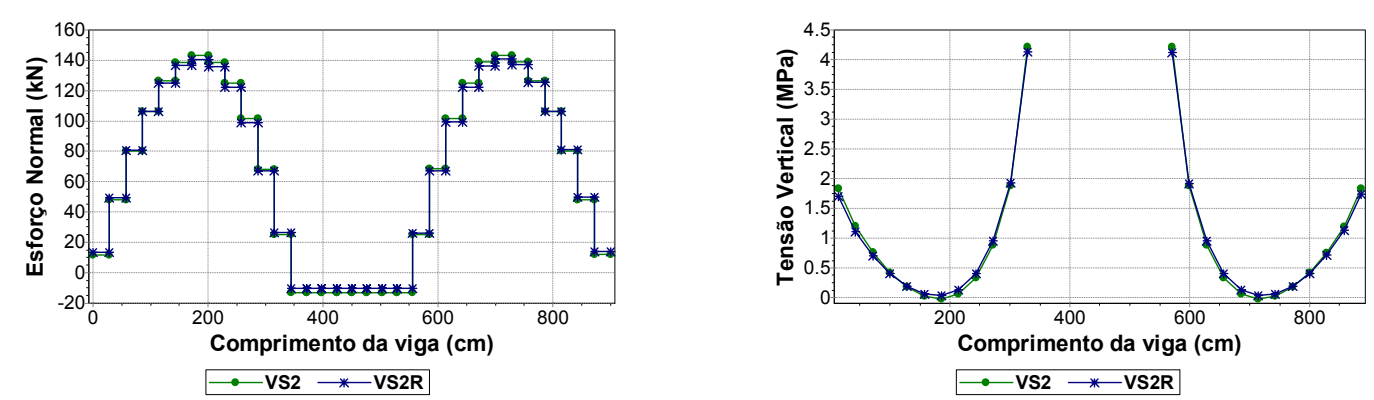

Figura 5.44 - Esforço normal e tensão vertical - viga V26

$O$ efeito arco reduz significativamente o esforço cortante nos trechos que servem de suporte para as paredes (da viga V43 à V31 e da viga V23 à V09). Na região entre as vigas V31 e V23, os valores do cortante para o Modelo 1 e para o Modelo 2 são muito parecidos. As simulações com variação da rigidez dos apoios também apresentam resultados idênticos, como ilustra a Figura 5.45 .

A Figura 5.46 apresenta os diagramas de momento fletor, onde se visualiza uma redução apreciável no fletor positivo devido à consideração do efeito arco. Apesar de menos acentuado, até mesmo o fletor negativo sobre o pilar P20 é minorado devido a este efeito. Analisan- 
do-se cuidadosamente a escala vertical do diagrama, é possível constatar uma pequena alteração nos valores máximos devido à variação da rigidez dos apoios. Contudo, tal diferença é muito pouco significativa.
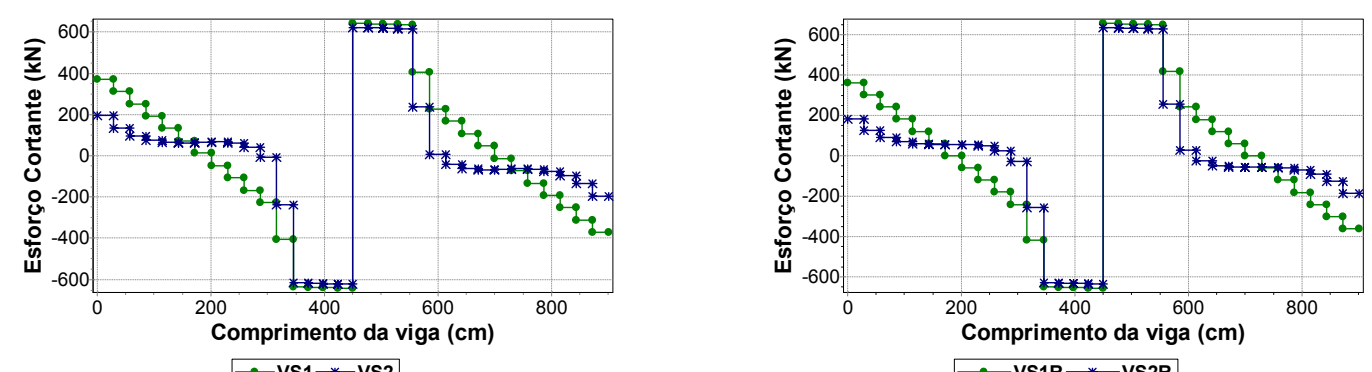

Figura 5.45 - Esforço cortante - viga V26
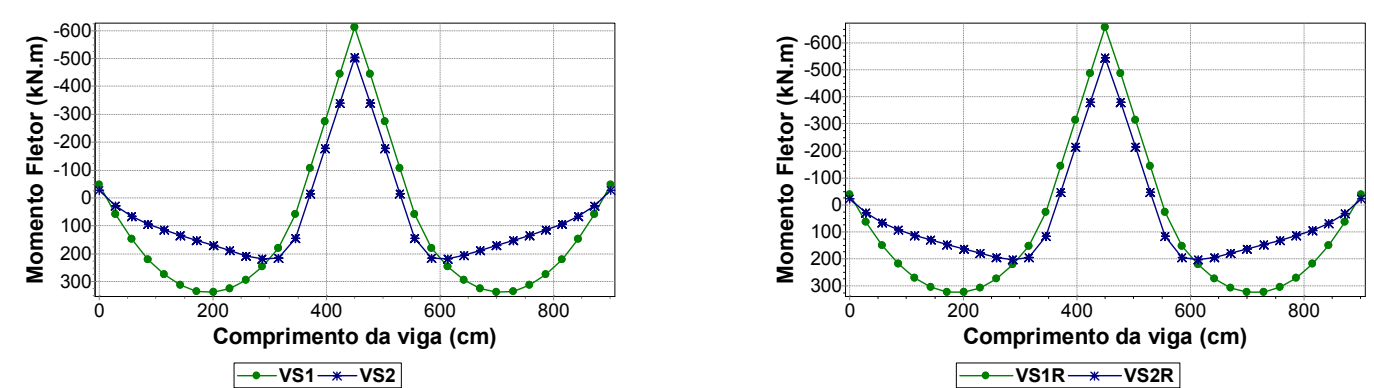

Figura 5.46 - Momento fletor - viga V26

\section{k) Viga V28}

A influência do efeito arco na presente viga teve resultado singular. O Modelo 2 apresentou redução dos deslocamentos nos vãos extremos. Porém, onde se desenvolveram os maiores valores, ou seja, no vão central, o efeito arco provocou um aumento nos deslocamentos, como se observa na Figura 5.47. Em termos de deslocamentos relativos, os valores observados nos vãos extremos foram semelhantes para o caso de pilares rígidos ou deformáveis. Entretanto, quando se analisa o vão central, a modelagem com pilares deformáveis resultou em valores apreciavelmente menores.
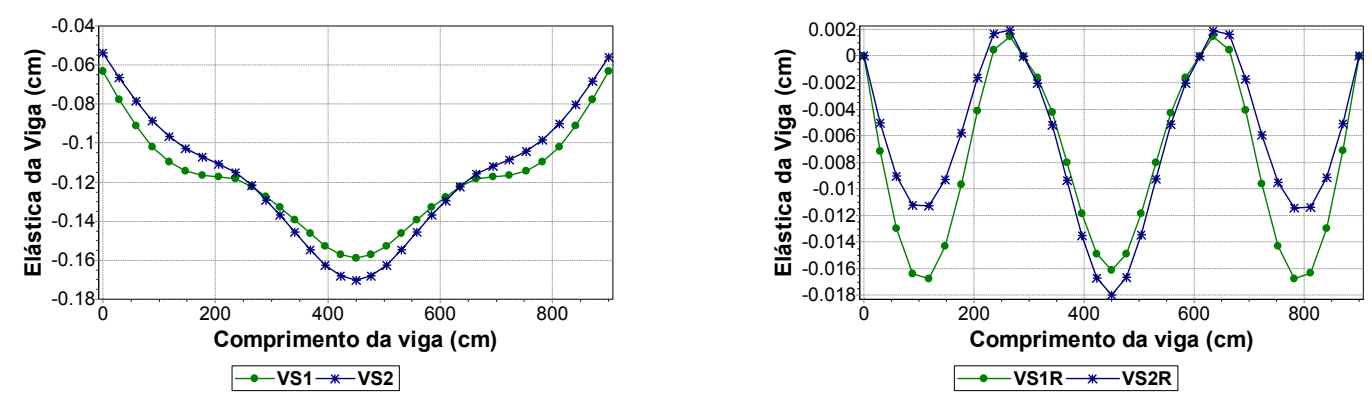

Figura 5.47 - Deslocamentos verticais - viga V28 
A modelagem com pilares deformáveis também reduziu um pouco os valores de tensão vertical máxima, com se observa na Figura 5.48. Entretanto, a ordem de grandeza dessa variação não é muito significativa. Essa mesma modelagem majora os esforços de compressão na região compreendida pelas vigas V37 e V17, sendo que nos demais pontos da viga as diferenças no esforço normal, para as duas simulações de apoio, não são tão significativas.
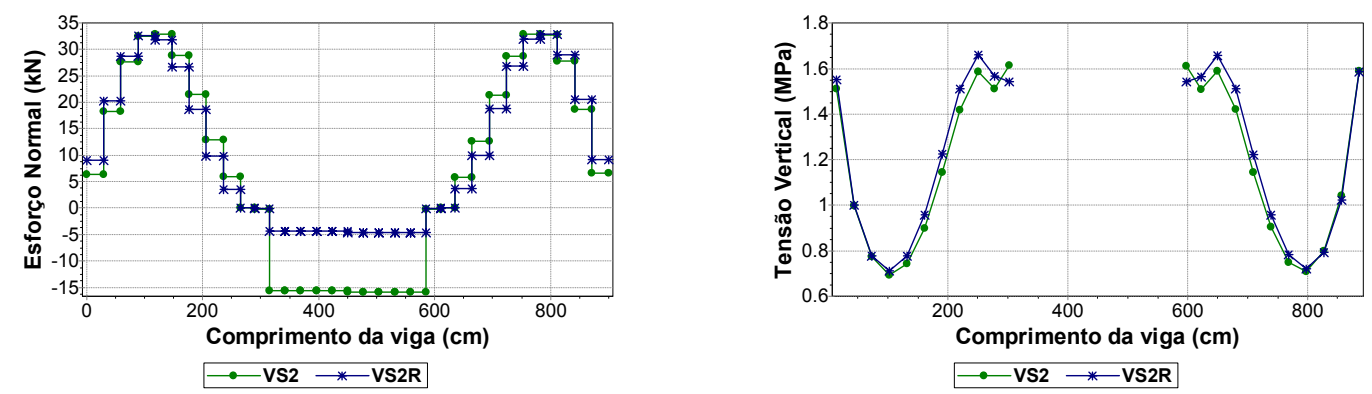

Figura 5.48 - Esforço normal e tensão vertical - viga V28
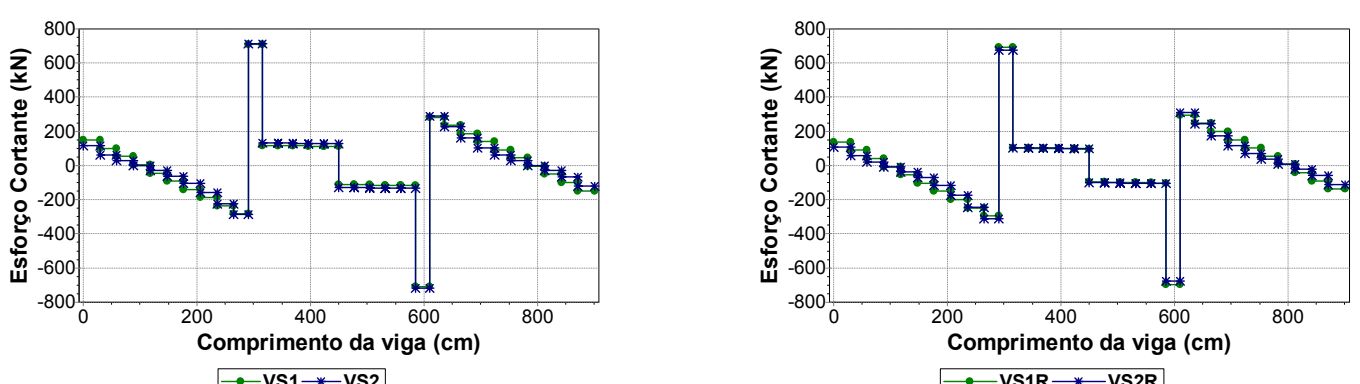

Figura 5.49 - Esforço cortante - viga V28

Da mesma maneira que para os deslocamentos, o efeito arco reduz o momento fletor nos vãos extremos (variação esta mais perceptível nos modelos com pilares deformáveis), havendo aumento do fletor positivo no meio do vão central (ponto de interseção com a viga V27). Os diagramas são apresentados na Figura 5.50.
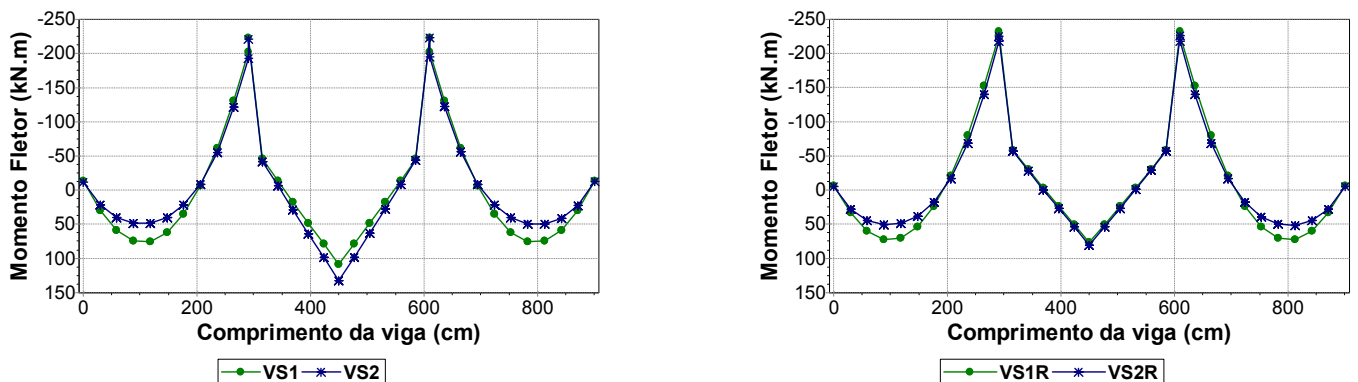

Figura 5.50 - Momento fletor - viga V28

\section{l) Viga V30}

A presente viga tem como apoios as vigas $\mathrm{V} 37$ e V17, sendo carregada por uma parede em toda a sua extensão. As curvas obtidas variando-se a rigidez dos apoios, tanto para o Modelo 1 quanto para o Modelo 2, apresentam resultados muito próximos. 
O efeito arco propicia reduções significativas nos deslocamentos (Figura 5.51), esforço cortante (Figura 5.53) e momento fletor (Figura 5.54), assemelhando-se ao comportamento de sistemas parede-viga encontrados na literatura.
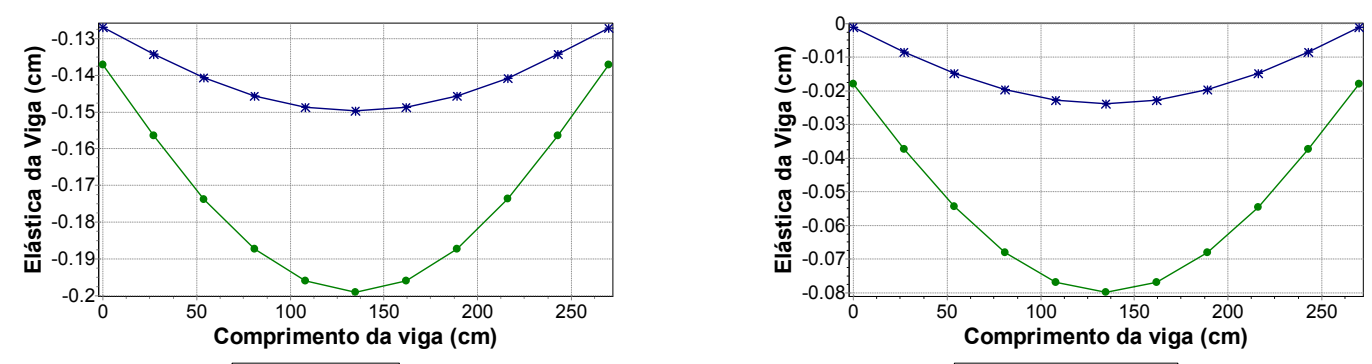

$-\bullet-\mathrm{vS} 1-$ * VS2

$\because-\mathrm{VS} 1 \mathrm{R} \rightarrow$ * VS2R

Figura 5.51 - Deslocamentos verticais - viga V30
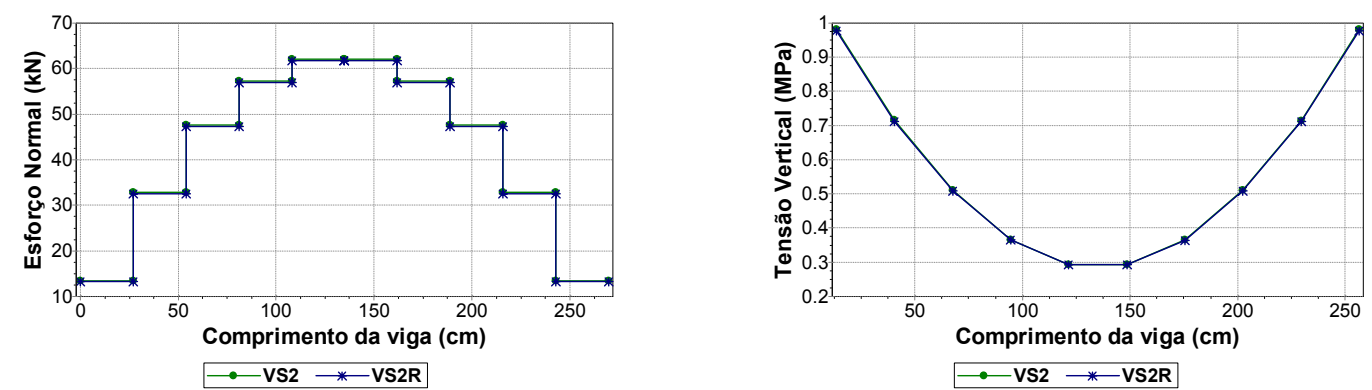

Figura 5.52 - Esforço normal e tensão vertical - viga V30
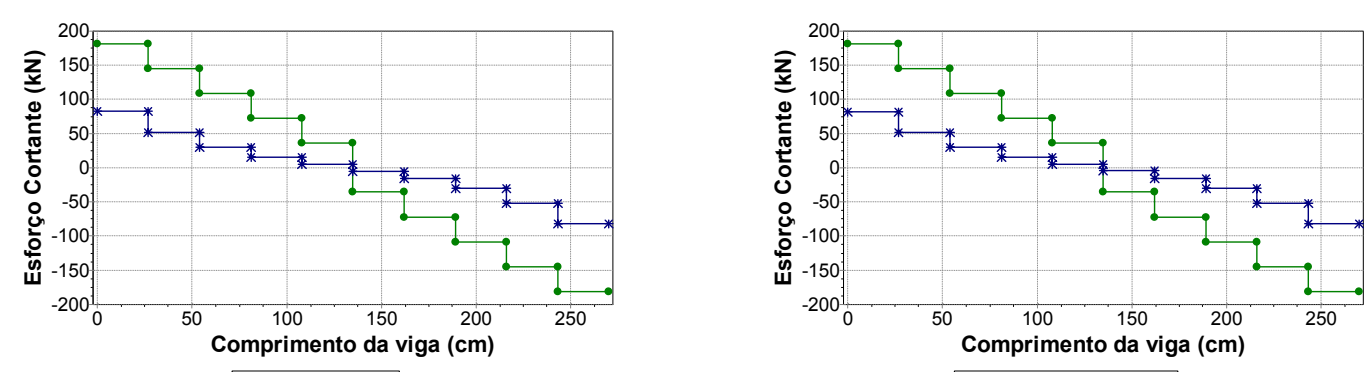

Figura 5.53 - Esforço cortante - viga V30
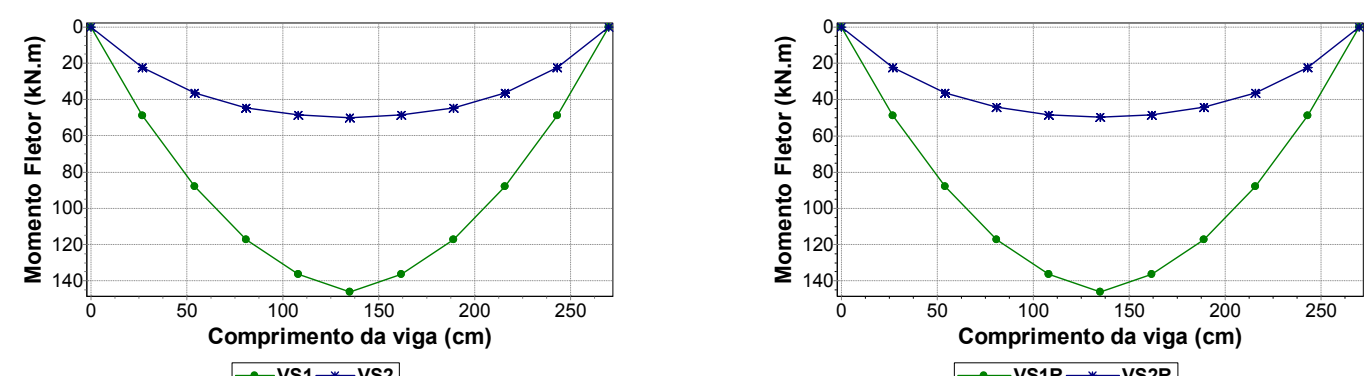

Figura 5.54 - Momento fletor - viga V30 


\subsection{EXEMPLO 2 - EDIFÍCIO MIRANTE DO UMARIZAL}

\subsubsection{Apresentação}

O Edifício Residencial Mirante do Umarizal é composto por oito pavimentos tipo sobre um pavimento de pilotis em concreto armado.

A planta da forma estrutural do pilotis é apresentada na Figura 5.55. Para otimizar o processamento da estrutura e também permitir o emprego de uma rede mais refinada, adotaram-se simetrias em torno dos eixos $\mathrm{X}$ e $\mathrm{Y}$, modelando-se apenas um quarto do pavimento. $\mathrm{A}$ Figura 5.56 ilustra a planta de modulação com a simetria considerada.

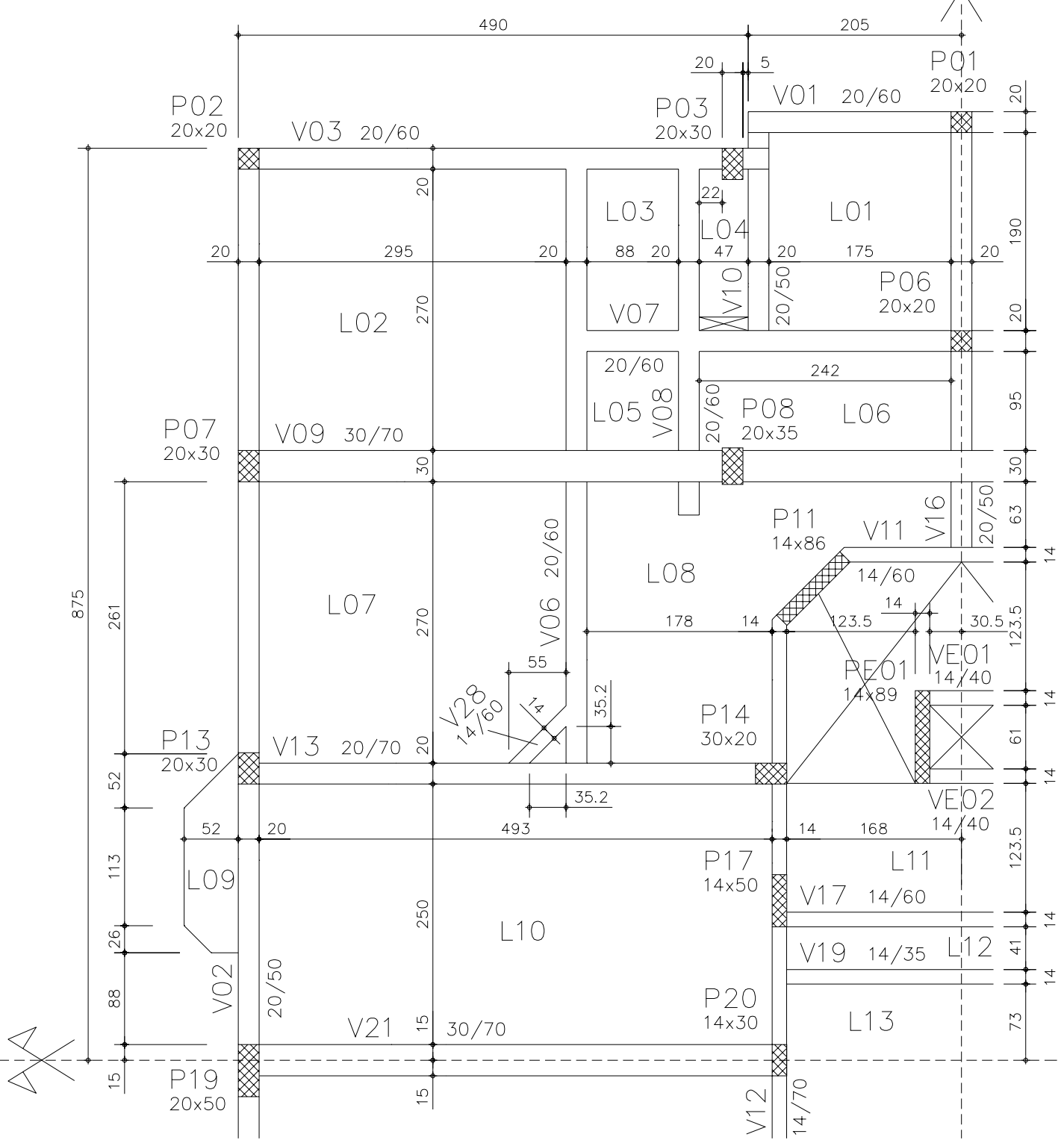

Figura 5.55 - Forma estrutural do pilotis do edifício Mirante do Umarizal 


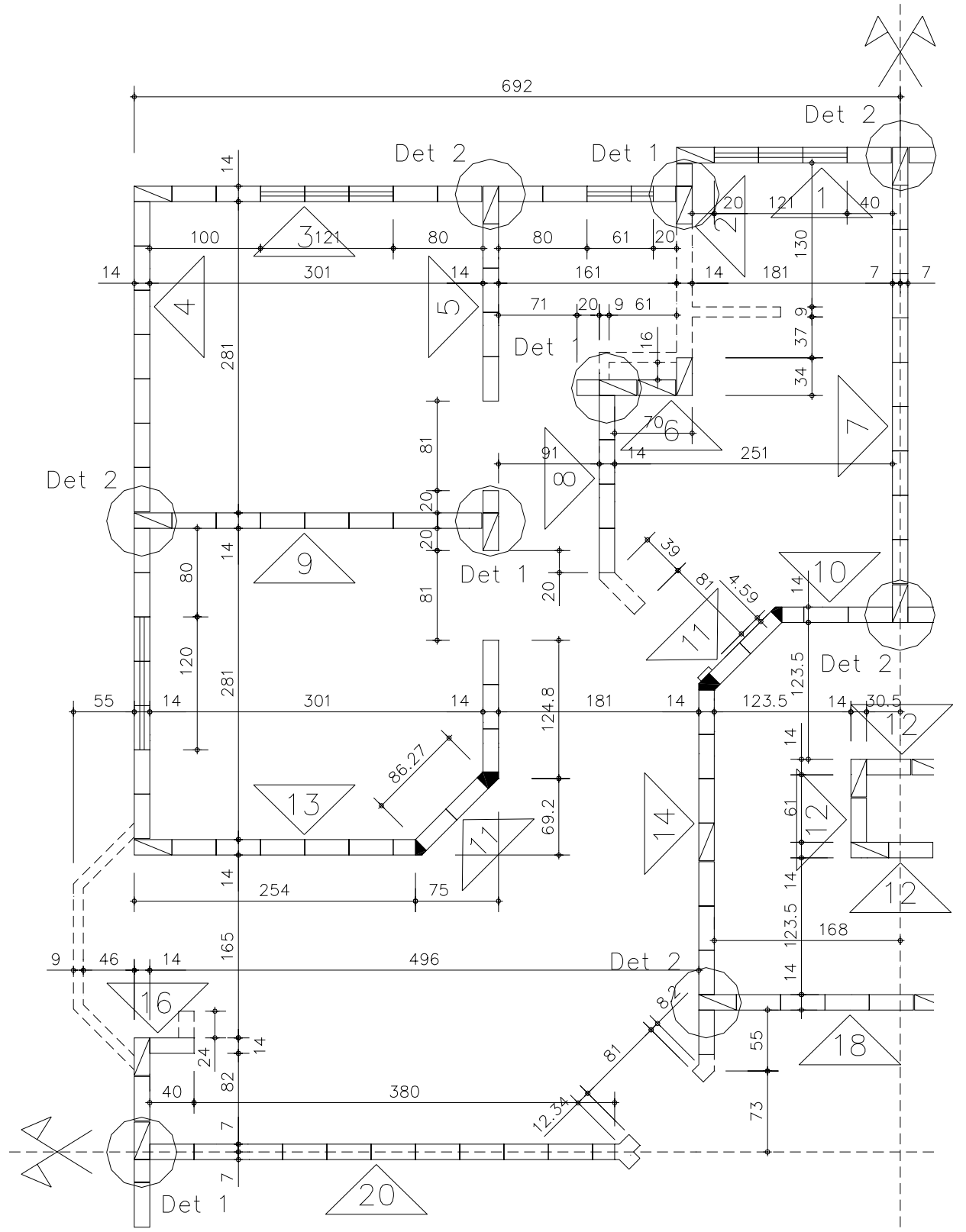

Figura 5.56 - Modulação do pavimento tipo do edifício Mirante do Umarizal

\subsubsection{Descrição dos Modelos}

A Tabela 5.2 apresenta alguns parâmetros e propriedades dos materiais empregados na estrutura do edifício analisado.

Tabela 5.2 - Parâmetros de modelagem do edifício Mirante do Umarizal

\begin{tabular}{ll}
\hline Espessura da parede $(\mathrm{m})$ & 0,14 \\
\hline Altura da parede $(\mathrm{m})$ & 2,68 \\
\hline$v_{\text {viga }}$ & 0,20 \\
\hline$v_{\text {parede }}$ & 0,20 \\
\hline $\mathrm{E}_{\text {parede }}\left(\mathrm{kN} / \mathrm{m}^{2}\right)$ & $3,84 \mathrm{E}+06$ \\
\hline $\mathrm{E}_{\text {viga }}\left(\mathrm{kN} / \mathrm{m}^{2}\right)$ & $2,13 \mathrm{E}+07$ \\
\hline $\mathrm{f}_{\mathrm{ck}}(\mathrm{MPa})$ & 20 \\
\hline
\end{tabular}


A Figura 5.57 apresenta uma vista das barras e nós carregados do chamado Modelo 1. Já na Figura 5.58, é ilustrada a rede, barras e cargas nodais do Modelo 2.

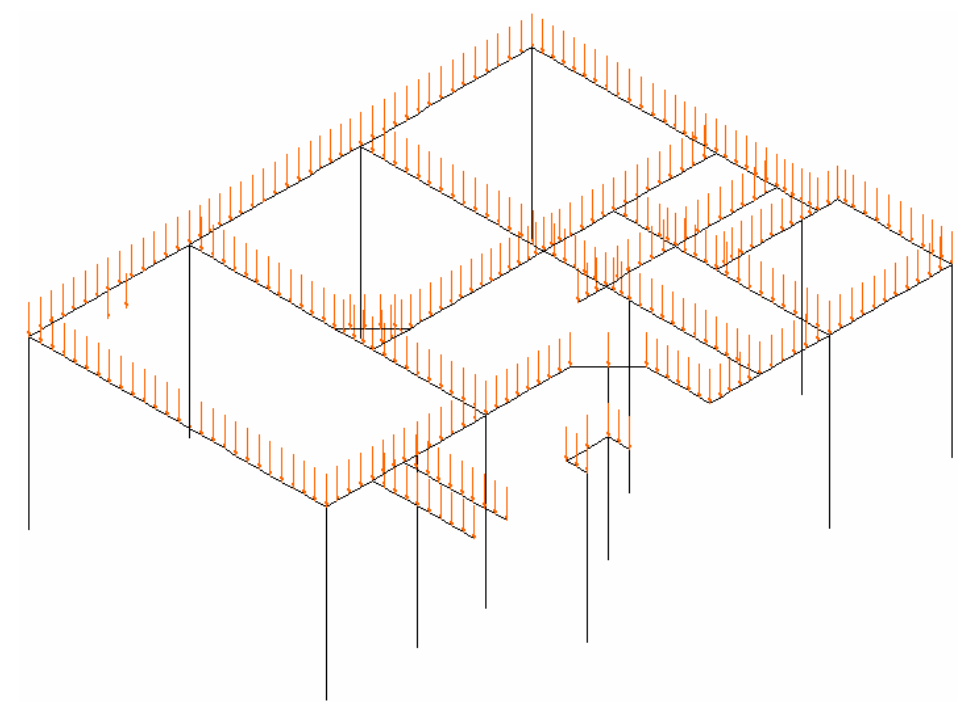

Figura 5.57 - Modelo 1 (MU1 e MU1R) do edifício Mirante do Umarizal

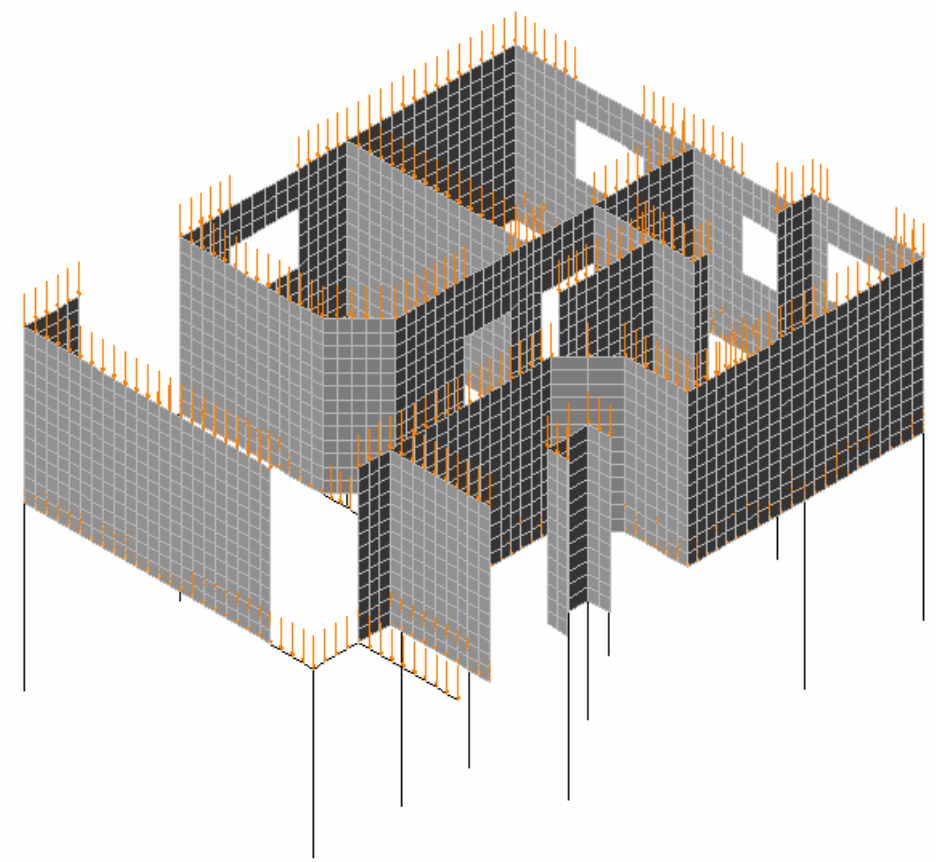

Figura 5.58 - Modelo 2 (MU2 e MU2R) do edifício Mirante do Umarizal

\subsubsection{Análise de Resultados}

Faz-se uma análise mais concisa do processamento do presente edifício, abrangendose apenas os resultados mais significativos de algumas vigas.

O primeiro exemplo desenvolvido (item 5.3) procurou apresentar de forma mais completa a interação entre um edifício em alvenaria estrutural e um pavimento de pilotis em concreto armado. Como foi possível constatar, a variação da rigidez do apoio não influenciou tão significativamente grande parte dos resultados expostos. Entretanto, principalmente para o es- 
forço normal e tensão vertical, algumas diferenças são mais facilmente observadas. Dessa forma, optou-se pela manutenção da sistemática utilizada durante a análise do primeiro edifício.

\section{a) Viga V03}

A Figura 5.59 apresenta os diagramas da elástica da viga. Como se percebe, a consideração do efeito arco propicia grandes reduções nos deslocamentos. Apesar de servir de apoio para duas vigas (V06 e V08), o efeito arco minora as reações de apoio destas vigas. Tal argumentação pode ser comprovada observando-se o diagrama de esforço cortante na Figura 5.61 , analisando-se os saltos nas abscissas $315 \mathrm{~cm}$ (interseção com V06) e $420 \mathrm{~cm}$ (interseção com V08). Ainda com relação aos esforços cortantes, houve diminuições dos seus valores máximos quando se considera o efeito arco. É possível perceber uma pequena diferença no esforço cortante sobre o pilar $\mathrm{P} 03$, com relação às modelagens com variação na rigidez dos apoios. Porém a magnitude desta diferença é pouco significativa.
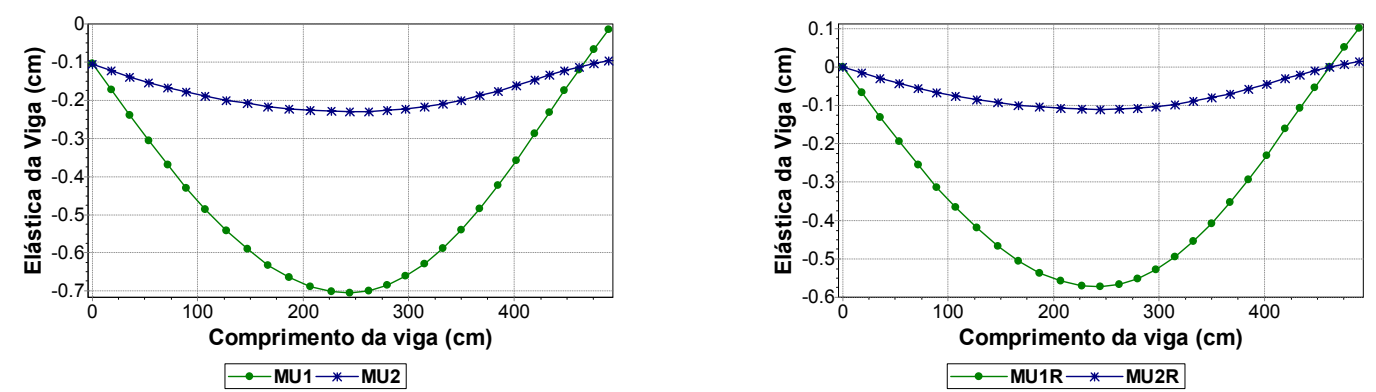

Figura 5.59 - Deslocamentos verticais - viga V03
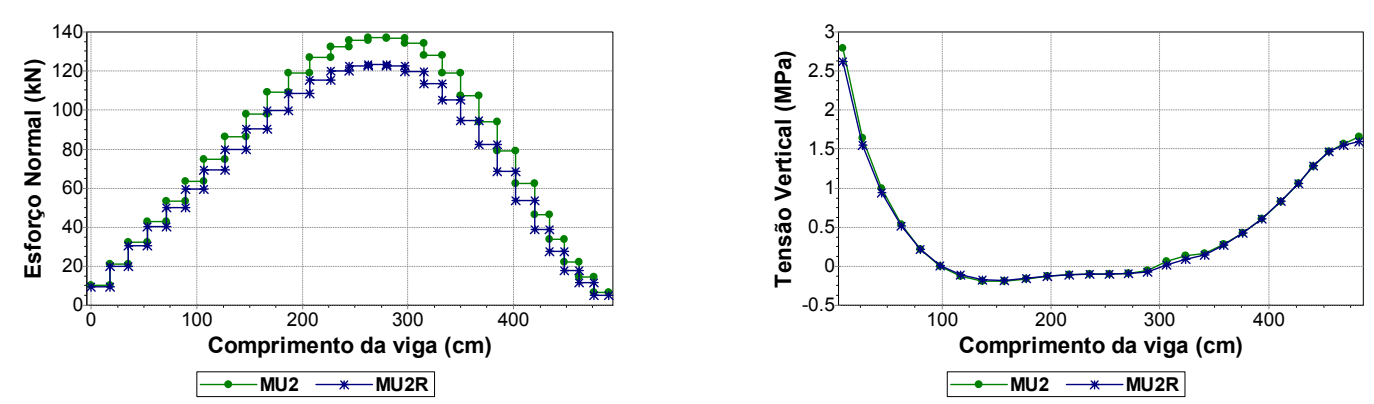

Figura 5.60 - Esforço normal e tensão vertical - viga V03
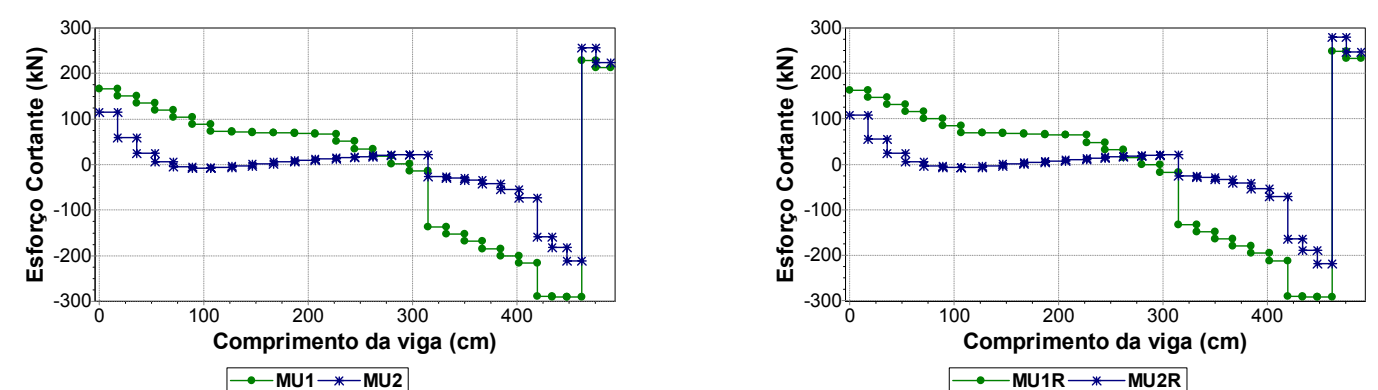

Figura 5.61 - Esforço cortante - viga V03 
O esforço normal também sofre um pequeno aumento quando se modela o pilotis com barras de pilares deformáveis, como se constata pela análise da Figura 5.60. A tensão vertical tem curvas praticamente idênticas variando-se a rigidez dos apoios.

\section{b) Viga V09}

Com parede sobre o trecho entre o pilar P07 e a interseção com a viga V06, os deslocamentos nessa região são bastante influenciados pelo efeito arco, como se observa na Figura 5.62. Com simetria definida no encontro com a viga V16, o trecho que vai do pilar P08 até essa interseção apresenta alguma diferença entre as modelagens com variação da rigidez do apoio.

No trecho com parede sobre a viga, que vai do pilar P07 até a interseção com a viga V06, o efeito arco minora consideravelmente o esforço cortante, como se observa nos diagramas da Figura 5.63. Também aparece uma pequena diferença entre as modelagens com variação da rigidez do apoio, estando esta localizada no trecho que vai do pilar P08 à viga V16.

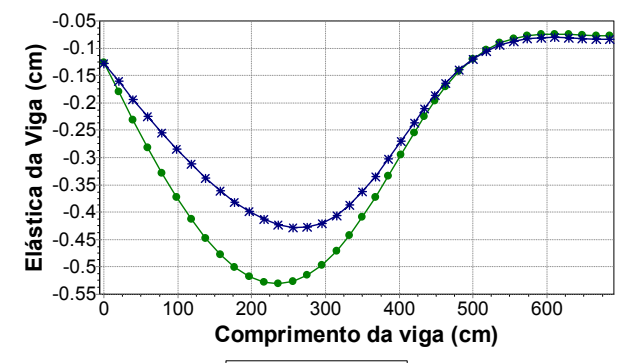

$\multimap-\mathrm{MU1} *$ * MU2

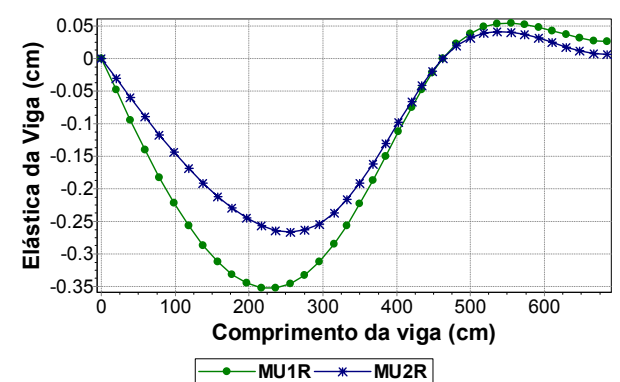

- -MU1R * * MU2R

Figura 5.62 - Deslocamentos verticais - viga V09
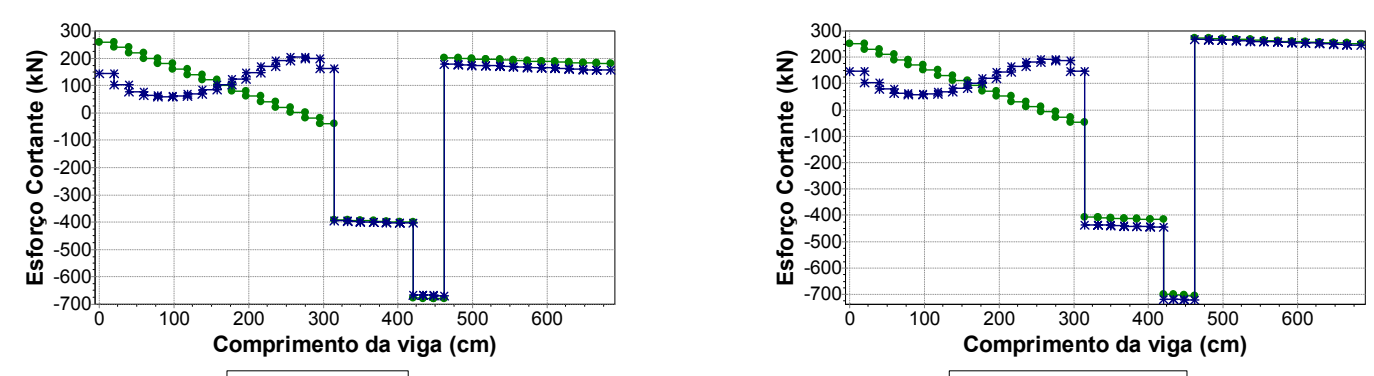

$\longrightarrow-\mathrm{MU1} *-\mathrm{MU} 2$

Figura 5.63 - Esforço cortante - viga V09
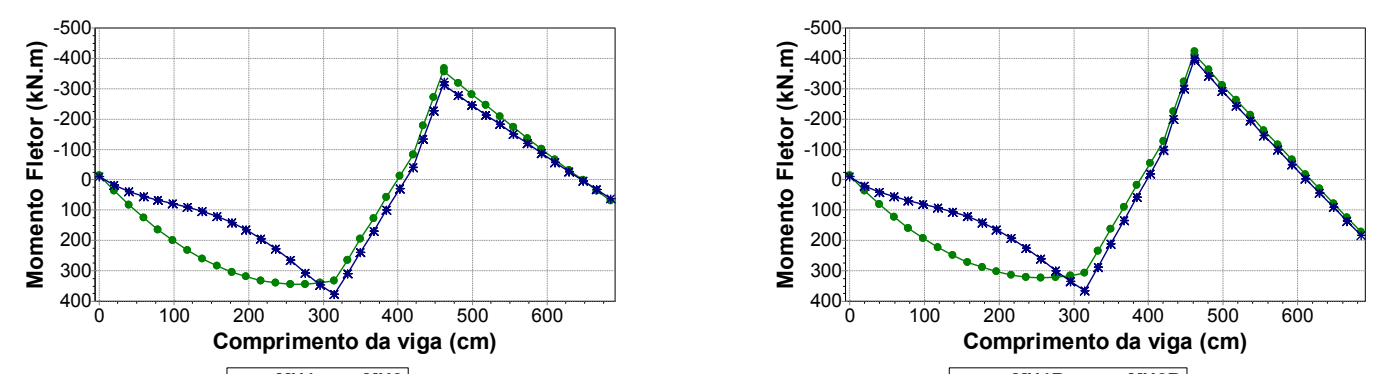

Figura 5.64 - Momento fletor - viga V09 
Apesar de reduzir o momento positivo no meio do vão entre o pilar P07 e a interseção com a viga V06, houve um pequeno aumento no valor do máximo momento fletor positivo quando se considera o efeito arco. A Figura 5.64 apresenta os referidos diagramas, podendose constatar um aumento no valor do máximo fletor negativo (sobre o pilar P08) na análise com apoios rígidos.

\section{c) Viga V21}

Barbosa (2000) verificou que, para a normal nas vigas, o efeito arco provoca esforços de compressão na região dos pilares e esforços de tração no meio dos vãos das vigas. Como se observa no diagrama da Figura 5.65 e em outros já analisados, nem sempre ocorre a configuração de esforços exposta anteriormente. Pode-se dizer que a presente viga é totalmente tracionada. Sob o trecho sem parede, o esforço normal é praticamente nulo.
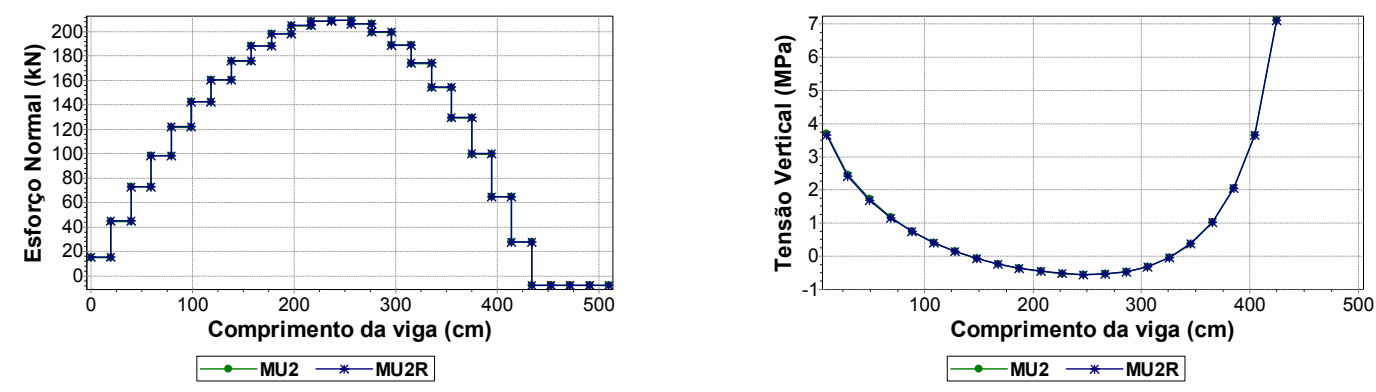

Figura 5.65 - Esforço normal - viga V21

A presente viga possui um único vão com pilares nas suas extremidades, sendo quase totalmente carregada por uma parede. É interessante observar que não há diferença alguma para o esforço cortante entre as curvas dos Modelos 1 e 2 (Figura 5.66), quando se varia a rigidez dos apoios.
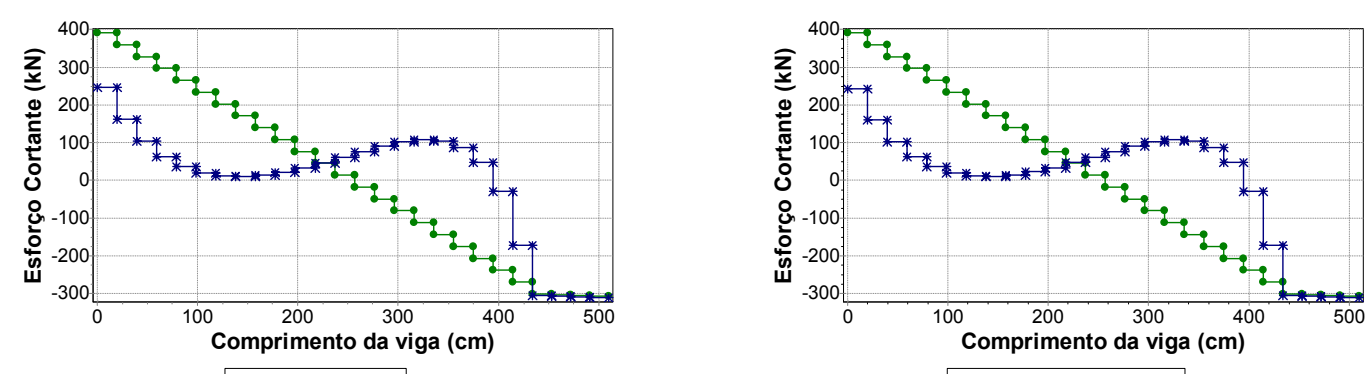

Figura 5.66 - Esforço cortante - viga V21

Assim como para o esforço cortante, a variação da rigidez dos apoios não influencia os diagramas de momento fletor da viga V21, como ilustra os diagramas da Figura 5.67. É perceptível um pequeno fletor negativo no apoio da esquerda. Isso se deve ao fato do pilar que se encontra neste ponto ter sua seção transversal um pouco maior, aumentando a rigidez à flexão da 
barra que o representa. Quanto ao efeito arco, é patente aos olhos a grande economia em armadura que se poderia obter com a sua consideração.
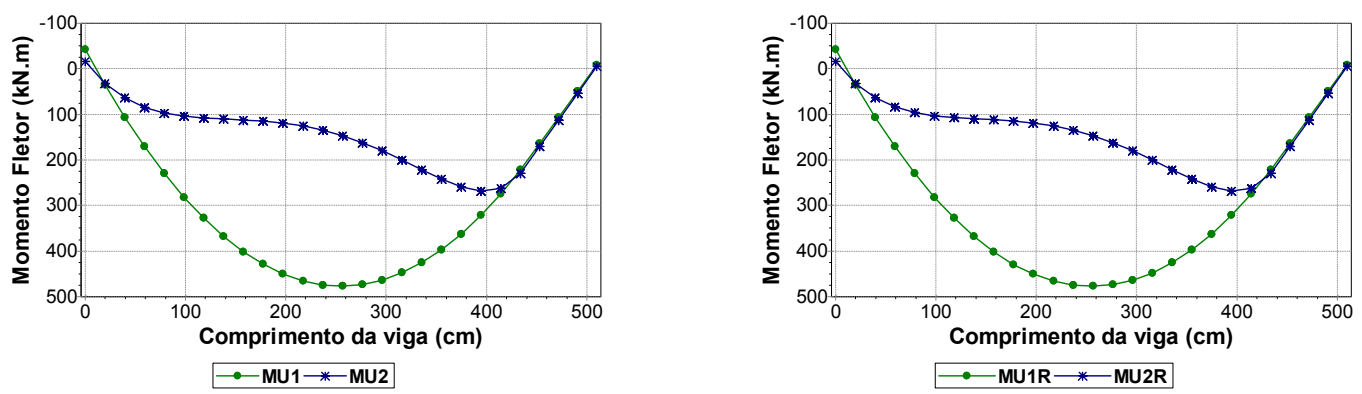

Figura 5.67 - Momento fletor - viga V21

\section{d) Viga V02}

Com uma simetria sobre o seu apoio esquerdo, a presente viga possui três vãos com praticamente as mesmas dimensões e tem apoios apenas sobre pilares. Os dois primeiros tramos possuem segmentos de abertura total e janela, sendo o último tramo totalmente carregado por uma parede. A diminuição dos deslocamentos devido ao efeito arco é muito significativa, principalmente no último tramo da viga. Os diagramas da Figura 5.68 ilustram o exposto.

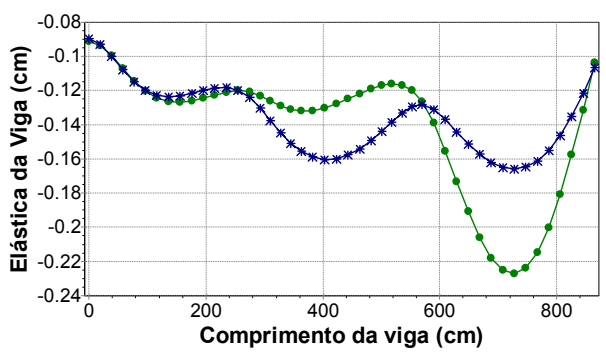

$\rightarrow-\mathrm{MU1} *$ *-MU2

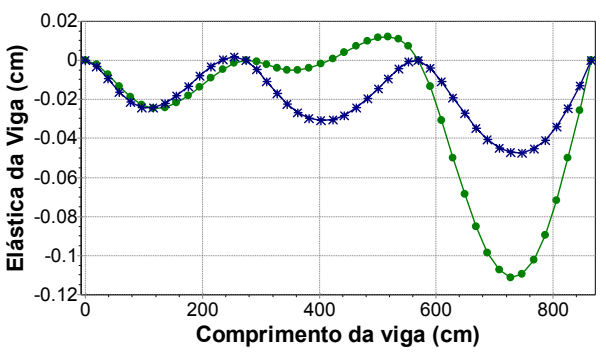

$\because$ MU1R $\rightarrow-M U 2 R$

Figura 5.68 - Deslocamentos verticais - viga V02

Os esforços normais e as tensões verticais (Figura 5.69) são os resultados que tem se mostrado mais sensíveis à variação da rigidez dos apoios. Entretanto, para a viga V02, apenas o esforço normal apresenta alguma diferença entre as modelagens com pilares deformáveis e apoios rígidos.
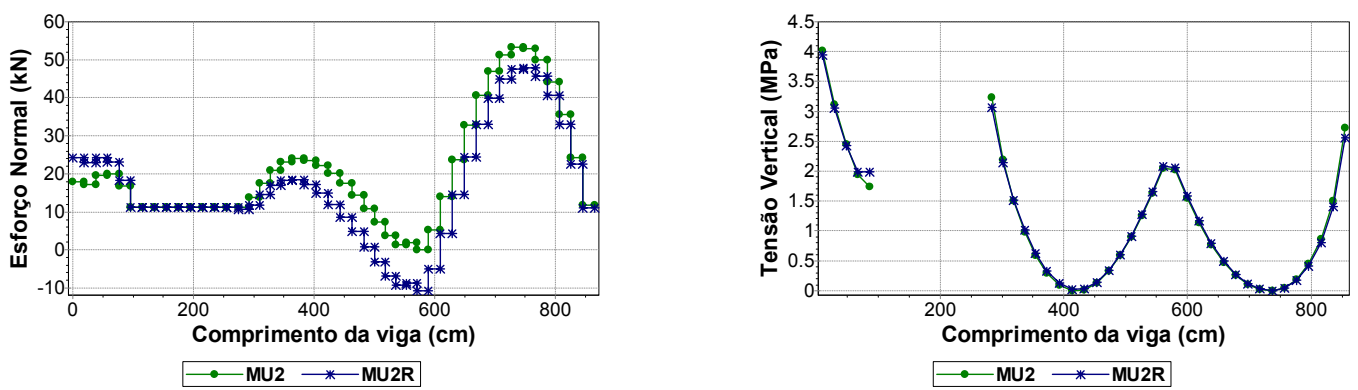

Figura 5.69 - Esforço normal e tensão vertical - viga V02 
A Figura 5.70 apresenta os diagramas de momentos fletores da presente viga, onde é possível perceber a diminuição no momento fletor positivo ocasionada pelo efeito arco no último tramo.
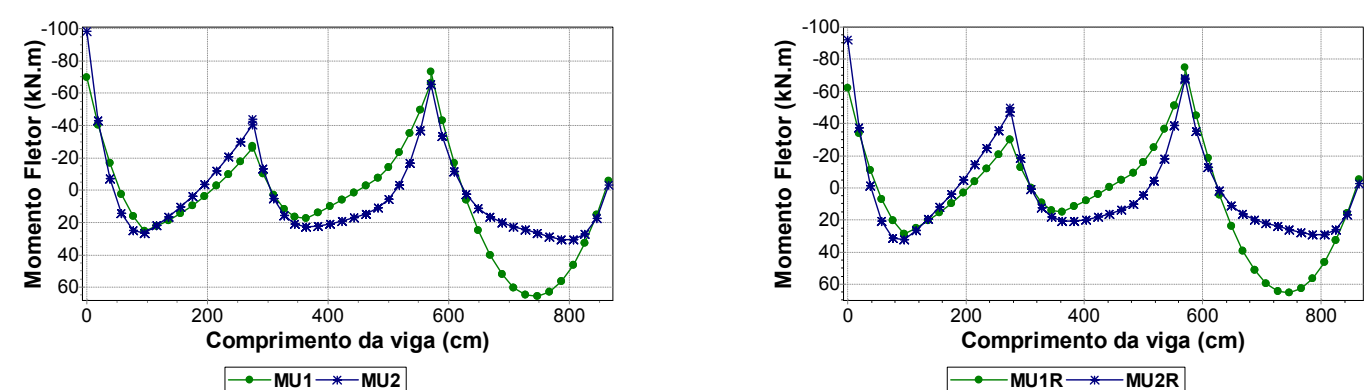

Figura 5.70 - Momento fletor - viga V02

\section{e) Viga V06}

A análise da viga V06 é de grande interesse, pois a mesma tem apoios apenas em outras vigas, não havendo pilares próximos (como é o caso da viga V08). A Figura 5.71 ilustra o diagrama de deslocamentos verticais. Não existem diferenças significativas entre as simulações com variação da rigidez dos apoios. Já a influência do efeito arco é mais evidente no tramo compreendido pelas interseções com as vigas V09 e V03, além de apresentar menores valores de deslocamento relativo. As vigas V07 e V08 formam uma grelha junto às vigas V09 e V06, tornando o segundo tramo da V06 menos deformável que o primeiro.
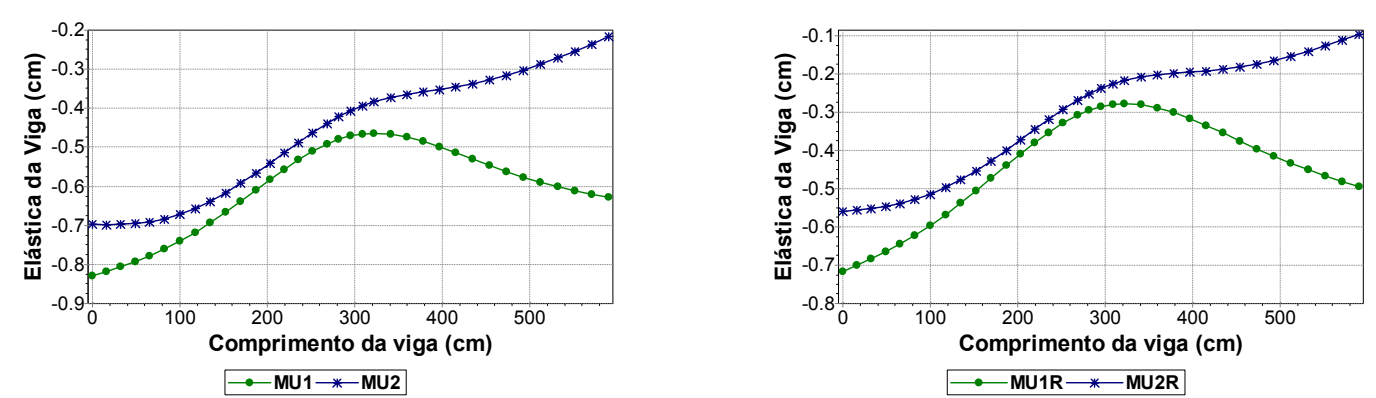

Figura 5.71 - Deslocamentos verticais - viga V06

Também vale observar a diferença encontrada nos resultados de esforços normais mostrados na Figura 5.72. Nos diagramas anteriores, os modelos com variação da rigidez dos apoios geralmente apresentavam esforços de tração em todo o comprimento da viga. Trechos comprimidos eram mais comumente observados sob regiões sem parede ou em pontos de pilares. O esforço normal variou significativamente entre os modelos com apoios rígidos e pilares deformáveis, sendo que, para o primeiro, os esforços de compressão têm predominado. Entende-se que tal situação tenha ocorrido devido à variação de seções transversais (e conseqüentemente da inércia) das vigas que apóiam a viga V06. As curvas de tensão vertical têm praticamente o mesmo comportamento no trecho de parede intermediário, apresentando diferenças um pouco mais perceptíveis nas paredes de extremidade. 

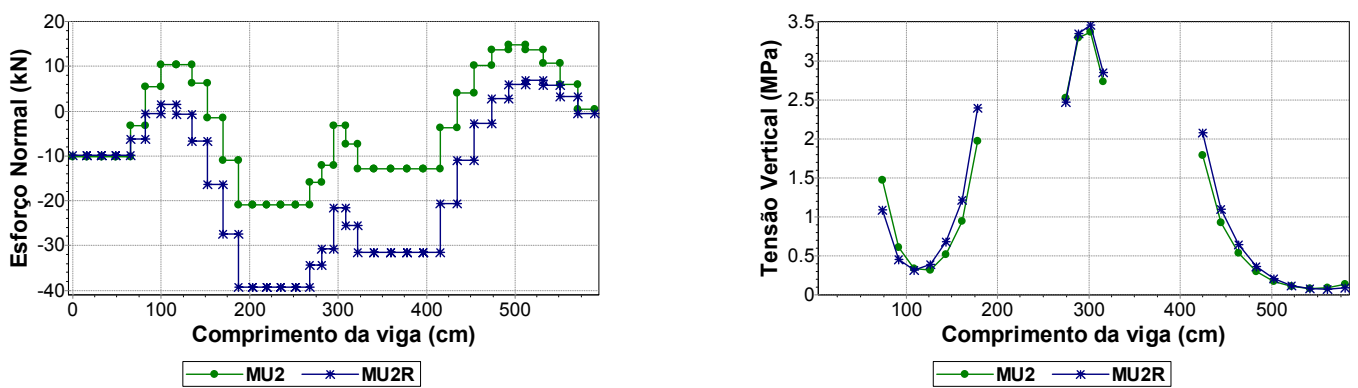

Figura 5.72 - Esforço normal e tensão vertical - viga V06
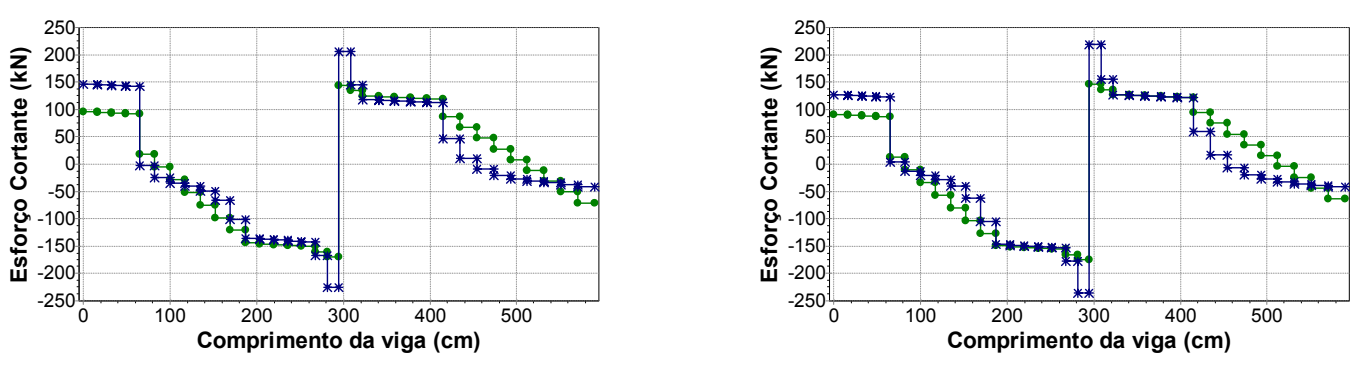

Figura 5.73 - Esforço cortante - viga V06

Houve aumento dos valores máximos de esforço cortante no Modelo 2 (que permite a consideração do efeito arco) para ambas as simulações de apoios, como observado na Figura 5.73 .

O diagrama de momento fletor da viga V06 reforça a conclusão de que não existe regra geral quando se estuda a influência do efeito arco na análise de esforços. Este efeito, na grande maioria dos casos, reduz o fletor positivo. Entretanto, como ilustra a Figura 5.74, o efeito arco aumenta o valor do momento fletor positivo, principalmente no primeiro tramo da viga, ao passo que reduz o fletor negativo sobre a viga V09. Também é observada uma pequena diferença devido à variação da rigidez dos apoios, podendo acarretar, por exemplo, na adição de mais uma barra de ferro na armadura negativa.

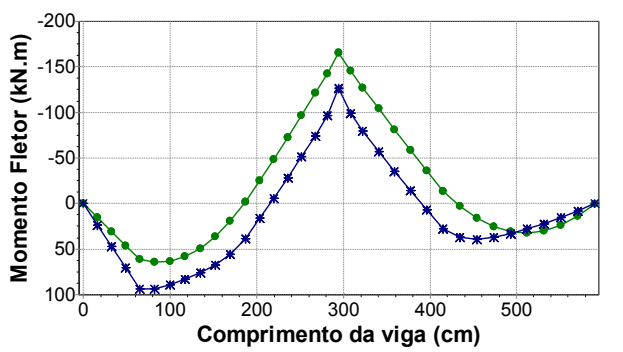

$\because-$ MU1 *-MU2

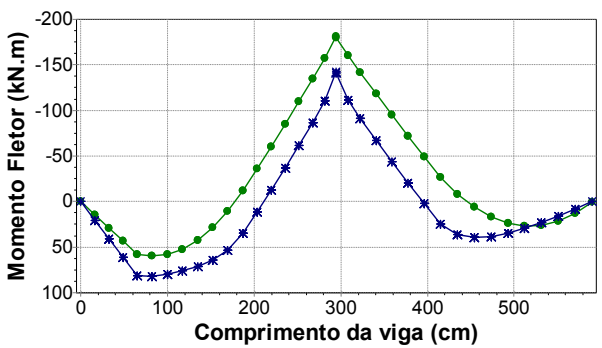

—MU1R—*-MU2R

Figura 5.74 - Momento fletor - viga V06

\section{f) Viga V16}

A Figura 5.75 apresenta os diagramas de esforço normal e tensão vertical da viga V16. Apesar da pequena magnitude dos valores, é interessante se destacar a influência que a variação na rigidez dos apoios proporciona. Enquanto a modelagem com pilares deformáveis man- 
tém a viga totalmente tracionada, o modelo com apoios rígidos apresenta um trecho comprimido que se estende da interseção com a viga V11 até o pilar P06. É nessa mesma região que se constatam as maiores diferenças entre as duas modelagens no diagrama de tensão vertical.
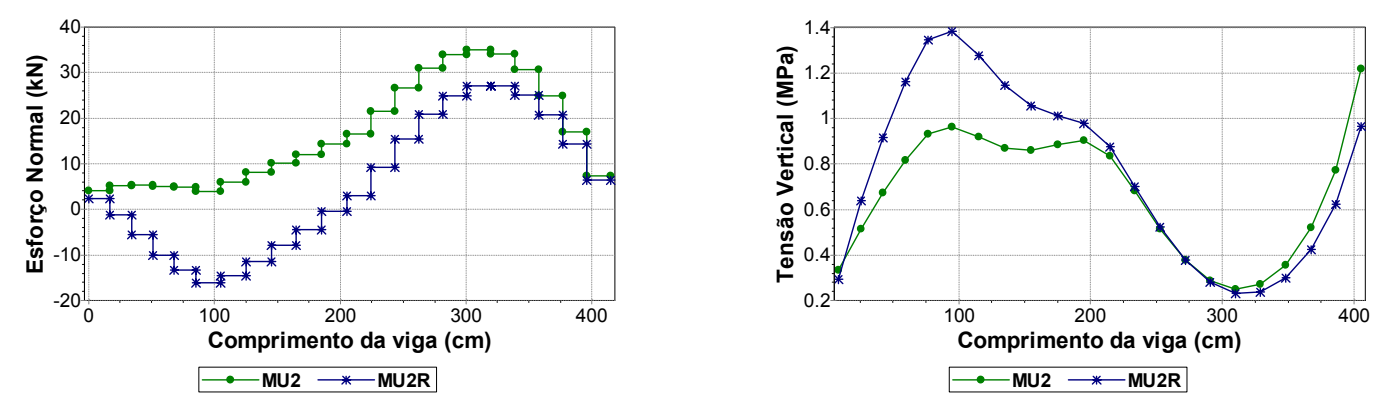

Figura 5.75 - Esforço normal e tensão vertical - viga V16

\subsection{EXEMPLO 3 - EDIFÍCIO LAGO AZUL}

\subsubsection{Apresentação}

O Edifício Residencial Lago Azul é composto por sete pavimentos tipo sobre um pavimento de pilotis em concreto armado.

A planta da forma do pilotis é apresentada na Figura 5.76. Para otimizar o processamento da estrutura e também permitir o emprego de uma rede mais refinada, continua-se a considerar simetrias em torno dos eixos $\mathrm{X} \mathrm{e} \mathrm{Y}$, modelando-se apenas um quarto do pavimento. A Figura 5.78 ilustra a planta de modulação com a simetria considerada.

\subsubsection{Descrição dos Modelos}

A Tabela 5.3 apresenta alguns parâmetros e propriedades dos materiais empregados na estrutura do edifício analisado.

Tabela 5.3 - Parâmetros de modelagem do edifício Lago Azul

\begin{tabular}{ll}
\hline Espessura da parede $(\mathrm{m})$ & 0,14 \\
\hline Altura da parede $(\mathrm{m})$ & 2,80 \\
\hline$v_{\text {viga }}$ & 0,20 \\
\hline$v_{\text {parede }}$ & 0,20 \\
\hline $\mathrm{E}_{\text {parede }}\left(\mathrm{kN} / \mathrm{m}^{2}\right)$ & $2,88 \mathrm{E}+06$ \\
\hline $\mathrm{E}_{\text {viga }}\left(\mathrm{kN} / \mathrm{m}^{2}\right)$ & $2,13 \mathrm{E}+07$ \\
\hline $\mathrm{f}_{\mathrm{ck}}(\mathrm{MPa})$ & 20 \\
\hline
\end{tabular}

A Figura 5.77 apresenta as barras e nós carregados do chamado Modelo 1. Já na Figura 5.79, é ilustrada a rede, barras e cargas nodais do Modelo 2. 


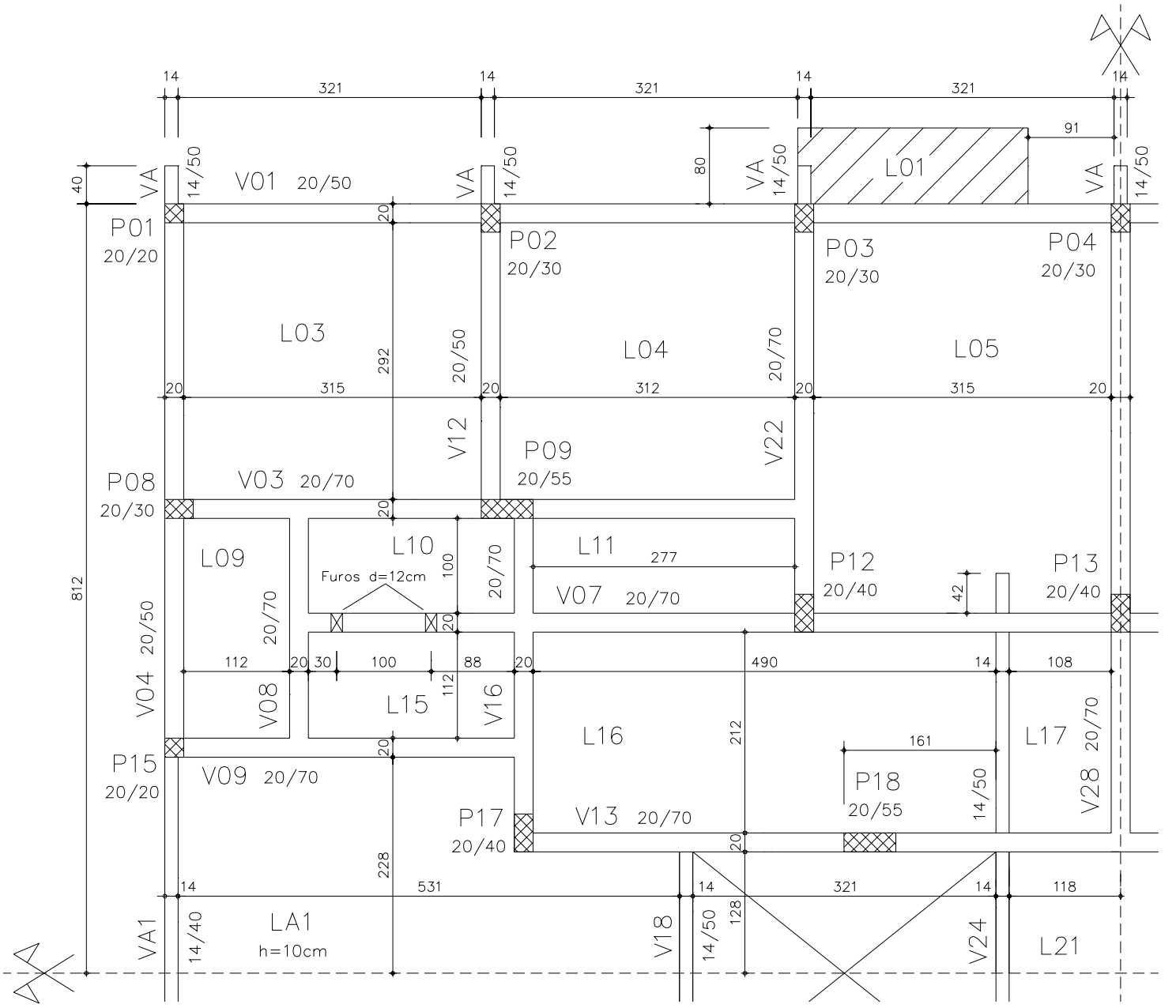

Figura 5.76 - Forma estrutural do pilotis do edifício Lago Azul

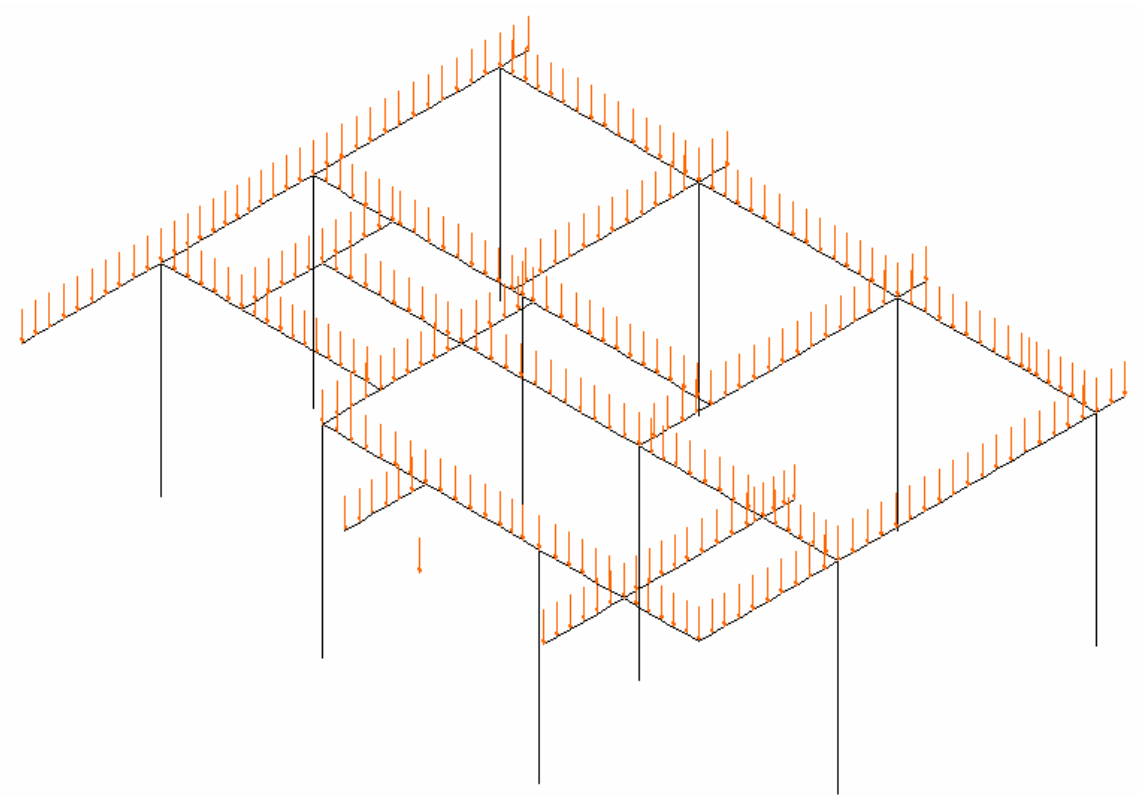

Figura 5.77 - Modelo 1 (LA1 e LA1R) do edifício Lago Azul 


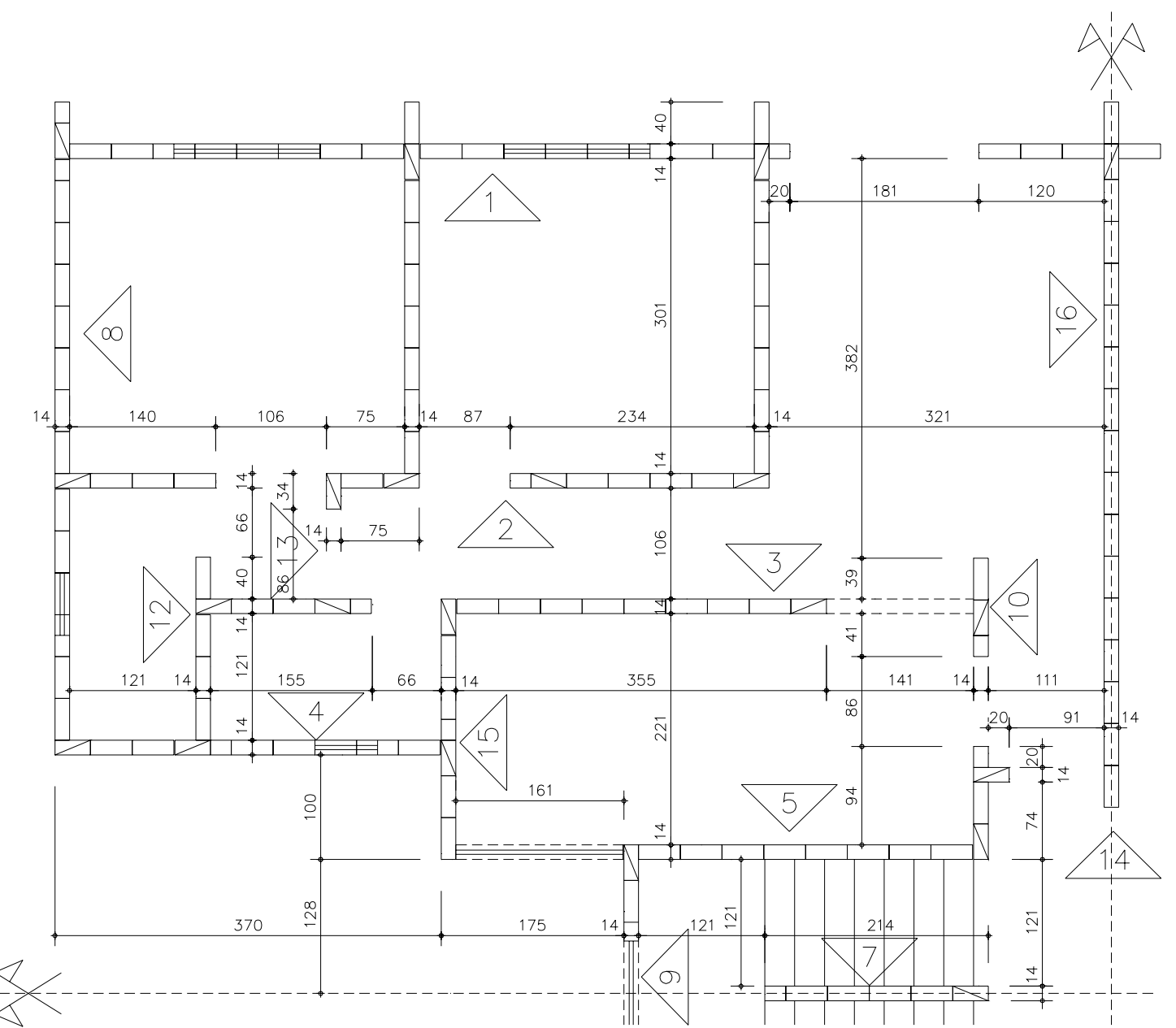

Figura 5.78 - Modulação do pavimento tipo do edifício Lago Azul

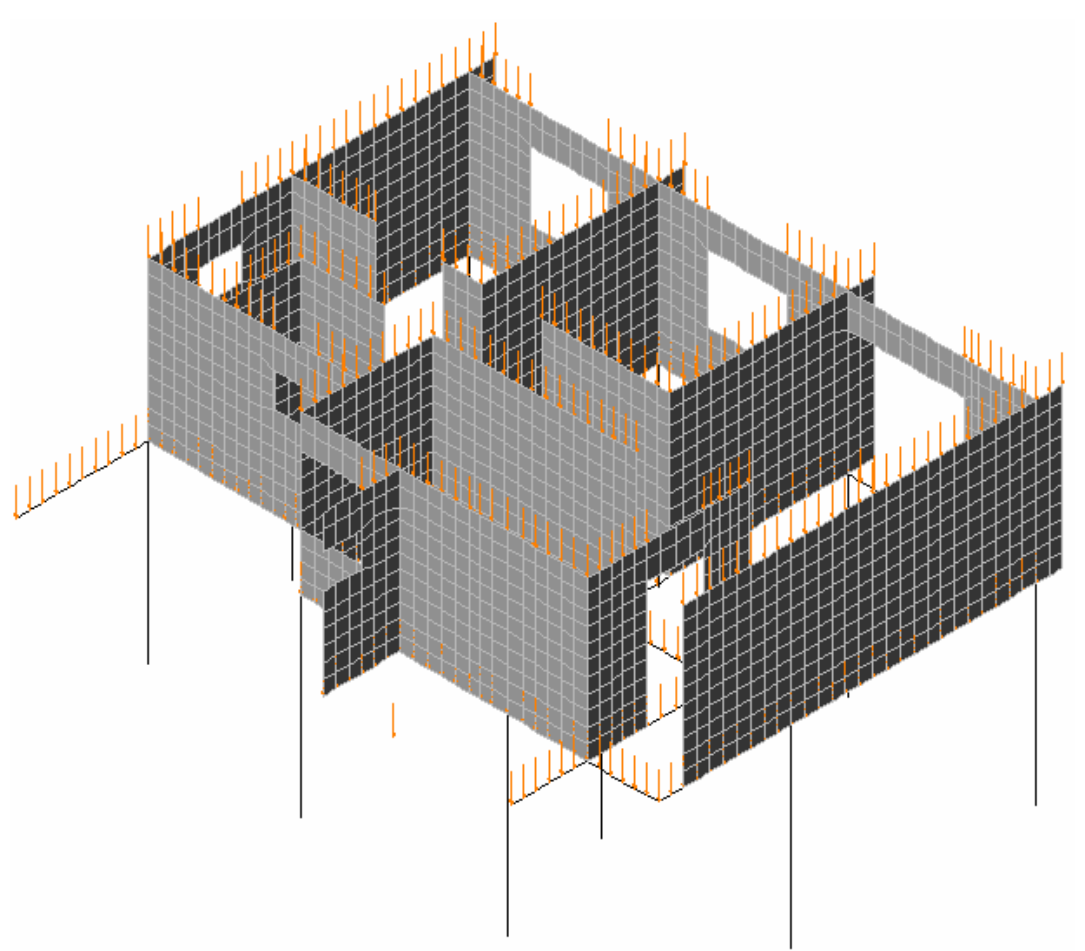

Figura 5.79 - Modelo 2 (LA2 e LA2R) do edifício Lago Azul 


\subsubsection{Análise de Resultados}

Faz-se uma análise mais objetiva do processamento do presente edifício, abrangendose apenas os resultados mais significativos de parte das vigas.

\section{a) Viga V01}

A Figura 5.80 apresenta os diagramas de deslocamentos verticais da presente viga, composta por três vãos iguais, tendo apoios somente em pilares. Percebe-se que os gráficos referentes ao Modelo 2 apresentam deslocamentos semelhantes nos três vãos, com o efeito arco reduzindo consideravelmente os deslocamentos do primeiro vão.
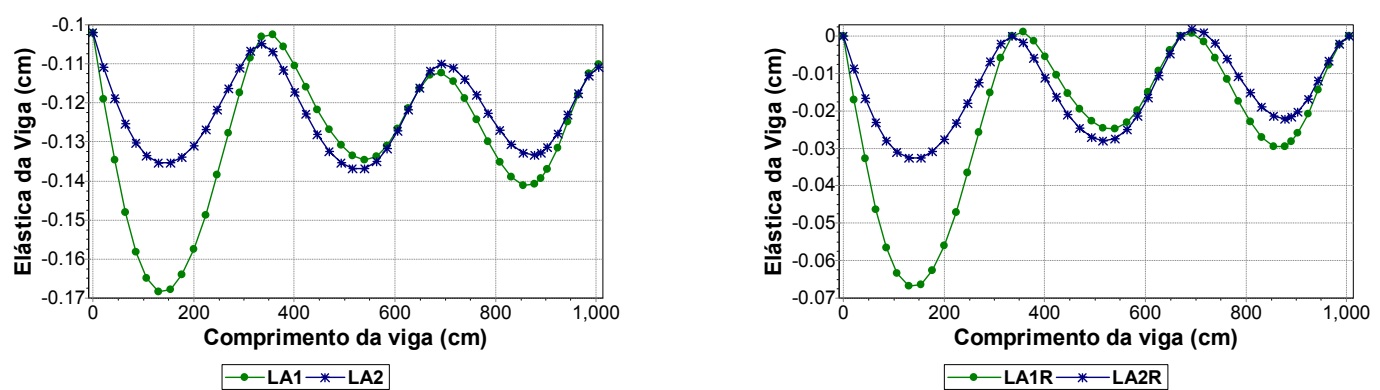

Figura 5.80 - Deslocamentos verticais - viga V01
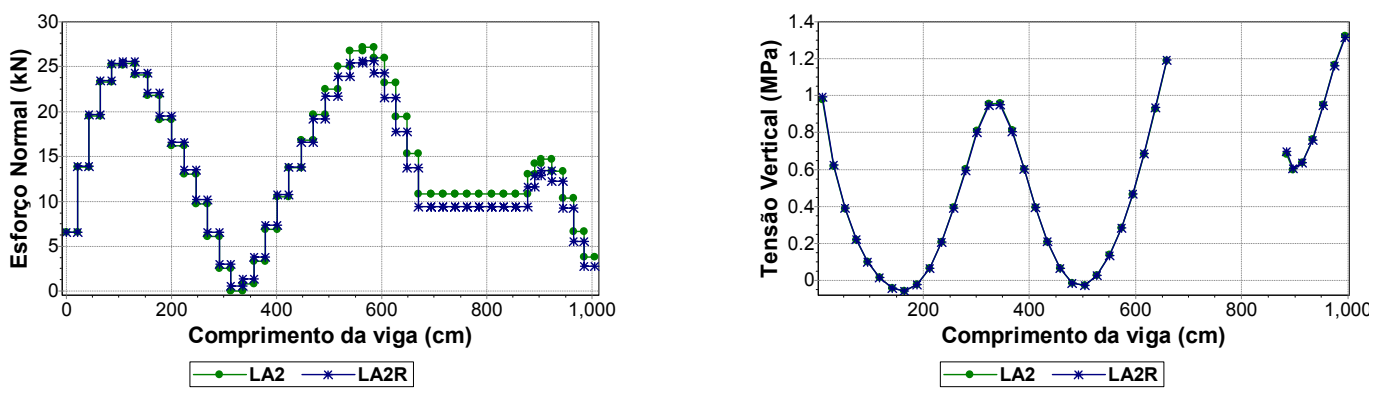

Figura 5.81 - Esforço normal e tensão vertical - viga V01
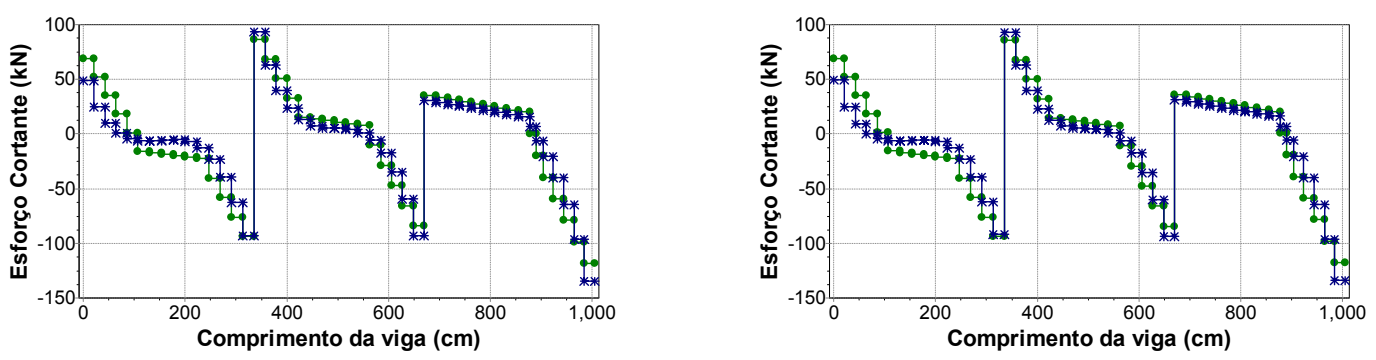

$\rightarrow-$ LA1 $*$-LA2

Figura 5.82 - Esforço cortante - viga V01

Sendo totalmente tracionada, a viga V01 não apresenta diferenças significativas entre as modelagens com variação da rigidez dos apoios, como ilustra a Figura 5.81. As curvas obtidas com os modelos de apoios rígidos e pilares deformáveis são idênticas no diagrama de ten- 
são vertical. Ainda com relação a este diagrama, destaca-se a aparição de dois pequenos trechos com tensões de tração, no meio do primeiro e segundo vãos.

Como se verifica na Figura 5.82, o esforço cortante é pouco influenciado pelo efeito arco. Percebe-se que em algumas vigas onde existem apoios de pilares, a influência deste efeito é desprezível para o esforço cortante, sendo também pouco influenciado pela variação da rigidez dos apoios.

\section{b) Viga V03}

No diagrama de momentos fletores mostrado na Figura 5.83 verifica-se que não existem diferenças significativas entre as curvas do Modelo 1 e do Modelo 2. Este é um caso típico onde se poderia reduzir a altura da viga, tornando-a mais flexível. Procedendo desta forma, deve-se ter o cuidado de avaliar com mais cuidado as flechas da viga, para que estas não excedam os limites normativos.
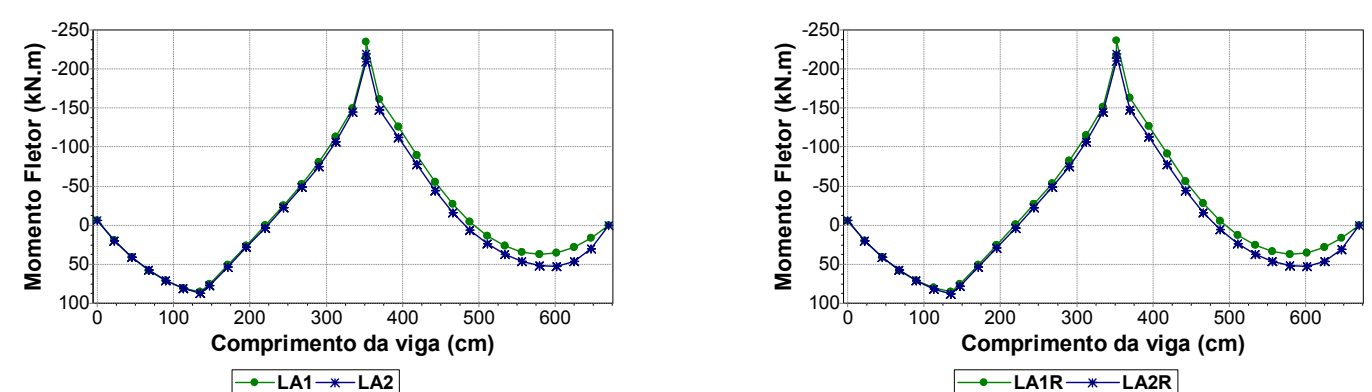

Figura 5.83 - Momento fletor - viga V03

\section{c) Viga V09}

Com a análise da viga V09 é possível, mais uma vez, verificar a grande influência do efeito arco em vigas com parede em praticamente toda a sua extensão. O pequeno trecho de janela não provoca maiores variações nos diagramas, como se pode verificar pela análise dos diagramas apresentados.

A Figura 5.84 apresenta os gráficos de deslocamentos verticais, onde é possível visualizar uma considerável diminuição da flecha para o Modelo 2. Novamente, não são encontradas diferenças significativas entre as simulações com variação da rigidez dos apoios.
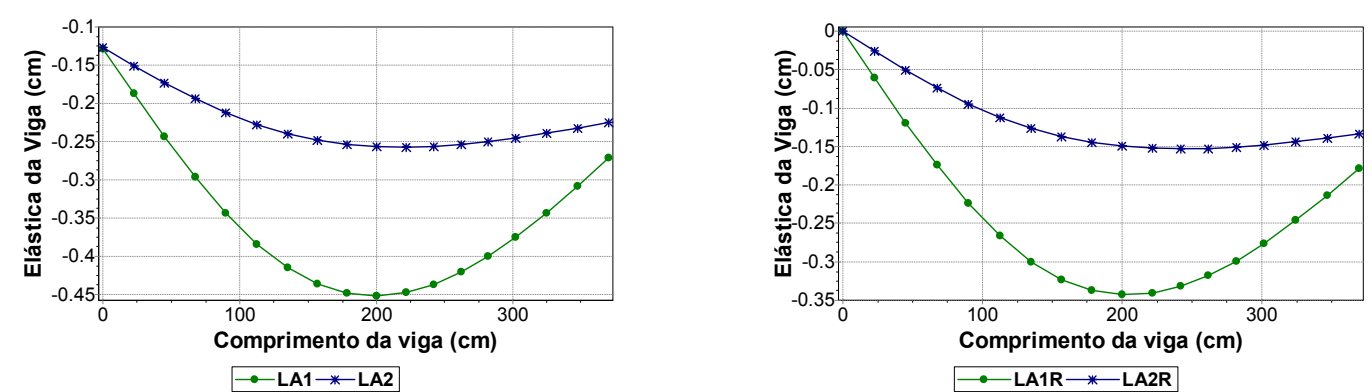

Figura 5.84 - Deslocamentos verticais - viga V09 
Outra questão interessante a ser observada encontra-se na análise dos diagramas de tensão vertical (Figura 5.85). As curvas com variação da rigidez dos apoios são idênticas, mas grande parte do trecho que vai da interseção com a viga V08 até a viga V16 apresenta tensões de tração. Em trabalhos anteriores (BARBOSA, 2000) verificou-se que a consideração de elementos de contato na interface parede viga impediria a ocorrência destas tensões de tração.
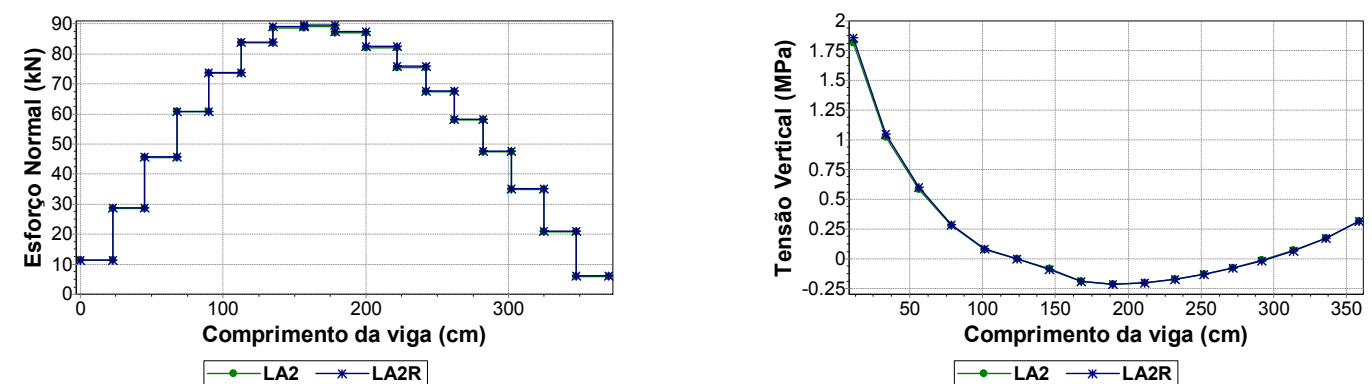

Figura 5.85 - Esforço normal e tensão vertical - viga V09

O esforço cortante (Figura 5.86) geralmente não sofre grandes variações devido ao efeito arco. Entretanto, vê-se uma diminuição significativa de tal esforço em toda a extensão da viga V09.

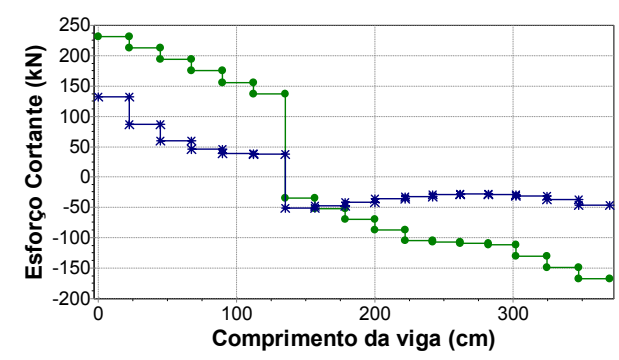

$\because$ LA1 $*$-LA2

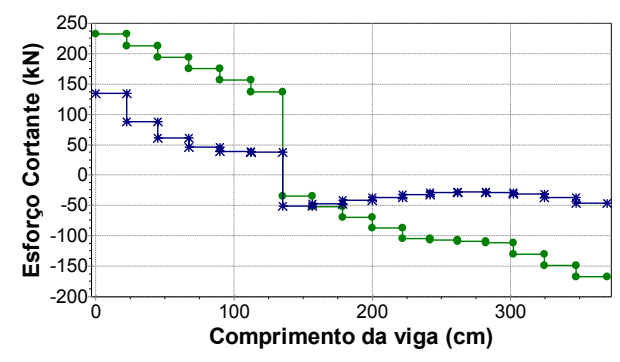

$\rightarrow$ LA1R $\rightarrow$ * LA2R

Figura 5.86 - Esforço cortante - viga V09

Observando-se os diagramas apresentados pela Figura 5.87, fica patente a expressiva diminuição do momento fletor obtida quando se considera o efeito arco. Isso ressalta a importância de tomar partido desse efeito, que na realidade sempre existe. Para tanto, basta realizar uma modelagem adequada, como a proposta no presente trabalho.
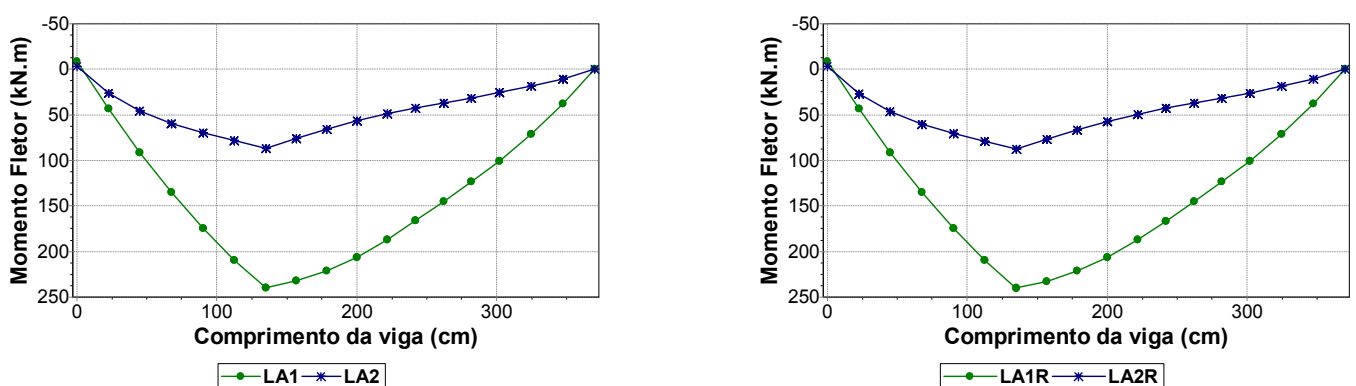

Figura 5.87 - Momento fletor - viga V09 


\section{d) Viga V04}

A influência do efeito arco nos deslocamentos (Figura 5.88) da presente viga é bastante grande, causando reduções expressivas da flecha, principalmente no segundo tramo. $O$ trecho de parede sobre o primeiro tramo possui uma abertura de janela na sua região central. No Modelo 1, esse trecho de janela fica sem carregamento. Já o segundo tramo é inteiramente carregado por uma parede.
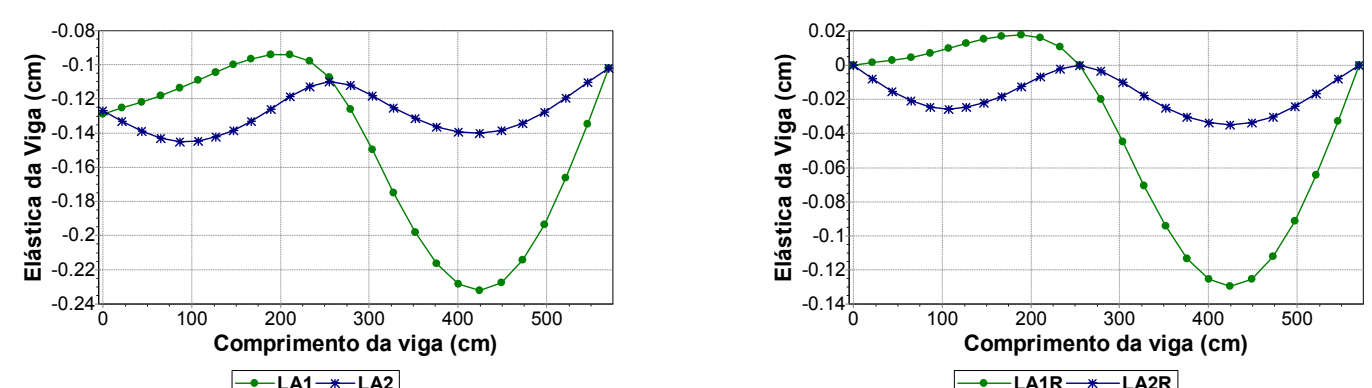

Figura 5.88 - Deslocamentos verticais - viga V04

\section{e) Viga V16}

A presente viga tem dois apoios de pilares nas suas extremidades, sendo interceptada por duas vigas. Os pontos de interseção com as vigas V09 e V07 são claramente visualizados pelas descontinuidades no diagrama de esforço cortante da Figura 5.90. O trecho com parede se estende do pilar P17 à viga V07, compreendendo o trecho tracionado do diagrama de esforço normal da Figura 5.89. Essa viga é mais um caso onde o efeito arco trabalha de forma efetiva, propiciando diminuições significativas até mesmo para o esforço cortante.
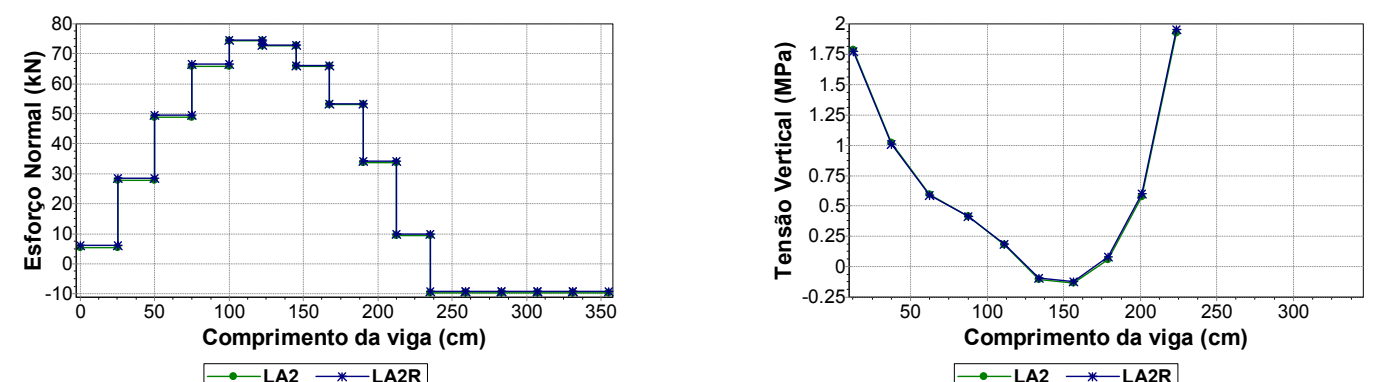

Figura 5.89 - Esforço normal e tensão vertical - viga V16
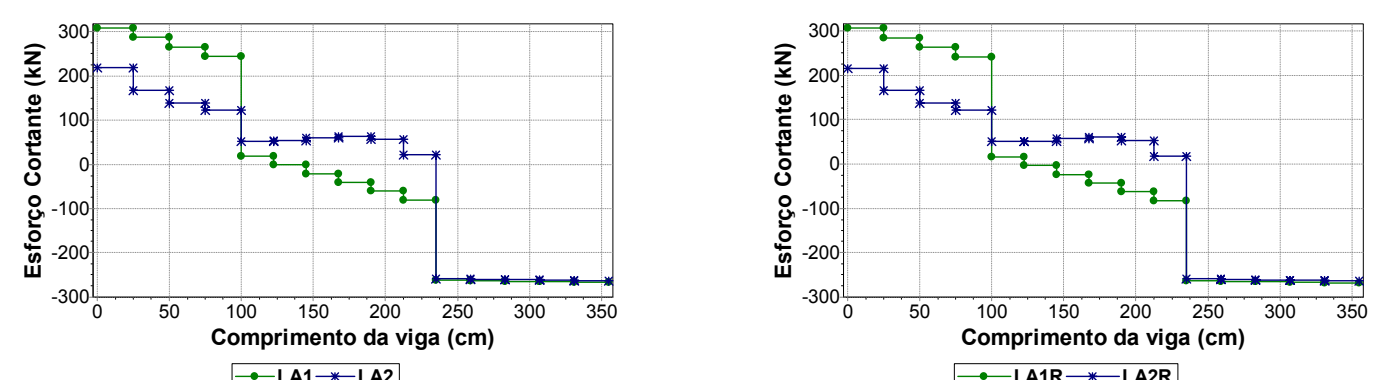

Figura 5.90 - Esforço cortante - viga V16 


\section{f) Viga V22}

Os diagramas da Figura 5.91 para esforço cortante, e da Figura 5.92 para momento fletor, demonstram que nem sempre o efeito arco é tão favorável na análise de momentos fletores e indiferente na análise de esforços cortantes. O trecho que vai da interseção com a viga V03 e se estende até o pilar P03 é totalmente carregado por uma parede. É nessa parede que o arco se forma, reduzindo significativamente o cortante. Ocorrem reduções do fletor positivo, mas estas são menos expressivas que a do esforço cortante. Também não são visualizadas diferenças entre as modelagens com variação na rigidez dos apoios.
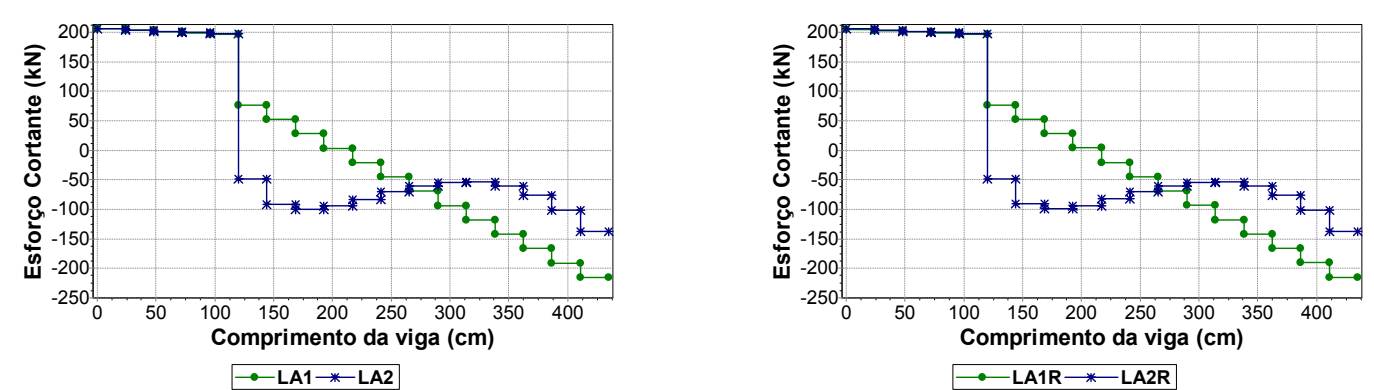

Figura 5.91 - Esforço cortante - viga V22
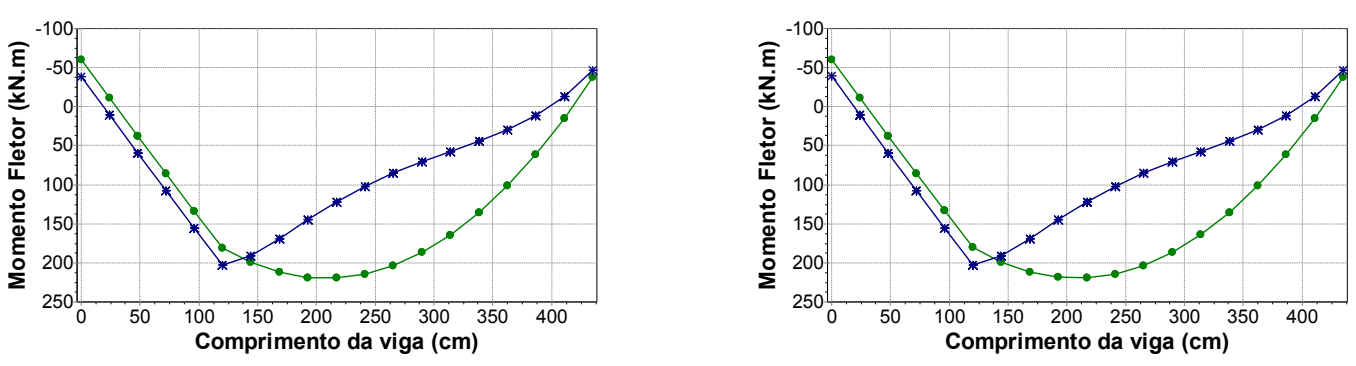

$\rightarrow-$ LA1 $*$-LA2

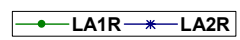

Figura 5.92 - Momento fletor - viga V22

\section{g) Viga V28}

Com a análise dessa viga pode-se perceber que o ganho em termos de deslocamentos e momentos fletores para vigas com paredes em toda (ou quase toda) a sua extensão é realmente bastante significativo. A Figura 5.93 apresenta os deslocamentos na viga, onde se podem ver as diminuições na flecha do segundo tramo (entre o pilar P13 e o pilar P04), devido ao efeito arco.

O trecho em balanço da viga (primeiro tramo) aparece totalmente comprimido, como se constata pela análise do diagrama da Figura 5.94. A parede que se estende sobre esta viga se inicia um pouco após a interseção com a viga $\mathrm{V} 13$, apresentando um pico de tensão vertical sobre o pilar P13.

O efeito arco é patente nos diagramas de esforços cortantes (Figura 5.95) devido à suavização que ele provoca nas curvas do Modelo 2. Entretanto, as reduções nos picos do esforço são pequenas. 

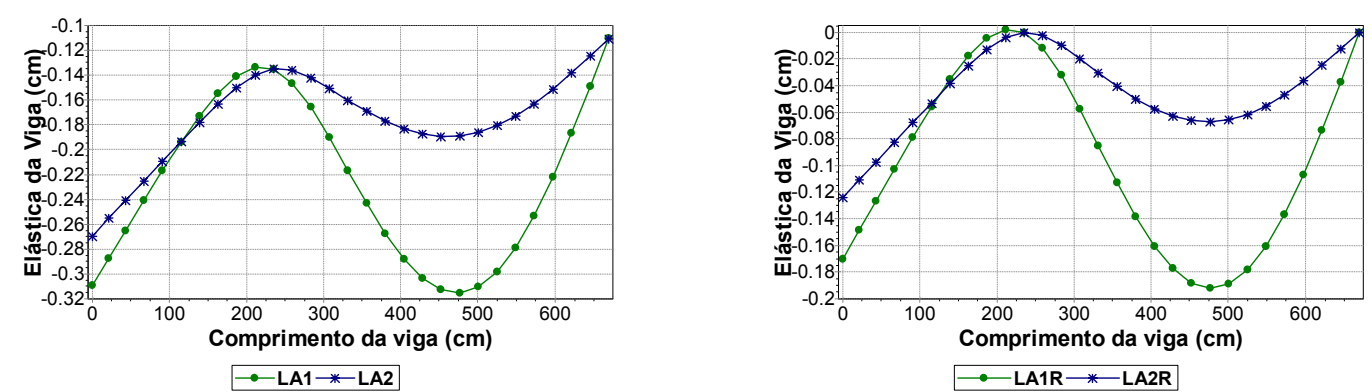

Figura 5.93 - Deslocamentos verticais - viga V28
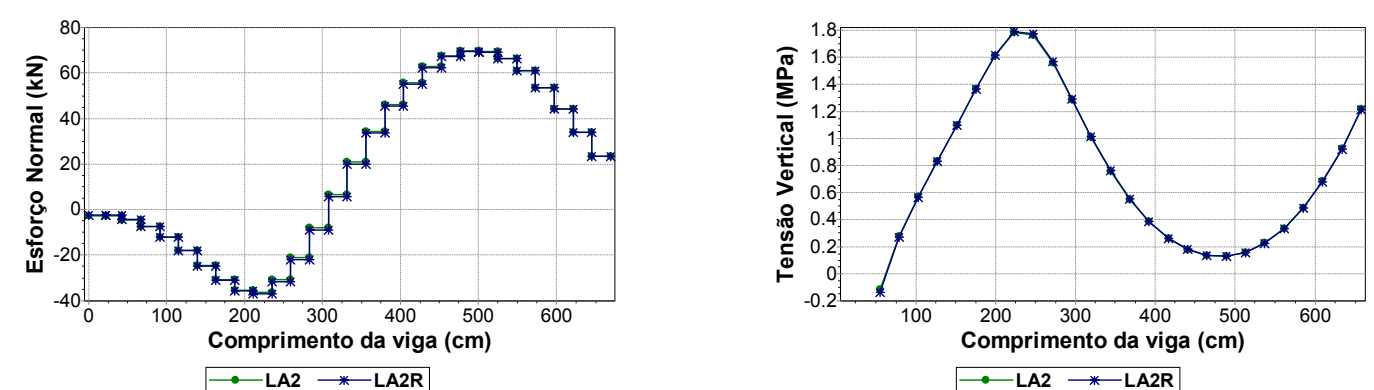

Figura 5.94 - Esforço normal e tensão vertical - viga V28
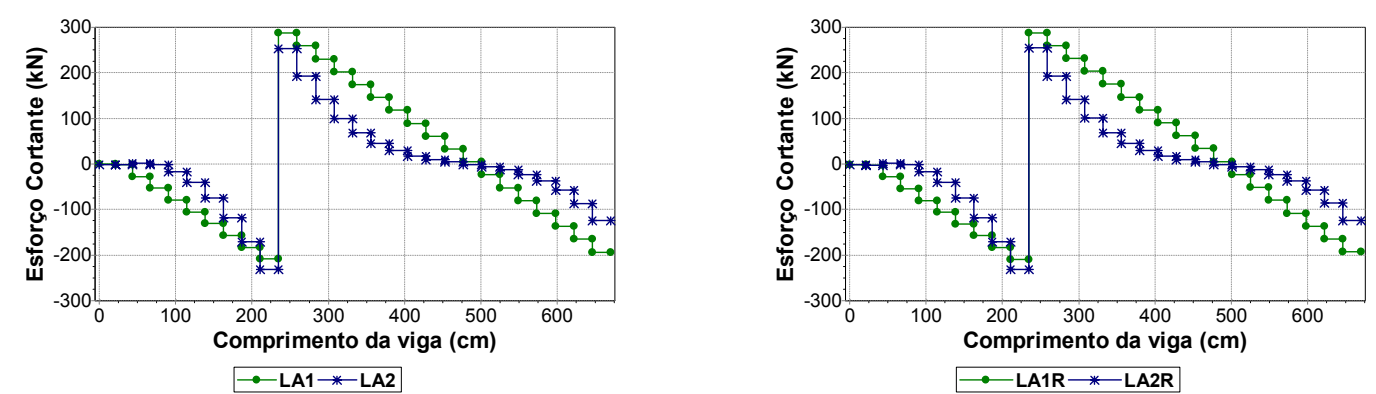

Figura 5.95 - Esforço cortante - viga V28

Como descrito em parágrafos anteriores, o momento fletor sofre reduções consideráveis quando se analisa o efeito arco, o que pode ser avaliado nos diagramas da Figura 5.96, ocasionando diminuições no pico de momento negativo sobre o pilar P13. Porém, o ganho mais expressivo se dá no fletor positivo do segundo tramo da viga V28.
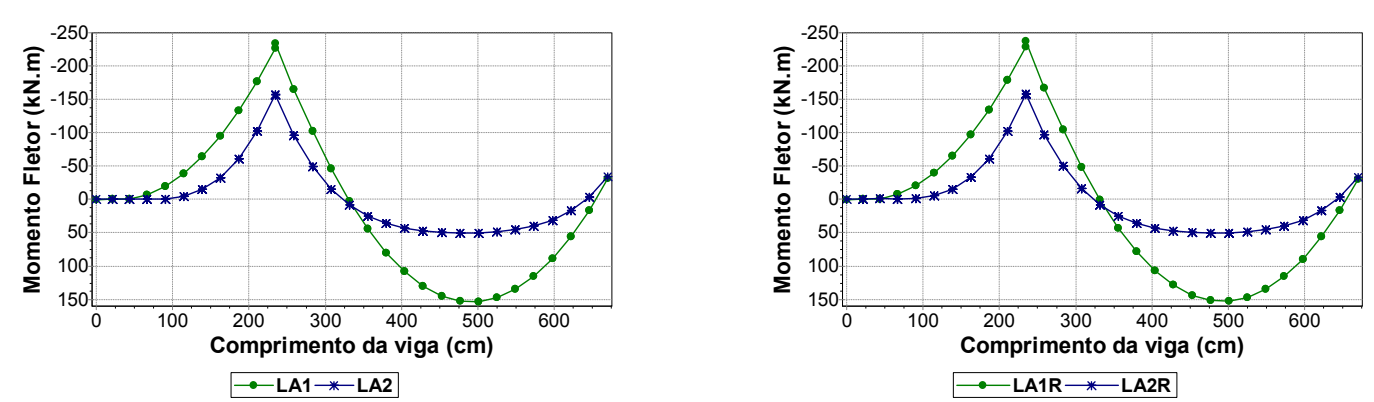

Figura 5.96 - Momento fletor - viga V28 


\subsection{EXEMPLO 4 - EDIFÍCIO LA DEFENSE}

\subsubsection{Apresentação}

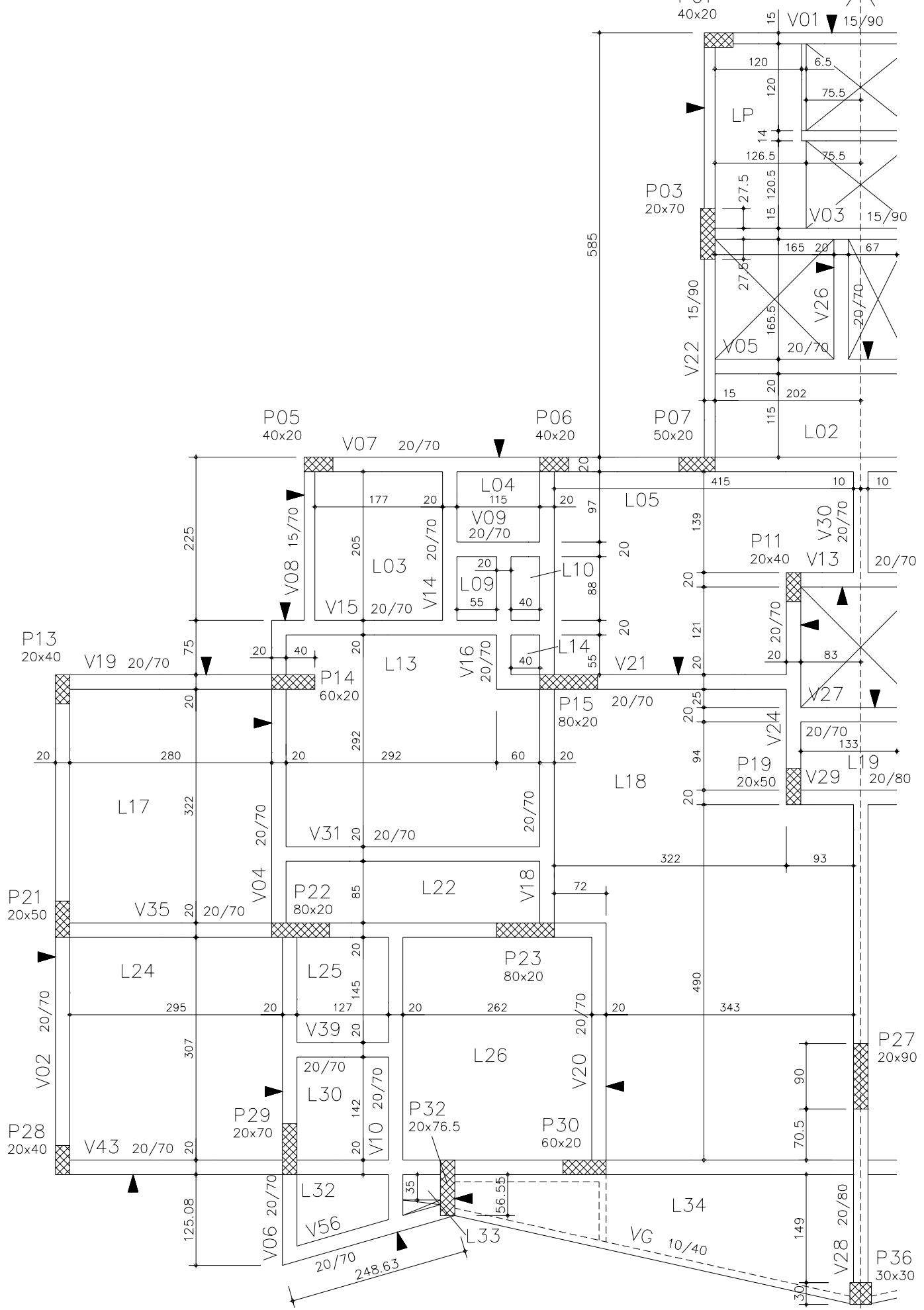

Figura 5.97 - Forma estrutural do pilotis do edifício La Defense 
O Edifício Residencial La Defense é composto por dez pavimentos tipo sobre um pavimento de pilotis em concreto armado.

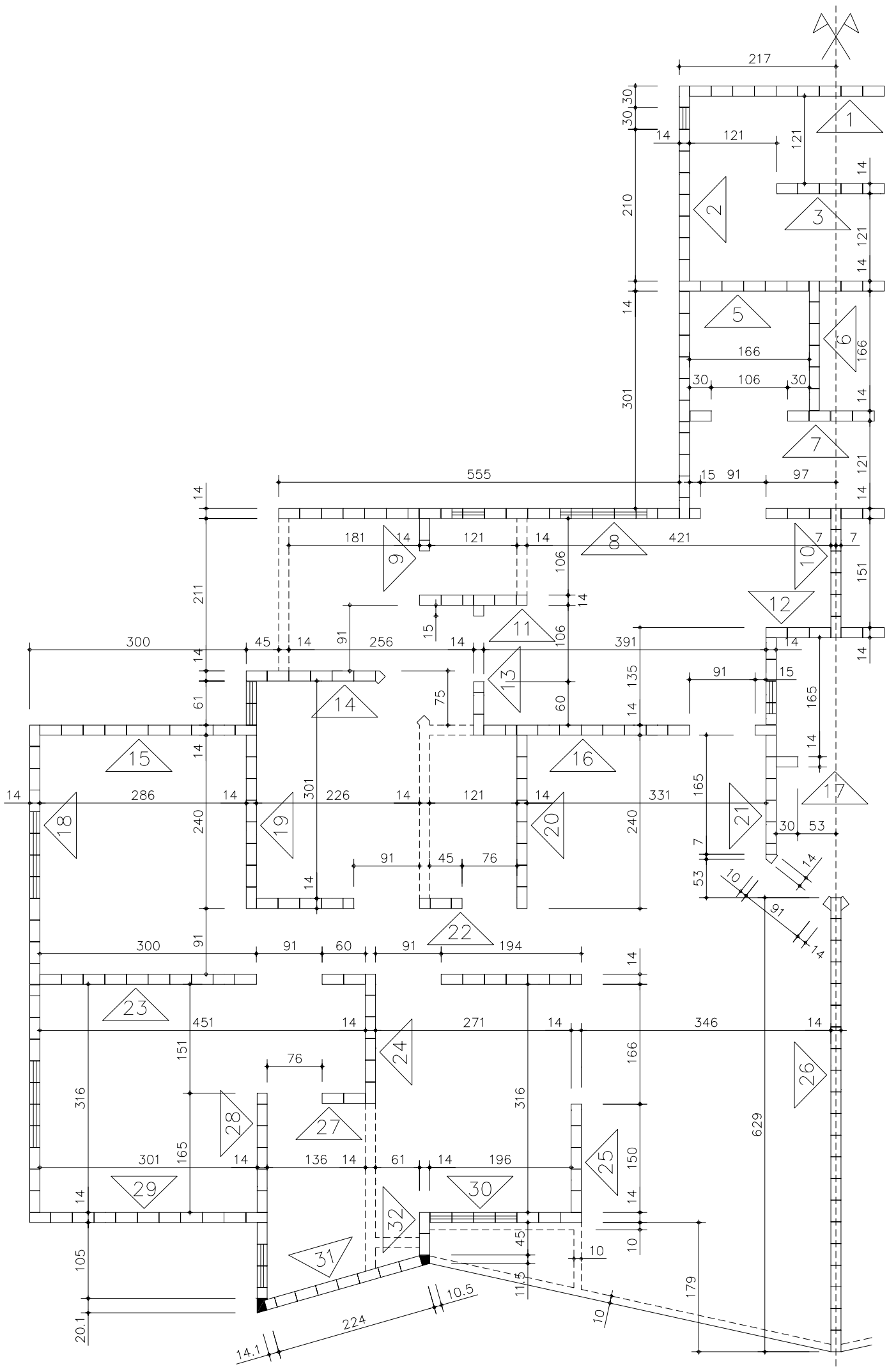

Figura 5.98 - Modulação do pavimento tipo do edifício La Defense 
A planta da forma do pilotis é apresentada na Figura 5.97. Para otimizar o processamento da estrutura e também permitir o emprego de uma rede mais refinada, adotou-se simetria em torno do eixo $Y$, modelando-se apenas a metade esquerda do pavimento. A Figura 5.98 ilustra a planta de modulação com a simetria considerada.

\subsubsection{Descrição dos Modelos}

A Tabela 5.4 apresenta alguns parâmetros e propriedades dos materiais empregados na estrutura do edifício analisado.

Tabela 5.4 - Parâmetros de modelagem do edifício La Defense

\begin{tabular}{ll}
\hline Espessura da parede $(\mathrm{m})$ & 0,14 \\
\hline Altura da parede $(\mathrm{m})$ & 2,72 \\
\hline$v_{\text {viga }}$ & 0,20 \\
\hline$v_{\text {parede }}$ & 0,20 \\
\hline $\mathrm{E}_{\text {parede }}\left(\mathrm{kN} / \mathrm{m}^{2}\right)$ & $4,80 \mathrm{E}+06$ \\
\hline $\mathrm{E}_{\text {viga }}\left(\mathrm{kN} / \mathrm{m}^{2}\right)$ & $2,13 \mathrm{E}+07$ \\
\hline $\mathrm{f}_{\mathrm{ck}}(\mathrm{MPa})$ & 20 \\
\hline
\end{tabular}

A Figura 5.99 apresenta as barras e nós carregados do chamado Modelo 1. Já na Figura 5.100, é ilustrada a rede, barras e cargas nodais do Modelo 2.

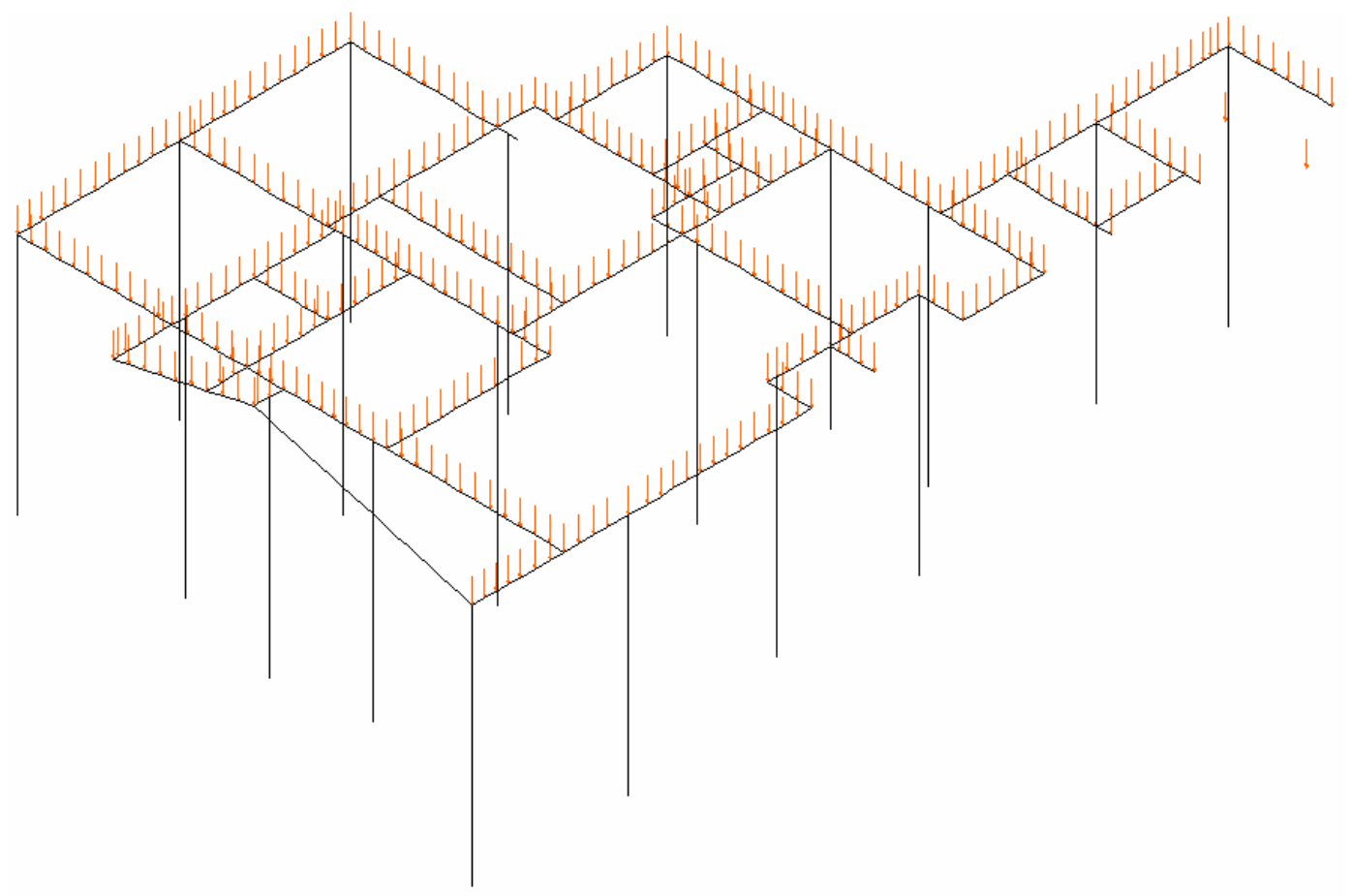

Figura 5.99 - Modelo 1 (LD1 e LD1R) do edifício La Defense 


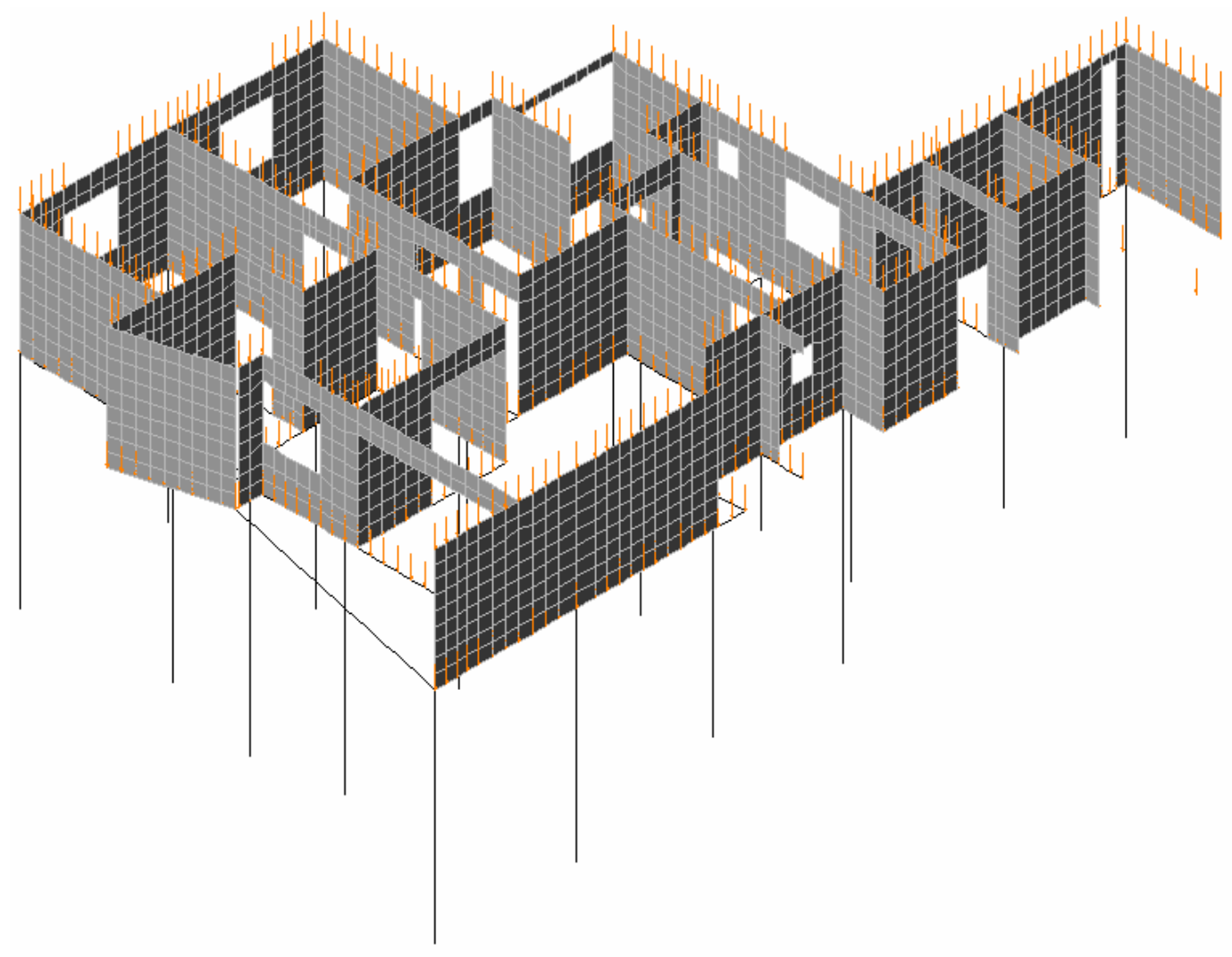

Figura 5.100 - Modelo 2 (LD2 e LD2R) do edifício La Defense

\subsubsection{Análise de Resultados}

Como nos dois exemplos anteriores, aqui também serão mostrados apenas alguns resultados mais significativos e interessantes.

\section{a) Viga V07}

A região entre os pilares P06 e P07 se encontra comprimida, havendo esforços de tração solicitando o restante da viga, como se observa no diagrama da Figura 5.101. O pico de tração entre os pilares P05 e P06 propicia o aparecimento de um pequeno trecho com tensões de tração, como se constata pela observação do diagrama de tensão vertical.
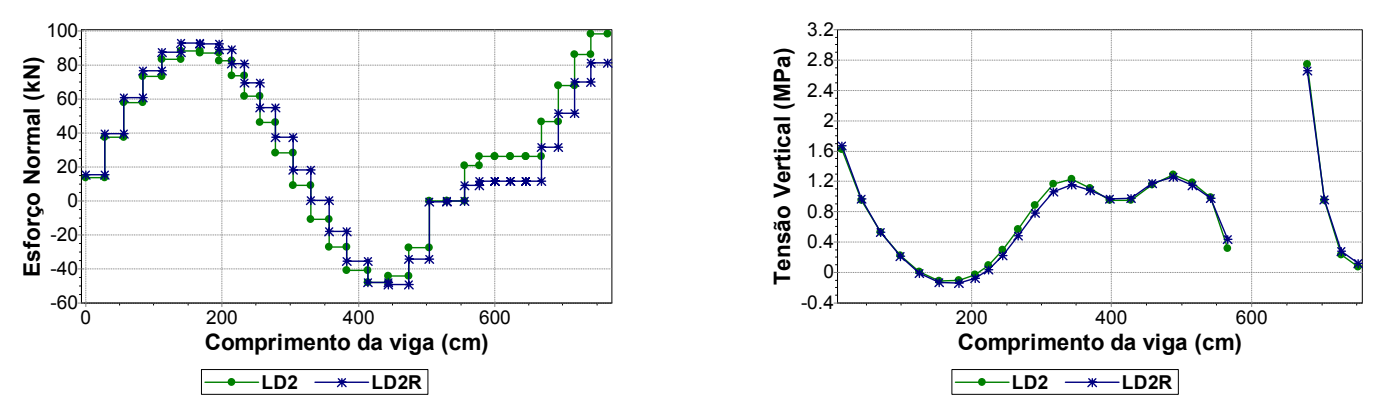

Figura 5.101 - Esforço normal e tensão vertical - viga V07 
A variação da rigidez dos apoios não provoca diferenças no esforço cortante da viga V07, como ilustra a Figura 5.102. É interessante observar a influência do efeito arco, pois este diminui o cortante nos vãos extremos e aumenta o valor do esforço no vão intermediário (delimitado pelos pilares P06 e P07).
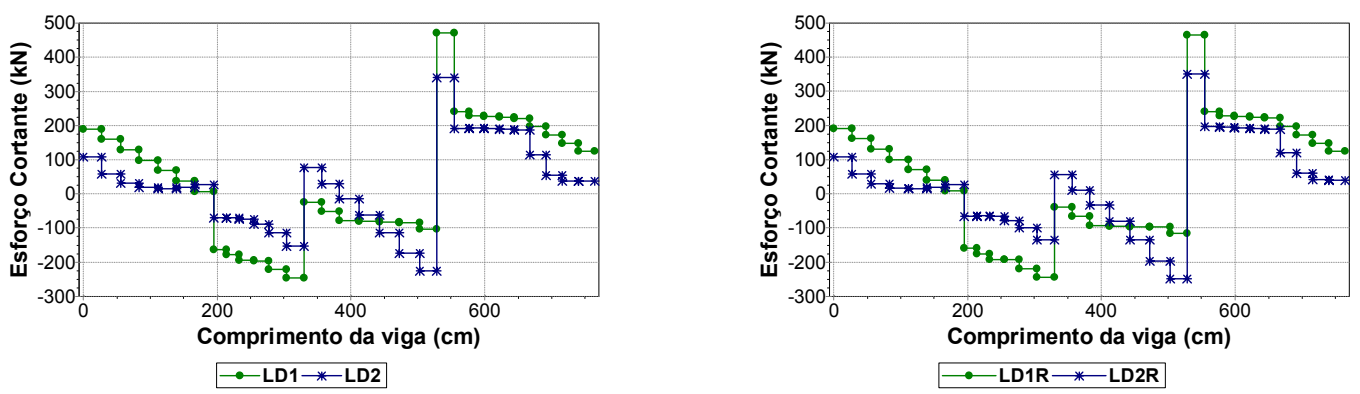

Figura 5.102 - Esforço cortante - viga V07

Ainda com relação ao efeito arco, a observação feita para o esforço cortante é válida também para o momento fletor. A Figura 5.103 ilustra o diagrama do fletor da viga V07, onde é possível constatar as reduções que ocorrem nos tramos extremos devido ao efeito arco.
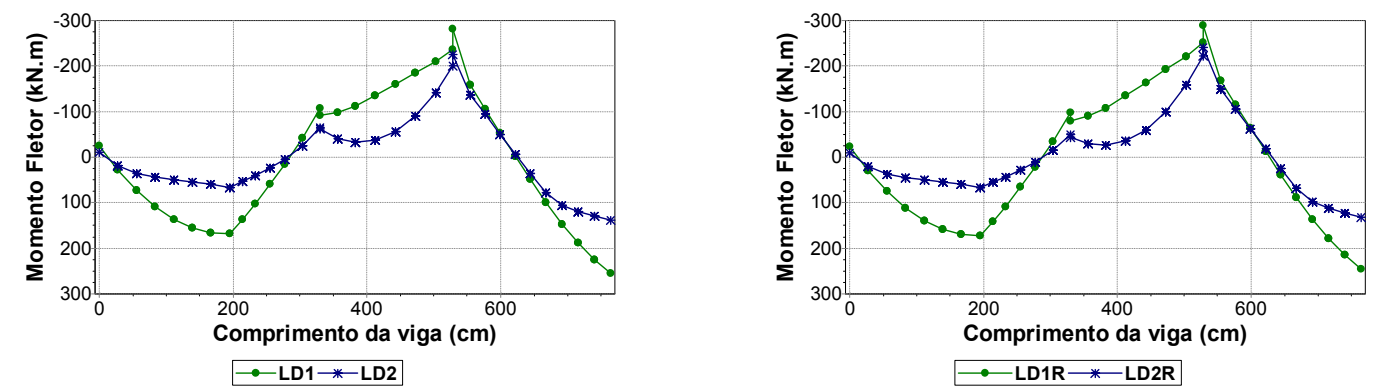

Figura 5.103 - Momento fletor - viga V07

\section{b) Viga V19}

A presente viga é composta por apenas um tramo, com apoios de pilares nos seus extremos. A Figura 5.104 apresenta os diagramas de momentos fletores obtidos. Para as duas últimas barras do diagrama, pode-se imaginar que os resultados apresentados sejam um pouco estranhos. Entretanto, isso ocorre porque elas são, na realidade, trechos rígidos.
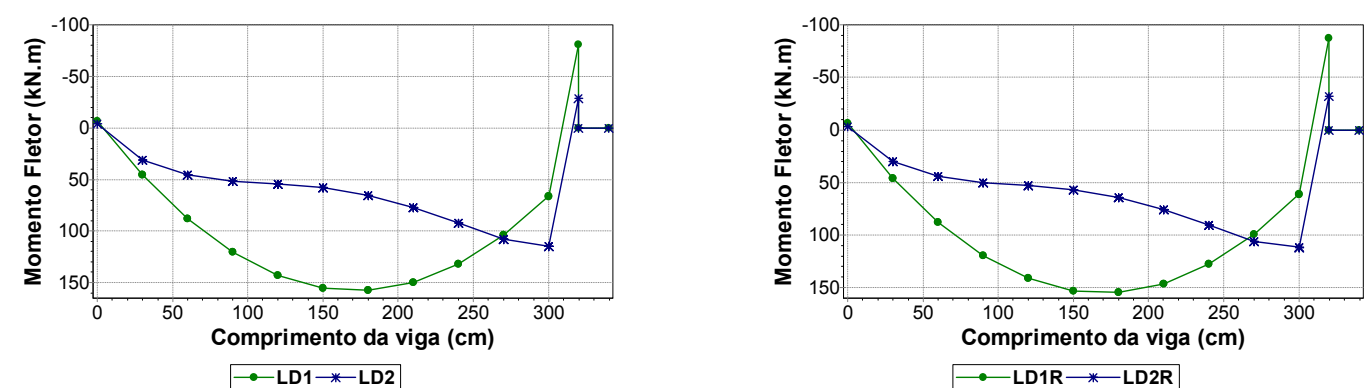

Figura 5.104 - Momento fletor - viga V19 
Como a viga se apóia no pilar direito na direção do seu eixo de maior inércia, aparece um pequeno momento fletor negativo na última barra que compõe a viga V19. Já o apoio da esquerda está na direção de menor inércia do pilar P13. Destaca-se esse ponto, pois se percebe que o efeito arco tem comportamentos diferentes em ambos os apoios. Mas é evidente a diminuição que ele proporciona ao fletor positivo.

\section{c) Viga V31}

A presente viga também é constituída por apenas um tramo, com apoios em duas outras vigas nas extremidades. Sendo assim, não apareceram momentos fletores negativos nos extremos, como se verifica na Figura 5.105. Também não foram encontradas diferenças entre as duas simulações de apoios. Já a influência do efeito arco é bastante evidente, ressaltando a grande vantagem em se considerar tal efeito, podendo-se reduzir significativamente a área de aço necessária para a armadura longitudinal.
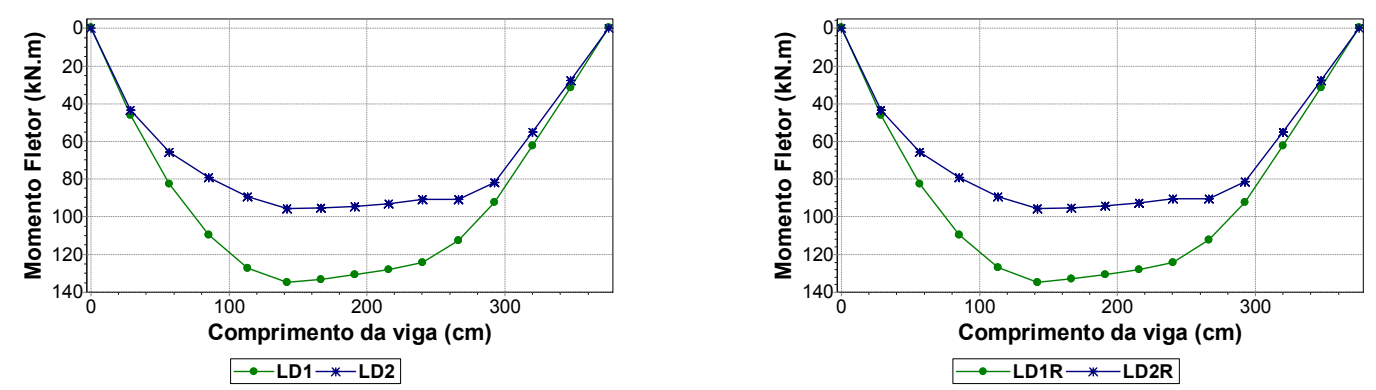

Figura 5.105 - Momento fletor - viga V31

\section{d) Viga V35}

Com três apoios de pilares e um pequeno balanço à direita, os deslocamentos encontrados na análise da presente viga são apresentados na Figura 5.106. O estudo com variação da rigidez dos apoios não apresenta diferenças significativas entre os modelos, embora valores menores de deslocamento relativo sejam observados na análise com pilares deformáveis. $A$ distribuição das paredes sobre a viga acaba incrementando os deslocamentos no primeiro tramo e no trecho em balanço, fazendo com que haja uma diminuição considerável nos deslocamentos do segundo tramo.
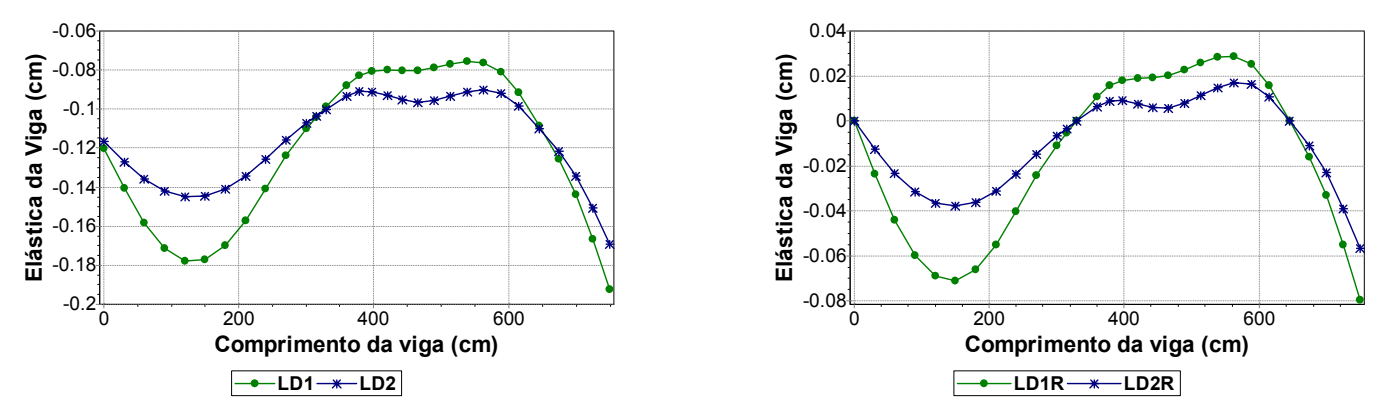

Figura 5.106 - Deslocamentos verticais - viga V35 
A partir do pilar P22 a viga é solicitada por esforços normais muito pequenos, diferentemente do primeiro tramo onde aparecem esforços de tração mais elevados, como se observa na Figura 5.107. Também é nesse mesmo trecho que foram obtidas as maiores tensões verticais na parede.
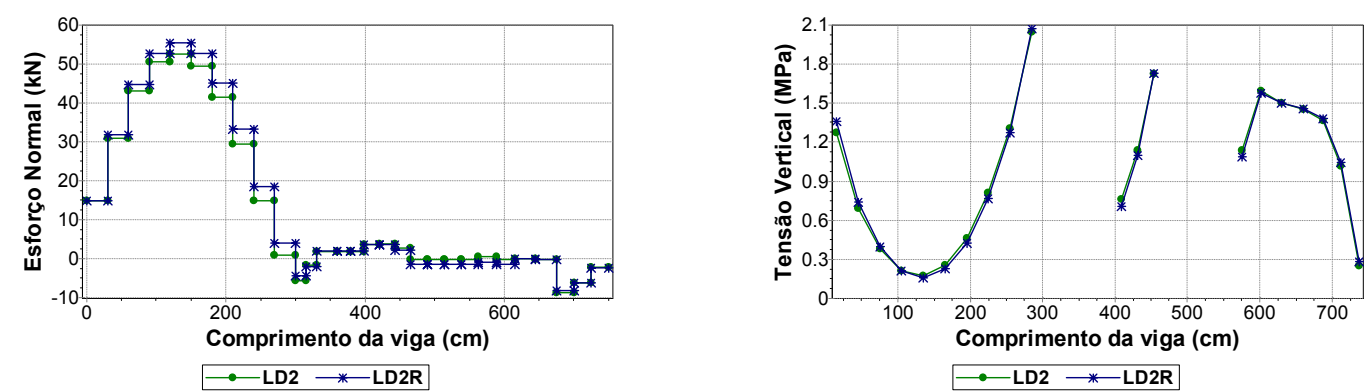

Figura 5.107 - Esforço normal e tensão vertical - viga V35

\section{e) Viga V43}

A presente viga possui parede sobre o primeiro tramo (entre os pilares P28 e P29), havendo um trecho com janela e uma pequena parede entre os pilares P32 e P30. Os menores deslocamentos encontram-se entre os pilares P29 e P30, apresentando o tramo da direta, com apoio sobre a viga V28, os maiores valores obtidos. É interessante salientar que as relações deslocamento/vão são adequadas quando comparadas com os limites normativos. Os diagramas são apresentados na Figura 5.108.
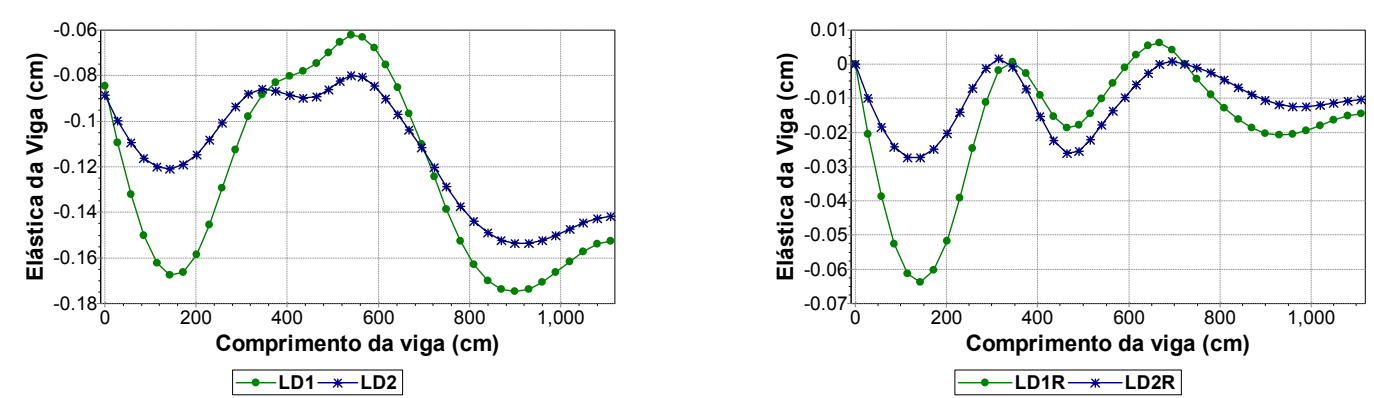

Figura 5.108 - Deslocamentos verticais - viga V43

Assim como para a viga anteriormente analisada (V35), o primeiro tramo apresenta esforço normal mais significativo quando comparado com os demais tramos. $O$ trecho compreendido pelo pilar P29 e a viga V20 está praticamente todo comprimido em ambas as modelagens. Já no último tramo, a modelagem com pilares deformáveis apresenta um incremento maior no esforço normal de tração, embora a ordem de grandeza dos valores seja pequena. A variação da rigidez dos apoios também não altera de forma significativa a tensão vertical, como ilustra a Figura 5.109.

Os diagramas de esforço cortante podem ser visualizados na Figura 5.110. Apesar das diferenças entre os Modelos 1 e 2 serem pequenas, a influência do efeito arco é mais evidente 
no primeiro tramo. Também há uma diminuição significativa do cortante sobre o pilar P30 quando comparada com o pico encontrado no Modelo 1.
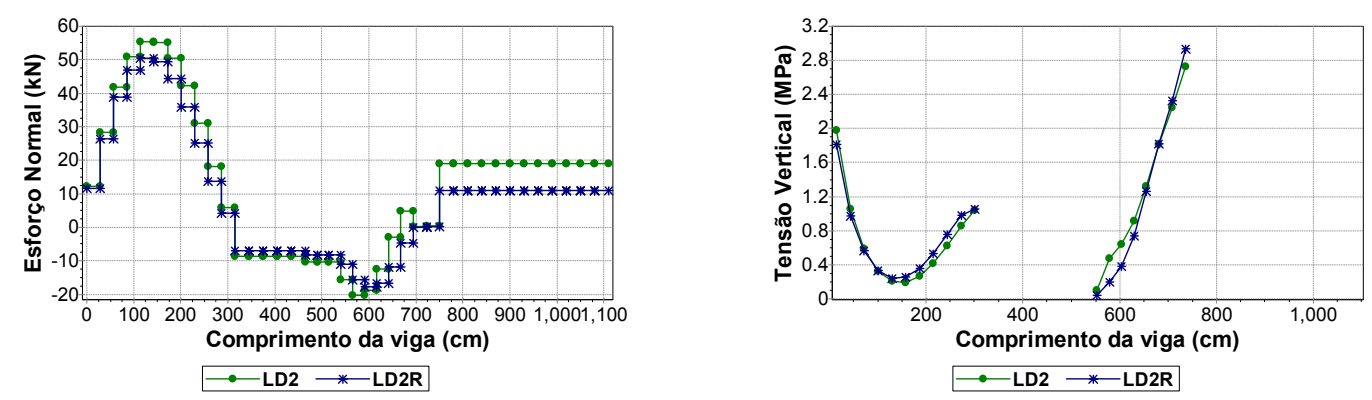

Figura 5.109 - Esforço normal e tensão vertical - viga V43
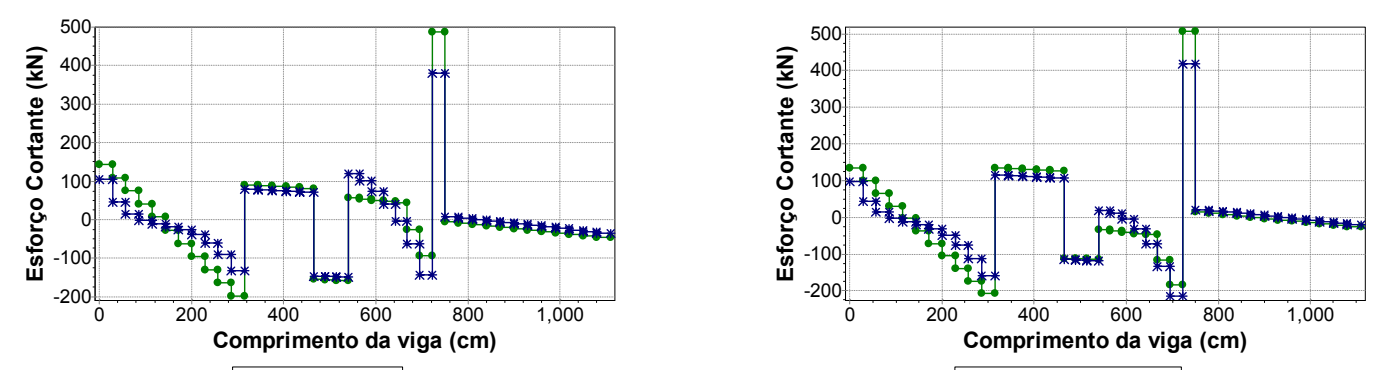

Figura 5.110 - Esforço cortante - viga V43

A influência do efeito arco é observada de forma mais clara no primeiro tramo da viga V43, como se constata pela análise dos diagramas da Figura 5.111. Grande diferença é encontrada para esta viga quando se realiza o estudo com variação da rigidez dos apoios. A modelagem com pilares deformáveis propicia o aparecimento de fletores negativos de magnitude semelhante sobre os pilares P29, P32 e P30. Na modelagem com apoios rígidos ocorre um aumento do momento negativo sobre os pilares P29 e P30, assim como um incremento no fletor positivo no encontro com a viga $\mathrm{V} 10$.
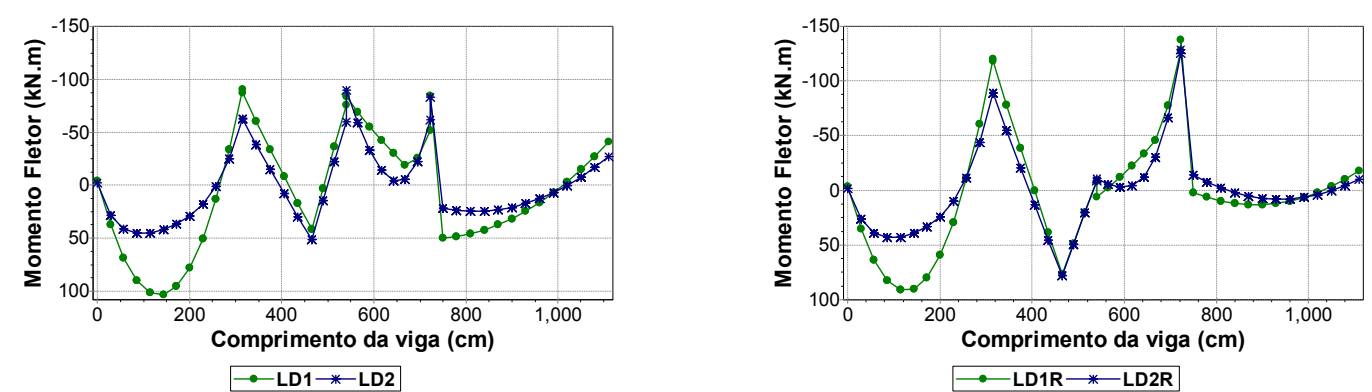

Figura 5.111 - Momento fletor - viga V43

\section{f) Viga V02}

Com três apoios de pilares constituindo dois tramos, a presente viga possui ainda uma abertura de janela bem no meio de cada tramo, o que explica o achatamento nos pontos de máximo da curva de esforço normal, apresentada na Figura 5.112. O modelo com apoios rígi- 
dos apresenta compressão apenas sobre o apoio central (pilar P21). Simulando-se os apoios por barras de pilares com sua inércia real, a viga aparece totalmente tracionada. A mesma figura apresenta o diagrama de tensões verticais, onde fica evidente o aumento das tensões sobre o apoio intermediário (pilar P21) e nas extremidades.
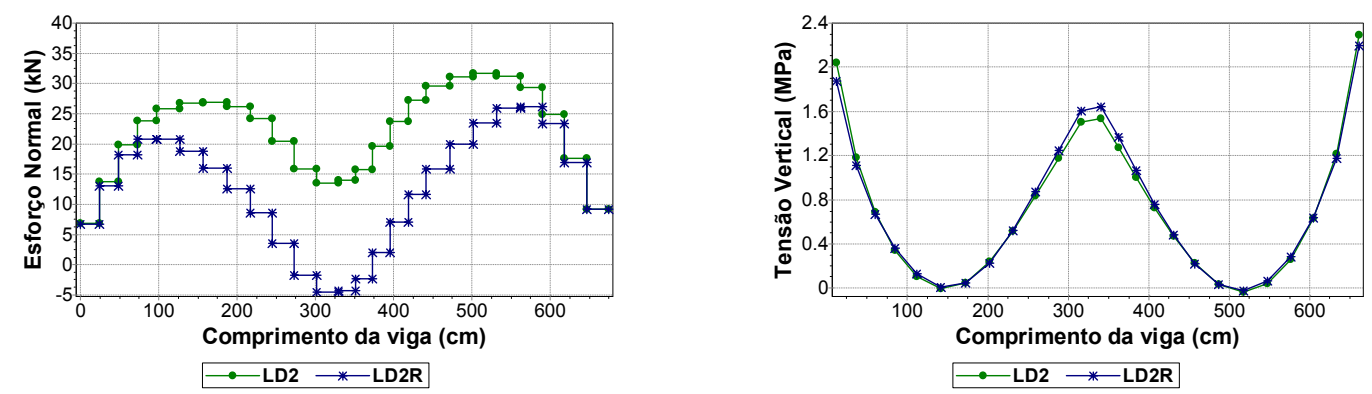

Figura 5.112 - Esforço normal e tensão vertical - viga V02

\section{g) Viga V10}

A curva de deslocamentos verticais da presente viga é apresentada na Figura 5.113. Com apoios apenas em vigas e um trecho de parede entre as interseções com as vigas V39 e V35, o resultado encontrado é bastante atípico, não tendo sido observado similar em nenhum outro edifício analisado. O efeito arco, sempre tido como favorável, aumentou os deslocamentos da viga nas duas simulações de apoios. Apesar disso, a flecha máxima, tomando-se como vão (L) o comprimento total da viga, é da ordem de $L / 3000$.
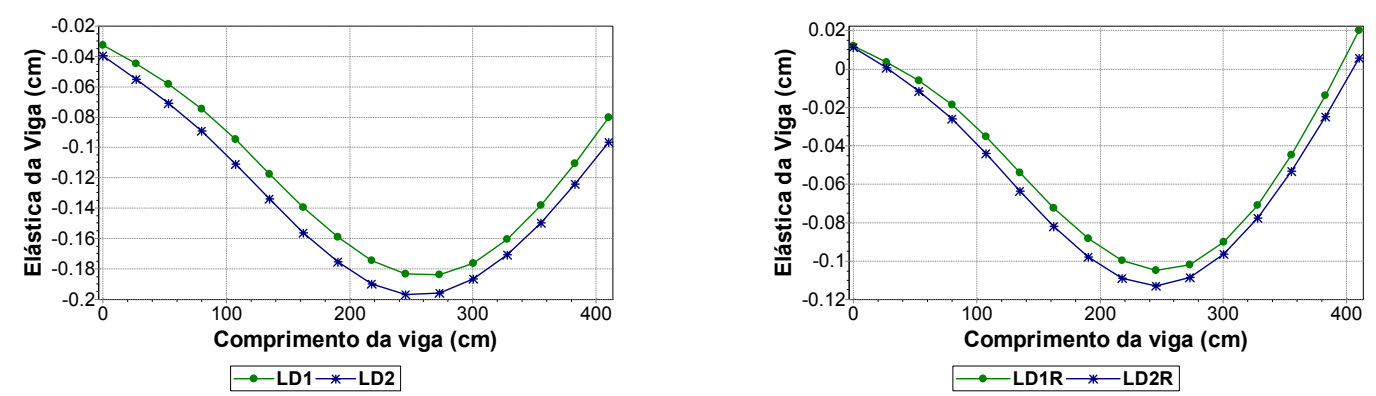

Figura 5.113 - Deslocamentos verticais - viga V10

\section{h) Viga V18}

A presente viga apresenta resultados semelhantes para o momento fletor, como ilustra a Figura 5.114. Com três apoios de pilares e interseções com três vigas, apresenta parede estrutural (sendo discretizada com elementos membrana no modelo para análise do efeito arco) apenas no trecho compreendido pela interseção com a viga V31 até o pilar P15. As diferenças entre os Modelos 1 e 2 para as duas simulações de apoios é praticamente desprezível, não havendo o aparecimento do efeito arco. 

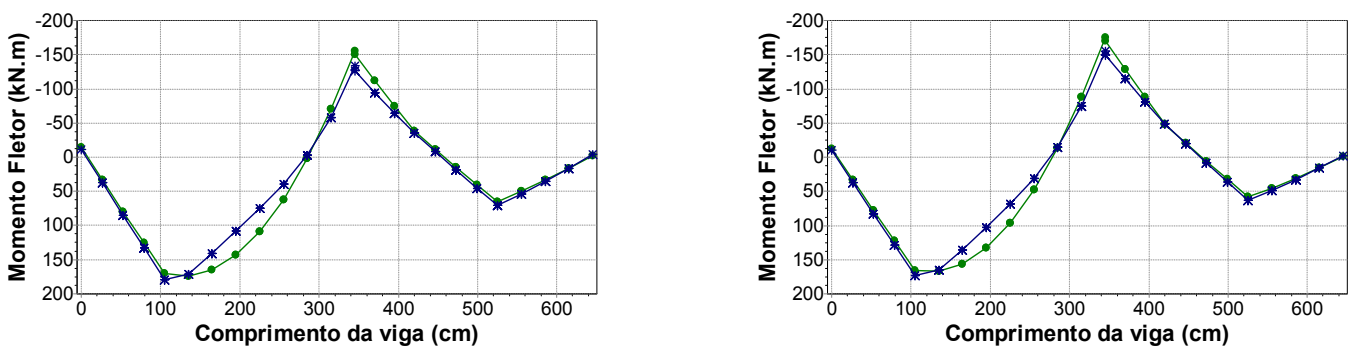

$\rightarrow-$ LD1 *-LD2 - - LD1R $\rightarrow$ - LD2R

Figura 5.114 - Momento fletor - viga V18

\section{i) Viga V22}

A presente viga possui parede em toda a sua extensão, excetuando-se uma abertura na extremidade direita, apresentando três apoios de pilares, além de receber uma viga no primeiro tramo.

Apesar de alterar um pouco a forma do diagrama de deslocamentos, a análise efetuada variando-se a rigidez dos apoios não provoca diferenças significativas na ordem de grandeza dos deslocamentos relativos da viga V22. A influência do efeito arco se mostra bastante positiva na redução da flecha do primeiro tramo, como evidencia a Figura 5.115.

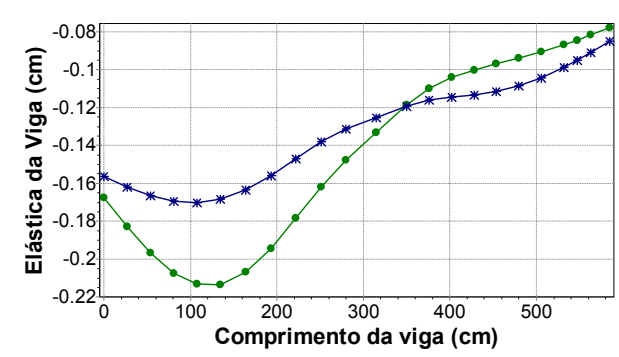

$\rightarrow-$ LD1 $*$ LD2

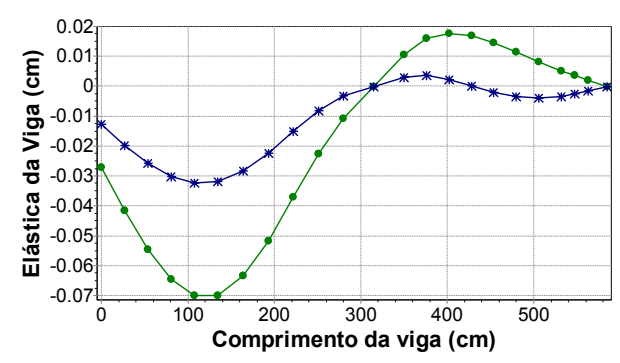

$\rightarrow$-LD1R * - LD2R

Figura 5.115 - Deslocamentos verticais - viga V22

Como observado na Figura 5.116, as maiores tensões verticais são obtidas sobre as barras rígidas (trecho rígido) que ligam a viga ao pilar P03. O esforço normal é desprezível no trecho que se estende do pilar P03 até o final da viga, apresentando tração máxima no primeiro tramo.
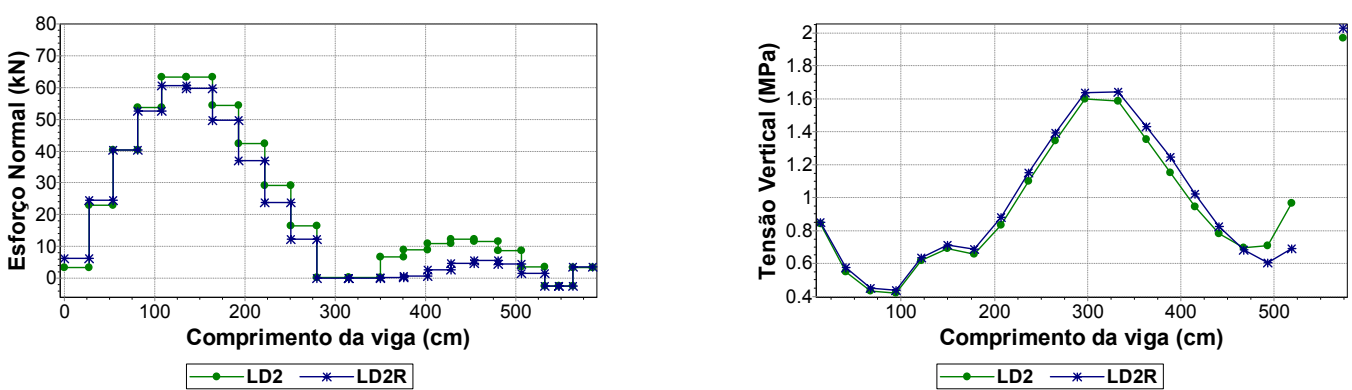

Figura 5.116 - Esforço normal e tensão vertical - viga V22 
Nas duas simulações de apoios o efeito arco diminui o esforço cortante no primeiro tramo, causando um aumento junto ao apoio do pilar P03. Entretanto, o valor máximo do esforço praticamente não sofre alteração, nem mesmo no estudo realizado com a variação da rigidez dos apoios (Figura 5.117).
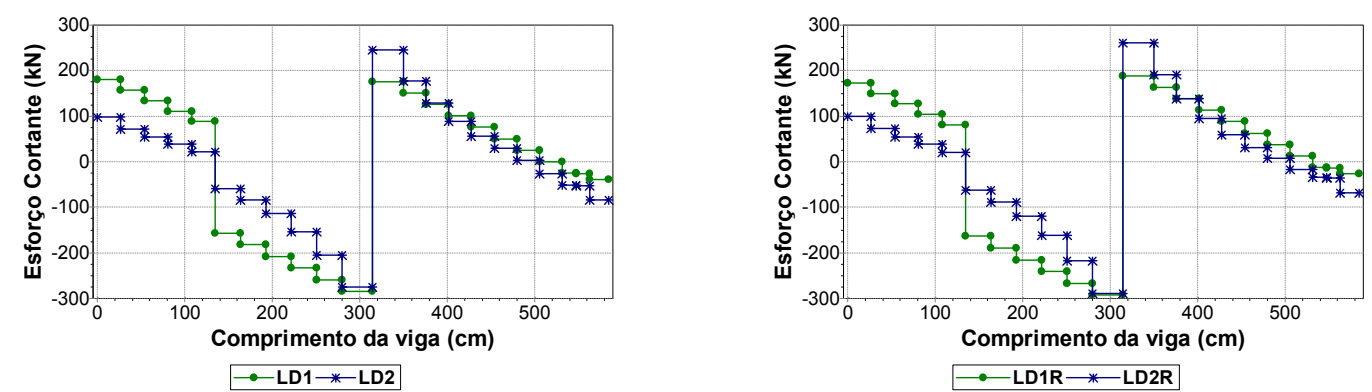

Figura 5.117 - Esforço cortante - viga V22

Os momentos fletores foram pouco afetados pelo estudo em que se varia a rigidez dos apoios. Ainda assim, o efeito arco reduz significativamente o momento fletor positivo no primeiro tramo, como se observa nos diagramas da Figura 5.118.
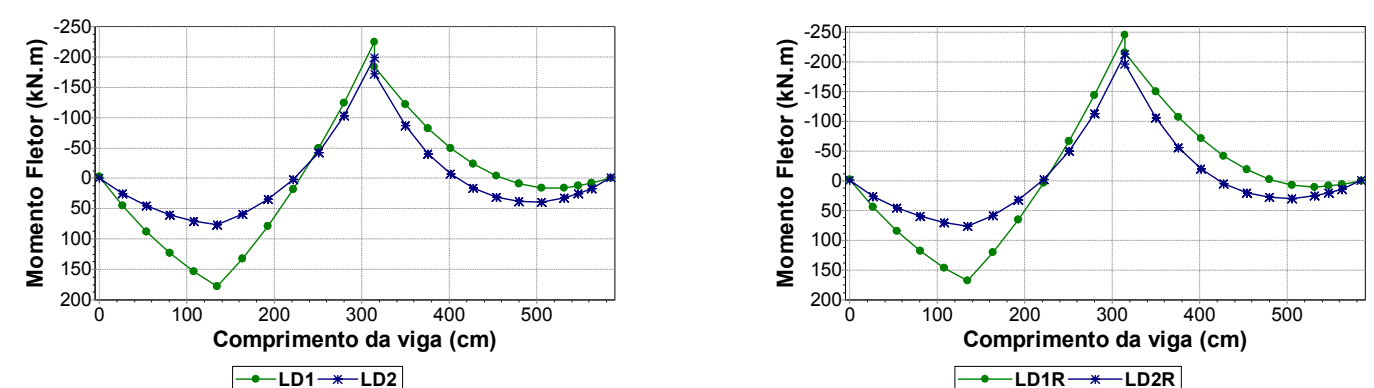

Figura 5.118 - Momento fletor - viga V22

\section{j) Viga V28}

A presente viga é totalmente carregada pelos dez pavimentos de alvenaria da estrutura do edifício. Possui um apoio de pilar na extremidade esquerda, outro pilar intermediário e apoio sobre uma viga na extremidade direita.
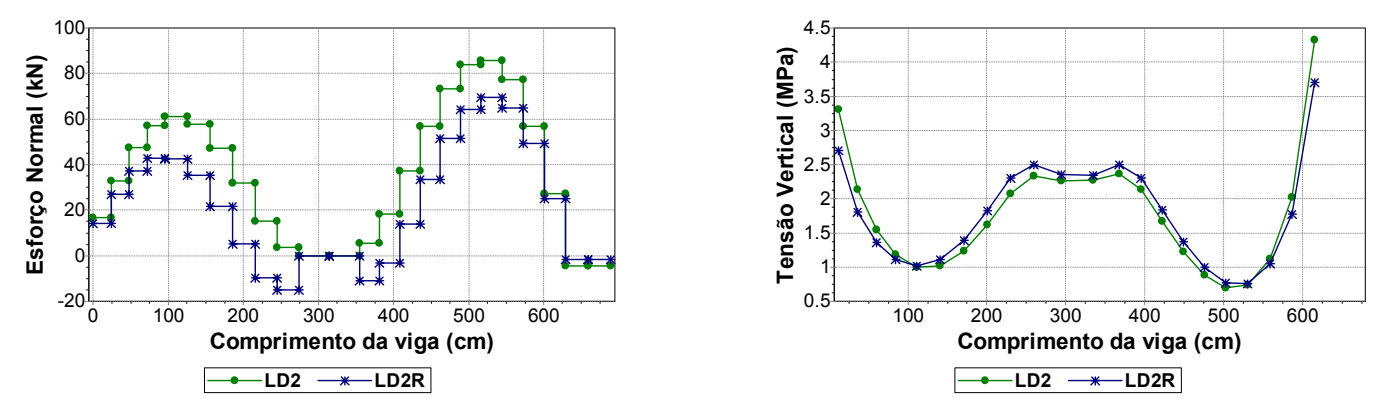

Figura 5.119 - Esforço normal e tensão vertical - viga V28 
A consideração dos pilares deformáveis novamente conduz a valores maiores de esforço normal, sendo que sobre as barras rígidas que ligam a viga ao pilar P27 aparece um trecho com esforço nulo. Essa modelagem também resultou num acréscimo das tensões verticais nas extremidades da viga, como observado na Figura 5.119.

\subsection{EXEMPLO 5 - EDIFÍCIO CASA PARA TODOS}

\subsubsection{Apresentação}

O Edifício Residencial Casa Para Todos é composto por quinze pavimentos tipo sobre um pavimento de pilotis em concreto armado.

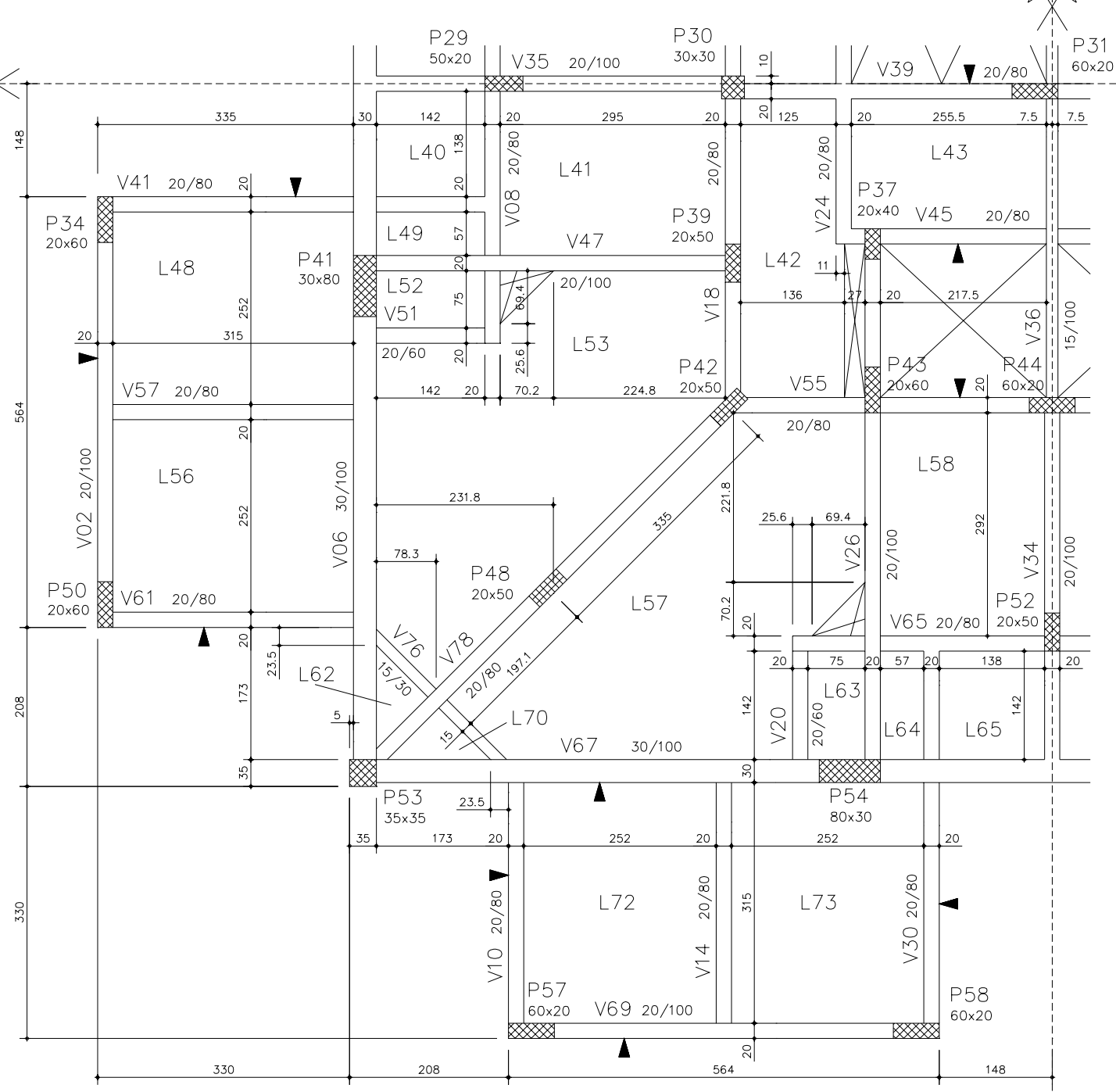

Figura 5.120 - Forma estrutural do pilotis do edifício Casa Para Todos

A planta da forma do pilotis é apresentada na Figura 5.120. Para otimizar o processamento da estrutura e também permitir o emprego de uma rede mais refinada, adotaram-se si- 
metrias em torno dos eixos $\mathrm{X}$ e $\mathrm{Y}$, modelando-se apenas o quarto inferior esquerdo do pavimento. A Figura 5.121 ilustra a planta de modulação com a simetria considerada.

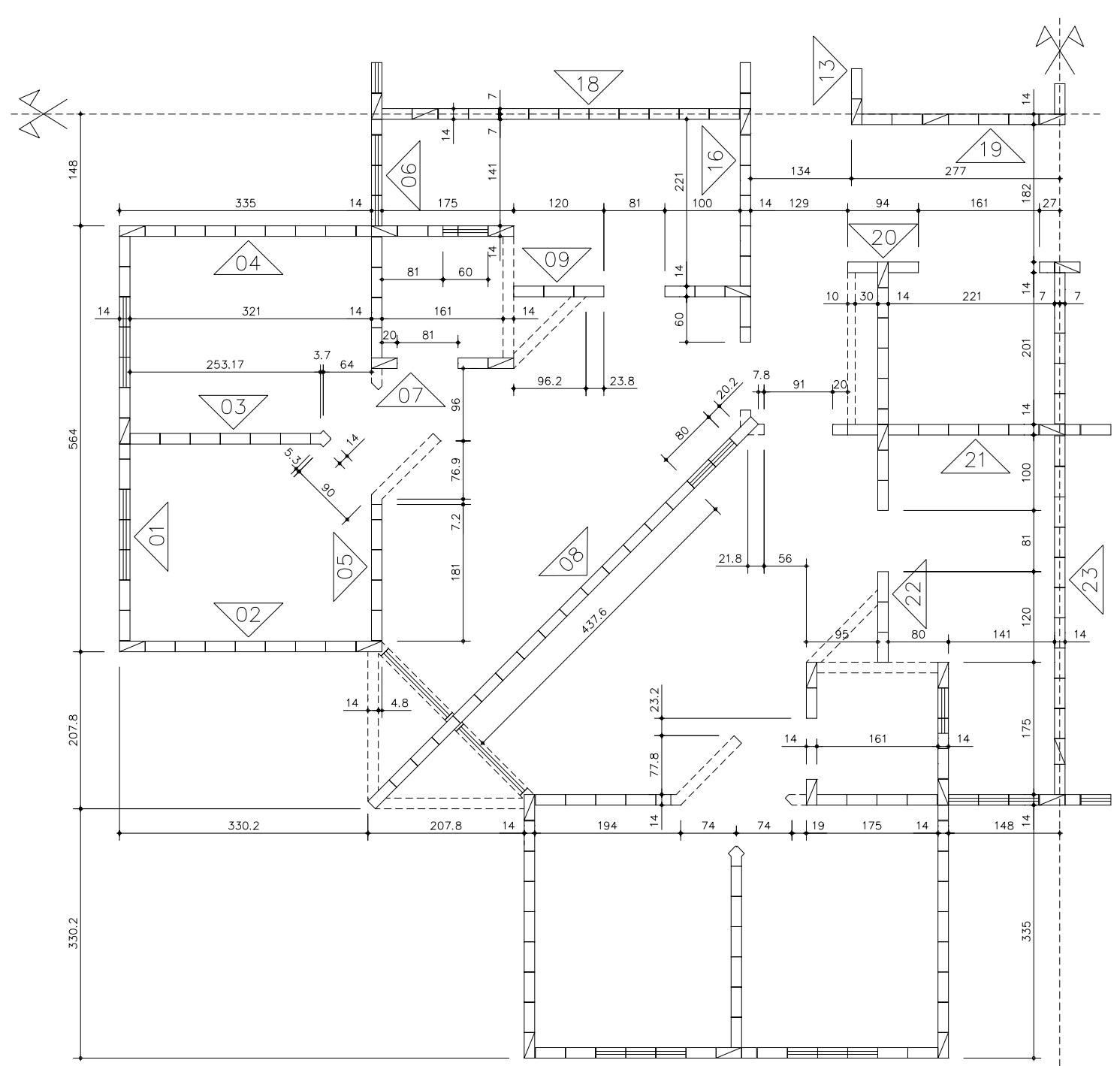

Figura 5.121 - Modulação do pavimento tipo do edifício Casa Para Todos

\subsubsection{Descrição dos Modelos}

A Tabela 5.5 apresenta alguns parâmetros e propriedades dos materiais empregados na estrutura do edifício analisado.

Tabela 5.5 - Parâmetros de modelagem do edifício Casa para Todos

\begin{tabular}{ll}
\hline Espessura da parede $(\mathrm{m})$ & 0,14 \\
\hline Altura da parede $(\mathrm{m})$ & 2,52 \\
\hline$v_{\text {viga }}$ & 0,20 \\
\hline$v_{\text {parede }}\left(\mathrm{kN} / \mathrm{m}^{2}\right)$ & 0,20 \\
\hline $\mathrm{E}_{\text {parede }}\left(\mathrm{kN} / \mathrm{m}^{2}\right)$ & $5,76 \mathrm{E}+06$ \\
\hline $\mathrm{E}_{\text {viga }}(\mathrm{MPa})$ & $2,13 \mathrm{E}+07$ \\
\hline $\mathrm{f}_{\mathrm{ck}}(\mathrm{MPa})$ & 20 \\
\hline
\end{tabular}


A Figura 5.122 apresenta as barras e nós carregados do chamado Modelo 1. Já na Figura 5.123, é ilustrada a rede, barras e cargas nodais do Modelo 2.

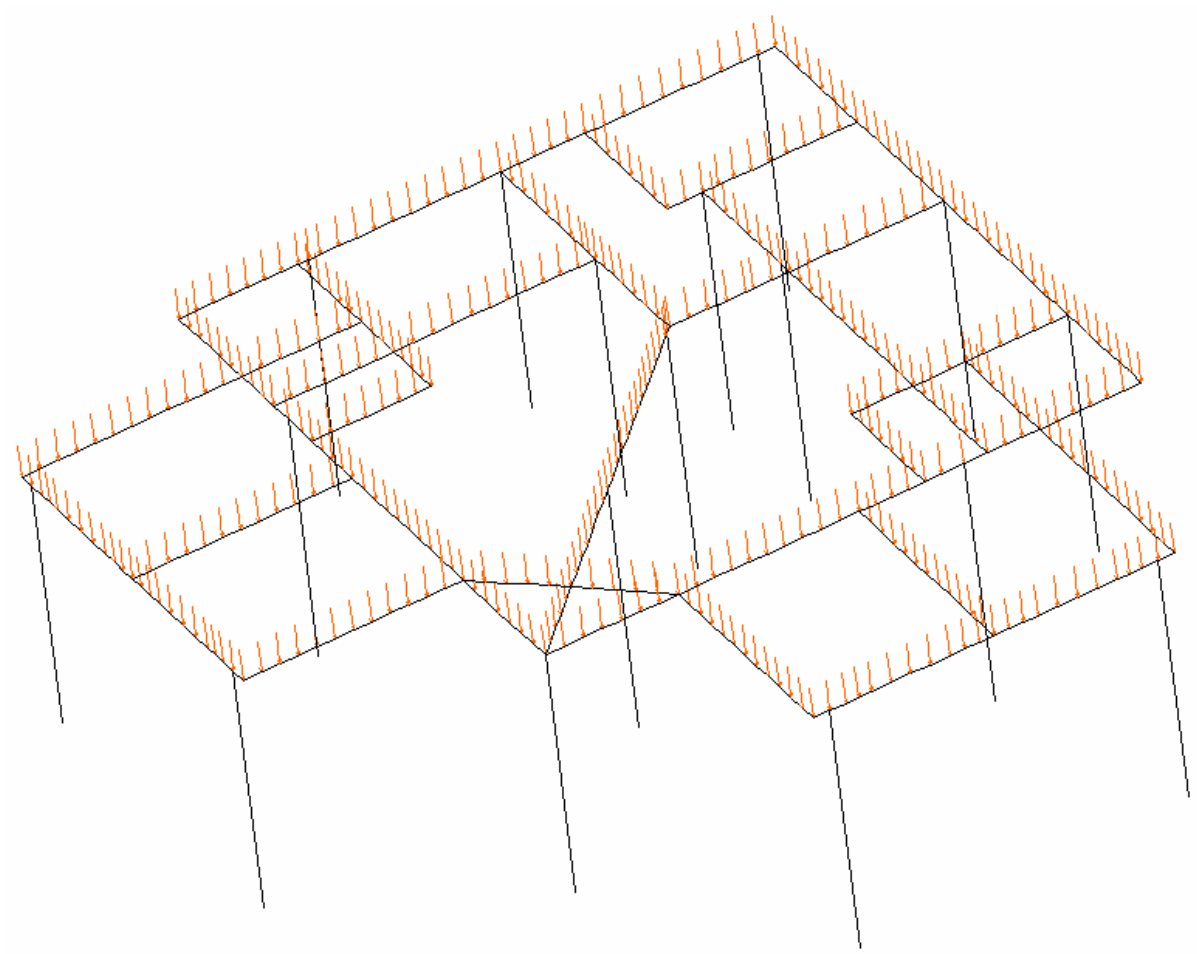

Figura 5.122 - Modelo 1 (CT1 e CT1R) do edifício Casa Para Todos

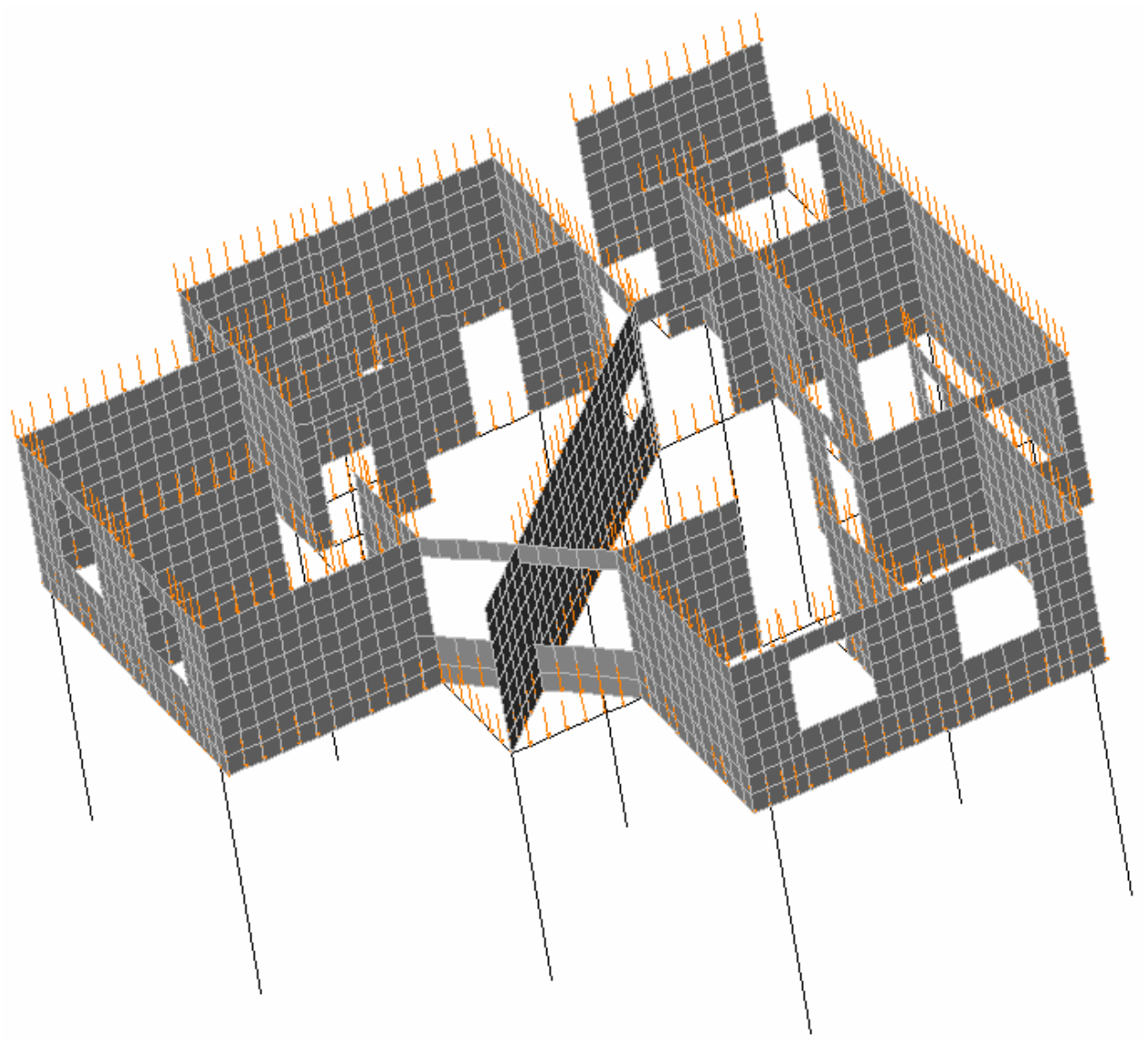

Figura 5.123 - Modelo 2 (CT2 e CT2R) do edifício Casa Para Todos 


\subsubsection{Análise de Resultados}

Faz-se uma análise objetiva do processamento do presente edifício, abrangendo-se apenas os resultados mais significativos de algumas vigas.

\section{a) Viga V41}

Apesar de se haver modelado apenas um quarto do pavimento, a viga V78 define um eixo de simetria inclinado. Sendo assim, os resultados obtidos para a presente viga são similares aos obtidos para a viga $\mathrm{V} 30$, devido à simetria com a viga $\mathrm{V} 78$.

A Figura 5.124 apresenta os diagramas de deslocamentos verticais, onde são observados os ganhos advindos da modelagem com o efeito arco (Modelo 2). Com um apoio de pilar à esquerda (pilar P34), outro apoio definido por uma viga mais rígida (V06), enquanto na direita se une à viga $\mathrm{V} 08$, o efeito arco é mais favorável no primeiro tramo (do pilar P34 à viga V06) em ambas as simulações de apoios.
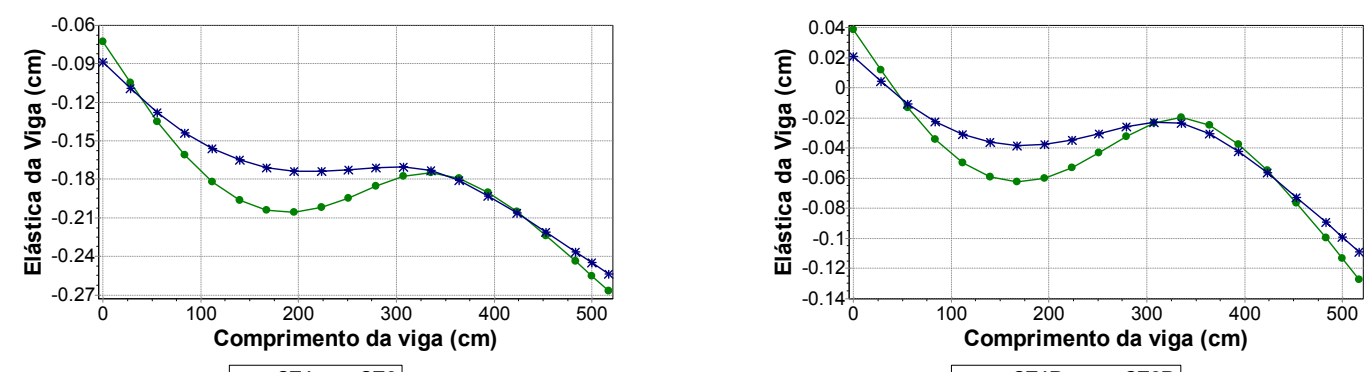

Figura 5.124 - Deslocamentos verticais - viga V41

Com parede em toda a extensão da viga, contando com apenas uma pequena abertura de janela à direita, percebe-se, pela análise do diagrama de tensões verticais da Figura 5.125, que a máxima tensão não ocorreu no pequeno trecho de parede à direita da abertura, mas sim sobre o apoio esquerdo (definido pelo pilar P34). Isso ocorre porque o último tramo da viga é uma balanço, sendo que a carga caminha na direção da interseção com a viga V41.
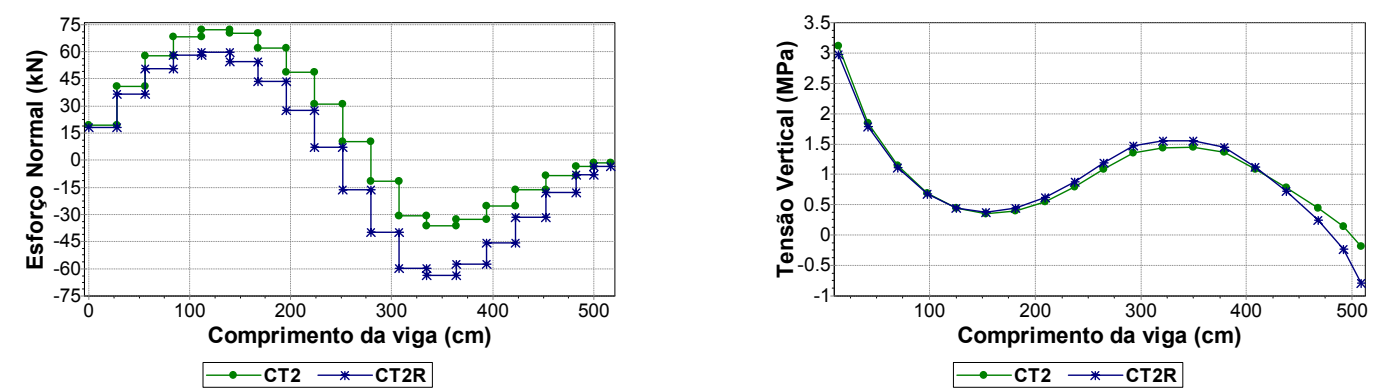

Figura 5.125 - Esforço normal e tensão vertical - viga V41 
$\mathrm{Na}$ comparação entre os Modelos 1 e 2, o esforço cortante sofre reduções significativas devido ao efeito arco, notadamente no primeiro tramo, como observado nos diagramas da Figura 5.126.
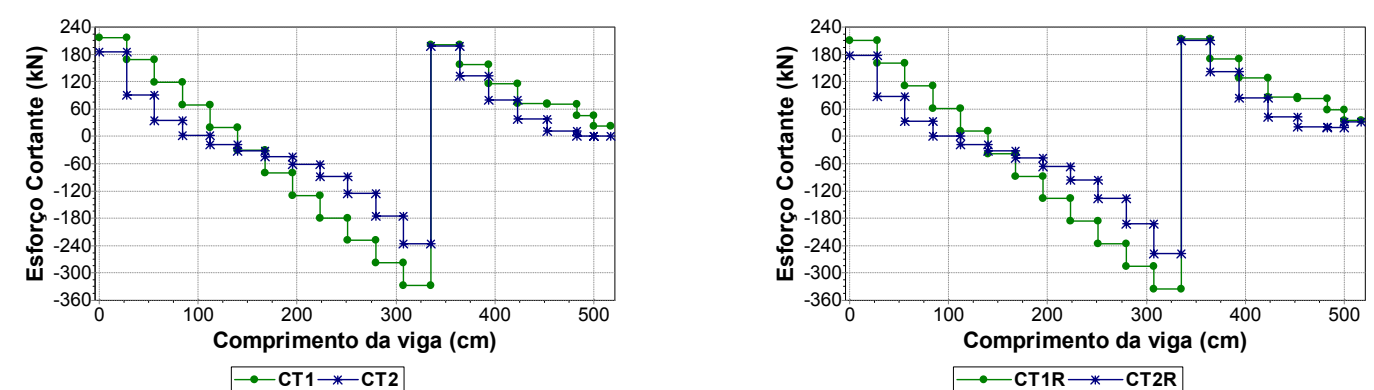

Figura 5.126 - Esforço cortante - viga V41

O efeito arco também reduz consideravelmente os momentos fletores, principalmente o fletor positivo, como apresentado na Figura 5.127.

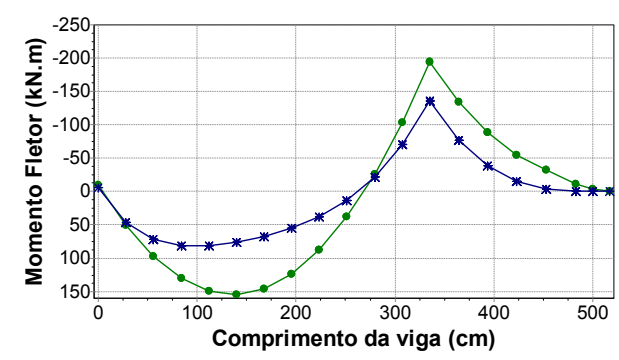

$\rightarrow-\mathrm{CT} 1-$ * CT2

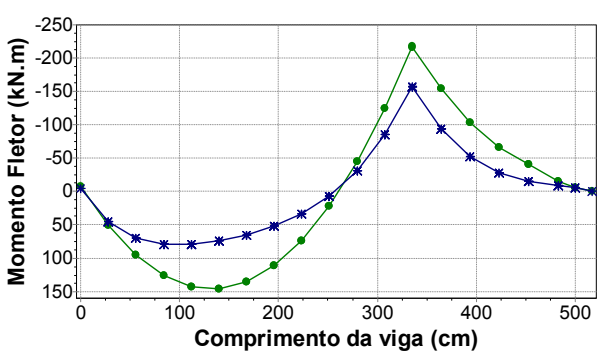

$-\mathrm{CT} 1 \mathrm{R} \longrightarrow$ - $\mathrm{CT} 2 \mathrm{R}$

Figura 5.127 - Momento fletor - viga V41

\section{b) Viga V47}

A presente viga possui parede no trecho que vai da interseção com a viga V08 até o pilar P39, tendo uma abertura de porta no meio desse vão. O efeito arco propicia reduções, mas estas não são tão grandes, como observado na Figura 5.128.

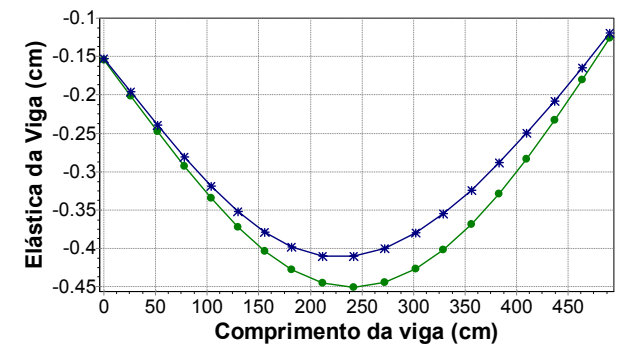

$-\mathrm{CT} 1-$ * $\mathrm{CT2}$

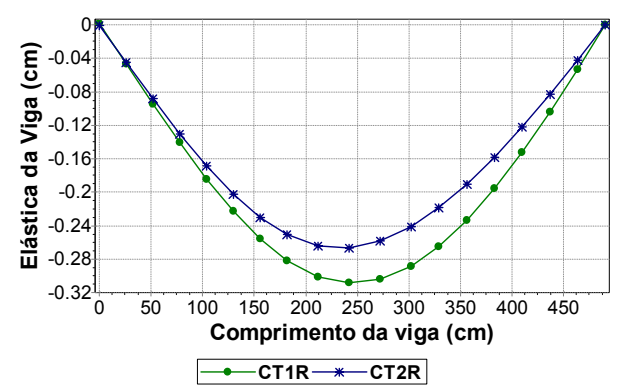

$\because \mathrm{CT} 1 \mathrm{R} \rightarrow$ - CT2R

Figura 5.128 - Deslocamentos verticais - viga V47

Ainda nesse mesmo trecho (entre a viga V08 e o pilar P39), o esforço cortante sofre um alívio significativo devido ao efeito arco, como se comprova pela análise dos diagramas da Figura 5.129. 

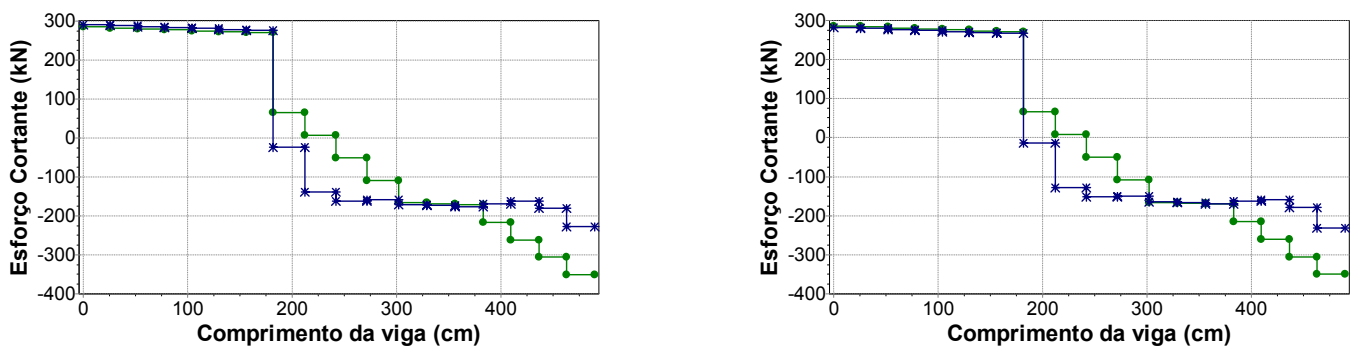

$-\bullet \mathrm{CT} 1 * \mathrm{CT} 2$

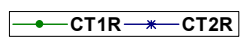

Figura 5.129 - Esforço cortante - viga V47

\section{c) Viga V55}

O trecho constante à esquerda do diagrama de esforço normal, mostrado na Figura 5.130 , compreende a única região da viga em que não há parede sobre a mesma, sendo definida por uma abertura de porta.

Com dois vãos delimitados por três apoios de pilares e simetria à direita, o diagrama de esforço normal demonstra a grande variação encontrada com as diferentes modelagens de apoios. Realizando-se a modelagem com apoios rígidos a viga é solicitada por esforços de compressão apenas na região sob o trecho da porta, havendo tração no restante da viga. Já na análise com pilares deformáveis, há predominância de esforços de compressão, que também tem sua magnitude acrescida quando comparada à análise anterior. A modelagem com pilares deformáveis também propicia o aumento da tensão vertical na extremidade esquerda da viga e uma diminuição significativa na parte intermediária, como exposto na Figura 5.130.
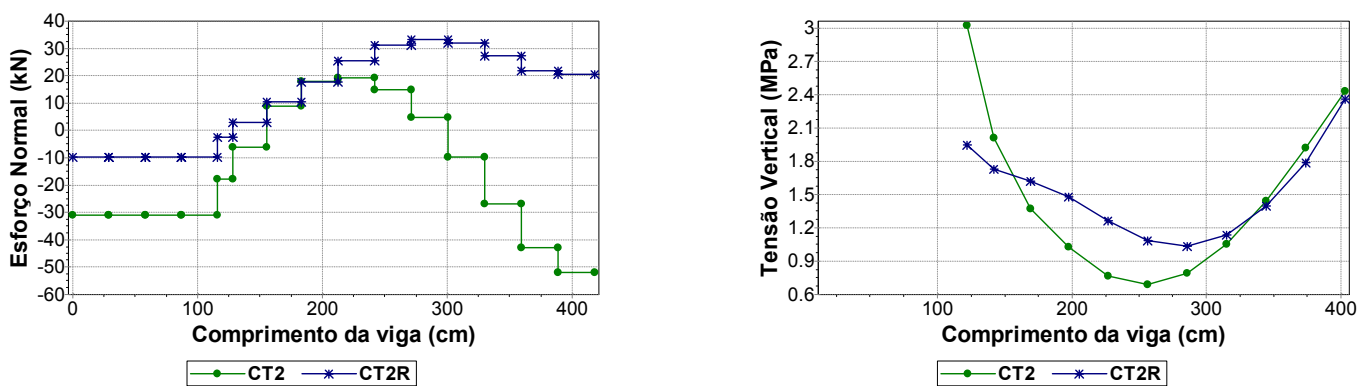

Figura 5.130 - Esforço normal e tensão vertical - viga V55

\section{d) Viga V57}

A presente viga possui parede sobre quase toda a sua extensão, com exceção das três últimas barras da direita. Com apenas um vão e apoios em duas outras vigas, o efeito arco influencia consideravelmente os deslocamentos verticais, como se atesta pelos diagramas da Figura 5.131.

Apesar de não ter havido redução no máximo esforço cortante, o efeito arco diminui significativamente o valor do mesmo no apoio da esquerda (viga V02), havendo ganhos consideráveis até próximo do final da região com parede (Figura 5.132). E, como era de se esperar, a variação da rigidez dos apoios não gera diferenças significativas entre as duas modelagens. 
Com os diagramas de momento fletor ilustrados na Figura 5.133 novamente se destaca a influência do efeito arco, propiciando reduções bastante perceptíveis no momento fletor positivo.

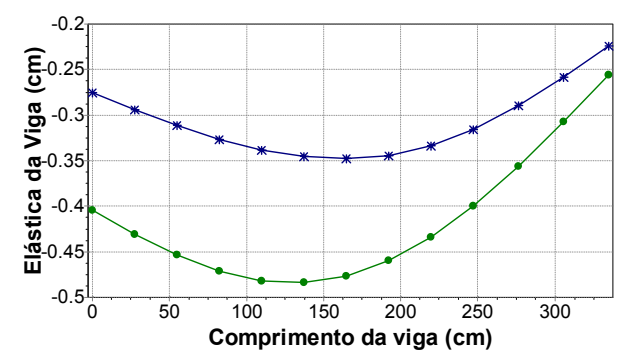

$-\mathrm{CT} 1 \rightarrow$ * $\mathrm{CT} 2$

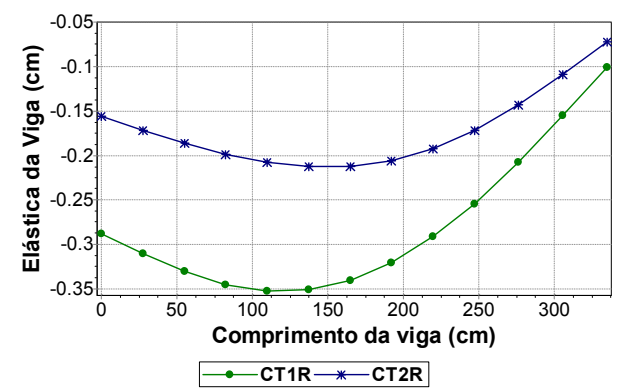

$\because$ CT1R * - CT2R

Figura 5.131 - Deslocamentos verticais - viga V57
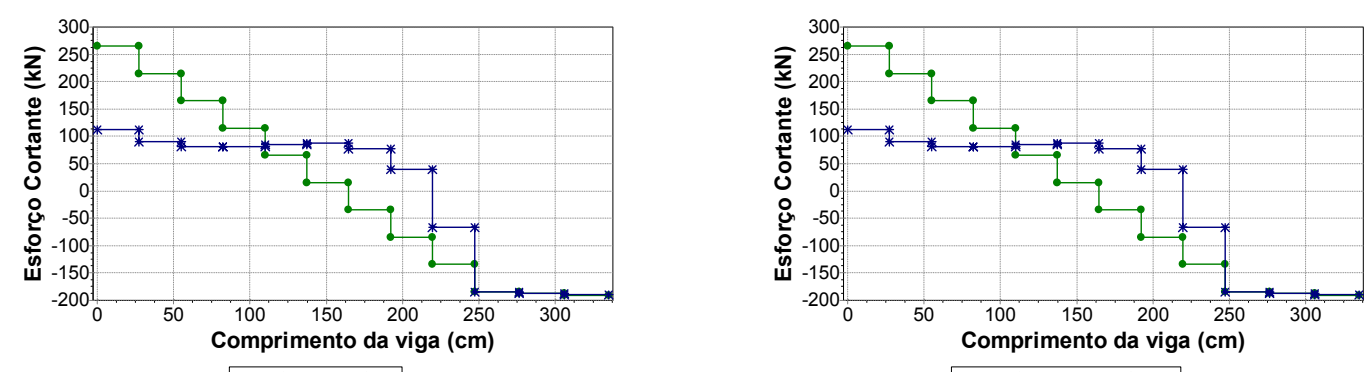

Figura 5.132 - Esforço cortante - viga V57
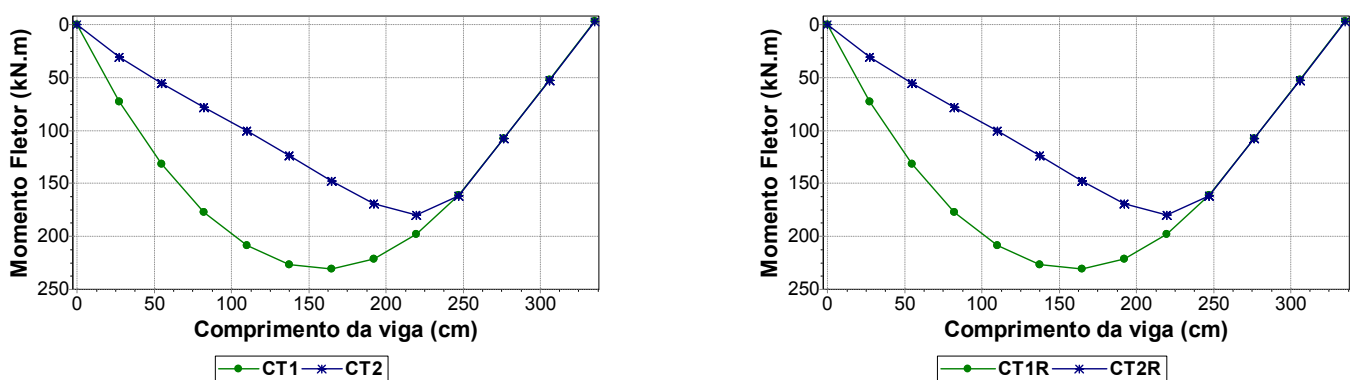

Figura 5.133 - Momento fletor - viga V57

\section{e) Viga V61}

Novamente se analisa uma viga de apenas um tramo, com parede em todo o seu comprimento, porém com apoio de pilar na esquerda (pilar P50) e de viga na direita (viga V06).
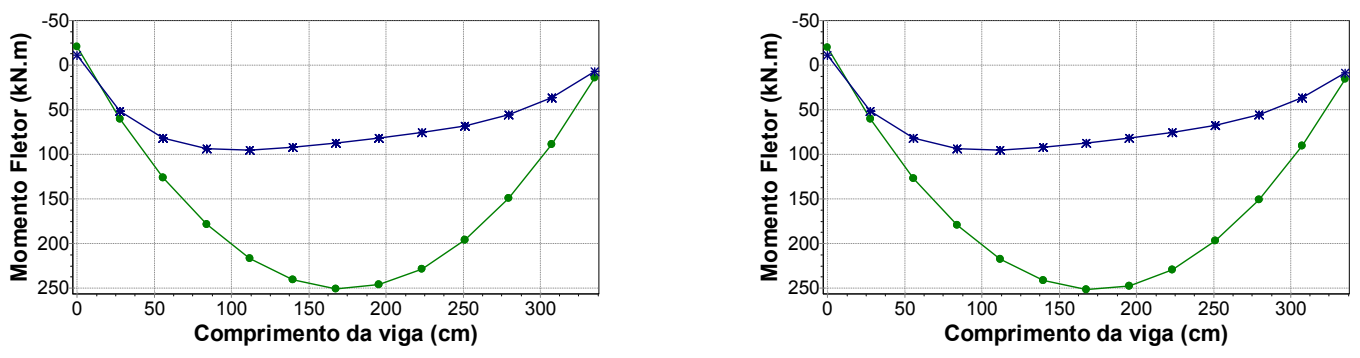

$-{ }_{-\mathrm{CT} 1} * \mathrm{CT} 2$ - CT1R $\#$ - CT2R

Figura 5.134 - Momento fletor - viga V61 
A Figura 5.134 apresenta os diagramas de momento fletor da presente viga, onde se constatam as diferenças encontradas entre os Modelos 1 e 2, havendo reduções expressivas no esforço analisado devido ao efeito arco.

\section{f) Viga V67}

Mesmo não havendo paredes sobre alguns trechos da presente viga, a influência do efeito arco é claramente observada nos diagramas de deslocamentos da Figura 5.135. O trecho aparentemente constante por volta da abscissa 600 do comprimento da viga denota as duas barras de trecho rígido da ligação com o pilar P54. O efeito arco conduz a maiores reduções no trecho compreendido pelos pilares P53 e P54.
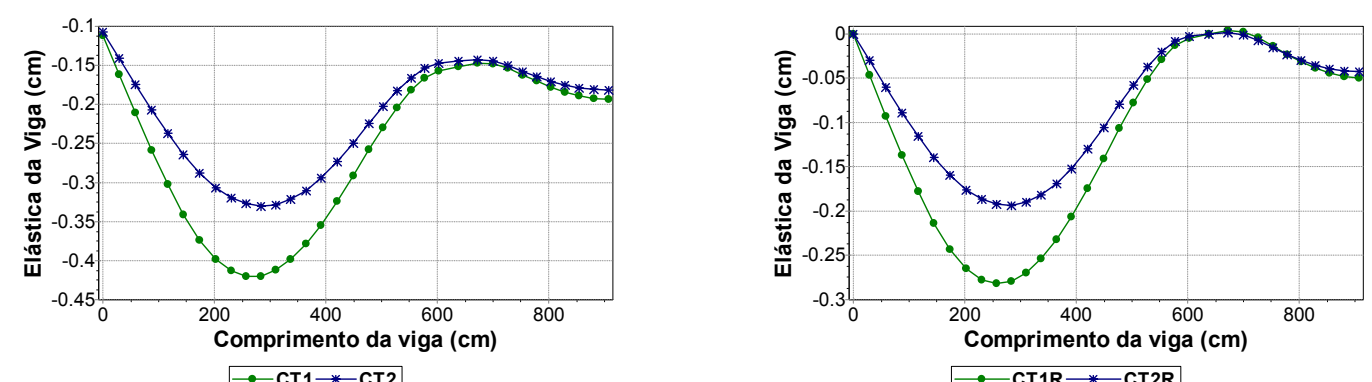

Figura 5.135 - Deslocamentos verticais - viga V67

No diagrama de esforço normal (Figura 5.136) os trechos sem paredes são bastante claros, definindo regiões constantes no gráfico. No trecho de parede entre as vigas V10 e V14, a presente viga é solicitada axialmente por um esforço de tração mais expressivo. É neste trecho que também aparecem as maiores tensões verticais. As modelagens com variação da rigidez dos apoios não fornecem diferenças significativas, sendo observada uma pequena alteração apenas no diagrama de esforço normal.
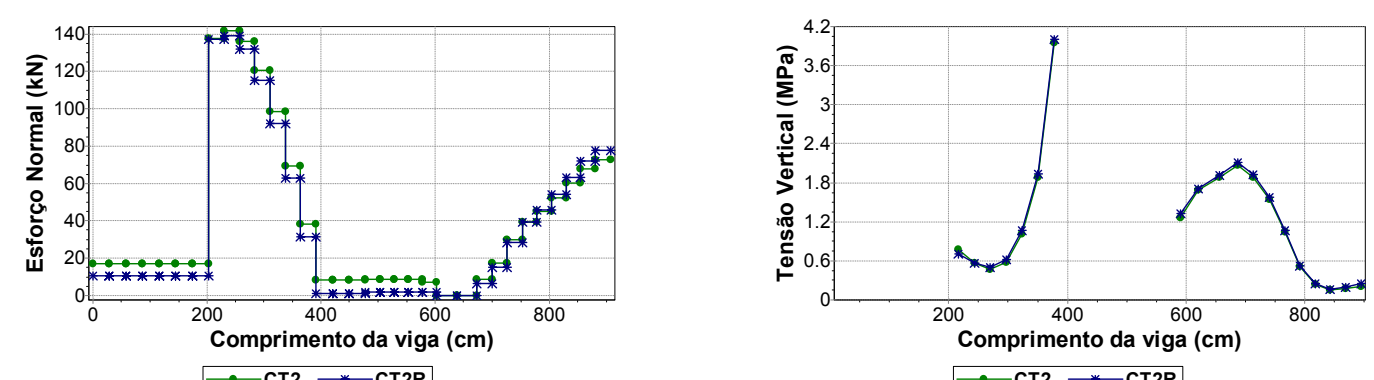

Figura 5.136 - Esforço normal e tensão vertical - viga V67

Devido à escala dos diagramas de momento fletor na Figura 5.137 as diferenças observadas podem parecer pequenas. Entretanto, analisando-se a ordem de grandeza dos esforços, percebe-se a expressiva redução proporcionada pela consideração do efeito arco. O momento fletor negativo também apresenta diminuição, porém numa proporção menor à observada para o fletor positivo. 


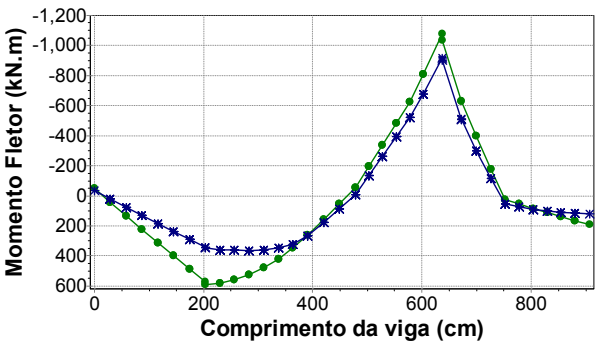

$\rightarrow-\mathrm{CT} 1-$ * $-\mathrm{CT} 2$

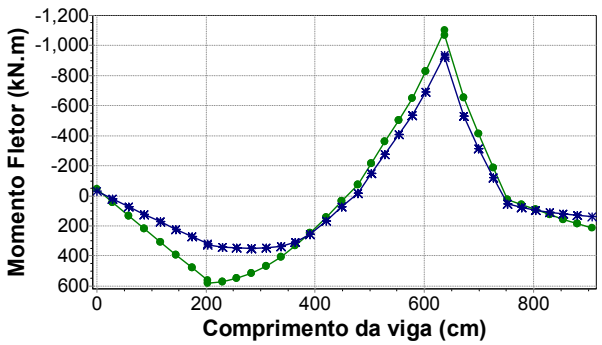

$\because$ CT1R $\rightarrow$ * CT2R

Figura 5.137 - Momento fletor - viga V67

\section{g) Viga V02}

A presente viga é formada por dois apoios de pilares em suas extremidades, servindo de apoio à viga V57 no seu ponto central. Como se observa na Figura 5.138, em ambas as extremidades existem duas barras com esforço normal nulo, correspondendo aos trechos rígidos que ligam a viga aos respectivos pilares. Possui parede em toda a sua extensão, com duas aberturas de janelas. Isso permite a atuação do efeito arco de maneira bastante efetiva. Entretanto, aparecem esforços de tração elevados, que atingem o máximo junto à interseção com a viga V57. Os dois pontos extremos do diagrama de tensões verticais correspondem à projeção do centróide dos elementos da base da parede sobre os trechos rígidos, apresentando as maiores tensões na parede sobre a viga V02.
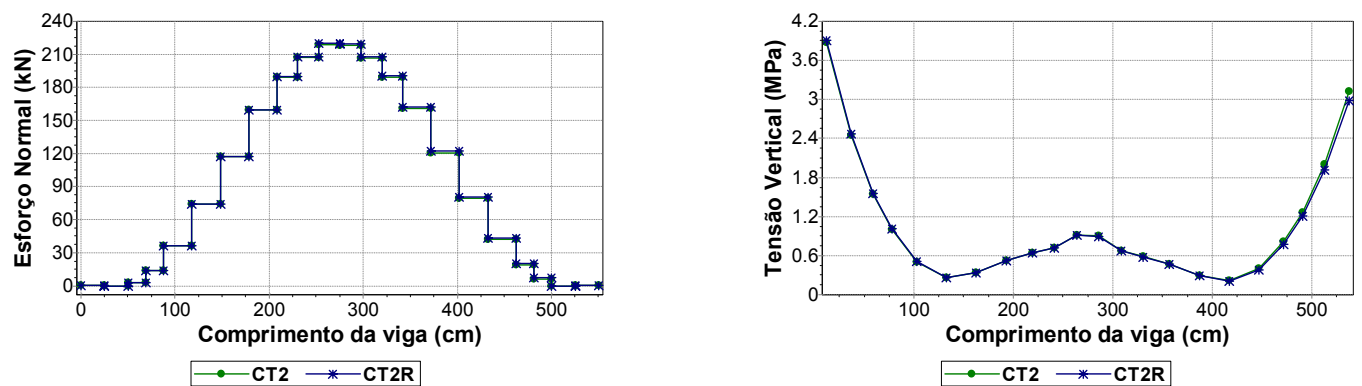

Figura 5.138 - Esforço normal e tensão vertical - viga V02

O diagrama de esforço cortante constante na Figura 5.139 novamente mostra que o efeito arco tende a ser favorável a este esforço em algumas vigas, podendo reduzir a área de armadura transversal da viga analisada.
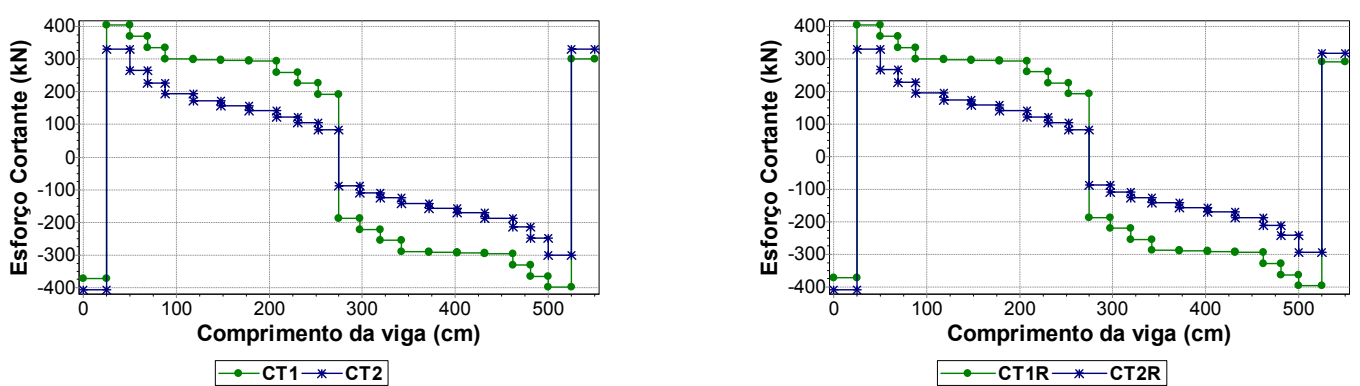

Figura 5.139 - Esforço cortante - viga V02 
Os ganhos devido ao efeito arco também são patentes no diagrama de momento fletor da Figura 5.140.
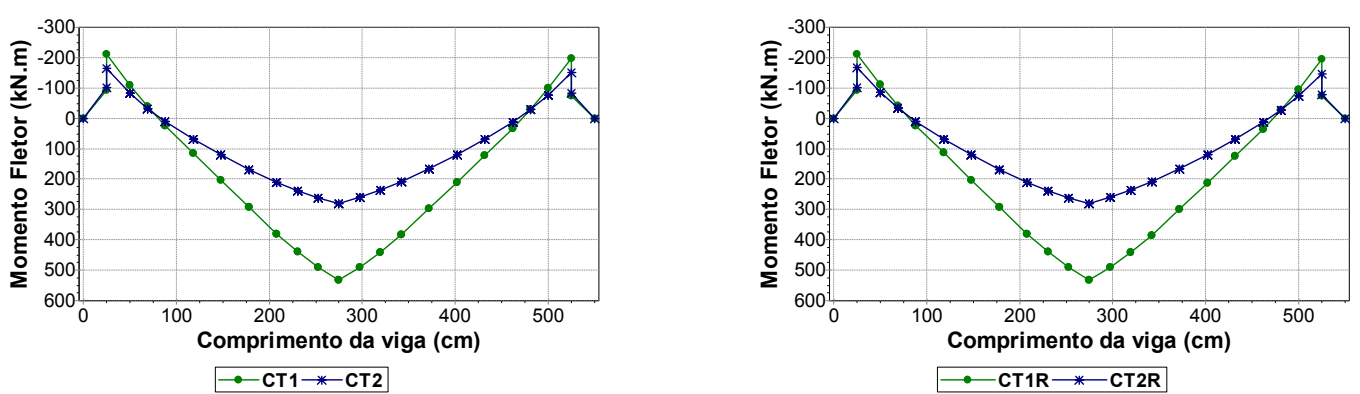

Figura 5.140 - Momento fletor - viga V02

\section{h) Viga V78}

A presente viga faz um ângulo de $45^{\circ}$ com o eixo das abscissas, sendo composta por dois vãos apoiados por três pilares. Possui parede em toda a sua extensão, contando com apenas uma pequena abertura de janela na sua direita. Em trabalhos anteriores (BARBOSA, 2000) foi atestado que, para o caso de paredes apoiadas em vigas contínuas, observavam-se regiões de compressão sobre os apoios. Como ilustra a Figura 5.141, aparecem esforços de compressão muito pequenos apenas nos encontros com os pilares extremos (P53 e P42), sendo que o modelo com pilares deformáveis resulta em maiores esforços de tração ao longo de toda a viga. Na mesma figura tem-se o diagrama de tensões verticais, onde são observadas algumas diferenças entre as duas modelagens de apoios.
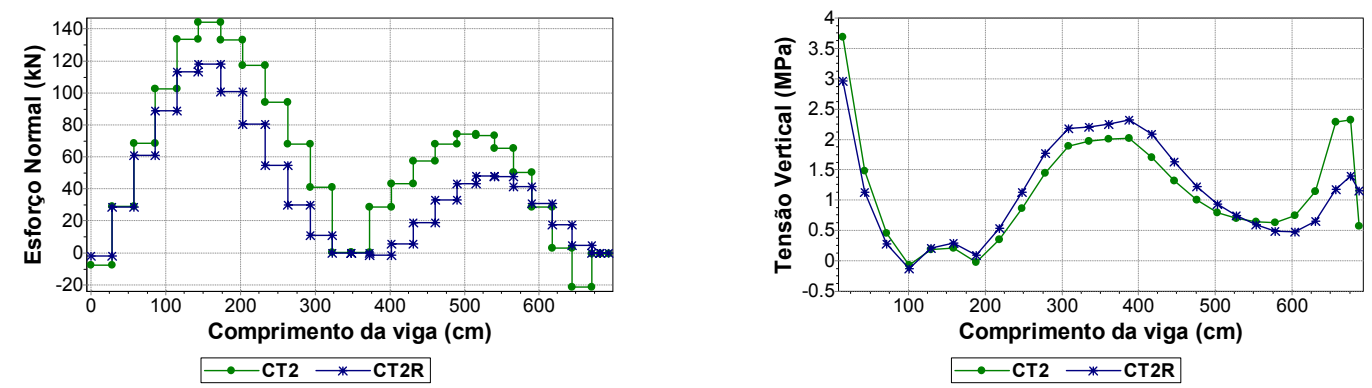

Figura 5.141 - Esforço normal e tensão vertical - viga V78 


\section{Capítulo 6 Conclusões}

O presente trabalho abrange duas etapas principais: implementação do programa gerador de dados, batizado de Sistema GMPAE (Sistema Gerador de Modelos para Pavimentos de Alvenaria Estrutura), e estudo de casos, avaliando-se cinco edifícios de alvenaria estrutural apoiados em pavimentos de pilotis em concreto armado.

\subsection{PROGRAMA GERADOR DE DADOS}

A idéia que norteou a implementação do programa desenvolvido está fundamentada em três pontos principais:

- Elaboração de uma ferramenta computacional de fácil manuseio e com interface amigável;

- Possibilidade de verificações quanto à correta geração da geometria;

- Visualização eficiente, simples e rápida dos resultados obtidos.

A janela principal do programa possibilita a importação da base de dados, com campos auto-explicativos, permitindo-se acessar facilmente parâmetros de configuração do modelo, etc. A segunda janela trabalha como um pós-processador, sendo que, com o modelo calculado pelo Sistema LASER, a interface implementada nesta janela permite a verificação da geometria, assim como dos resultados de esforços, tensões e deslocamentos por meio de gráficos gerados automaticamente pelo programa.

A preparação de relatórios também fica bastante facilitada pela interface de verificação de resultados, uma vez que todos os gráficos apresentados podem ser facilmente exportados como figuras, podendo ser coladas diretamente em editores de texto.

Desse modo, o trabalho adicional para a confecção de modelos que levam em conta a influência do efeito arco ficou bastante reduzido, sendo dependente da complexidade geométrica das paredes e densidade de aberturas a terem suas dimensões corrigidas. São necessários poucos minutos de trabalho no Sistema GMPAE para que se obtenha a visualização dos diagramas de resultados. Esta ferramenta computacional também facilitou sobremaneira a elabo- 
ração do estudo de casos, possibilitando a colocação de um grande número de gráficos com o trabalho mínimo de copiá-los da tela do aplicativo e colá-los no editor de texto.

\subsection{ANÁLISE DOS RESULTADOS OBTIDOS}

A análise de edifícios reais é de grande valia, pois permite a observação de situações não encontradas quando se estudam sistemas simples, como os de paredes sobre vigas biapoiadas encontradas na literatura. O estudo apresentado evidencia a complexidade do fenômeno denominado efeito arco. Demonstra a necessidade do uso de modelos de cálculo mais elaborados que permitam uma análise menos simplista deste efeito.

$O$ estudo de casos abrangeu edifícios com sete, oito, dez e quinze pavimentos. Outros prédios menores também foram analisados. Entretanto, para que o estudo de casos não ficasse demasiadamente extenso, optou-se por não colocá-los, pois o efeito arco não se mostrou tão significativo como nos edifícios apresentados.

Não é muito simples definir parâmetros mais diretos para se analisar um sistema complexo. O que se percebeu foi uma grande influência da geometria das paredes nos resultados. Trechos com janelas, que na abordagem simplificada (sem a consideração do efeito arco) não carregam as vigas, agora contribuem na distribuição do carregamento.

O estudo de casos é fundamentado na comparação entre o modelo tradicionalmente desenvolvido em escritórios de projeto (Modelo 1, com cargas uniformemente distribuídas sobre as vigas do pilotis) com o proposto na presente pesquisa (Modelo 2, com as paredes modeladas com elementos membrana e as cargas atuando no topo das mesmas). Sendo assim, a análise entre o Modelo 1 e o Modelo 2 permite verificar a influência do efeito arco nos resultados obtidos. Durante o desenvolvimento do trabalho notou-se que, dependendo de como os apoios de pilares eram simulados, alguns resultados eram alterados. Dessa forma, mais dois modelos foram desenvolvidos. E, confrontado-os com os modelos descritos anteriormente, pode-se verificar a influência da definição de pilares deformáveis ou apoios rígidos nos resultados analisados.

Os deslocamentos verticais encontrados em todas as simulações se mostraram inferiores aos limites prescritos pela normalização vigente (NBR 6118:2003). Observa-se que, na grande maioria das vigas, o efeito arco trabalha positivamente diminuindo os deslocamentos relativos. Tal afirmação deve ser feita com ressalvas em algumas situações onde existem apoios em vigas ou trechos em balanço com paredes em toda a sua extensão.

O estudo dos modelos com variação da rigidez axial dos pilares não apresenta diferenças significativas para o momento fletor e para o esforço cortante na grande maioria das vigas analisadas. Entretanto, diferenças que podem ser consideradas importantes ocorreram, em alguns casos, nos valores obtidos para o esforço normal e tensão vertical nas paredes, obviamente quando se utiliza o modelo que permite a consideração do efeito arco.

A elaboração de modelos que propiciam a interação das paredes com a estrutura de apoio permite verificar a aparição de esforços normais nas vigas. Nas análises desenvolvidas 
notou-se a predominância de esforços de tração nas vigas. Estes são mais evidentes nos tramos com apoios de pilares que são cobertos por trechos completos de paredes. Regiões sujeitas a esforços de compressão também foram notadas, mas em menor grau e com a ordem de grandeza dos valores bem menor do que a observada para os esforços de tração. Trechos de viga sobre pilares e regiões sem carregamento de parede foram as mais comuns a apresentar compressão axial no estudo desenvolvido. O esforço normal é o resultado que se mostrou mais suscetível à variação da rigidez dos apoios. Em linhas gerais as diferenças, quando aparecem, são pouco significativas. Entretanto, vigas sobre apoios de pilares que recebam outras vigas e submetidas a carregamentos não uniformes são fortes candidatas a apresentarem diferenças no esforço normal para as duas modelagens de apoios.

O esforço cortante foi o menos previsível dos valores analisados no presente trabalho. Os demais resultados seguiram determinados padrões na grande maioria dos casos. Em linhas gerais, o efeito arco é favorável à cortante em um número significativo de vigas, principalmente nas regiões compreendidas entre apoios. Já sobre os mesmos, as diferenças encontradas não foram tão consideráveis. Entretanto, a norma brasileira NBR 6118:2003 permite reduções nos valores do esforço cortante sobre os apoios, seguindo o exposto no seu item 17.4.1.2.1. Desse modo, como o efeito arco tem ocasionado diminuições no cortante entre os apoios para alguns casos analisados, a sua consideração propiciaria ganhos reais no dimensionamento das vigas. Já a consideração de apoios rígidos ou deformáveis não influencia de maneira efetiva o esforço cortante, uma vez que não foram encontradas diferenças significativas entre as duas modelagens. Porém, como é o caso da viga V27 do Exemplo 1 (ver item 5.3.3 f), uma geometria particular, incluindo apoios em vigas e pilares, pode resultar em diferenças mais perceptíveis entre as modelagens com variação da rigidez dos apoios.

A maior vantagem ocasionada pela consideração do efeito arco ocorre no estudo dos momentos fletores. Apesar de não se ter realizado o cálculo das armaduras, é bastante evidente a economia que se pode obter com a influência do efeito arco. Essa economia é bastante clara para o momento fletor positivo, embora também ocorram reduções no momento fletor negativo. A variação da rigidez dos apoios influenciou os resultados obtidos para o momento fletor no mesmo caso observado para o esforço cortante, ou seja, vigas com apoios em pilares e outras vigas. Como exemplificação do exposto, pode-se verificar os resultados da viga V43 do Exemplo 4 (item 5.6.3 e).

A análise tradicional em projetos de alvenaria estrutural leva a uma carga uniforme na base das paredes pertencentes a um mesmo grupo. Com a elaboração de modelos simulando as paredes com elementos membrana, podem-se obter curvas de tensões na base das paredes. Pelos resultados obtidos, nota-se claramente que ocorrem acréscimos de tensão sobre os apoios, com uma diminuição das tensões sobre os vãos. Além disto, o estudo dos diagramas apresentados permite verificar a influência da variação da rigidez dos apoios nas tensões verticais. Este resultado segue o mesmo padrão de diferenças encontradas para o esforço normal. Vigas com apoios sobre pilares e outras vigas e carregamentos não uniformes tendem a apre- 
sentar alguma diferença entre as duas simulações com diferentes rigidezes para os apoios. Entretanto, esta variação geralmente é pouco significativa.

O exposto nos parágrafos acima tem como finalidade sintetizar os pontos favoráveis ou não à consideração do efeito arco na elaboração de modelos de alvenaria estrutural apoiados em pilotis de concreto armado. Devido à complexidade do fenômeno abordado, não é recomendada a utilização de modelos simplificados.

A presente pesquisa destaca a facilidade proporcionada por um programa simples, com a função principal de gerar uma rede em elementos finitos para as paredes, tendo-se uma base de dados já executada em projetos tradicionais.

\subsection{SUGESTÕES PARA NOVOS TRABALHOS}

Para que seja possível aprimorar os modelos propostos na presente pesquisa e permitir uma maior flexibilidade no processamento dos resultados, propõem-se as seguintes pesquisas futuras:

- Montagem de arquivos de dados para outros programas de cálculo;

- Inclusão de não-linearidades física e geométrica;

- Inclusão de elementos de contato entre a parede e a estrutura de concreto;

- Consideração do carregamento devido à ação do vento sobre a estrutura de concreto. 


\section{Bibliografia}

AMERICAN CONCRETE INSTITUTE (1992). ACI 530-92 - Building code requirements for masonry structures. Detroit, Michigan.

ASSOCIAÇÃO BRASILEIRA DE NORMAS TÉCNICAS (1989). NBR 10837 - Cálculo de alvenaria estrutural de blocos vazados de concreto. Rio de Janeiro.

AUSTRALIAN STRANDARD (1998). AS 3700 - Masonry structures. 2 ed. Homebush, Austrália.

BARBOSA, P.C. (2000). Interação entre Paredes de Alvenaria Estrutural e Vigas de Concreto Armado. São Carlos. 106p. Dissertação (Mestrado) - Escola de Engenharia de São Carlos, Universidade de São Paulo.

BURHOUSE, P. (1969). Composition action between brick panel walls and their supporting beams. Proceedings of the Institution of Civil Engineers, v.43, p.175-194, June.

BRITISH STANDARDS ASSOCIATION (1992). BS 5628 - Code of practice for structural use of masonry. Part 1. Unreinforced masonry. Londres, Inglaterra.

CANTÚ, M. (2000). Dominando o Delphi 5: a bíblia. São Paulo: Makron Books.

CAPUZZO NETO, V. (2000). Estudo teórico e experimental da interação de paredes de alvenaria estrutural submetidas a ações verticais. São Carlos. 111p. Dissertação (Mestrado) Escola de Engenharia de São Carlos, Universidade de São Paulo.

CAPUZZO NETO, V.; CORREAA, M.R.S.; RAMALHO, M.A. (2000). A theoretical and experimental study of intersecting bonded walls under vertical loads. In: INTERNATIONAL BRICK/BLOCK MASONRY CONFERENCE, 12, Madrid, Spain, 25-28 June, 2000. Proceedings. Madrid, Universidad Politécnica de Madrid. v.2, p.1493-1508.

CORNEL, G. (1996). Delphi: segredos e soluções. São Paulo: Makron Books.

CORRÊA, M.R.S.; RAMALHO. M.A. (1990-1992). Relatórios sobre o comportamento de paredes estruturais de alvenaria - modelos em elementos finitos. Encol S/A, Brasília, Brasil.

CORRÊA, M.R.S.; RAMALHO, M.A. (1994). Procedimento para análise de edifícios de alvenaria estrutural submetidos a ações verticais. In: INTERNATIONAL SEMINAR ON STRUCTURAL MASONRY FOR DEVELOPING CONTRIES, 5, Florianópolis, Brazil, 21-24 Aug. 1994. Proceedings. Florianópolis, Univ. Fed. Santa Catarina / University of Edinburgh/ ANTAC, p. 305-314. 
CORREAA, M.R.S.; RAMALHO, M.A. (1998). Procedure for the analysis of masonry buildings under vertical loads. In: AUSTRALASIAN MASONRY CONFERENCE, 5., Gladstone, Australia, 1-3 July 1998. Proceedings. Rockhampton North, CQU Publishing Unit, 1998. p.57-66.

CORREAA, M.R.S., Page, A.W. (2001). The Interaction of Load-Bearing Masonry Walls Subjected to Vertical Loads. Research Report No. 218.12.2001, Department of Civil, Surveying and Environmental Engineering, The University of Nescastle, Australia.

CORREAA, M.R.S.; RAMALHO, M.A. (2003). Projeto de edifícios de alvenaria estrutural. São Paulo: Editora PINI Ltda.

DAVIES, S.R.; AHMED, A.E. (1976). Composite action of wall-beams with openings. In: INTERNATIONAL BRICK-MASONRY CONFERENCE, 4., Brugge, April.

DAVIES, S.R.; AHMED, A.E. (1977). An approximate method for analyzing composite walls/beams. In: INTERNATIONAL SYMPOSIUM ON LOAD-BEARING BRICKWORK, British Ceramic Society, London. p.305-320.

HENDRY, A.W.; SINHA, B.P.; DAVIES, S.R. (1997). Design of masonry structures. London: E \& FN Spon.

HENDRY, A.W. (1998). Structural Masonry. Second Edition. London: Macmillan Press Ltd.

LU NENG-YUAN; FENG MING-SHUO; SHI GUO-BIN; MO TING-BIN (1985). The behavior and strength of brick and reinforced concrete composite wall beams. In: INTERNATIONAL BRICK/BLOCK MASONRY CONFERENCE, 7th, Melbourne. Proc. v.2, p.1101-1111.

PAGE, A. W. (1978). Finite element model for masonry. Journal of the Structural Division, ASCE, v.104, n.8, p.1267-1285, August.

PAPIA, M. (1989). An alternative analysis model for composite wall-beam systems. Computers and Structures, v.32,n.1, p.149-155.

RAMALHO, M.A. (1990). Sistema para Análise de Estruturas Considerando Interação com o Meio Elástico. São Carlos. Tese (Doutorado). Escola de Engenharia de São Carlos, Universidade de São Paulo.

RIDDINGTON, J.R.; STAFFORD SMITH, B. (1977). The composite behavior of elastic wallbeam systems. Proceedings of the Institution of Civil Engineers, Part 2, v.63, p.377- 391, June.

RIDDINGTON, J.R.; STAFFORD SMITH, B. (1978). Composite method of design for heavily loaded wall-beam structures. Proceedings of the Institution of Civil Engineers, Part 1, v.64, p.137- 151, February.

ROSENHAUPT, S. (1962). Experimental study of masonry walls on beams. Journal of the Structural Division, ASCE, v.88 , n.ST3, p.137-166, June.

ROSENHAUPT, S.; SOKAL, Y. (1965). Masonry walls on continuous beams. Journal of the Structural Division, ASCE, v.91, n.1, p.155-171, February.

STOCKBRIDGE, R.J.M. (1967). A strudy of high-rise load bearing brickwork in Britain. M. Arch. Thesis, University of Edinburgh, Scotland.

TOMAZELA, C.A. (1995). Ação conjunta parede-viga na alvenaria estrutural. São Carlos. 249p. Dissertação (Mestrado) - Escola de Engenharia de São Carlos, Universidade de São Paulo.

WOO, M.; et al. (1999). OpenGL programming guide: the official guide to learning OpenGL, version 1.2 / OpenGL Architecture Review Board. Addison-Wesley. 
WOOD, R.H. (1952). Studies in composite construction. Part 1: The composite action of brick panel walls supported on reinforced concrete beams. London, Her Majesty's Stationery Office. 25p. (National Building Studies, Research Paper n.13).

WOOD, R. H.; SIMMS, L. G. (1969). A tentative design method for the composite action of heavily loaded brick panel walls supported on reinforced concrete beams. Garston, UK, Building Research Station.6p. (BRS Current paper CP26/69).

WRIGHT JR., R.S.; SWEET, M. (1996). OpenGL superbible: the complete guide to OpenGL programming for Windows NT and Windows 95. Waite Group Press. 